\title{
ENABLING THE CURIOUS PRACTITIONER: PERCEPTIONS ON THE INTEGRATION OF RESEARCH AND PRACTICE IN THE EDUCATION OF MUSIC THERAPY STUDENTS AT MASTERS' LEVEL
}

A Thesis Presented in Fulfilment of the Requirement for the Degree of Doctor of Philosophy in Music

New Zealand School of Music,

Wellington, New Zealand

SARAH LEIGH HOSKYNS

April 2013 


\section{Abstract}

This $\mathrm{PhD}$ research explored perceptions about the integration of research and practice in the Masters' training of music therapists. Using constructivist case study methodology, the study analysed viewpoints of international educators, researchers and students about how research could helpfully be integrated into the practical and conceptual learning of music therapy trainees. The synthesis of research and practice in the professional music therapy field has regularly been advocated but recent studies and reviews suggest there is significant need for development of pedagogical theory and guidance for educators and students in the interface between placements and university-based learning in key areas, including research. Participants included a purposeful sample of 19 music therapy practitioners, researchers, educators and students in the wider international profession of music therapy and at music therapy training programmes in Europe and Australasia. Data sources included focus groups of professionals, two site visits to training programmes (comprising interviews, observations, field notes and concluding improvisation session) and a researcher reflective journal. Core themes identified in the thematic analysis concentrated on cherishing students' fire and curiosity; facilitating the acknowledgement and management of change; and helping students embrace complexity in their music therapy education. Evidence from this study indicates that moving beyond 'research competency' and the development of individual academic skills towards collaborative, engaged learning with peers and supervisors, has potential to nurture sustainable, practice-based researchers of the future. Devising integrative strategies for learning and assessment, undertaken in diverse ways and to suit varied contexts for training, was perceived to be inspiring for students and educators and rehearsed significant professional tasks. These strategies - despite tensions experienced in their development - had potential to deepen personal learning, develop creative and critical skills that characterise graduate attributes of University Masters' courses, and prepare graduates for evidence-based practice in health and education workplaces. An integrative model for a more holistic approach to learning, combining individual and collaborative approaches and using opportunities inside and outside the programme was developed, allowing for differences in culture and approach of the institutions which host music therapy training. The challenges and solutions explored in this research, while being particular to this qualitative music therapy study, have potential relevance to other applied areas of professional practice and research, such as arts therapies, allied health disciplines, education and nursing. 
To my parents, Ann and Benedict,

who provided music lessons, a space to practice and loving interest.

In memory of Jacob Barnes, loving musician.

$1989-2011$ 


\section{Acknowledgements}

I would like to acknowledge the following people:

My magnificent and constantly supportive team of supervisors: Associate Professor Sue Cornforth and Professor Leslie Bunt for your consistent 'on-the-ground', insightful help and wise limits on my work, and Dr Allan Badley and Professor Donald Maurice for early and later stage administrative supervision in warm, enthusiastic fashion

The eighteen participants in the study (Hannah, Zelda, Catherine, Paloma, Quentin, Eddie, Kirsty in the Focus Groups; Bella, Beatrice, Alex, Helena, Abby, Naomi at 'Kindstown' and Anna, Patrick, Hilly, Florence and Hope at 'Friendsville') who were so willing and interested to share their knowledge and feelings about the topic (pseudonyms provided here)

My dear and inspiring colleague Dr Daphne Rickson, who provided invaluable scrutiny and peer debriefing, constant encouragement and new insights for the study

Our students on the MMus Therapy Programme at Te Kōkī, NZSM for inspiration and feedback Carolyn Ayson, Rebecca Travaglia, Claire Molyneux, Andrew Filmer and Ali Talmage for a mixture of transcription, peer debriefing, engaging conversations and warm support

Elizabeth Smith, music librarian at Massey University Wellington, endlessly willing problem-solver for all library research issues

Dr. Morva Croxson and Barbara Mabbett for ongoing friendship, and respectively for covering my teaching for a trimester and providing proof-reading assistance

My PhD student colleagues in the VUW Faculty of Education Research Cluster Group and group leaders Associate Professors Sue Cornforth and Catherine Manathunga for shared learning and inspiration

Liam Dewhurst for crafting and inspiration with designs for figures, Julian Raphael for generous help with musical examples and Dori Raphael for her illustration

Professor John Psathas and Dr Dave Lisik for invaluable advice about composition

Bridget and Roger Sanders and Jiff Stewart for inspiring conversations about art, story-telling and health research; and to Andy Willmoth for sharing experience of TASC International as a teacher consultant 
Professor Elizabeth Hudson and Executive Committee of Te Kōkī, NZSM for generous financial support with study and similarly Massey University for a MU Women's Award; the Music Therapy New Zealand, Sir Roy McKenzie Research Fund and the Faculty of Graduate Research, Victoria University for assistance with travel and transcription costs

My Wellington family, Julian, Dori and Nino for coping with the long haul of my $\mathrm{PhD}$ study, and for your ongoing jollity, food and music-making; also to Isabelle, Gabriele and the Simpson family in similar regard

My family and whanau abroad, who have always maintained interest and support in generous and manifold ways, despite the distance.

Warmest thanks to you all.

\section{Statement of Ethical Approval}

The research has been approved by the Faculty of Humanities and Social Sciences Human Ethics Subcommittee under delegated authority from the Victoria University Human Ethics Committee, Approval \#: 15689, July 2008. 


\section{Table of Contents}

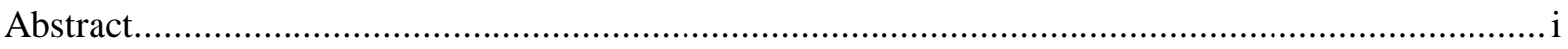

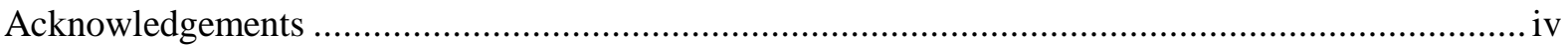

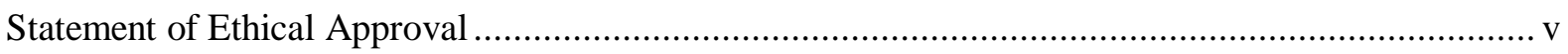

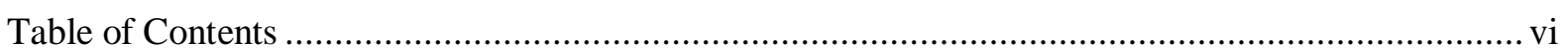

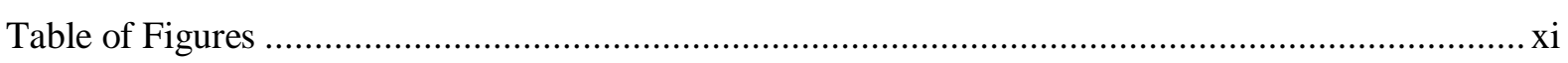

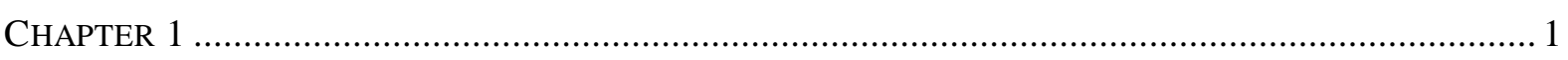

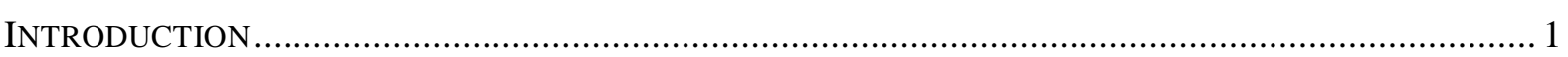

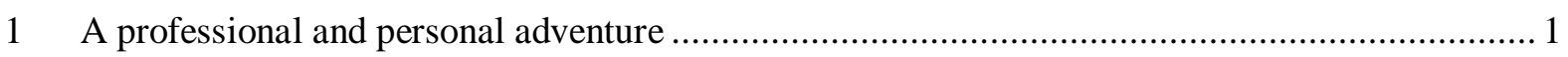

1.1 Regulation of music therapy and arts therapies in the United Kingdom ............................. 2

1.2 Masters' level entry to the music therapy profession ....................................................... 4

1.3 International growth in evidence-based practice (EBP) .............................................. 5

1.4 The development of varied frameworks for research ......................................................... 6

1.5 Brief background to music therapy, training and practice .............................................. 8

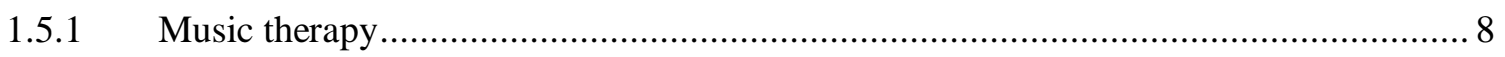

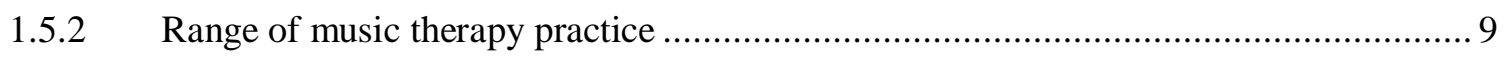

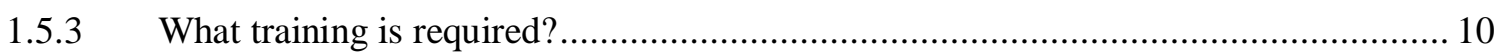

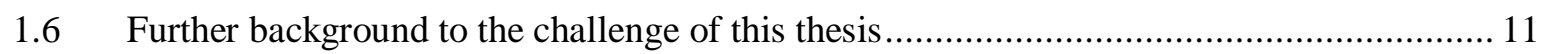

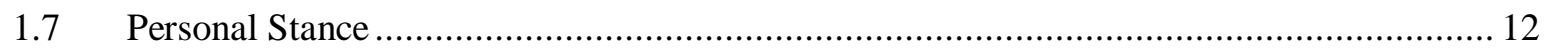

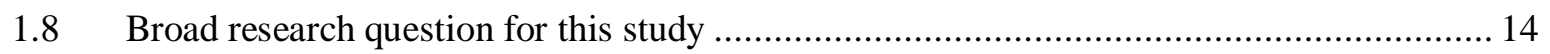

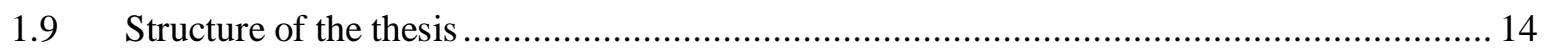

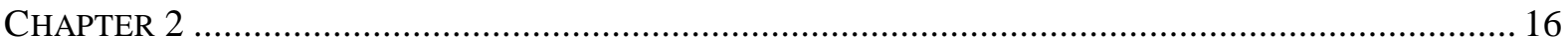

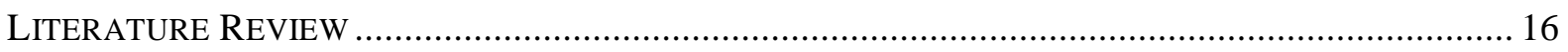

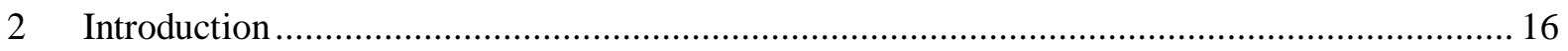

$2.1 \quad$ Theoretical debates about what constitutes research in music therapy …............................ 18

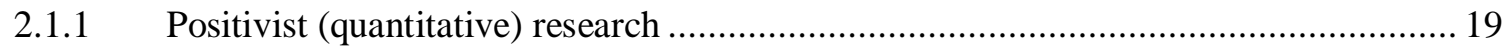

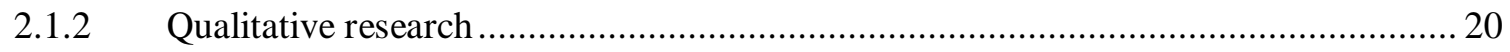

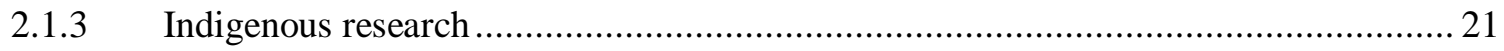

2.2 Theoretical debates and research addressing the relationship and potential integration of

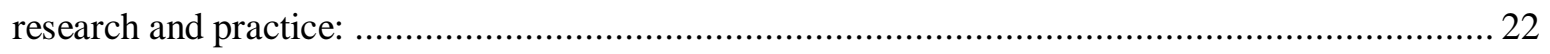

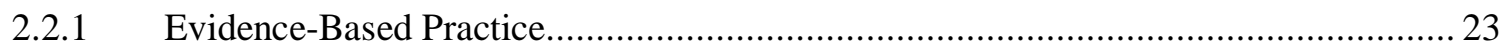

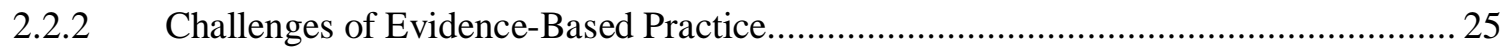

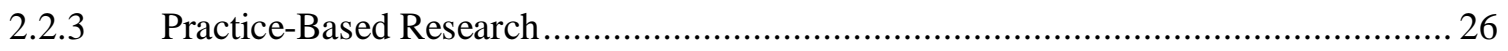

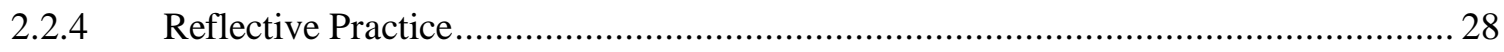

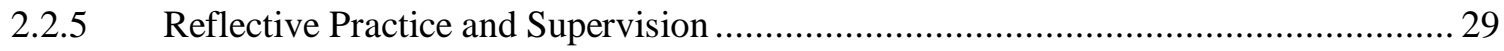

2.3 Studies and theoretical perspectives on music therapy training........................................... 30 
2.4 Studies and theoretical perspectives on training in related fields ..................................... 32

2.5 Studies and theories about encouraging students to engage with research......................... 34

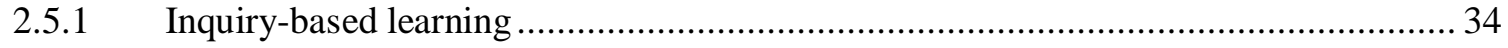

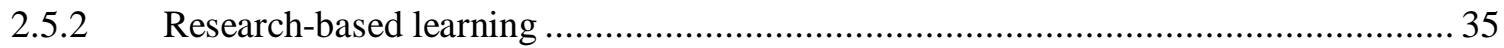

2.5.3 TASC International: Thinking actively in a social context ...................................... 35

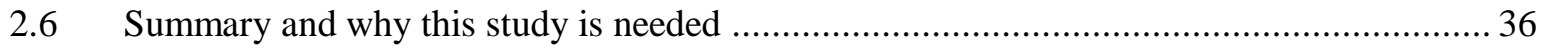

2.7 The research question and subsidiary questions for the current study .............................. 37

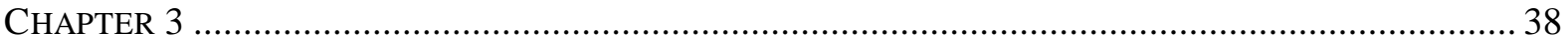

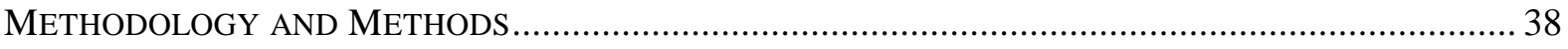

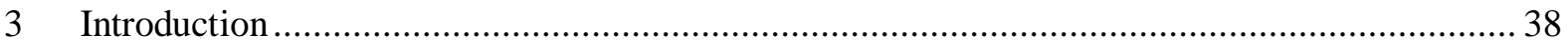

3.1 Theoretical perspective that informs the research ....................................................... 38

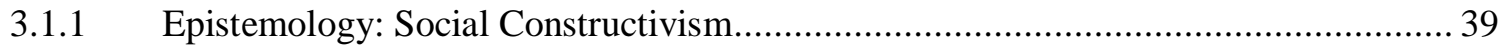

3.1.2 The use of the researcher as instrument in the research.......................................... 41

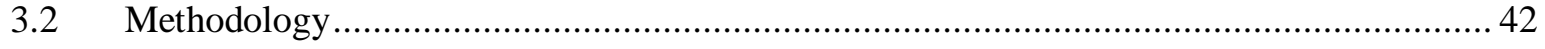

3.2.1 Qualitative Exploratory Case Study Research ....................................................... 42

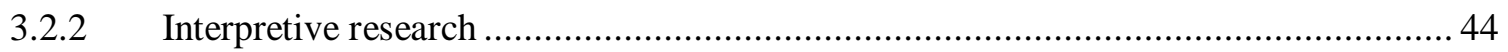

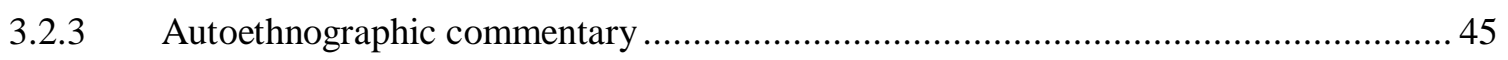

3.2.4 Authenticity, trustworthiness and the controversy of 'validity' ................................ 45

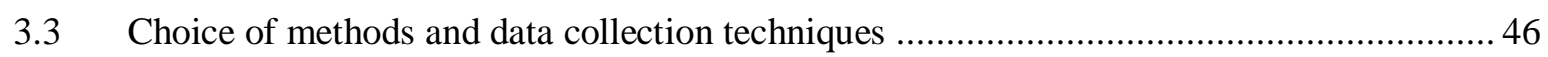

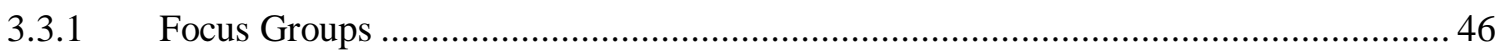

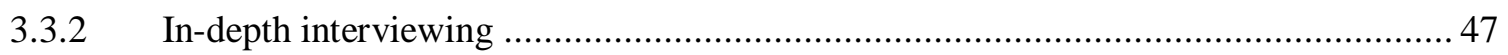

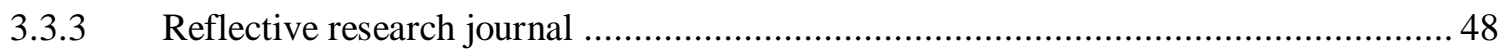

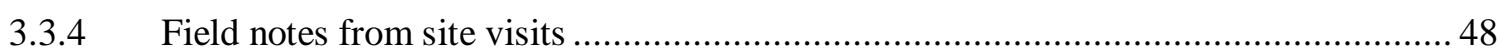

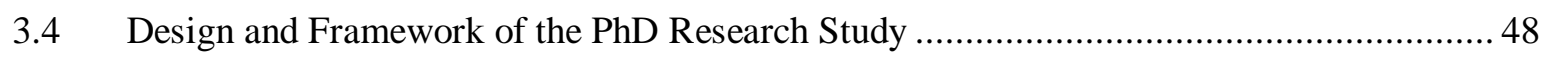

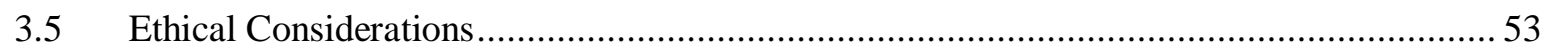

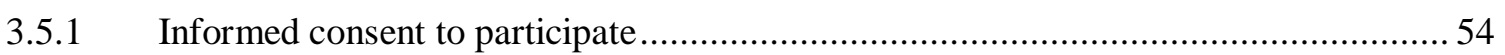

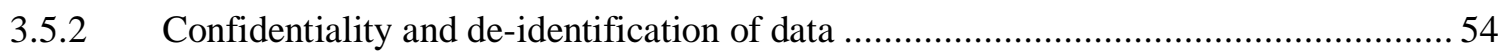

3.5.3 Avoiding issues of power and vulnerability for students and staff ............................. 55

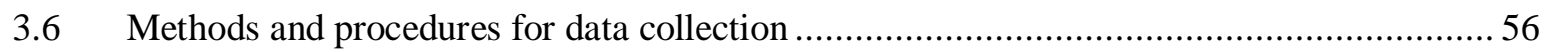

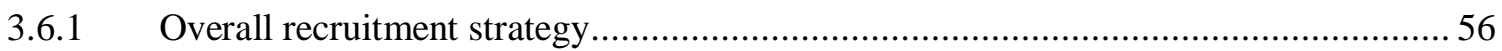

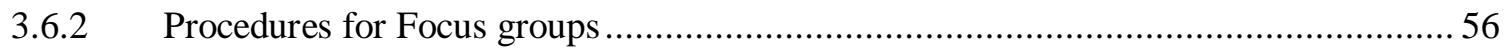

3.6.3 Procedures for two site visits to educational settings (Europe and Australasia) .......... 58

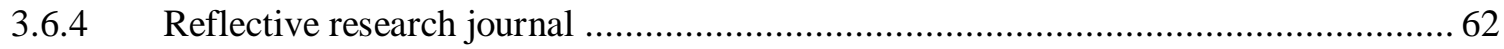

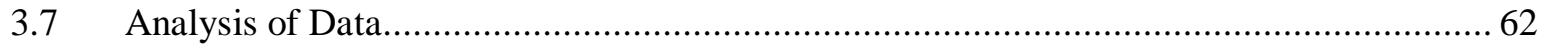

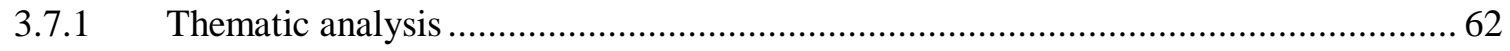

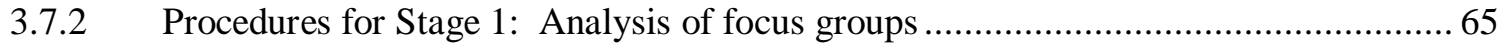


3.7.3 Procedures for Stage 2: Analysis of the site visits

3.7.4 Procedures for Stage 3: Triangulation of data sources from Stage 1 and 2 alongside research journal

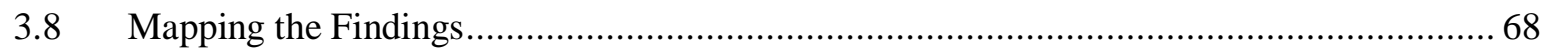

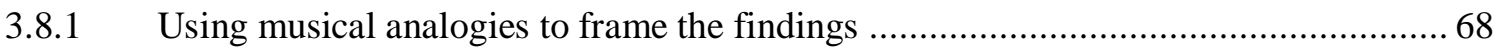

3.8.2 The musical forms used as metaphors in the findings ............................................ 70

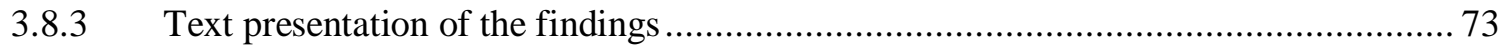

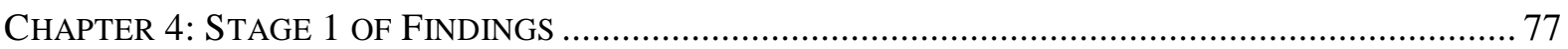

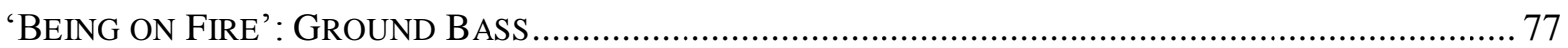

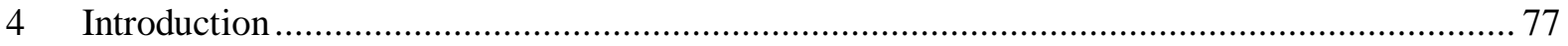

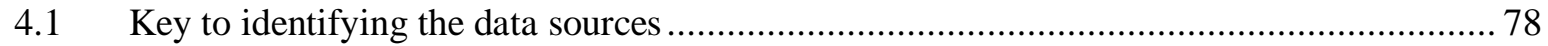

4.2 Core theme for this chapter: Stage 1: 'Being on fire' ..................................................... 79

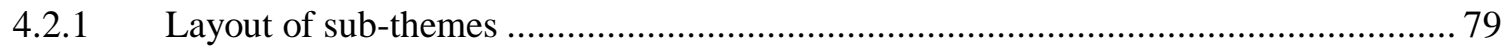

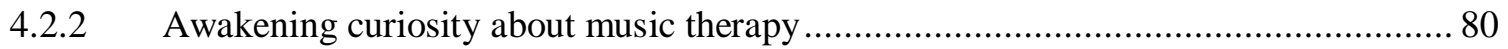

4.2.3 Experiencing the excitement of search and inquiry about practice ............................. 84

4.2.4 Being inspired by client-led thinking as a way into research................................... 88

4.2.5 Being inspired by an interactive loop - the 'back and forth' from research to practice92

4.2.6 Valuing the inspiration and influence of mentors ….................................................. 96

4.2.7 Being inspired and held by a collaborative model of research................................ 100

4.2.8 The quest and travelling into the unknown .......................................................... 105

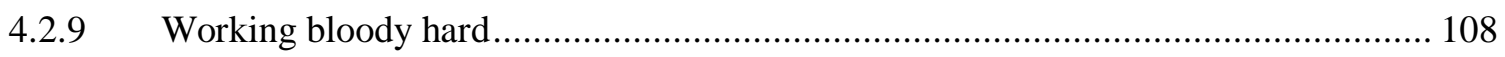

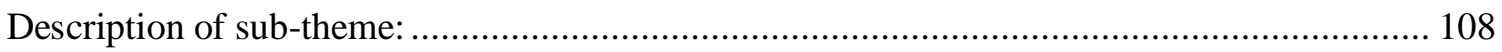

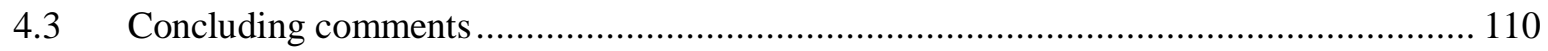

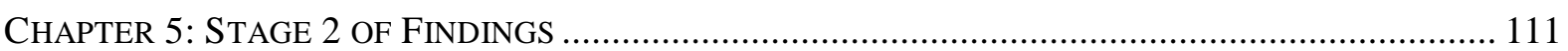

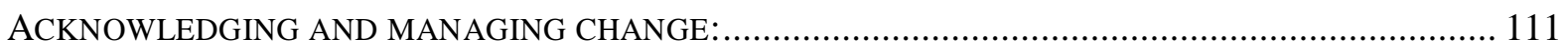

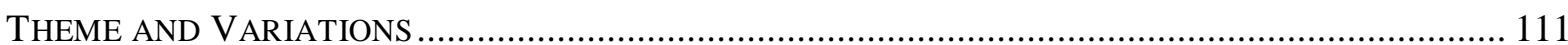

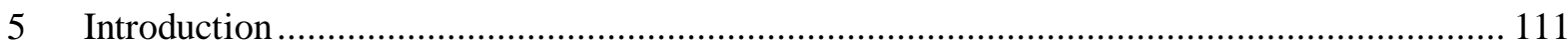

5.1 Core theme for this chapter: Stage 2: 'Acknowledging and managing change' ................ 112

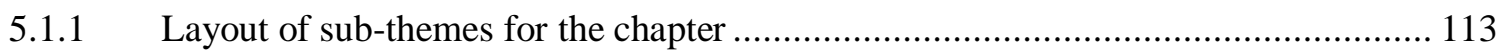

5.1.2 Valuing our heritage and traditions of knowledge ................................................ 114

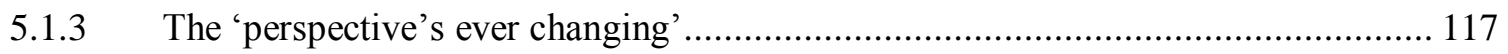

5.1.4 The evolving of professional language and definitions in music therapy ................... 120

5.1.5 The discipline constantly re-aligns in relation to various contextual influences........ 124

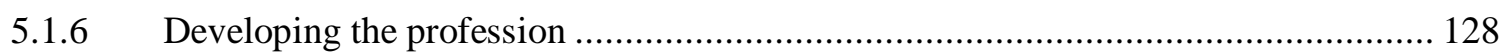

5.1.7 Experiencing being at a crossroads: the opportunity for change ............................. 132

5.1.8 Using critical appraisal in research and practice ..................................................... 134 


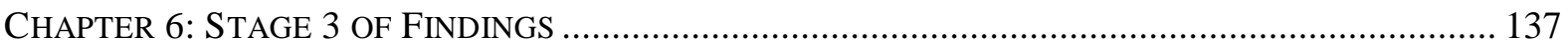

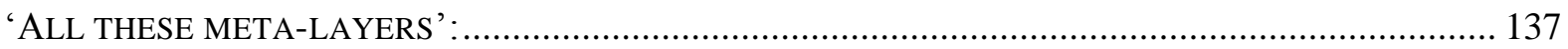

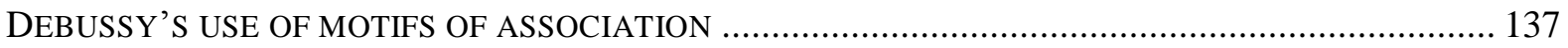

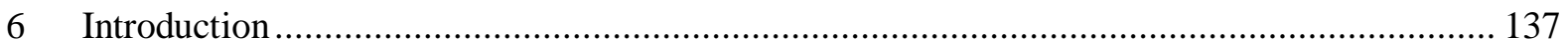

6.1 Introducing Debussy's use of 'motifs of association' .................................................. 138

6.2 Core theme for this chapter: Stage 3: 'All these meta-layers' .......................................... 141

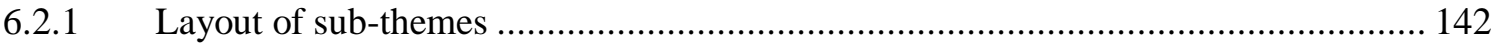

6.2.2 Recognising the complexity of the discipline ('many layers').................................. 143

6.2.3 Foregrounding tasks (as in Debussy's motifs of association) as a strategy for dealing

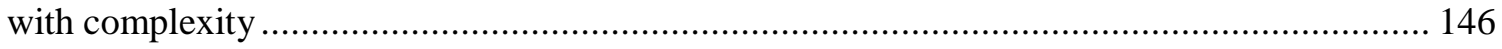

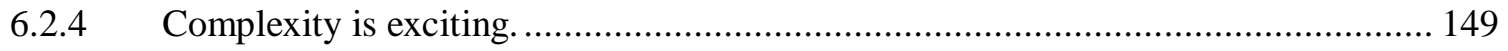

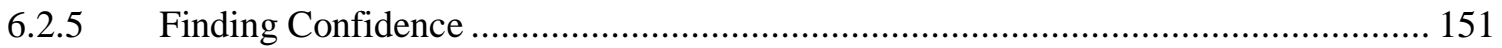

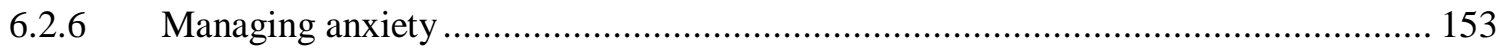

6.2.7 Challenges to integration - refining and balancing programmes ............................. 154

6.2.8 Musical reflection on the complexity of research about practice ............................. 157

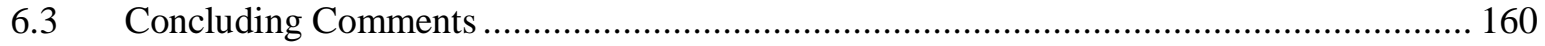

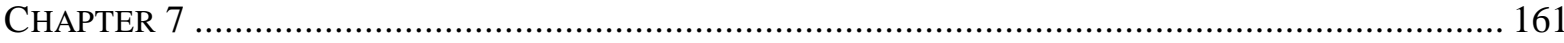

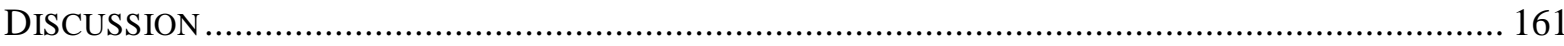

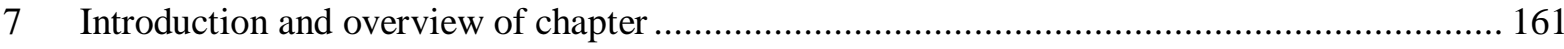

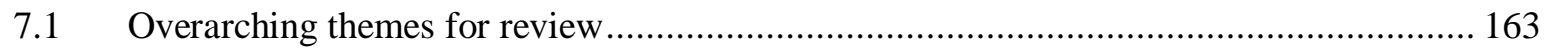

7.1.1 Creating varied and unique research-practice pathways .......................................... 163

7.1.2 Developing creative solutions and strategies for integrating research and practice ... 170

7.1.3 Integrating practice and research learning through an ethical lens............................ 178

7.1.4 The value of aiming for engaged scholarship ...................................................... 180

7.1.5 Linking research and practice to creativity. ............................................................ 184

7.1.6 Valuing collaboration and community between students and staff .......................... 186

7.1.7 A working model for integrating practice and research in Masters' training ............. 187

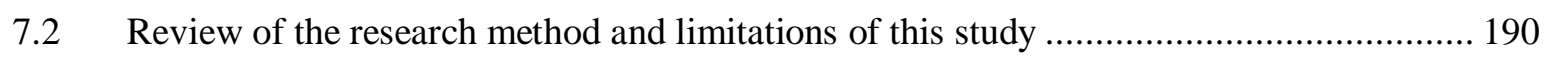

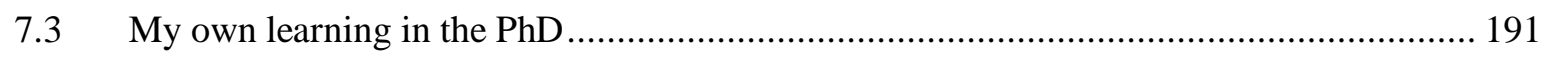

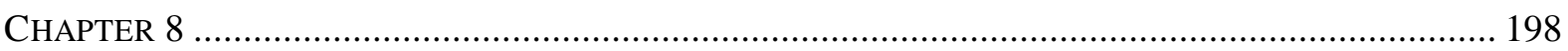

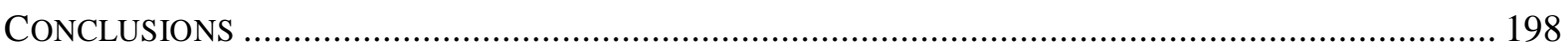

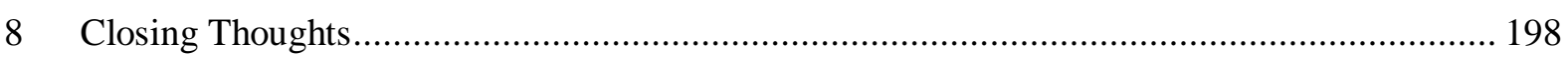

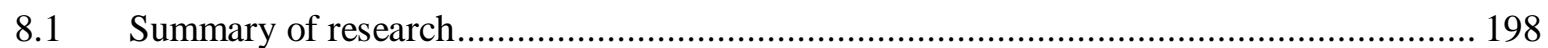

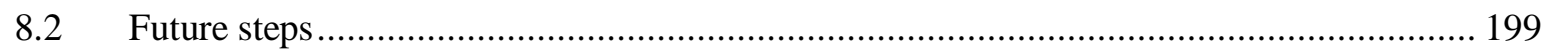

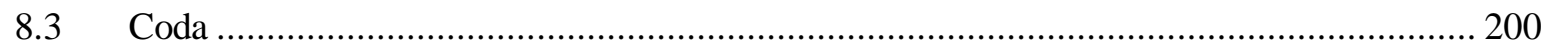




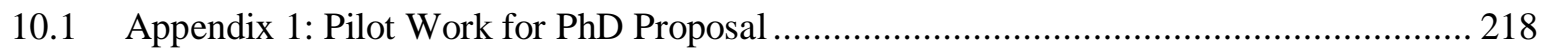

10.2 Appendix 2: List of Participants in the Research: Settings and Roles ........................... 220

10.3 Appendix 3: Example of Information Sheet for a Focus Group ....................................... 221

10.4 Appendix 4: Example of a Consent Form for a Focus Group ....................................... 224

10.5 Appendix 5: Example of an Information Sheet for Interviewees at Site Visits ................ 225

10.6 Appendix 6: Example of Consent Form for Interviewees at Site Visits........................... 227

10.7 Appendix 7: Example of Advertisement for Expressions of Interest in a Focus Group .... 228

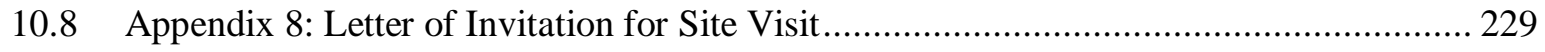

10.9 Appendix 9: Briefing and Prompt Questions available for the Focus Groups ................... 231

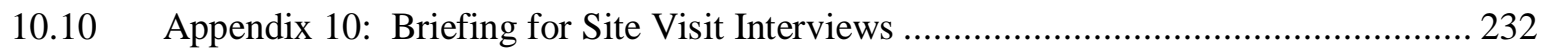

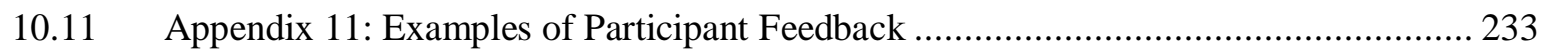

10.12 Appendix 12: Some Examples of Initial Coding for Group-BA: Developing Preliminary

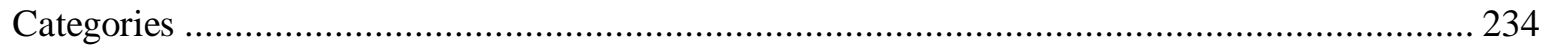

10.13 Appendix 13: Examples of Core Categories for Focus Group-E ................................ 235

10.14 Appendix 14: Example of an Extract of an Interview Transcript Site FV ..................... 237

10.15 Appendix 15: Example of Coding and Analytic Memos for Student Florence, Site FV.240

10.16 Appendix 16: Examples of Provisional Themes for Two Participants at Site FV: Student

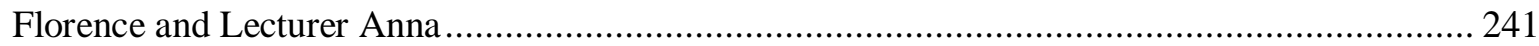

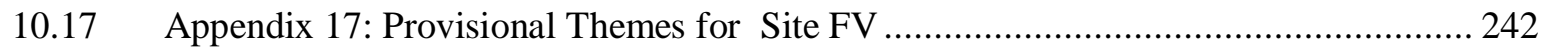

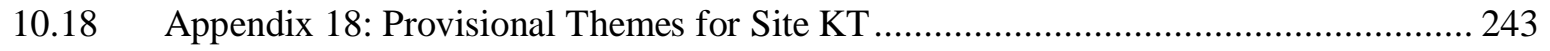

10.19 Appendix 19: Example of a Research Journal Entry ................................................ 244 


\section{Table of Figures}

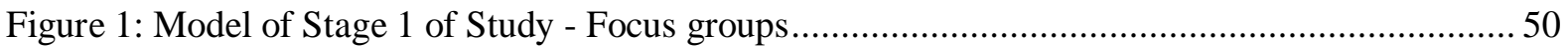

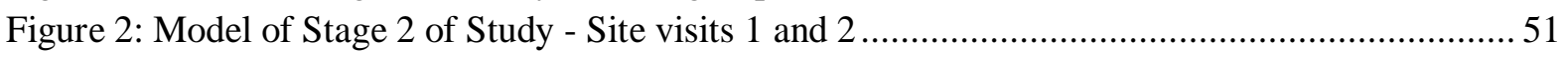

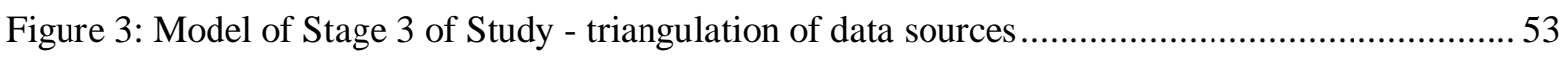

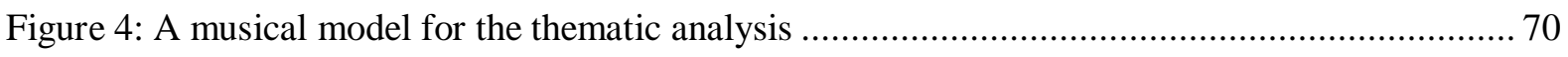

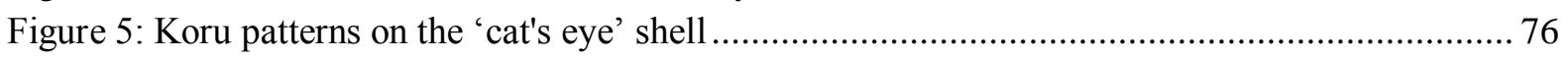

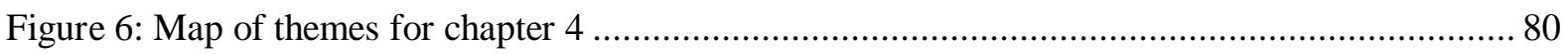

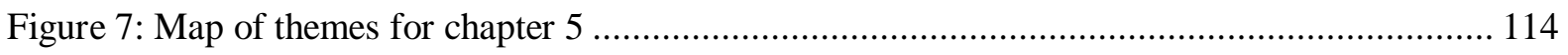

Figure 8: Photo of the South Wairarapa landscape: an impressionist viewpoint ............................ 138

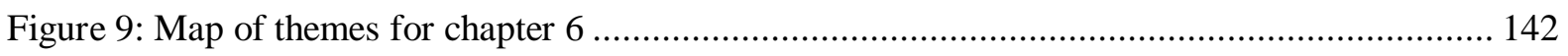

Figure 10: Contexts for seven music therapy programmes and the challenges for integration.......... 166

Figure 11: Summary of seven programme contexts and curriculum strategies for integration of

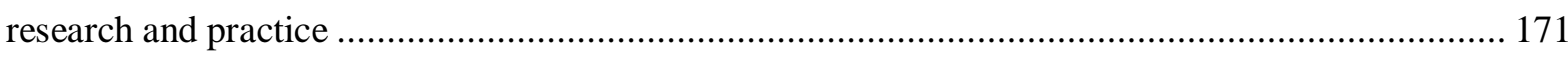

Figure 12: Table of competencies for research for qualified music therapists in Three countries ..... 175

Figure 13: Interaction between emotional engagement and critical thinking - parallels in research and

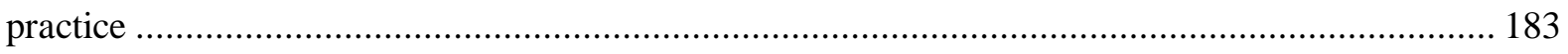

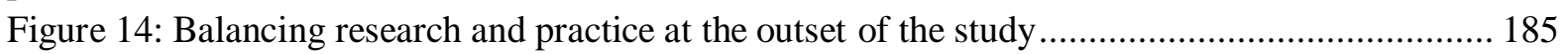

Figure 15: Matrix of processes integrating research and practice (inside-outside; collaborative-

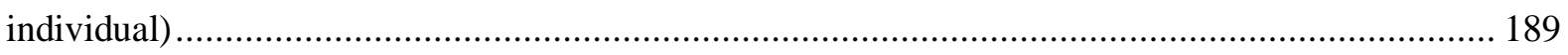

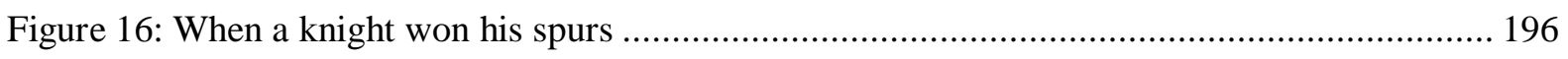

Figure 17: "Every analyst who is awake whilst working is engaging in research" - after Winnicott

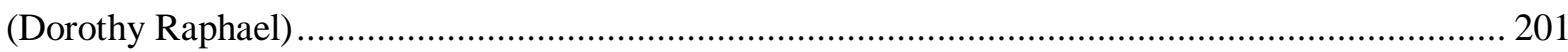




\section{CHAPTER 1}

\section{INTRODUCTION}

\section{A professional and personal adventure}

The topic for this $\mathrm{PhD}$ research - the integration of research and practice for music therapists-intraining - grew from a seed planted around the time of the new millennium. It was the result of being a professional in a certain time and place, and of course my own interest and engagement, but I felt beckoned by the subject as it was a particular challenge to me within my location and history as a music therapy educator. The forces at play for me included:

1) The changes in the regulation of music therapy in the UK - specifically the introduction, by Act of Parliament in 1997 of formal state registration of the arts therapy professions, which required government-appointed review and evaluation of training courses . These changes resulted in intense scrutiny about safety of the public and particular attention to clinical competency of arts therapists.

2) The transition (for many arts therapy courses in Europe and Australasia) to Masters' level entry to the arts therapies professions (and away from postgraduate diploma or Bachelor level entry) and wide-ranging discussions with my UK colleagues about how our music therapy programmes were preparing for this transition (Courses Liaison Committee of the Association of Professional Music Therapists, UK)

3) Worldwide growth in the requirement for research evidence for healthcare practice (Wigram, 2002) and the need to prepare students for this environment.

4) The growing interest in and respect for diverse approaches to research in music therapy (Kenny, 1998; Langenberg, Aigen, \& Frommer, 1996; Smeijsters, 1997; B. Wheeler, 2005b)

Since the sowing of this seed, I had been engaged in various writing and research projects about the training and education of music therapists, (Bunt \& Hoskyns, 2002; Flower, Hoskyns, \& Purcell, 2004; Hoskyns, 2005), which made me especially interested in the qualities and experience of music therapy learning and teaching. In 2004, I had made all the transition plans for the Guildhall School Music Therapy Programme in London, where I was then Head of Department, to become a researchbased Masters' degree, but then I moved continents to a new post in Aotearoa New Zealand early in 2005. There I found myself in a brand new Masters' training programme with research firmly placed 
in the second year of learning (Krout, 2003), but with no previous context for it. The first students were starting their second year with me alongside and they were combining their learning about practice with research. The subject beckoned me more insistently.

The four issues stated above require some expansion and context to assist understanding of the interest in the integration of research and practice and why the current research thesis might be relevant at this time.

\subsection{Regulation of music therapy and arts therapies in the United Kingdom}

The significant contribution to the arts therapies professions in the United Kingdom of becoming 'State Registered' by Act of Parliament in 1997 is observed by varied commentators (Bunt \& Hoskyns, 2002; Karkou \& Sanderson, 2006; Odell-Miller \& Sandford, 2009). This created a substantial change in the legal status of the disciplines and resulted in legally protected titles for the name of 'music therapy', and the other individual arts therapies. Only practitioners trained on programmes approved by the (then) "Council for Professions Supplementary to Medicine" (CPSN), which later became the Health and Care Professions Council (HCPC-UK) could be registered and call themselves music therapists.

The implications for training programmes in the arts therapies were substantial. Standards of training needed to be discussed thoroughly across the different professions, art and music therapy in the first stage and later drama and dance-movement psychotherapy. Each profession had nominated representatives on the Joint Quality Assurance Council (JQAC) of CPSN,${ }^{1}$ and these standards had to be agreed and ratified in order to approve training programmes in a steady plan of development from 2001 to 2003. The register for Arts Therapists opened in 2003. Standards of proficiency were published first in 2003 and then updated in 2007 and 2012 (HPC-UK, 2012).Wigram and colleagues noted the huge variety of lengths and approaches to music therapy training across Europe in the unpublished 'WEK' survey of education providers undertaken in 1993. ${ }^{2}$ They also reported the ongoing discussion by European music therapy educators about establishing a common standard for training, which proved very challenging in the European context, as programmes varied at that time from one-year postgraduate diploma in the UK (after varied Bachelors' degrees) to a 5-year training (Bachelors' and Masters' degrees) in Scandinavia (Wigram, De Backer, \& Van Camp, 1999). OdellMiller and Sandford (2009) observed 10 years later that the UK music therapy professional

\footnotetext{
${ }^{1}$ I acted as the JQAC representative for the Association of Professional Music Therapists UK, (APMT) from 2000 to 2003 to help develop the standards. Draft standards for music therapy were reported from discussions with APMT colleagues about what were vital competencies and skills to be mastered in training. Members of JQAC, amongst others, then became 'Visitors' in the approval process for all the arts therapies training courses. This was a rigorous and difficult process that challenged many university providers to offer adequate staff time and attention to 'protecting the public'.

${ }^{2}$ Wigram references this unpublished survey conducted by Wigram, Erdonmez and Koortegaard (with their surnames signalling the acronym).
} 
community had worked very hard together across substantially different theoretical backgrounds to agree such rigorous standards of training and competencies, which could inform approval processes for training by HCPC-UK .

A large part of the Arts Therapists standards of proficiency concentrated on the quality of clinical care and the wide-ranging responsibilities to provide safe treatment. This was specifically important as HCPC-UK is charged by law to protect the public, and standards of proficiency were negotiated in order to be able to assess training programmes and subsequently graduate registrants to be competent and safe practitioners in their field. Odell Miller and Sandford (2009) witnessed the value of the detailed work across professions providing a foundation for negotiating together and holding the values of the art forms:

Our alliance and partnerships with other arts therapies professions is strong. For all negotiations with the government, we have tried to maximise the benefits of joining with our art therapy, dramatherapy and more recently, dance movement psychotherapy professional bodies. This has been useful in having a shared common voice to innovate and secure further recognition whilst maintaining necessary difference as these art forms suggest. (p. 2)

So an important factor in building the standards was to agree the length and basic level of training programmes (creating a framework for delivery). For music therapy programmes to grow in length and be more linked to a joint level, and for universities and music departments to afford to deliver them, Masters' courses needed to be the norm. The establishment of Masters' courses inevitably led to the implications of 'research' being built into the framework. No universities would be able to consider a Masters' that did not have a focus in research, because of the expense of delivering such a programme, without the benefit back to the institution in terms of research outputs ${ }^{3}$. There were also significant advantages to the music therapy discipline of encouraging a research-minded profession, but to deliver the research competencies at the same time as providing a safe, proficient entry-level professional practitioner was a new and ongoing challenge. Wigram De Backer and Van Camp (1999) had asserted this, anticipating such developments: "Training music therapists to a satisfactory musical, clinical and academic level is a complex and difficult task..." (p. 282)

There was also a significant parallel development in Masters' courses Europe-wide, as 40 countries signed up to the 'Bologna Accord' from 1999 (Rubin, 2005). The next section considers this and other

\footnotetext{
${ }^{3}$ Gfeller reminded the music therapy community that much of the research that is conducted in the field is generated and monitored by universities, because of the research agendas that drive the tertiary sector. See Gfeller (1995) chapter on 'The status of music therapy research' in B. Wheeler (Ed) Music Therapy Research: quantitative and qualitative perspectives. $\left(1^{\text {st }} \mathrm{Ed}\right)$ Gilsum: Barcelona.
} 
developments with professional Masters' degrees that have had an impact on Masters' level music therapy programmes.

\subsection{Masters' level entry to the music therapy profession}

For music therapy and other arts therapies in the UK, the standardisation process to become 2-year postgraduate Masters' training programmes was an important progression to meeting the range and extent of the standards of proficiency of State Registration under HCPC-UK (Karkou \& Sanderson, 2006). However other influences on the need to develop Masters' programmes as a standard requirement for professional registration created some more complex pressures, and in particular regarding the input of research. This issue has been documented widely in other professions (teaching and counselling for example) where the challenges to be a good classroom teacher or counsellor/ psychotherapist and a good researcher can come into conflict (Houston, Ross, Robinson, \& Malcolm, 2010; McLeod, 2002b) - however the dilemma has not been very specifically represented in research on music therapy training at Masters' level, although music therapy educators at Bachelors' level in the USA have consistently emphasised the input and necessity for learning about research in undergraduate programmes (Davis, Gfeller, \& Thaut, 2008; K. Goodman, 2011).

The introduction of the 'Bologna' agreement for the 40 European countries which signed the declaration in 1999 had a powerful impact on the tertiary sector's planning of postgraduate education, with strong efforts to standardise and streamline all the courses which they delivered.

The Bologna Accord clarifies the meaning of degrees by establishing a division between undergraduate and graduate study and introducing the "bachelor" and "master"framework to education in European countries that sign the agreement. It also defines standard degree requirements, a standard grading scale, a common transcript, and quality-assurance checks to ensure common practices and quality standards. (Loades, 2005b, p. 1)

However Loades (2005a) observed in a further report on the Bologna agreement that the risks for the universities were substantial and "institutions that do not live up to the challenges could find their very existence in jeopardy" ( p. 2). Thus many institutions hosting music therapy programmes were working towards more competitive, shorter focussed Masters' programmes across their delivery of postgraduate education with common practices of research which could dovetail together. The UK professional associations in the arts therapies therefore had two very important legislative frameworks to respond to: the universities themselves needing to craft and standardise, and the HCPC-UK requiring protection of the public. These two 'forces', as I described them in the opening, were not 
necessarily complementary and required real attention on the part of the education community to preserve the 'balance' in Masters' programmes that was strongly advocated by Wigram and colleagues in their chapter on developing the identity of the music therapist in training (Wigram, et al., 1999).

An additional layer in the consideration of Masters' education in all the allied health and education sectors continues to be the challenge of giving relevant attention to developing quality research learning at the same time as providing suitable professional education, which requires high ethical standards of practice in community settings. Barnacle and Dall'Alba (2011) for example have argued how very complex this process is and that specific 'research training' in generic skills such as communication, collaboration and critical thinking may not be wholly beneficial to researchers as it implies developing technical skills "rather than the craft or artistry of research required for genuine skilful performance" ( pp. 465-466). Taking this viewpoint, the balance of training the practitioner and the researcher continues to be challenged in the modern university across many disciplines.

\subsection{International growth in evidence-based practice (EBP)}

Music therapists and art therapists have written robustly and with strong leadership about the importance of engaging with the international agenda for evidence-based practice (Edwards, 2005b; Gilroy, 2006; Pavlicevic, Ansdell, Procter, \& Hickey, 2009). I will explore the literature in more detail in chapter 2, but the argument for creating practitioner-researchers is further emphasised by this third imperative at play in $21^{\text {st }}$-century education and healthcare. Certainly the requirement for any therapist to be aware of the need for research evidence in the public service, practice workplace is unavoidable and arts therapies education providers would be negligent to leave students and graduates unprepared in this regard.

However, the issue about how best to develop the knowledge and aptitude for evidence-based practice is hotly contested, and clearly varies across disciplines. In medicine and the sciences there is a straightforward pathway to the gold standard of research (which would include randomised controlled trials for treatment interventions and large samples of participants to the research experiments). There is potential for this to be organised when there are large medical research teams and government funding, and an ideological framework that is underpinned by developing a hypothesis, experimenting and proving the hypothesis right or wrong. The smaller person-centred disciplines have had to be 'smart', very prepared and hard working to achieve a respectable place in the evidence-based world. Curtis Jenkins (2002) and McLeod (2002a) gave powerful examples of ways that counselling and psychotherapy could respond through the 'CORE' system of audit in primary health care, a system 
much more sympathetic to practitioners and service-users, ${ }^{4}$ and through systematic case study research (McLeod, 2002a). Wigram and Edwards in music therapy gave similarly strong examples in the early years of the millennium, arguing how specific evidence of assessment of practice in Autistic Spectrum Disorder (Wigram, 2002) and awareness of the importance of using information in the Cochrane database (Edwards, 2002) could contribute to music therapists' responsiveness to EBP in various aspects of their work. The specific work with systematic reviews developed by music therapists in various areas for the Cochrane Database is discussed in Chapter 2. As experienced music therapy educators, with an acute sense of the centrality of EBP to music therapy's development, Wigram and Edwards have made particularly substantial contributions to the growth of student and graduate music therapy researchers in Europe and Australia.

\subsection{The development of varied frameworks for research}

Competency in research (and specifically in training) has consistently been an emphasis in the traditions of music therapy developed in the USA (Dileo Maranto \& Bruscia, 1987; Gfeller, 1995; K. Goodman, 2011; Madsen \& Furman, 1984; Schwartzberg \& Silverman, 2011) and interest in research grew rapidly in Europe and Australia during the 1990s as witnessed by commentators such as those referenced here (Bunt, 1994; Grocke, 2009; Ruud, 1998). However, as Bruscia (1989) argued in a statement of a personal premise he held about the content of music therapy education at undergraduate and graduate levels in the USA: "Music therapy is a clinical discipline. That is, its primary purpose is the practical application of music for therapeutic purposes. Theory and research are means to that end, rather than ends in themselves." (p. 84)

Bruscia's plea in the late 1980s for the possibility to develop in-depth and high level clinical or practitioner skills in higher degrees, as well as academic and experimental research capability was heartfelt, and in his address to educators, he was concerned with developing clinical practice to greater levels of mastery, and to maintain clinical integrity at the heart of the discipline. Perhaps this return to the 'soul' of clinical work was one way to respond to the strong development of positivist research in the music therapy discipline; a movement which had gained much credence and respect for the work in a general way over the previous forty years, but which specifically addressed predictive and measureable aspects of practice rather than emotional and spiritual elements. This reconnection with clinical practice amongst a substantial group of educators and researchers encouraged

\footnotetext{
${ }^{4}$ The CORE audit system used within the UK health service measured changes reported by patients thought to be beneficial and also included measure related to working alliance motivation and psychological mindedness of the patient.
} 
a flowering of interest and capability internationally in qualitative research during the 1990s which used the therapeutic, artistic and subjective skills of practitioners more fully. ${ }^{5}$

Further to this, the work of other researchers has pushed the diversity and boundaries of possible research approaches:

1) Austin and Forinash fostered the consideration of arts-based research (Austin \& Forinash, 2005)

2) Kenny developed thinking on indigenous approaches to inquiry (highly relevant in New Zealand, where Tangata Whenua, Māori research is of special interest) (Kenny, 2004)

3) Aigen and Lee made contribution respectively to music-centred and 'aesthetic music therapy' research (Aigen, 2005; Lee, 2003)

4) Ruud, Stige, Ansdell and Pavlicevic created a critical methodology of community music therapy research, drawing on ethnography and critical theory (Ansdell \& Pavlicevic, 2004; Ruud, 2010;

Stige, 2002; Stige, Ansdell, Elefant, \& Pavlicevic, 2010).

These steps have stimulated and enriched the connections that research can make with culture, participatory and collaborative action, creativity and art, and allowed educators to develop a diverse platform from which students and graduates can launch their interest and involvement, engaging with the diversity, and also the 'heart' of their work in ways that can suit personal style and varied research questions.

So returning then to my own place in the thesis, picking up Bruscia's gauntlet in the 1980's which was reiterated by Kenny (1998) and Abrams (2010) in subsequent decades, how was I - also as a practitioner and teacher - in my space and time going to make a student music therapy research component relevant, compelling, user-friendly and above all not undermine the clinical competencies which we as a department were charged to deliver? I felt it my duty and passion to find out how to integrate research in our training it so that it served the clinical competencies appropriately. Moreover I wanted it to be interesting, exciting even, for students to be involved. I knew I did not have many answers, just experience, curiosity and passion. My colleague was a great help, and many conversations and experiments ensued with our new programme in Aotearoa New Zealand. Nevertheless, it seemed worthy of inquiring more widely of those with more experience with including research in their courses, and with diverse contexts and backgrounds. My thesis was conceived.

\footnotetext{
${ }^{5}$ Smeijsters (1997) highlights the first international symposium for qualitative research being a particularly important context with colleagues from Europe, Canada and USA beginning to develop strategies for inquiry, in the preface to Multiple Perspectives. Wheeler in the two editions of Music Therapy Research (1995 and 2005) discusses the important changes in the development of qualitative research internationally.
} 


\subsection{Brief background to music therapy, training and practice}

\subsubsection{Music therapy}

Music therapy is a recognised profession in health, education and community services in many countries across the world, and its history from the treatment of World War II veterans in the 1940s and the establishment of the first training curriculum at Michigan State University in 1944 has been documented widely in the international literature (Bunt, 1994; Davis, et al., 2008; Karkou \& Sanderson, 2006; Standley \& Prickett, 1994). For readers outside the field, music therapy is characterised by holistic practice, involving participant 'client(s)' and therapist in music-making, listening or reflecting in words (depending on the field of work, from neonates to eldercare) and is guided by a range of theories from behavioural, client-centred/humanistic, medically-based, psychodynamically-informed, through to aesthetic, music-centred and community-orientated. The issue of definition of the field of music therapy practice is obviously a contested one, depending on which theoretical standpoints authors embrace, and it is interesting to observe over time the varied focus that has been given to rather medical terms such as 'treatment' and'disorder'(Alvin, 1975), more psychotherapeutic words such as 'relationship' 'dynamic' and 'client' (Bruscia, 1998a), musiccentred ideas of improvisation and musical process (Aigen, 2005; Association of Professional Music Therapists, 2001), and community-centred terms including 'participation', 'collaboration', 'inclusive' and 'health musicing' (Bonde, 2011; Stige, 2002). ${ }^{6}$

A broad definition with a focus on promoting health and sharing relationship through music, often quoted in the international literature, was offered by Bruscia (1998a) in a key work exploring the issues and implications of developing definitions of music therapy. Wheeler, Shultis and Polen (2005) use this definition in their training guide as a starting point for student music therapists to reflect on their own ideas about the field so that they might be able to appreciate "benefits and limits of a working definition" (p. 5). The breadth of terms across a number of theories made it useful in this regard. "Music therapy is a systematic process of intervention wherein the therapist helps the client to promote health, using music experiences and the relationships that develop through them as dynamic forces of change.” (Bruscia, 1998, p. 20)

A further comprehensive description of the scope of music therapy practice is given by the World Federation of Music Therapy:

\footnotetext{
${ }^{6}$ 'Health musicing' is described by Stige as 'the study and learning of the relationship between music and health'. (Stige 2002, p198). The evolution of the term is discussed by Bonde in a theoretical article for Music \& Arts in Action (Bonde, 2011).
} 
Music therapy is the use of music and/or musical elements (sound, rhythm, melody and harmony) by a qualified music therapist, with a client or group, in a process designed to facilitate and promote communication, relationships, learning, mobilisation, expression, organisation, and other relevant therapeutic objectives, in order to meet physical, emotional, mental, social and cognitive needs. Music therapy aims to develop potentials and/or restore functions of the individual so that he or she can achieve better intra- and interpersonal integration and consequently a better quality of life through prevention, rehabilitation or treatment. (World Federation of Music Therapy, 1997)

\subsubsection{Range of music therapy practice}

Music therapists in the $21^{\text {st }}$ century work in a wide range of health, education, social care and community contexts and with people across the lifespan. To illustrate, this includes the support of premature babies and their parents (S. Malloch, et al., 2012; Shoemark, 2011) right up to work with elderly people with dementia (Hanser, Butterfield-Whitcomb, Kawata, \& Collins, 2011) and end-oflife and palliative care, including clients, families and staff members (O'Callaghan \& Magill, 2009). Bunt's 1994 survey of areas of practice in the UK encompassed children with learning, emotional, cognitive, speech and language and sensory challenges, "the older person, including people with both neurological and psychiatric problems; the adult offender"(p. 9), and specialist services in hospices including cancer care and people living with HIV and AIDS. This added to the long-established work in the UK National Health Service in adult mental health and adult learning disability. He also anticipated that this range would grow and consolidate as music therapy became more established and this of course has happened in the last 20 years. Davis, Gfeller and Thaut (2008) give an overview of client fields where music therapy is offered in the USA, and they include key chapters on music therapy with: intellectually disabling conditions; autism spectrum disorders (ASD); physical disorders; elderly populations; behavioural-emotional disorders; neurologic rehabilitation; music therapy, medicine and well-being; hospice (palliative care); correctional (forensic) psychiatry; and sensory disorders . Increasingly music therapists are responding to the wider social context of the care of participants in their practice as witnessed by the references quoted at the beginning of this section, where family members and staff within the team are included in the musical engagement and considered part of the 'work'. Culturally-centred practice (Kenny, 2002; Shapiro, 2005; Stige, 2002) feminist music therapy approaches (Curtis, 2013; Hadley, 2006) and inclusive and collaborative work in community music therapy (Ansdell \& Pavlicevic, 2004; Stige, et al., 2010) have been increasingly valued in recent years. 


\subsubsection{What training is required?}

To qualify for entry to train as a music therapist, Darnley Smith and Patey (2003) advised that prospective students need flexible musicianship, personal suitability and "intellectual curiosity" (pp. 56-59). The curricula for music therapy education at both Masters' and Bachelors' levels internationally is centred on competencies or standards of proficiency, established by professional associations for music therapy in their respective countries. While competencies vary in detail and emphasis in varied international contexts, they focus on a) musical skills (for example voice, guitar, keyboard and percussion, plus the student's own orchestral or indigenous instrument such as 'cello, flute, mbira, djembe or Maori taonga puoro) and improvising, listening to, arranging and composing music (American Music Therapy Association, March 2009); b) psychosocial skills and knowledge, including knowledge of psychological theories, theories of group work, communication theories and processing, lifespan development, theories of stress, grief and loss; (Australian Music Therapy Association, 2004); c) clinical foundations, including knowledge of the characteristics of conditions, illnesses, syndromes and treatment: knowledge of local policies of health and welfare, disability, human rights, education and treatment, ethical issues of treatment (B. Wheeler, et al., 2005); d) music therapy knowledge, including history and theories of music therapy, music therapy research, application of music to behaviour and wellbeing (Australian Music Therapy Association, 2004); e) music therapy practice, including placement experience, planning, goal formation, assessment, evaluation, ethical professional behaviour, responsibility and teamwork, supervision and reflective practice (Bunt \& Hoskyns, 2002); f) cultural sensitivity and safety, self-awareness and care which may include personal therapy and/or experiential learning (HPC-UK, 2012).

I would suggest that broad holistic attention, throughout the course of training to be a registered music therapy practitioner, therefore needs to be given to students':

- being

- doing

- thinking

It is the balance of all these areas which Wigram and colleagues noted to be particularly important, but also particularly challenging to combine and monitor in a helpful way in the European music therapy curriculum (Wigram, et al., 1999). 


\subsection{Further background to the challenge of this thesis}

Challenging the gap between research and practice has been a topic of interest and concern to international allied health disciplines (McAllister, Paterson, Higgs, \& Bithell, 2010). It seems to have become a particularly pressing issue in recent years for example in clinical psychology (Stewart, Wiltsey Stirman, \& Chambless, 2012), psychotherapy (Goldfried, 2010), social work (Wells, Maschi, \& Yoder Slater, 2012), and nursing (McCormack, 2011). Music therapy shares some similar issues and Aldridge and Wigram for example both wrote in the early 1990s of the importance of supporting and encouraging clinicians to be interested in research (Aldridge, 1990; Wigram, 1993). It has continued to be of concern in the discipline and holistic, collaborative projects such as Wheeler's edited book Music Therapy Research in its first and second edition have contributed to demystifying and encouraging engagement in research by the practice-based discipline. As a matter of ethical responsibility, therapists need to offer service-users, or clients the confidence that they are using a meaningful and 'effective' approach that will assist wellbeing and development. Therefore there is an on-going need to train students in the field with an interest for and willingness to engage in research so that a model and lead is given.

Why is my focus in this thesis on 'integration' rather than something rather looser or just parallel in existence between the two areas? Does integration perhaps suggest blending and synthesis when perhaps all that is needed is friendly co-existence? Hints from other educators in music therapy and related professional fields imply that there is always a lack of time for including all that is needed in training curricula. Ferrer's (2012) research with active members of American professional bodies in music therapy specifically noted this concern by practitioners and educators in her conclusions. There is also a reasonably widespread reticence in education and allied health fields for practitioners and researchers to work closely together, for example the observation of such challenge in teaching (Cochran-Smith \& Lytle, 2009) in psychotherapy (Wolfe, 2012) and occupational therapy (Welch \& Dawson, 2006). So the consideration of integration of research and practice is both expedient - there will never be enough time to include all that is needed in education programmes - and also involves a desire and responsibility to address the problem of division_of research and practice at an early stage (in training) when ideas and opinions are forming.

On another level, the work of creative practising artists to sustain and develop their artistic journey and career has always implicitly involved 'research' of the medium. Some varied examples might be:

- the study of the clarino playing of a fellow Greek folk musician Manos Achalinotopoulos by contemporary New Zealand composer John Psathas (2010), (like Manos, of Greek heritage) in order to prepare for a composition The New Zeibekiko embedded in the sounds and rhythms of Greek culture. 
- experiments by Kronos String Quartet (2013) with the use of specific tonal and rhythmic patterns of La Sidounak Sayyada, a Syrian composition by Omar Souleyman in performance as part of Kronos Quartet's 40 ${ }^{\text {th }}$ birthday international tour in 2013

- the development of ideas about 'line' by visual artist Paul Klee, including numerous pencil and pen and ink sketches, and many reflections in notebooks, developing an "entire graphic vocabulary"(Naubert-Riser, 1988, p. 26)

- the investigation of the nature of location and the detailed history of the 'setting' for her novel Trespass, in rural France by writer Rose Tremain (2010).

The focus of such 'research' may be of a different type and approach to the research of health providers, but the imperative for artists to understand critically what they are doing with the medium, to search for new ideas and processes that will serve the discipline and their own values to the best possible levels is - I would argue - part of a related 'drive' and involves a creative impulse and a use of thought and documentary skill to store, develop and refine. The search for 'beauty' and 'truth', perhaps, as the poet John Keats described it (or many beauties and many truths, as a post-modernist researcher would say).

Arts therapies are interesting hybrids of the impulse of the arts to create new patterns and events and products in the world and the impulse of education, medicine and social care disciplines to develop 'effective' approaches to promoting health wellness and growth and caring for or treating people when they are ill. There are specific challenges across the arts therapies to find appropriate methods for research which might embrace the art, the healthcare or health promotion arm and authors such as Gilroy(2011b), Rolvsjord, Gold and Stige (2005) and Abrams(2010) (amongst many) have written about a range of solutions to these challenges. Others will be considered in the following chapter reviewing the literature.

\subsection{Personal Stance}

I should explain that I have been involved in the training of music therapists for more than 30 years (as a clinical supervisor and tutor initially) and then for the last 23 years as a programme leader, first at Guildhall School of Music and Drama, London and now for the Master of Music Therapy degree at Te Kōkī, the New Zealand School of Music based in Wellington, co-teaching practical and theoretical courses and supervising research with music therapy colleague, Dr Daphne Rickson. I have also continued to be a practitioner (most active in my first 20 years), and at different periods a researcher (with a focus on adult group work in neuro-disability and with recidivist offenders, and more recently 
on education of music therapists). So the dialogue between practice, research and teaching has been embodied within me throughout my career.

Recent graduates, current students, my fellow lecturer, our external examiners and I have been involved in an ongoing 'conversation' about how to manage our research input to the current Masters' programme I am involved with in New Zealand. Despite interesting challenges in this process, I have found this a very stimulating topic and it feels helpful to draw my own teaching and ideas about clinical practice into this research. Thus I am my own 'practitioner-researcher' as a teacher of music therapy and this seems a valuable parallel to the research-practice question I am considering here.

In any qualitative study of data, it is important to identify personal values and biases so that they can be kept in mind when we are analysing data. The following paragraph outlines my stance as researcher, taken from my research journal (RJ). ${ }^{7}$

My starting point for this research has been one of genuine ambivalence about the place of research in the training courses that we have generated for our music therapy profession. Part of me says, it is really sensible that we include it readily in the training process, because then it is familiar and 'up close', and everybody gets used to the idea that research is important. (We've got to do it anyway, if we are to be taken seriously as health professionals. Why not embrace it and go for it!) I was really attracted to music therapy initially in 1980 because I saw it as a research-focused profession. I thought it might not be, and the projects I became aware of, were rigorous and interesting. However the other part of me says: we want our clinicians to be talented, intuitive, practical musical people who engage with the public and who have the maximum opportunity to develop those values, skills and resources.

Students often say on our current programme that it is hard to switch between clinical and research modes and that they spend too much of their time on the research part. ... That makes me really sad, the students get bogged down in words and distanced from the musicalcreative process that they started out wanting to be involved with.

(RJ, $3^{\text {rd }}$ April 2009)

As I looked back on this statement when beginning the analysis of data I was very aware that my own perspective of 'ambivalence and balancing' between the domains of research and practice was very important to recognise. Other people may be very different in their perceptions. The intention of the research is to reflect the range of views represented by the participants - not just to validate my own.

However, my own views are powerful, especially because as a qualitative researcher I am interpreting, filtering and crafting the viewpoints of participants. I write in the methodology what

\footnotetext{
${ }^{7}$ References from my research journal will appear as a quotation in italics throughout the thesis, with the citation pink in colour. See also Section 3.8.3 for colour codes for the other data sources.
} 
steps I have taken to create transparency and to provide findings for this research that can be considered authentic and trustworthy. (See section 3.2.4 for details about the process.) Nevertheless, experience is also a kind of evidence and my own presence as a participant and observer in this research is acknowledged and hopefully justified in the course of this study.

\subsection{Broad research question for this study}

As I embarked on this study in 2008 , the broad question of interest to me as a curious educator was as follows:

\section{'How can research be integrated into the practitioner education of music therapists at} Masters' level?'

Further details of the sub-questions relating to the main steps in the study are addressed at the end of Chapter 2.

\subsection{Structure of the thesis}

The thesis is written using first person in keeping with traditions established in qualitative research (Guba \& Lincoln, 1994; B. Kamler \& Thomson, 2006) and it follows a well-established pattern of three preparatory chapters moving from this introduction (Chapter 1), through a review of literature (Chapter 2) and the methodology and methods of the study, which is located as Chapter 3. The first section of the thesis is followed by three central findings chapters which focus on the core themes I constructed from close analysis of the research data.

The findings chapters are entitled 'Being on Fire' (Chapter 4), 'Acknowledging and Managing Change' (Chapter 5) and 'All these meta-layers' (Chapter 6) and each is associated with a musical form, which exploits and plays with themes in a particular way. Chapter 4 is allied to Purcell's use of chaconne or ground bass; Chapter 5 is underpinned by Bach's theme and variation form and Chapter 6 is connected with Debussy's use of motifs of association (a kind of leitmotif) in opera. I attributed some specific meanings to these core themes; 'being on fire' was a constant repeating 'mantra' that remained steadfast (the chaconne); 'acknowledging and managing change' meant evolution and development of the material (theme and variations); 'all these meta-layers' was about complexity and the challenge of seeing a path (and here 'motifs of association' acted as a guide). 
The last stage of the thesis encompasses the discussion of the research (Chapter 7) and a short conclusion (Chapter 8). In the latter stage of the writing I have considered what the presentation of findings suggests for current and future education of postgraduate music therapy students, and have drawn together the distinctive perceptions of 19 involved contributors demonstrating the collaboration of their knowledge and feeling at a particular point in time. Although these accumulated ideas cannot be generalised, they have deepened my own understanding and I trust they could resonate with some recognisable themes and stimulate the curiosity of other interested readers. 


\section{CHAPTER 2 \\ LITERATURE REVIEW}

\section{Introduction}

The literature review for this study takes a wide perspective to gather from a range of professions the experience and history of integrating research into professional clinical training. Music therapy is the central discipline under consideration here, but other arts therapies, professions allied to medicine, and the fields of education, counselling, psychotherapy, psychology and nursing, are subject to similar influences and have experienced related challenges in the development of practitioner training expertise (see section 2.3). The search strategy for this study used 'Discover' within the EBSCO Databases including: Scopus, Web of Science, PsychInfo, Sage Online Journals, JStor, Academic Search Elite, RILM, to access relevant recent research articles about research and practice in the training of music therapists and other clinical practitioners, and to consider the issues about preparing students effectively for professional life as practitioner-researchers. Hand searches through music therapy journals, books by educators and music therapy education textbooks have also provided important source material.

Keywords included: music therapy education; music therapy training; music therapy research and practice; teaching evidence-based music therapy (EBP/EBM); integration of research and practice; practice-based research; practice wisdom; reflective practice; research-based learning.

The development of research alongside practice has been a significant contributor to the growth of the music therapy profession since its emergence as an identified field in the USA in the mid-1940s. The particular contribution of the American Journal of Music Therapy, JMT, (which began publishing scholarly research in 1964) and particularly the leadership of Charles Braswell to creating a research culture in music therapy was observed in a volume of reprints of the JMT (Standley \& Prickett, 1994). However in the prologue to the same volume (reprinted from 1968), Duerkson cited a challenge to the growth of research in the 1960s, noting that clinicians did not tend to have time, funds or energy to devote to research, and it was generally a separate task of the universities, training programmes and specialist research units to encourage and cultivate research (Duerkson, 1994). It is interesting to register this early tension in the relationship between research and practice, a feature that continues regularly to be the concern of other practitioner disciplines in the $21^{\text {st }}$ century for example psychotherapy, counselling, social work, occupational therapy as articulated in the previous chapter . Duerkson's observation was reiterated from the perspective of the practitioner 14 years later in 
Lathom's (1982) survey of American music therapists' views about their current functions, where a large proportion of the 464 registered therapist respondents did not consider research to be part of their interest or responsibility in employment .

Despite such findings, or perhaps because of them, there have been a few key studies since the1960s investigating approaches to involving students in research. Schwartzberg and Silverman's (2011) thorough review of studies involving music therapy students identifies that though the majority of studies in the educational field has been concerned with other areas of competency (such as clinical skills, field experience, choice of repertoire, and student experience of training), there were a small number of important articles investigating research capabilities of students. These included Michel and Madsen's (1969) inquiry about undergraduate students' use of behaviour modification (where research was found to be an essential part of undergraduate training); Hanser and Madsen's (1972) comparison of undergraduate and graduate research where no significant difference between graduate and undergraduate reports on research and related grades were identified, and one further comparative study by Madsen and Furman (1984) that indicated the potential for undergraduate students to be involved in research, whilst noting that graduates did demonstrate higher competency for research . However, whilst there continues to be ongoing active interest to investigate clinical aspects of students' music therapy education - Schwatzberg and Silverman (2011) review 15 other studies in this regard - there has been a gap in studies on the development of student research, specifically at the graduate level, and in a broad way this suggests that the current inquiry is timely, particularly examining postgraduate research in an exploratory qualitative way.

The tradition of Masters' or postgraduate degrees becoming the entry level for registered practice has developed in Europe and Australasia, and is imminently to be instigated in the USA (Ferrer, 2012) as noted in the first chapter. This allies music therapy more strongly to graduate professions such as clinical psychology which require Masters' or Doctoral degrees as qualifications for practice, and the issue about the presence of research in the training programmes has become more pressing. ${ }^{8}$ However, first, it is important to establish how some important debates about research in the field have developed and viewpoints and challenges about how they might affect the topic.

This first section of the review will be followed by studies and debates about the relationship (and potential integration) of research and practice (section 2.2); theories and studies about training in music therapy relevant to the topic (2.3); training in related fields (2.4) and studies about encouraging students to engage with research (2.5). The chapter ends with a summary of findings from the literature (2.6) and finally an outline of the main questions and sub-questions for the current research study (2.7).

\footnotetext{
${ }^{8}$ Funding issues are sometimes part of the challenge. For example in New Zealand, clinical degrees are expensive to run: research degrees are supported by central government and are much more likely to be financially viable for universities to develop.
} 


\subsection{Theoretical debates about what constitutes research in music therapy}

Debates about the nature and meaning of research have become a topic of much interest during the course of this research journey and it is significant that Wheeler (2005a), Edwards (2005a) and Ruud (2005) in the first three chapters of Music Therapy Research $\left(2^{\text {nd }} E d\right)$ all acknowledge the diversity of research pathways that have developed internationally over the past 40 years, and the different ways in which practitioner music therapists have developed knowledge about the discipline. Such factors as underpinning theories of practice (Ruud, 2005; B. Wheeler, 2005a), the kind of settings (medical and non-medical) and clients for whom music therapy is provided (Edwards, 2005a), philosophical belief about how knowledge is gained (Aigen, 1996; Ruud, 2005), and the dissemination of knowledge through the growth of peer-reviewed journals in individual countries (Edwards, 2005a) have influenced the way the music therapy discipline has understood and approached research.

Guba and Lincoln's (2005) chapter on the development of research paradigms in the Sage Handbook of Qualitative Research ( $3^{\text {rd }} \mathrm{Ed}$ ) looked back at the research landscape over 10 years from 1994-2005 and observed that rather than specific paradigms such as positivism, post-positivism and constructivism being in such obvious strong contention, there was increasing blurring and shifting of the boundaries: "Indeed the various paradigms are beginning to "interbreed" such that two theorists previously thought to be in irreconcilable conflict may now appear, under a different theoretical rubric, to be informing one another's arguments" (p. 192). They noted that this was influenced by the nature and growth of disciplines contributing to research knowledge, and a number of music therapy researchers have observed similar patterns in the development of paradigms in music therapy.

Ruud (2005) surveyed the wide ways of knowing that have developed across music therapy practice and recognised the profession's need to hold the science and art of the discipline in mind in the research frameworks employed. He also observed the frameworks of positivism, post-positivism, constructivism, post-structuralism, including critical theory, and how these positions have developed and influenced each other and shaped knowledge about music therapy (Ruud, 2010). Robb's (2012) editorial to the Journal of Music Therapy acknowledged similarly a complex web of theories that are now underpinning music therapy's remit to practice and the value of seeing their complementary appearance within one volume of the journal was a source of pride and pleasure for the American Music Therapy Association . O'Callaghan (2009) reflected on the value of both objectivist and constructivist research contributions to music therapy in oncology and palliative care and concluded that the combination of both approaches provided important multi-faceted understanding. She also noted that medical practice had shifted understanding of the value of plural approaches to evidence particularly through the contribution of wide-ranging and valuable qualitative research . Stige's (2002) perspective was that there were two dominant paradigms which have prevailed over the 
history of the music therapy discipline till the new millennium, but proposed the consideration of an important third which involves a social, critical and cultural framework identified by Alvesson and Skoldberg. Stige highlights the elements of their definition which centre on reflexivity: "the awareness that we construct ourselves while constructing the objects or phenomena that we study..." (Stige, 2002, p. 308). Stige's introduction of social and cultural theory in this conceptualising about research has also underpinned changes in music therapy practice, and the growth in the last 10 years of cultural and community-orientated approaches, particularly in Europe and Australasia (Stige, et al., 2010).

Each of these perspectives points to a rich and potentially challenging research environment to which educators might introduce their students. As Robb highlighted, the theoretical position of the research is highly important and guides the nature of inquiry, and similarly the theoretical perspective of education programmes may be an indicator for the sort of research that is deemed valuable to highlight to students and for which to create a training pathway. This literature review surveys a number of areas in healthcare and education for information and research to clarify and guide the current research, and the complex challenges observed. First I will provide an overview of some of the debates and perspectives on research which have affected the discipline, and which impinge on educational theories and practices.

\subsubsection{Positivist (quantitative) research}

Brew (2001, 2012), in an extensive examination of research and teaching in universities, identified some specific trends in the way that university departments have approached research. Two of these descriptions parallelled positivist and constructionist approaches. She described the positivist tradition as the 'domino view' (citing her own 2001 research) whereby you focussed on the solutions to problems and "you are trying to basically come up with a solution to the problem that you or others have identified for you, and you're hoping at the end of finding this solution you're able to push the frontiers of knowledge" (p. 104).

The building of music therapy research between 1960s and the 1990s focussed strongly on the positivist tradition in America, and Edwards (2005a) observed the importance of the growth of peerreviewed journals, from one journal to six, during that period as significant parallel growth. The two processes were mutually supportive, studies had a suitable destination for publication, and journals had a reason to 'be' with a steady supply of research. Gfeller (1995) reflected on the choices of research approach open to university programme staff working with music therapy students in the 1990s. She observed that there were distinct challenges to lecturers choosing clinically-focussed studies because of the constraints placed upon them by university environments. Her chapter in the first edition of Music Therapy Research presents an interesting rationale for why basic (quantitative) 
research may have grown so specifically at that time. Gfeller reflected that it would have been less time-consuming, easier to fund (because of the link with behavioural sciences), and the university settings would have been more separate from clinical communities and thus recruitment for applied studies more difficult to progress (with ethical constraints adding to the time commitments). These observations reveal some of the complexities of decision-making about the involvement of students on university music therapy courses in research. The traditions and funding of the institution and expertise of the staff will inevitably colour the available choices about research approaches, and universities continue to have strict agendas about the requirements for research from employees and postgraduate students.

Bruscia (2005b) outlined the differences in philosophy behind quantitative and qualitative topics in research, reminding that quantitative researchers would usually be seeking answers to closed questions, and determining if a hypothesis is true or false. The focus is on the interaction of variables and the control of the study. This contrasts with qualitative studies where the questions would be specifically open-ended, inviting interpretation and rich description. However both these paradigms may be able to espouse Wheeler's very broad and simple definition of research as a "return to searching" in the idea of looking repeatedly at materials or data, as some sort of middle ground. Wheeler (2005a) also quotes a personal communication with Eagle in his short description to "embark again and again on a journey of discovery and explanation" (p. 3). However the definitions of what constitute research between the two fields remain many-layered, contested areas.

\subsubsection{Qualitative research}

Denzin and Lincoln (2005a) reported on the complex historical field through which qualitative research has evolved in the third edition of the Sage Handbook of Qualitative Research. They offered defining characteristics of qualitative research practice which consisted of:

- Situated activity that locates the observer in the world

- A set of interpretive material practices that make the world visible

- Representations such as field notes, interviews, conversations, artifacts and memos to self which can transform

- An interpretive, naturalistic approach attempting to make sense of the meanings people bring to their worlds ( p. 3)

These kind of qualities are also captured in the important texts and articles about qualitative music therapy research which developed in the 1980s and 1990s, through international collaborations between music therapy scholars and practitioners. Langenberg and colleagues (1996) and Smeijsters (1997) reported in detailed complementary volumes on the excitement and changing possibilities for 
clinical research, generated by the meeting and exploration of scholars interested in the constructivist or qualitative paradigm. Brew $(2001,2012)$ contrasted the 'domino' approach to research (which was quoted in 2.1.1) with what she described as the 'layer' approach: "In contrast, in the layer way of conceptualising research the focus looks inward... you're trying to assemble it into meaningful patterns and orders...Here, research is interpreted as a process of discovering, uncovering or creating underlying meanings.” (p. 104)

In a landmark edition of the Journal of Music Therapy celebrating qualitative research, Aigen (1998), Bruscia (1998), Kenny(1998) and Ruud (1998) all noted the sea-change in possibilities for the interface between practice and research that could be brought about by qualitative approaches to music therapy. Researchers would be able to draw on more personalised, client-centred and artistically focussed data and draw closer to the 'qualities' of clinical practice. However these researchers also indicated the complexities, rigorous standards for integrity, and varied training and expertise that might be needed for the development of this emerging field. This was an exciting but challenging period in music therapy's growth in research.

\subsubsection{Indigenous research}

An important area of research methodology that emerges for consideration in the music therapy field and which will be ripe for development as the profession has grown in its awareness and understanding of the different cultural spaces inhabited by practitioners and participants in therapy and research, is indigenous research. Ethical health and education research in Aotearoa New Zealand requires all health practitioners to consider the principle that health outcomes for Māori people should be determined by Māori (as laid out in the Treaty of Waitangi). Thus any health research which involves Māori participation needs honest, meaningful partnership and collaboration with the local Iwi community. Tuhiwai Smith (2005), University of Auckland, has been a leading international writer on indigenous research, and she emphasises the 'tricky ground' that research sits on in bicultural communities, and that researchers need to ask careful questions of themselves, participants and advisers when research is developed with indigenous participants. Colonial practices can recur in many hidden ways in the process of questioning and developing research .

Kenny $(1989,1998,2004)$ has written over a long period of different cultural ways of knowing that have informed her inquiry and could contribute meaningfully to music therapy research. Collaborative work with a group of indigenous scholars and advisers produced guidelines for holistic aboriginal research in Canada, and emphasised an awareness of history and politics for First Nations in Canada. The guidelines outline and describe the importance of developing collaborative meaningful research by and with aboriginal people, which honours spiritual, emotional community processes, and the interconnectedness of life (Kenny, 2004). A recent book by Hadley (2013) interviewed 20 music 
therapists about their experience of race, and three 'first people', including Kenny were participants in the study. Hadley emphasises that these music therapists all speak strongly of the spiritual part of their understanding of music therapy practice, and it seems that this aspect of music therapy's quality and characteristic may have the potential to be especially well-observed in an indigenous approach to research. Inspiring contributions to the knowledge base of the discipline could unfold, as more indigenous practice and research evolve.

An article developed from indigenous scholar Ethel Stelómethet Gardner's (2008) thesis on the musicality of native American language was published in the Voices Journal in 2008, giving rich example of the way that an indigenous methodology can provide excellent fit with the subject matter. Kenny supervised this doctoral project. A master of music therapy student in Aotearoa New Zealand, Dennis Kahui (2009) developed his own Māori perspective on his practice using Kapahaka ${ }^{9}$ with young people with mental health challenges, and in our Master of Music Therapy programme, this was the first endeavour to support an indigenous project, jointly supervised with Dr Bronwyn Campbell from Māori Studies, Massey University. The contribution of Māori studies was very important to this project, and five years on from the start of Dennis' research we can be better informed about how future projects might evolve from Tuhiwai Smith and fellow Māori researchers.

\subsection{Theoretical debates and research addressing the relationship and potential integration of research and practice:}

Considering the research question, this section of the review directly addresses the core of my question which is concerned with how to relate practice and research. A number of strategies and concepts come to the fore here, and they are explored through the lens of a variety of professions.

As noted in Chapter 1, Aldridge (1990) and Wigram (1993) were concerned to support and encourage clinicians to be interested in research. They recognised the difficulties experienced by clinicians to be confident and informed about research strategies and also the importance of developing research which would be relevant to the concerns and interests of practitioners. Both authors worked strenuously in Europe, to build interest in practice-based research, and successfully developed research centres at University of Herdecke, Germany, and Aalborg University, Denmark, where students could grow into the 'researcher position' and also supported departments respectively at the

\footnotetext{
${ }^{9}$ Kapahaka is a specialist arts and cultural practice of New Zealand Māori, and uses spiritual connection singing, movement, dance, gesture, expression, in varied ways in different Iwi, (or tribal communities) in Aoteroa.
} 
Nordoff-Robbins Centre London and at Anglia Ruskin University Cambridge UK and the University of Melbourne, Australia to build research-active teams.

Kenny's (1989) development of 'The Field of Play' had a key interest in the links and integration of research and practice, and presented the challenge of designing research tools directly informed by practice, and Wheeler (2005a) observed Kenny's consistent interest in the challenges presented by combining practice and research as well as the benefits. The issue of the interface between practice and research also pursued in an exchange of writing by two Australian researcher-clinicians, Edwards (2006) and Shoemark (2006), who share passionate interest in the play between the domains of practice and research. Recognition was raised by both authors of the varied agendas of research and practice and Edwards reflects on how difficult it is to raise the possibility to explore the "delight of the inexplicable, the creative unknowing" in the research we pursue and that academic expectations are regularly "privileged" over artistic ones . Both authors have gone on to create opportunities for the integration of the two 'fields' and to work with students to explore research, but their dialogue was timely and interesting for the challenges that I anticipated meeting in this study.

From another perspective across the field of how research and practice relate for students, Ansdell and Pavlicevic (2001) published a guide to student arts therapists considering directly the issue of developing practice-based research for entry-level therapists. The textbook offers a valuable and very practical contribution to this area and embraces the idea that universities might support students to research their practice with clients .

Wheeler (2005a) observed the growing awareness of music therapy educators that students "should" be involved in applied research and drew attention to a Debate Day in Aalborg (focussed on clinicians researching their own work) which has since grown into substantial multi-levelled clinical research at Aalborg, and connected it with the web-based forum connected to the Nordic Journal of Music

Therapy, led by Trondalen and Wigram (p. 9). Wheeler ends this section of her overview of the field with a reminder of the complexity of the relationship between practice and research but indicates the importance of both clinicians and researchers becoming involved in the debate. It seems at the point that Wheeler published this overview, the topic of this thesis was suitably timely.

\subsubsection{Evidence-Based Practice}

As introduced in the previous chapter, evidence-based practice (EBP) is a key factor in $21^{\text {st }}$-century healthcare and it impacts on management of services, on practitioners charged to deliver 'effective' evidence-based services, and also on students learning about their fields. In music therapy the terms 'Evidence-based Practice' and 'Evidence-based Medicine' have been used widely, and sometimes interchangeably as the discipline operates in both health and education sectors. In the course of this thesis I choose to refer to 'Evidence-based Practice' (EBP) as a combined term for both areas, just to 
create ease of language. Like the term 'research' itself, EBP evokes different definitions and nuances, and Taylor (2008) observed that in the nursing literature at least 14 separate definitions had been found. Abrams' (2010) article on the possibilities for an integral understanding for music therapy's evidence-base created his own working definition for EBP as follows: "When client and therapist work together through music to promote health, guided by grounds sufficient to help ensure that the work is valuable" ( p. 360) This of course is a much 'softer' idea of evidence than the medical profession promotes, but Abrams' argument (along with other music therapists who have written about the challenge: for example Edwards (2005b) and Pavlicevic et al (2009)) is that music therapy needs to be involved in setting the parameters, and it can only do so if music therapists also create potential frameworks, especially if we are uncomfortable with the evidence hierarchy as it currently exists.

EBP is a highly significant area where music therapy practice and research are brought together in the professional literature and music therapy's relationship with EBP is clearly developing and expanding through contributions to research and writing. Significant increases in the number of Cochrane systematic reviews of research being published have assisted music therapy's standing with the evidence base. For example, a recent important review on outcomes for cancer patients added to the library is a collaborative study by Bradt Dileo, Grocke, \& Magill(2011). Additionally music therapists are both suggesting pathways for adhering to the principles and engaging with the process of EBP, and also for making appropriate and robust challenges to its development as evidenced by Abrams above.

A range of literature from nursing, teaching, counselling, music therapy and other therapeutic professions suggests that the development of research literacy and 'research-mindedness' in students and new graduates is increasingly important across all these professions (Freshwater, Taylor \& Sherwood, 2008; Lytle \& Cochran-Smith, 1992; McLeod, 2004; Rolvsjord, et al., 2005; Smith, 1997; Welch \& Dawson, 2006; B. Wheeler, 2005b; S. Wheeler \& Elliott, 2008). Although the debates about this are many and varied, two major themes emerge:

1) the need for professions to develop their knowledge and evidence base in order to refine theory, demonstrate effectiveness, to justify and develop employment (in the smaller professions), and to respond to professional registration requirements;

2) the value of research as a mode of professional development, maintaining professionals critical interest and developing their skills in the field.

With the professional bodies calling for increased awareness and facility with research, it is clearly relevant that tertiary institutions consider how practitioners will be prepared for this, and how attitudes and skills might be developed (Bilsker \& Goldner, 2000; Kedge \& Appleby, 2009). 


\subsubsection{Challenges of Evidence-Based Practice}

Many authors in healthcare professions including music therapy have written in the last decade about the challenges of EBP and how to encourage and develop effective use of evidence amongst practitioners. Some brief examples are in nursing (Freshwater, 2008), art therapy (Gilroy, 2006), occupational therapy (Welch \& Dawson, 2006), music therapy (Pavlicevic, et al., 2009), counselling and psychotherapy (McLeod, 2004). Pugsley (2008), a medical educator, discusses the dissonance that can occur between professional values about evidence-based practice and the specific quality of teaching and learning in the education of doctors. She notes that "communities of practice need to be fostered to enable researchers to collaborate and disseminate good practice" ( p. 866). In classroom teaching of science, a study by Ratcliffe and colleagues (2005) investigated the perceptions of a sample of participants, including primary and secondary classroom teachers and curriculum policymakers about the "nature, actual use and potential" of research in the classroom. They concluded that "increasing use of research evidence requires researchers to translate outcomes of research into practical actions and practitioners to be skilled in using evidence systematically in evaluation of their own practice" (p. 169).

A common problem for arts therapists articulated by Rolvsjord and colleagues (2005) is the challenge of accounting for the flexible measures needed for responsive client-centred practice, in the frameworks used for randomized controlled trials (RCTs). The EBP movement, they argue, is deeply grounded in a medical model that uses 'therapist induced interventions' and the language of "treatment, interventions, and mechanisms" rather than music and other therapists' terminology of "therapy, collaborations and processes" (p. 21). This argument is also supported by Abrams' more recent work (Abrams, 2010).

Many of these authors acknowledge that music therapists and others need to present the evidence in order to progress as relevant and efficacious disciplines, and to find ways, within the respective professions, for undertaking or contributing to appropriate RCTs but also recommend robust arguments to respond to these challenges. These would include educating clinicians (and by implication student clinicians in the habit of being research-aware and research-friendly) so that appropriate forms of evidence can be developed for person-centred professions.

It is ironic that that music therapy and other allied professions have greatly developed their interest in research since qualitative frameworks have become more prevalent routes into inquiry, yet qualitative studies rank quite low down the hierarchy of 'evidence'. Qualitative studies appear only above expert opinion, but greatly below RCTs and systematic reviews. (Evans , 2003 cited in Pavlicevic, et al., 2009, p. 17). This produces a dilemma - the research that practitioners might want to undertake tends 
to be related to the meaning and quality of the intervention; the research required by health providers and governments is about outcomes and effectiveness.

One of the arguments often returned to by researchers in clinical fields has been the value and importance of case studies. McLeod (2002a) articulates this clearly in an interesting article in Healthcare and Counselling Journal. Wheeler (2005b) devotes Chapters 24 and 35 to quantitative case study design and qualitative case study research in the key text 'Music Therapy Research', that has helped define the parameters for research approaches in $21^{\text {st }}$-century research in this profession. Case studies are meaningful forms for practitioners and students and seeing these as starting points for research may assist the bridging necessary for practitioners to become interested and curious about research.

Interestingly, even the directors of institutes for EBP begin to see the difficulties to conduct RCTs for professions whose clinical care involves complex relationship factors in treatment, as has been aptly noted by British colleagues Pavlicevic et al. (2009) in their guide to therapists developing understanding of clinical effectiveness. "There are all sorts of observational techniques we can use and have been used very effectively over the years... we ought to be prepared to accept the results of those sorts of studies". Sir Michael Rawlins, Chairman of the National Institute for Clinical Excellence (NICE) Foundation, U.K. (p. 15) If music therapists can take an active place in the development of their own research strategies and contribute critically to the arguments as Pavlicevic and colleagues contend, there is a much better chance of the values of the evidence-based movement being influenced. This starts, of course, with the education of new therapists.

\subsubsection{Practice-Based Research}

Practice-based research is described by Epstein (2001) as "the use of research-inspired principles designs and information gathering techniques within existing forms of practice to answer questions that emerge from practice in ways that inform practice" (as cited in Callaghan, 2005, p 220). Since Gfeller's (1995) observations about the difficulties of university researchers engaging in clinical research (section 2.1.1), there has been a strong and steady expansion of published research in the international music therapy journals which can be identified as practice-based research (for example in the Nordic, British and Australian Journals, and in the clinically based Music Therapy Perspectives, and the Journal of Music Therapy from the USA). The rise of qualitative methodologies for doctoral research such as phenomenology (Forinash, 1990; Grocke, 1999), naturalistic inquiry (Aigen, 1991) and grounded theory (Amir, 1999; O'Callaghan, 2001) led to a culture of more confident engagement with the complexities of real-life research as witnessed by Wheeler's (2005a) overview of music therapy research methods and approaches. 
Some examples of the range and variety of topics that have been published since the millennium in this expansion of the practice-base to research include: Aldridge's (2005) outline of case study designs employed by researchers in learning disability, medical environments and mental health; Edwards' (2007) vivid anthology of international studies using music to promote health in oncology, neonatal and acute hospital care, inter-cultural practice in a postwar environment and in refugee and asylum seeker communities; Wosch and Wigram's (2008) collection of studies exploring microanalysis of musical phenomena, and Bergstrom (2011)'s contribution to the use of graphic notation as a strong practice and research tool in music therapy. Ansdell and Pavlicevic (2010) reviewed Nordoff and Robbin's contribution in the 1970s to developing a form of practice-based research in their identification of "Gentle- Empiricism" in the Nordoff Robbins' tradition. They observed that this had been a natural and rigorous process leading practice into a form of reflective research, wholly relevant 40 years later. An interdisciplinary study by Ansdell and colleagues (2010) in a variety of fields using Stern's theory of the present moment was another example where complex issues in mental health music therapy practice could be explored in a research framework.

Significant contributions to advancing theory about practice-based research have been made in teaching and learning and in counselling and psychotherapy through the work of researchers Lytle and Cochran-Smith (1992), McLeod $(2002,2004,2010)$ and Cochran-Smith \& Lytle $(1993,2009)$ in numerous publications over a long period . I have chosen to focus mainly on these widely-cited authors in this area of research to give a sense of the depth contributed by other disciplines. Music therapy has some important parallels with counselling/psychotherapy and teaching and the resonance of the sorts of issues concerned was striking in reading the commentary of these authors. One of the interesting features in surveying their work was the practical and theoretical parallels that occurred between their disciplines and music therapy in:

- the complexity of the field work studied

- the ethical constraints

- the challenges of helping student researchers who are good practitioners to also be good researchers

From their perspectives of counselling and teaching professions, these authors have argued for the value of research as professional development for practitioners. McLeod (2002b) observed that involvement in research can raise the self-esteem of practitioners helping them feel they are making a difference - and contributing to knowledge in an energetic and interested way. This is strongly underpinned in the education field in Lytle and Cochrane Smyth's (1992) in-depth study of teacher research. Professional development has a significant contribution to make in helping practitioners avoid 'burn-out', and encouraging practitioners to see research as valuable or relevant professional development will be a key responsibility in education for the future. 
Welch and Dawson's (2006) action-research study in occupational therapy showed the important influence of support and collaborative learning groups to increase the confidence of practitioners' working in the EBP environment in the UK. An example given showed one person's attitude to the idea of researchers being people who "are good at reading and theory and that kind of stuff, but they don't have the people skills or the problem solving skills we need in practice" changed to an attitude of confidence in her own ability to understand and become involved in research. The authors also emphasised the point that "insider knowledge of the dynamics between therapists was essential to the formation of collegial relationships... honest and respect... that enabled learning to act as a catalyst" (p. 234). This suggests that the role of the researcher should not just be left to 'research experts' from other fields, but needs to be taken up and embraced by each profession. Practitioners are much more likely to trust people with insider knowledge of the discipline and again this has implications for training student therapists at an early point to be research-minded. McCormack (2009) argued for the relevance and value of practice-based research in the nursing profession, but was cautious to emphasise that "the creation of critical spaces" for nurses to understand and develop knowledge about their practice was of prime interest when a research focus is created (p51).

While a number of authors have strongly advocated for the huge value and interest to practice that relevant practice-based research generates, a concern that echoes in the literature is that practitioners worry about time. Pettifer (2004) interviewed counsellors for a special issue on research in the Healthcare Counselling and Psychotherapy Journal and reported that while there was enthusiasm for post-Masters' research "they baulked at the idea of giving yet more of their (unpaid) time' - there was just too much else for them to do" (p. 2). O'Callaghan (2005) also observed the large amounts of time and effort required to complete journal entries after a full day of clinical practice, set against unique rewards (particularly in terms of developing clinical insights) of undertaking reflexive journal analysis as a form of practice-based research.

A suggestion that the integration of practice and research was a fairly rare approach, but one that is attractive to students, was made by Henton (2012) in counselling psychology.

\subsubsection{Reflective Practice}

Reflective practice is a very widely used term that has grown and developed by the use of many disciplines in clinical practice and education. This term is one that is centred in practice but the notion of 'reflection' has an emphasis in thinking and perhaps theorising about practice, and as such immediately suggests a leaning towards the possibility of research-mindedness. As a practice-led concept, it is helpful to include here as it helps us to consider the iterative relationship between practice and research (it can lead from either direction). Two definitions from the disciplines of teaching and nursing provide some context here. Educators Osterman and Kottkamp (1993) offered a 
description of reflective practice as "a means by which practitioners can develop a greater level of self-awareness about the nature and impact of their performance, an awareness that creates opportunities for professional growth..."(p. 2) Taylor's (2006) definition from the discipline of nursing calls on the history of Schön's influence in the field of reflective practice in architecture training (see next section 2.2.5). She links human reflection to physical properties of reflection, thus reflection is "... the throwing back of thoughts and memories, in cognitive acts such as thinking, contemplation, meditation and any other form of attentive consideration, in order to make sense of them, and to make contextually appropriate changes if they are required". (as cited in Taylor 2008, p. 26)A further definition from nursing practice developed by Professor Christopher Johns (2009) places an interesting emphasis on being and doing. "Reflection is learning through our everyday experiences towards realising one's vision of desirable practice as a lived reality. ... Reflection is a special quality of being...."( p. 3)

Both Johns', and Osterman and Kottkamp's definitions put emphasis on practitioner development and learning (which has an interesting intersection with student training). All definitions imply or go on to describe the importance of experienced guide or supervisor to test out reflections - and the link with supervision will be explored in the following section, 2.2.5.

Schön's (1987) seminal text on education in reflective practice made a strong link with the challenges of research in academic environments encountering "the problems of real-world practice" (p. 4) - and his basic assumptions about reflective practice are very helpful when thinking about training in practice disciplines.

\subsubsection{Reflective Practice and Supervision}

Another strand of development in the music therapy profession over the past decade has been that of developing the music therapist's skill at reflection on clinical practice through supervision. In many countries, clinical supervision is now an essential requirement for professional development of music therapists. A growing number of publications about clinical supervision and helping both student and experienced practitioner to deepen understanding of their work through 'reflective practice' have appeared before and after the millennium (Brown, 1997; Forinash, 2002: Gentleman Byers \& Forinash, 2004).

Interest in reflective practice has developed strongly over recent years across a number of the health and education professions reviewed in this brief survey and it was exciting to see a new volume from nursing make a thorough exploration of how practice and research might be linked easily and productively and that the cross-disciplinary movement for reflective practice could assist the integration of the two areas (D. Freshwater, Taylor, \& Sherwood, 2008). Taylor (2008), from her perspective in nursing practice, has developed valuable thinking in the ways that reflective practice 
can bridge practice and research questions, and can help the nursing profession "attain higher levels of awareness and change strategies" in relation to varied topics of interest. She argues its use in "finding and validating" knowledge in nursing (p. 21).

In her own music therapy research and supervision of practice with students, O'Callaghan (2005)has pioneered strategies and thinking for linking student work and practitioner reflection in interesting ways that are embedded in and point towards research. Her student Barry, and O'Callaghan (2008) co-wrote a study about a student developing practice wisdom and this article explores specifically the technique for the student of thinking reflexively about practice in the form of journal documentation. O'Callaghan (2005) demonstrates its strong value for developing the practitioner as she describes "by combining the two roles into a clinician-researcher, one's practice wisdom can be uncovered and extended, and professional curiosity can be reinvigorated, arguably resulting in improved clinical practice and job satisfaction"(p. 227).

Here music therapy can be linked to other areas of learning which have 'fieldwork' or practice-based components. Schön's (1987) ground breaking work in the teaching of architecture has influenced many tertiary level educators in their thinking about developing the reflective practice capacities of students in many fields. Interest in reflective practice is an important development in tertiary education and crosses many disciplinary boundaries. For the purposes of the current study it seems that the concept of reflective practice may be explored as a useful pivot between the initial process of thinking and wondering about practice and the process of thinking required to develop research ideas (Barry \& O'Callaghan, 2009). This leads towards the idea of research growing out of practice interests and reflection as a normal and regular part of casework. Baker's (2007) action research study on using a problem- based learning strategy to develop clinical reasoning similarly employed a reflective stance by students.

\subsection{Studies and theoretical perspectives on music therapy training}

The cyclic nature of challenges in the music therapy field was emphasised to me in reviewing materials about undergraduate music therapy training, about which there is more substantial research and literature than the postgraduate field. Madsen \& Furman (1984) reported on the priority for developing of research at undergraduate level. They observed the problem that failing to draw undergraduates into research as part of their first degree would lose an important opportunity both for the profession and for individual therapists. With no modelling or training as researchers, students would go off in other directions and "the profession will have difficulty availing itself of research efforts" (p. 171). They concluded in their comparative study of graduate and undergraduate work, that 
the capacity for research-mindedness was clearly present in 'younger students' and valued having it alongside the clinical learning.

The close and interdependent relationship between practice and research is an important topic in the professional healthcare field for music therapy practitioners once qualified and registered, which has inevitable implications for training. However, in training, the processes, as described in the available research and literature, often appear to be developed somewhat separately, perhaps because research appears as a more advanced skill, as indicated in the following publications: (Ansdell \& Pavlicevic, 2001; Bunt \& Hoskyns, 2002; Darnley-Smith \& Patey, 2003; Davis, et al., 2008; Dileo Maranto \& Bruscia, 1987, 1988; Hanser, 1999; B. Wheeler, et al., 2005; Wigram, Pederson \& Bonde 2002). In some of these books on training, the text may be devoted rather specifically to clinical skills (Hanser, 1999; B. Wheeler, 2005b) or to research skills (Ansdell \& Pavlicevic, 2001) and the other aspect noted respectfully, but not in specific detail. In others theory and practice is discussed and woven through the book (Dileo Maranto \& Bruscia, 1988; Bunt \& Hoskyns, 2002; Darnley-Smith \& Patey, 2003; Davis, et al., 2008) but 'research' as topic is focused in one or two chapters (often as a higher level activity) and therefore framed separately.

In looking for indications about integrating clinical and research skills in training, a number of sources made quite definite links between the two processes. Baker (2007) outlined an action research project on the development of clinical reasoning skills in music therapy students - researching her own practice of teaching. This was focused on clinical work, but it drew importantly on processes that are intrinsic to research - thinking, evaluation, critical approaches to practice and formulation. As noted above, Barry and O'Callaghan (2009) made specific links about a practice strategy (reflective journal writing) being of particular value for assisting students to develop research thinking. Luce's doctoral research (2001) and subsequent published report of music therapy student teaching (2008) emphasised group learning and collaboration as a way to marry and connect the developmental and learning needs of undergraduate students. Although at an earlier stage in the tertiary system, with possibly less independent research capability required, the principle of holistic learning in collaborative learning consensus groups with peers was generally valued by students as an important tool for building knowledge and conceptual understanding about practice, as they moved through the training process. Baker and Krout's (2012) study on collaborative peer songwriting showed how reflective documentation about the learning of songwriting skills increased insight and reflective capacity about clinical practice - findings that show interesting connections between practice learning and the potential for research. Hahna's (2011) doctoral research investigated feminist ways of knowing in music therapy training, and her findings in the thesis, and in Hahna and Schwantes' (2012) survey on feminist pedagogical approaches, indicated that critical thinking and reflective capacity were enhanced by collegial, supportive classroom environments and the active personal involvement of educators. 
Dileo Maranto and Bruscia $(1987,1988)$, and Goodman (2011) took a 'competencies' approach to training, and it is interesting that Goodman's recent text on training provides a more central place for 'research competency' within the framework of student education, perhaps reflecting the growing agenda of evidence-based learning and teaching. I wondered about the indications from the literature that practice and research seemed to be outlined and advocated as separate skills whilst recognising that the details of individual training programmes are not generally published. Writing about training may not be capturing a full picture of current educational practice. This further suggested that more research reviewing pedagogical approaches to music therapy training might be indicated. It seemed that some reasons for separation of practice and research in the training programmes (in music therapy and other disciplines) might include how differently music therapy educators we may conceive learning about practical patient-centred skills, and developing thinking, analytic and documenting skills. It may also be theory-specific (the orientation of the theoretical teaching, whether strongly empirically driven, or human-centred in its treatment approach). Silverman (2011) and Wheeler (personal communication) eminent researchers and trainers in the USA both discussed the importance of early research training in quantitative approaches at Florida State University and how this inspired future steps. It may be that where Bachelor's degrees in music therapy have traditionally been the centre of training, such as in North and South America, that practical clinical approaches happen first and research becomes the province of the higher 'research led' degrees. As the introduction of research-orientated learning for undergraduate students becomes more prevalent (such as in Inquiry Based Learning, (Cleverly, 2003; Healey, 2006) and integrated research and teaching as advocated by Brew (2001, 2010), University of Sydney (see section 2.5 below) it seems that models of integrated research and practical/theoretical learning might be considered and developed in many fields, including those for practitioner training. In the course of this review a central aim is to gather knowledge about patterns of connection or separation of the processes, how they have developed, and what is the current state of play in the discipline in 2011-12 and the backdrop for the study developed in this thesis.

\subsection{Studies and theoretical perspectives on training in related fields}

A range of training disciplines which involve placements or practicum out in the community to develop practice skills were useful comparable territory to consider here. Education, and other allied health disciplines have of course thought deeply over decades about the way that the curriculum might deliver practice and research as integral components in student learning. Many of the debates are complementary to those which have developed in music therapy, and thus there is much to be learnt. Issues range from developing research-mindedness in nursing (Smith, 1997) and research awareness 
in counselling and psychotherapy (Wheeler \& Elliot, 2008), to skills with the research literature in dance movement therapy (Higgins, 1996), distinguishing between research-informed "capital K knowledge" and simpler level 'knowing' in the practice environment (Lytle \& Cochran Smith, 1993, p 440), building evidence-based understanding (McNamara, 2002; Gilroy 2006) and to reflective practice in all professions ( for example, Freshwater et al 2008; Gentelman Byers \& Forinash 2004; Osterman \& Kottkamp, 1993) .

Nursing and teaching, and allied health professions such as counselling and psychotherapy and social work have some clearly defined stages in their progress with these issues. For example, Esterhuizen and colleagues (2008) outlined some particular robust steps for changing the nursing curriculum from a skills-based, rather passive learning environment to one where the student professional is using systematic and critical thinking, able to "reflect in-and on-action" and where "individual's development and personal growth" is maximised (p. 178). They emphasised that this reflective capacity is one that is inquiring, questioning and linked to lifelong learning, thus teaching attitudes for a whole career in the discipline. It is interesting that though the focus of this curriculum is to train the practitioner, there are clear synergies with the training of the researcher.

McLeod (2001) advocated for qualitative research to be encouraged as an approach of choice for practitioner researchers and for students in counselling and psychotherapy. He also encouraged educators to teach student researchers in a straightforward 'generic' method which assumes that different schools of qualitative research (e.g. phenomenology, hermeneutics and ethnography) share a set of guiding principles for inquiry and have a common "way of knowing" (p. 130). He observed the difficulties experienced by students, in the academic environment of universities, to be "distinctive and original" and to choose appropriately within a complex host of different qualitative approaches in the short timeframe allowed by Masters' courses, and thus advocated that simplifying and guiding their research in this way was a practical solution.

Sigafoos (2009) advocated a contrasting approach to teaching research to practitioner psychologists, involving learning a careful and detailed understanding of systematic reviews (developing competence at the reading and writing of this part of the research). This approach allowed the development of confidence and active understanding of the way the literature informs research trends. In work with colleagues Schloss and Wendt (2007) Sigafoos described systematic reviews in his paper to education psychologists as "the fast-food of research". A more active research role could then, at a later stage, build on this approach. This kind of strategy for research teaching is in part also encouraged in nursing by Smith (1997) in undergraduate training for student nurses. 
O'Callaghan (2005) noted the importance of developing professional expertise in social work through the use of process notes. She and other social workers indicated the possibilities for learning and critical reflection provided by this regular discipline. Before training in music therapy, O'Callaghan was a qualified social worker, and she cited Richardson's (2000) article on the value of writing as an inquiry method, observing that for practitioners “... writing is ... a way of 'knowing' - a method of discovery and analysis" which she considers can offer a " research practice through which we can investigate how we construct the world, ourselves and others..." ( as cited in O'Callaghan 2005, p. 220). Making the usage of process notes and clinical documentation as the foundation for research inquiry is described by Epstein (2001) as "clinical data-mining" and in a slightly different framework as by Heaton (2004) as "secondary analysis of data". Barry and O'Callaghan (2008) discussed the value for music therapy students of developing a research approach founded on such use of process notes and reflexive journal writing. Hoskyns (2012) outlined the use of the research method secondary analysis of data as the basis for music therapy student research projects at the New Zealand School of Music.

\subsection{Studies and theories about encouraging students to engage with research}

A number of disciplines have developed strategies with the undergraduate curriculum in the last ten years as pathways to encourage students to engage with research. The strategies identified seek to develop awareness of research as an apprenticeship that builds over years of university study. Some integrated schemes of learning are identified below.

\subsubsection{Inquiry-based learning}

Inquiry-Based learning (IBL),also known as Enquiry-Based Learning is an area of pedagogy that is used in the tertiary field and also amongst younger students of school age. The Centre for Inquirybased Learning in the Arts and Social Sciences at the University of Sheffield described inquiry-based learning as a strongly student-centred strategy which is often collaborative and builds on students' academic approach and on their capacity to be lifelong learners. "IBL is a term used to describe approaches to learning that are based on a process of self-directed inquiry or research. Students conduct small or large-scale inquiries that enable them to engage actively and creatively with the questions and problems of their discipline..." (CILASS, 2006). It was an active evaluated research strategy at the University of Sheffield, funded by the Higher Education Funding Council between 2005 and 2010. Lattas (2009) critiqued the influence of IBL on the university curriculum in the humanities in Australia. She noted that while IBL tended to be based in science and education faculties in the UK - and recognising own faculty's wariness of having systems enforced on 
established cultures and traditions which were working well - affirmed how closely the values of IBL connected with teaching and research-led practices that she and her colleagues espoused.

Price (2003) observed that by using an enquiry-based approach in the nursing profession, practitioners "develop the sort of inquisitive, transferable and co-operative skills so important to practice development" (p. 43). ${ }^{10}$ In another comprehensive approach to IBL in nursing, implemented at Anglia Polytechnic University (now Anglia Ruskin University) UK, Cleverly (2004) observed that the benefits of an IBL approach were that pre-registration nurses were more able and accomplished to transfer theoretical and research based concepts to their practice than they had been with a more traditional approach to nursing training.

Fry, Klages and Venneman (2013) conducted a study with undergraduate and postgraduate education students examining whether employing inquiry-based reflection enhanced participants' capacities to reflect, critique and evaluate their teaching through journal writing. The inquiry- based strategy had significant advantages over other assessment approaches at developing the reflective abilities of student teachers.

\subsubsection{Research-based learning}

Angela Brew (2001, 2010), based at the Institute for Teaching and Learning, The University of Sydney has pioneered a related model of 'research-based learning', which draws university students at undergraduate level into real life research of the students' departments. Through participation in projects as part of study, students contribute as apprentices to the progressing and dissemination of research projects by senior students and staff. Part of Brew's interest is in the scholarship of learning and teaching, and making the process of university teaching more transparent and effective (Brew \& Ginns, 2008) however she also advocates for effective modelling of research practice by lecturers, so that research is less hidden from view. In this model, student confidence and familiarity with research is underpinned by the regular presence of research-led teaching, from the very beginning of university life. Brew's integrative approach also encourages university researchers to dovetail their two responsibilities for teaching and research into one process, potentially saving time and energy, and inspiring more students into postgraduate research careers.

\subsubsection{TASC International: Thinking actively in a social context}

Wallace (2008b) developed TASC ("Thinking Actively in a Social Context") from the inspiration and influence of activist educator and theorist Paolo Freire. She was concerned in her teaching of children and of student educators, to create equality of opportunity and satisfaction, meaning and ownership of

\footnotetext{
${ }^{10}$ Price (2003) prefers the term EBL "Enquiry-based learning" to IBL "Inquiry-based..." but explains that the theory has become diversified and developed as it has been used. Locality and context have affected the way the language has developed.
} 
learning in any classroom. The theoretical framework of the TASC Wheel was developed with the stages (spokes on the wheel) of "Gather-Organise; Identify; Generate; Decide; Implement; Evaluate; Communicate; Learn from Experience" - which connect strongly with the developmental cycle of a research process (Wallace, 2008a, pp. 7-8). She was particularly interested in the development of children's thinking skills ideas and in the creation of suitable supportive and interactive environments in which to investigate and problem- solve issues of importance to the young learner. Whitehead (2008) made a specific connection between TASC and practice-based research, specifically action research by teachers on their own practice in the classroom. The TASC process has been used by Wallace (2008b)and Whitehead (2008)in encouraging practitioner and student research. A wide range of international classroom case studies using TASC are described in Wallace's edited book. Wallace and colleagues' more recent research (2012) has been developed quite specifically with gifted children and she suggests how the theory of TASC can be applied to learners at all levels of the curriculum.

Each of these innovative strategies to involve students in research from earliest days of undergraduate study, bring research and teaching into close allegiance, and provide an interesting challenge to the idea that we need training before researching. Wallace (2008) promotes in TASC the idea of 'researching' as being essential to the process of lifelong development of thinking skills, from early years to adult learners. Inquiry based learning and research-based learning both suggest that the idea of the training comes from within the research process, by being alongside experienced guides and mentors undertaking and modelling research. Collaboration with peers is also an essential part of the strategy. The disciplinary practice and the research become parts of the same process, underpinning and enhancing each other. Research is integral to the practice in these models of education.

\subsection{Summary and why this study is needed}

The literature review has indicated that there is a need for research to be taught alongside practice in music therapy training at Bachelors' and Masters' level. Evidence-based practice in health and education requires student practitioners to be competent in research at a basic level, and standards of proficiency for practice for registered music therapists across several countries also indicate research skills are needed. Though music therapy textbooks provide general descriptive information about research teaching, and there are a substantial number of studies about the practicum framework in music therapy training, there are few studies inquiring about the integration of the curriculum and how the complex personal, practical and thinking skills might be combined in research and practice for Masters' students. Those that have focussed on the pedagogy of music therapy, generally at 
undergraduate level, indicate further research is needed to build philosophy of teaching in the discipline and to ascertain how to deliver competencies in ways suited to the discipline.

A diverse range of approaches to research about practice indicate that there is good potential across a range of theoretical perspectives to encourage and 'grow' research-practice capacity and to meet competency requirements but there is scarce evidence in music therapy about how these approaches might be implemented. Three relevant approaches with undergraduate students integrating research and practice have been researched in other disciplines (nursing, science and education) and these could inform educators.

I can conclude that there is a need for this study and the following questions were devised to inquire further.

\subsection{The research question and subsidiary questions for the current study}

\section{Central question:}

How can research be integrated into the practitioner education of music therapists at Masters' level?

\section{$\underline{\text { Sub-questions }}$}

1. What are music therapy practitioners', educators' and researchers' experiences of, and ideas about, combining research and clinical practice particularly in the training of music therapy students? And what challenges and benefits do they identify?

2. How do members of two contrasting international music therapy training programmes (with varied roles and responsibilities in the programme) tell their stories about research and practice in their particular institutional setting and country?

3. How do the researcher's ideas and perceptions about the topic of integrating research and practice develop and change over the process of the research project? 


\section{CHAPTER 3 \\ METHODOLOGY AND METHODS}

\section{Introduction}

This chapter provides an overview of the research, outlining the theoretical perspective informing the study (3.1), the research methodology - exploratory qualitative case study (3.2), the design and overall framework of the study (3.3), and ethical considerations (3.4). This is followed by a description of the specific methods used for the study in section 3.5, including participant recruitment and procedures used to collect data (two initial focus groups; two site visits and an ongoing reflective research journal spanning the whole research journey) and an outline of the approaches to data analysis taken in the study (3.6). The principle analytic technique was thematic analysis, which is a flexible approach for a range of text-based data sources, and the procedures of coding and categorising are indicated. The process of building themes in each data source is captured and then how the main themes from the sources were triangulated through a process of comparison, review and re-working in order to find a synthesised collection of core themes with constituent sub-themes with which to answer the research question. The chapter ends with an outline of the framework for reporting the findings (3.7).

I begin with an outline of my theoretical framework of values and assumptions as the researcher.

\subsection{Theoretical perspective that informs the research}

As observed previously, this research asks a central question about how research can be integrated with practice in music therapy training. Answering this main question required some strategies to ask practitioners what they think, to enquire of educators in institutions round the world what they were doing in the area of training in a broad way, and to examine some specific examples of departments and individuals endeavouring to deliver practice and research in training. Crotty has observed that it is important to link research questions to appropriate theories of knowledge (Crotty, 1998) and in being really simplistic about this, I was aware that I had a passionate interest and a set of views that was driving my inquiry, but what would be the viewpoints of other informed parties, and how would these viewpoints relate to previous research and literature on the topic? 


\subsubsection{Epistemology: Social Constructivism}

Social constructivism is described by Kuper, Reeves and Levinson (2008) as "a belief about knowledge which holds that the reality we perceive is constructed by our social, historical and individual contexts" (p. 405). It has a history in the writings and practice of Piaget, and is centred in the concept that people (children) construe the meaning of the world and build their thinking through the assimilation and accommodation of their own particular experiences. Each person's construing process is unique and we form our own schemata to represent the world around us (Burr, 2004; Piaget, 1955). A number of other disciplines have built on Piaget's theories and Lincoln and Guba's (2005) influential work in qualitative research has revolved extensively around constructivist thinking. They describe the characteristics or ontology of constructivism as "relativism - local and specific co-constructed realities" (p. 195) and I was drawn to their research perspective that was focussed on naturalistic inquiry, in real-world settings with complex perspectives, and the possibility of many different viewpoints. I was also particularly interested in the writing of N. Goodman(1978), philosopher and theoretician and his ideas about 'world making'. There are many worlds and multiple perspectives, and so knowledge about our worlds (and for the purposes of this research I considered these 'worlds' to be practice in music therapy or the music therapy profession) are built according to our own unique circumstances.

I realised that throughout my career as a music therapist I have been interested in constructivist philosophy. As a student and new graduate music therapist working with young children I was informed by the work of Piaget (1953), finding 'assimilation and accommodation' of sensory-motor and then more abstract experiences, particularly relevant concepts. When qualified and working with offenders, I found Kelly's (1955) ideas about individuals building their own constructs about their worlds illuminating, and developed research (Hoskyns, 1988) about offenders' constructs of their music therapy groups,) and when researching teaching of music therapists as a lecturer, the reflective practice concepts of Schön (1987), practitioner-educator, caught my attention as very relevant to practitioner-researcher challenges (Flower, Hoskyns \& Purcell , 2004). ${ }^{11}$

N. Goodman (1978) wrote a series of lectures dedicated to Kant at Stanford University, where he discussed a changing movement in philosophical thought from a fixed and structured world of objective truth through to the embracing of the varied symbol systems of science, arts, philosophy and everyday perceptions. He observed "The movement is from unique truth and a world fixed and found to a diversity of right and even conflicting versions or worlds in the making” (p. x). Goodman's

\footnotetext{
${ }^{11}$ I was interested to find Kinsella's article about links between Goodman and Schön in an issue of ReflectivePractice and appreciated being made aware of the connection between Schön and Goodman. (Reference: Kinsella, E.A. (2006) Constructivist underpinnings in Donald Schön's theory of reflective practice: echoes of Nelson Goodman. Reflective Practice, 7(3), 277-286)
} 
theory used many analogies with the visual arts to explain how individuals might differ in their world making: for example different patterns or colours might be emphasized in two artists' versions of a subject, and he cited Piero della Francesca and Rembrandt's portrayals of Christ to convey this. He suggested that works of art 'illustrate' rather than name or describe, and that abstract music and art, by expressing forms and feelings are "no less symbolic referential functions and instruments of world making" (p. 12). Goodman's links with artistic process in his theorizing make the ideas persuasive to the arts therapist researcher. Smeijsters (1997), European music therapy practitioner-researcher, further encouraged the appreciation of multiple perspectives in music therapy research reminding that this "does not mean looking for what is 'true' or 'false' but assessing the coordinates of your own position in a luxurious landscape of possibilities" (p. ix).

Recognising the importance of varied viewpoints on my research topic, seemed of special significance in my study as there were some key and different roles in practitioner training that might have particularly contrasting perspectives (for example students need digestible manageable coherent training; educators need to fulfil the requirements of professional bodies and educational institutions and want to run exciting learning environments; practice supervisors wish for students to absorb the application of their learning and to be helpful team members; researchers want effective, persuasive research; the professional body wants good practitioners and relevant, helpful research, and ultimately clients need effective well-informed professionals to work with them).Within a constructivist framework, whereby we make our own worlds and construe our professional reality according to our developing experiences, this research attempts to bring together the varied worlds of practitioners, educators, researchers, students to review their perceptions and to build a picture of the diversity and connections occurring across the sources of data. Music therapy researcher, O'Callaghan (2001) found this paradigm suitable to the complex practice environment of music therapy in oncology and valued that constructivism acknowledges "multiple realities exist which are apprehensible and alterable" and it seemed similarly helpful in the current study.

Burr (2004) indicates that constructivism shares some assumptions with social constructionism but differs from it in the extent "to which the individual is seen as an agent in control of the construction process and the extent to which the constructions are a result of social forces" (p. 186). Hepburn (2006) suggests that for constructivist thinkers such as Piaget and Kelly, there is a strong emphasis on the constructions "as something mental (like images or pictures) produced through interaction with objects or some features of the external world". However, in 'social constructivism' the constructs would also be seen as mental, but "generated as much through social relationships and conversations as well as interaction with objects" (p. 39). My research seeks to account for different constructions on the integration of research and practice and I assume that my participants have developed their perspectives through their histories, learning environments, interactions with others and experiences of self, as conceptualized in social constructivism. As Lincoln and Guba (1994) have observed, there 
are strong connections between the investigator and the object of the investigation. Knowledge develops as multiple versions of reality are examined, contrasted and given interpretation, and the researcher aims to find "consensus construction" (p. 111). ${ }^{12}$

\subsubsection{The use of the researcher as instrument in the research}

There is much written in the qualitative research literature about the impact and role of the researcher within and upon the research, for example in numerous chapters in Denzin and Lincoln's (2005b) handbook and other references here (Aigen, 1996; Lichtman, 2013; Willig, 2001). Lichtman (2013) observes that whatever approach is taken in the qualitative domain, the large majority of research "acknowledges the role of the researcher as a filter through which data are collected, organized, and interpreted" and advises researchers to "face head-on the subjective nature of their role" (p. 159). B. Wheeler and Kenny (2005) note the personal experience and engagement of the researcher and that he or she is likely to be involved with the participants, sharing a working context, participating with them in their experiences as a central way of understanding the research process. The role involves being empathic, "fully present when observing or interviewing", non-judgmental and trustworthy with information (p 65).

As I was developing the proposal for my research project, I realised the valuable learning I was gathering about teaching students and how I was experiencing research myself, and therefore how students might be guided into the process of researching practice. I documented my own experiences with learning and teaching as a music therapy lecturer as pertinent to my research question, and also my responses to gathering and analysing data, and these materials formed the backbone of my researcher journal. In keeping with constructivist thinking, reflective practice has been a particular area of interest to me, as it helped to make a connection between work as a clinician, educator and researcher. The steps of thinking back on practice, developing concepts and mini-theories about teaching music therapy and research with students and for myself, and developing questions which have led to research - all these have their origin in Schön's 'reflection-in-action' (Schön, 1987). Reflective practice is an obvious and inbuilt process for practitioner therapists, through the emphasis on supervision, as observed in the previous chapter. The neat pivot it has provided into research, in substantial projects in nursing (D. Freshwater, et al., 2008) and in the development of music therapy research with 'process notes' in music therapy (O'Callaghan, 2005) and 'gentle empiricism' (Ansdell \& Pavlicevic, 2010) certainly helped my own understanding of the potential for integrating research and practice for students.

\footnotetext{
${ }^{12}$ As I learnt about different theories of knowledge as my research developed I observed that social constructionism could also have been a most interesting stance with which to view my topic, but this I leave for future studies.
} 


\subsection{Methodology}

\subsubsection{Qualitative Exploratory Case Study Research}

'How' questions invite focused, in-depth study, and a qualitative case study framework that allowed data to be gathered in a variety of ways was a suitable strategy for this study. A qualitative research approach also permitted me, as the researcher, to take account of my involvement in and passion for the subject, to acknowledge this and to create transparency in the process of analysis and interpretation. I am aware that I have my own particular (partial) perspective on this topic, and as an experienced practitioner and educator, this has value, but that others in the field - students, practitioners, researchers and educators - also have unique and significant perspectives that are shaped by their own history and experience in the field of music therapy, their culture, location and their place in time. This feature of qualitative case studies is specifically valued by Mabry (2008) and Lichtman (2013) in their outlines of the methodology but they also draw attention to the delicacy and complexity of the task of using researcher-self in the analysis. Mabry exercises caution for researchers in attending to 'proximity' (of researcher to case), and 'validity' in approaching the use of subjective reactions and interpretations, while also valuing the contribution "by offering intense focus on cases of interest, their contexts, and their complexity" (p. 216).

My aim in designing the study was to capture some of these varied perspectives in detail, as individual voices contributing to the field, and also as groups of people working together in educational settings, and to represent the diversity and synthesis of these participants' views through an overall case study of research and practice in music therapy education. While these perspectives are all individual voices contributing to a landscape of views, and no one voice or particular institution has the 'truer' picture, it was anticipated that case study method could explore the richness and diversity of these views and allow key messages about research and practice from teachers, researchers and learners to be revealed.

As discussed in the literature review, music therapy research over the past 20 years has diversified and expanded in its use of research methodologies, and the developing respect given to carefully designed qualitative studies and to mixed-methods research has been emphasised (Grocke, 2009; B. Wheeler \& Kenny, 2005). Case study research, one such qualitative methodology, has been used widely in social science, and increasingly in clinical fields, to inquire into complex real-life environments (Stake, 2005; Yin, 2009). Though it is not possible to generalise from such specific focus, case study researchers have developed increasingly rigorous approaches to data gathering and management, (McLeod, 2002a, 2010; Yin, 2009) and argued for a natural process of generalisation which occurs when the informed reader can share or understand the opinions feelings, ideas or practices described. Case study research in music therapy has an evolving and increasingly distinguished tradition, with 
important contributions to the discipline observed by Aldridge (2005) and Smeijsters \& Aasgaard (Smeijsters \& Aasgaard, 2005). More usually this would involve single case study design with the 'case' being a music therapy client or clients. There are nevertheless some exceptions to the topics noted - for example groups, situations, and a collection of 19 cases in childhood cancer by Aasgaard (Smeijsters \& Aasgaard, 2005) and the development of hypotheses in a case series by Wigram (2005) - but the bulk of music therapy research using this approach has been single-client based. I entertained the possibility of inviting participation from a number of 'cases' of music therapy programmes and creating comparisons (i.e. a multiple case study design), however it seemed preferable to conceptualise the case in this research as the challenge or problem of integrating research and practice in student training, and I shall go on to outline the limits and features of this case and how this associates or fits with definitions and frameworks for qualitative case study research developed in the literature.

As I developed the proposal for this study I maintained a solid interest in engaging with multiple perspectives about the topic "integrating research and practice for students". Originally I imagined the topic as mixed-methods research, employing a survey, focus groups, and 'narrative interviews' with researcher, educator and student music therapists. However as I undertook the first focus group and developed my survey in 2008, and took some specialist advice about the survey questions, I realised that I was most interested in the specific and particular qualities of open-ended answers to questions in the survey, rather than in generating numbers of responses about what sorts of research designs suited students and how people managed ethical processes, across the international scene of MT training. The adviser noted that my survey design was much more qualitative in nature than quantitative, and therefore my 'mixed methods' seemed rather less mixed than I had originally thought. So I was asking 'how can research be integrated in the clinical/practice training of music therapy students' and I wished to find out from particular instances how it was that participants thought the integration was effective or not, and how they reflected or theorised about the issue, I wanted their specific stories. As Stake (1995) has observed, despite Yin's suggestions about generalisation above:

The real business of case study is particularization, not generalization. We take a particular case and come to know it well, not primarily as to how it is different from others but what it is, what it does. There is emphasis on uniqueness, and that implies knowledge of others that the case is different from, but the first emphasis is on understanding the case itself. (p.8)

Stake (1995) distinguishes between intrinsic and instrumental case studies in qualitative inquiry, and the current research topic would loosely fit the idea of an instrumental study, where a research question including "a puzzlement, a need for general understanding" (p. 3) is applied to a specific case, and the case I proposed was members of the music therapy profession involved in training. Yin 
(2009), whose emphasis is more on quantitative or mixed methods case studies, describes a two-fold technical definition of case studies. The first is an empirical inquiry that investigates a contemporary phenomenon in depth and within its real-life context, especially when the boundaries between phenomenon and context are not clearly evident. The second stage of the definition identifies data collection and data analysis strategies to cope with a technically distinctive situation in which there will be many more variables of interest than data points. It relies on multiple sources of evidence with data needing to converge in a triangulating fashion, and "it benefits from the prior development of theoretical propositions to guide data collection and analysis." (p. 18)

The current inquiry fits the main parts of Yin's definition, including the process of triangulating multiple sources of evidence. My approach to theory has been to acknowledge that there will be varied valuable perspectives on this topic and to observe, develop and refine concepts that emerge from the participants' evidence about their experience of practice and research, and to look for and interpret emerging insights in the findings and discussion. My interest has been centred on developing theory rather than testing existing theories in this field, and though this is rather a messy approach, it befits real-life, complex environments, where as yet as there is limited research.

\subsubsection{Interpretive research}

Kenny (1998) articulated the value of considering an approach to researching, entitled The Cultures of Inquiry, as we place ourselves in the research field. She created this research landscape as a kind of compass with points (north south, east and west) where different categories of research might be placed, linked to her own Native American heritage and way of knowing (pp. 209-210). As I started out on the journey I was drawn both to phenomenological and narrative approaches, which might draw on rich essences in the case of phenomenology, or on the form and content of stories of individuals and groups as in the case of narrative research. However what stuck with me was the endeavour to understand and make sense of participants' perceptions of the research-practice challenge and further thought and consultation helped me place my study within a broad category of interpretive or hermeneutic research. (Kenny positions this close to theoretical study in the northern point and phenomenology in the east). Hermeneutic research, like music therapy practice in the humanistic and psychotherapeutic tradition, is focussed on a search for meaning in data.

Stake (1995) observes that the interpretive role of the researcher, the intention to find meaning across the data sources, in qualitative case studies is an essential part of the research process. He notes that there are two strategic ways that new meanings might be reached in case studies, which are "through direct interpretation of the individual instance and through aggregation of instances until something can be said about them as a class" (p. 74). This idea of the interpretive analytic process which cross 
references between the particular and shared qualities of the data sources I found helpful as explanation of the methodology of the case study.

\subsubsection{Autoethnographic commentary}

The reflections recorded in my research journal were subject to analysis alongside the other data sources of focus groups, interviews and field notes of observations, which are outlined in the following sections outlined in 3.3. As I began to subject my reflections to review, I had the opportunity to use my 'voice' in the research to comment and draw attention to aspects of the findings. The use of researcher voice has an autoethnographic flavour, as is evidenced in the findings in Chapters 4-6. It helped to acknowledge my position in the interpretations, but also to keep my ideas in place, enabling me to look more critically both at my own opinions, and the way in which they intersected with the participants' perspectives. Somerville (2011) makes use of her own situated researcher-voice in a chapter of the co-edited book, Place Pedagogy Change, which she entitles "Body/place journal writings". In this chapter she critically examines the experience of her own embodied self in a specific place within her research in the discipline of 'Place Studies'. It was an inspiring model in this regard and helped to develop a style and tone to the writing. For the improvisation sessions with participants at each Site Visit, I also used a specifically autoethnographic frame for writing, which described the music and also offered my interpretations about the experience as related to the research question. I was aware of the process of gradually becoming more 'reflexive' than reflective as I developed this autoethnographic tone to the writing, and this is discussed further in Chapter 7.

\subsubsection{Authenticity, trustworthiness and the controversy of 'validity'}

Guba and Lincoln (2005) assert that nowhere in the controversies between paradigms has there been more contested dialogue than in the area of 'validity' of research. They observe that 'validity' has to be attended to by qualitative researchers because even though it is a term much more familiar and comfortable to the positivist researcher, it does beg the question "Are these findings sufficiently authentic (...trustworthy, related to the way others construct their social worlds) that I may trust myself in acting on their implications?" (p. 204). They draw attention to the care and rigour needed for the development of method, together with the process of interpretation, and it is in these areas that I offer observations about the conduct and process of this study. There is a need to be interpretively rigorous, to engage in ethical relationships, and to raise awareness and involvement of participants, and to be authentic, open and direct in the voice of the researcher.

In this research I used a combination of processes recommended by Bruscia (1998b) in his guidance on standards for qualitative research and Guba and Lincoln as cited above, including the following: 
- Engaging the assistance of two colleagues as peer-debrief consultants, who read data transcripts, and sampled some analysis and gave feedback. In both cases valuable amendments were made to the analysis.

- Member-checking of interview transcripts (encouraging participants to check and correct the data) and then sharing of some analysis process later on in the research analysis, for which some valuable reflections were offered.

- Triangulating the data sources in a cyclical fashion in the analysis, coding and categorising themes in each area, and then comparing, reviewing and re-shaping the themes to accommodate the similarities and differences.

- Aiming for transparency about my own reactions by including autoethnographic commentary alongside participants' voices.

\subsection{Choice of methods and data collection techniques}

\subsubsection{Focus Groups}

Definitions of focus groups vary in the literature and draw on different terms like group interview, focus group interview, and focus group discussions. Rosalyn Barbour (2007) draws attention to the fact that the debates about methodology underpinning the use of focus groups can be "impassioned and potentially contradictory" ( p. 405) and observes that researchers seem to be using complex terms to describe remarkably similar research approaches. She therefore advocates a simple definition:

"...any group discussion may be called a focus group as long as the researcher is actively encouraging of, and attentive to, the group interaction" (J. Kitzinger \& Barbour, 1999, p. 20).The following definition by Krueger and Casey (2000) is more detailed but also draws attention to the importance of interactive process:

A focus group study is a carefully planned series of discussions designed to obtain perceptions on a defined area of interest in a permissive, non-threatening environment. Each group is conducted with six to eight people by a skilled interviewer. Group members influence each other by responding to ideas and comments of others. (p 5)

Attention is drawn in the literature to the value and importance of the 'dynamic group' for the process of gathering data in focus groups. This is not just a time-saving way of collecting material and ideas from larger numbers of people (a kind of mini-interview for six in the same time frame) but rather, there is a vital interest in the interactions between participants (Halkier, 2010; J Kitzinger, 1994; Warr, 2005). It makes the method of particular interest to therapists, because we develop skills and experience in the facilitation of groups in the course of our training and in daily practice. Therefore, 
the use of supportive, non-directive questioning, the focus on facilitating others, and on building connections between participants (which are the basic tools of group work) are a natural province for music and other arts therapists.

Warr (2005) emphasises the value of focus groups in that they represent “ ...a mixture of personal beliefs and available collective narratives" (p. 200) and it seemed that this method would reveal a spectrum of opinion and tap into both the specific values of individual educators and the professional influences that their own countries' policies and research experience had exerted. Anecdotal experience in meetings in the UK in the early years of the $21^{\text {st }}$ century, indicated that other programme leaders were experiencing the challenge of providing effective research training within clinical programmes, and group presentations and discussions were interesting and productive as problem-solving strategies. Kamberelis and Dimitriadis (2005) assert the value of groups of people thinking together in the pursuit of knowledge: "Real world problems cannot be solved by individuals alone; instead, they require rich and complex funds of communal knowledge and practice" (p. 903). In music therapy terms this seems to be particularly valuable, as we have personal histories of training and experience that clearly affect our ideas and practice powerfully, but we also work in professional groups to develop the strategies and policies of our discipline. In this project it was particularly helpful to engage in focus group conversations at the outset of the study to raise my consciousness of the debates and stances that people held, as the topic had not been widely documented. This allowed general 'meaning' to be generated on the topic and to create pathways for more in-depth exploration in the Site Visits (with interviews as the central method).

\subsubsection{In-depth interviewing}

Individual interviewing is a familiar and widely-used method in qualitative research, and in this study provided a complementary tool to focus group inquiry. As students and staff members from the same Site Visits could offer valuable perspectives, it was helpful to talk with people individually so that power issues could be avoided and there was opportunity for rich in-depth commentary. Willig (2001) notes that the interview is a very flexible approach, allowing the interviewer "to interact with the interviewee in a manner that is appropriate to the subject matter", whilst also advising researchers "to acknowledge that aspects of the researcher's identity may have influenced participants' responses".

In the Site Visit interviews for this research I recognised the value of encouraging the distinctive stories of individuals and so chose an unstructured style of interviewing where questions are developed from the content of participants' interviews, rather than pre-set questions. Lichtman favours this style of interviewing and references McCracken (as cited in Lichtman, 2013) 's The Long Interview (1988) where following a set of biographical questions, the interviewer allows "respondents to tell their own story in their own terms" ( p. 192). 


\subsubsection{Reflective research journal}

Lichtman (2013) observes the regular use of self-reflection by qualitative researchers in her overview of the qualitative research field in education. She describes it as varying from a kind of quality control in an interview, to fully documented self-reflection, and such a range is obvious in the Sage Handbook edited by Denzin and Lincoln ( 2005b). Documenting responses to the research process in various kinds of journals and diaries is a very familiar and valued method in qualitative research. Lichtman reminds that "all information is filtered through the researcher's eyes and ears" and writing journals encourages a critical and aware approach (p. 21). She recommends writing early and often about the ongoing experience to increase responsiveness to the research process. Bruscia (2005a) cites Ely's description of the researcher's reflective stance in the research journal as follows:

"conversations with oneself about what has occurred in the research process, what has been learned, the insights this provides and the leads these suggest for future action" (p. 179).

\subsubsection{Field notes from site visits}

Natural observations of class seminars, lectures, and special sessions by outside visitors were made as an additional way to gather information about the whole context of the music therapy programme site I was visiting. Field logs and diaries are an essential part of ethnographic research, but also form a regular aspect of other qualitative studies, and Bell (2010) advises that they are "records or logs of professional activities" and provide "valuable information about work patterns" that are encountered by the researcher (p. 173).

Programme documents (syllabus and course modules) were provided on the visit for consultation and reference. These sources, together with class observations, were documented in a field diary and they were useful notes to consult to understand the framework that students and staff worked in, and supplemented the interview data. Case study research methodology recommends a variety of data sources to cross-refer information and to gain different pictures of the phenomena of the case (Yin, 2009).

\subsection{Design and Framework of the PhD Research Study}

This research had a 2-part preparatory period. The preparation prior to enrolment included some pilot work I prepared for a keynote conference presentation in 2006, undertaking a semi-structured interview with two colleagues (programme directors from the UK) and an informal review with my own students (see Appendix 1). This was followed by the first seven months of enrolment (January- 
July 2008), when I expanded the proposal, undertook ethical analysis and submitted an ethical approval application. As I prepared the proposal, ideas from the preparatory conversations, together with available research literature, informed and shaped my thinking.

Next came three main stages of data gathering and analysis, which are identified below.

1. Stage 1: Two focus groups. Having received ethical approval for the research to begin in July 2008, the two focus groups could commence. These were undertaken around 18 months apart in July 2008 and January 2010, (governed by time and possibilities for travel), and they aimed to develop understanding of the perceptions of practitioners, educators, researchers and students about the challenges and benefits to all of combining research and practice in music therapy training. Focus groups were particularly relevant at this stage of the research, because I was interested both in the specific perspectives of individuals but also in how the different parties' views affected each other and what dialogues might occur. The two focus groups were recorded, transcribed, member checked, and initial analysis for codes and categories undertaken. Reflections on the data gathering and initial analysis were dated and gathered in my research journal, documenting ideas and responses to the process.

Figure 1 provides a model of this stage in the process, indicating the progress of conducting a group, documenting and coding and going back round the process (in circular fashion) to review and refine meaningful categories. I recorded entries in the reflective research journal throughout this and later stages of the research. 


\section{STAGE ONE OF RESEARCH \\ Laying Ground in Focus Groups}

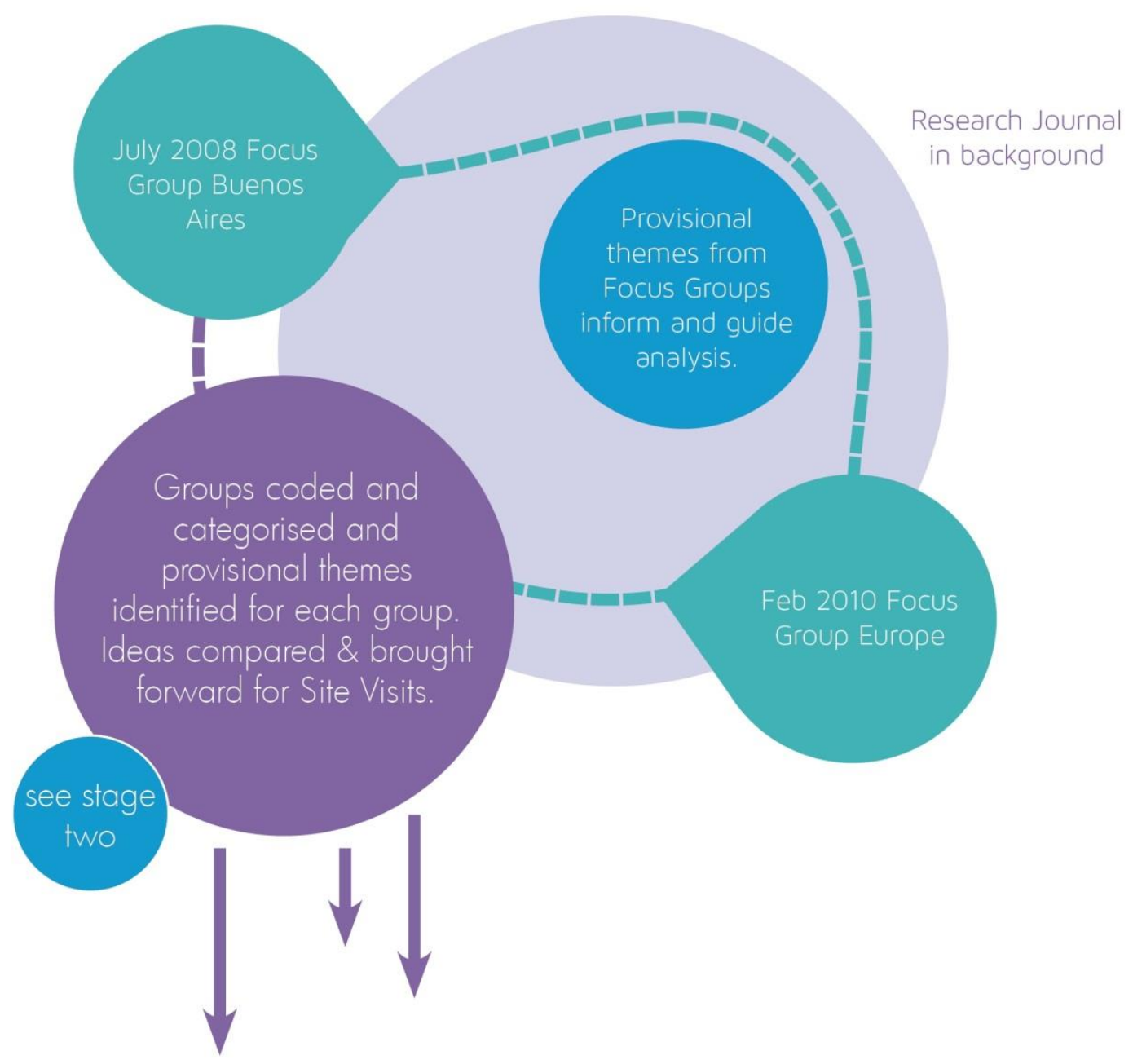

FIGURE 1: MODEL OF STAGE 1 OF STUDY - FOCUS GROUPS

2. Stage 2: Site Visits in 'Eurostralia' (One in Europe, one in Australasia)

a) First Site Visit to Friendsville University College Music Therapy Programme. ${ }^{13}$ Over the course of three days, I conducted individual interviews with three music therapists (who had combined roles as lecturer-supervisor, lecturer-researcher, supervisor-researcher) and two students. These were recorded and transcribed. This was combined with attendance at some available classes and presentations at the university setting, a meeting with the programme director (who was not interviewed formally) and an invited summary music

\footnotetext{
${ }^{13}$ The names 'Friendsville' and 'Kindstown' are fictitious titles for University settings for music therapy programmes, as is the invented continent of 'Eurostralia'. See section 3.5.2 for an explanation of the reasons for de-identifying the programme sites.
} 
improvisation session with participants. Programme documentation was also viewed, and field notes of the visit recorded. Provisional categories were derived from each interview, informed by field notes and other documents, and then collated for the Site.

\section{STAGE TWO OF RESEARCH}

Site Visits In Eurostralia

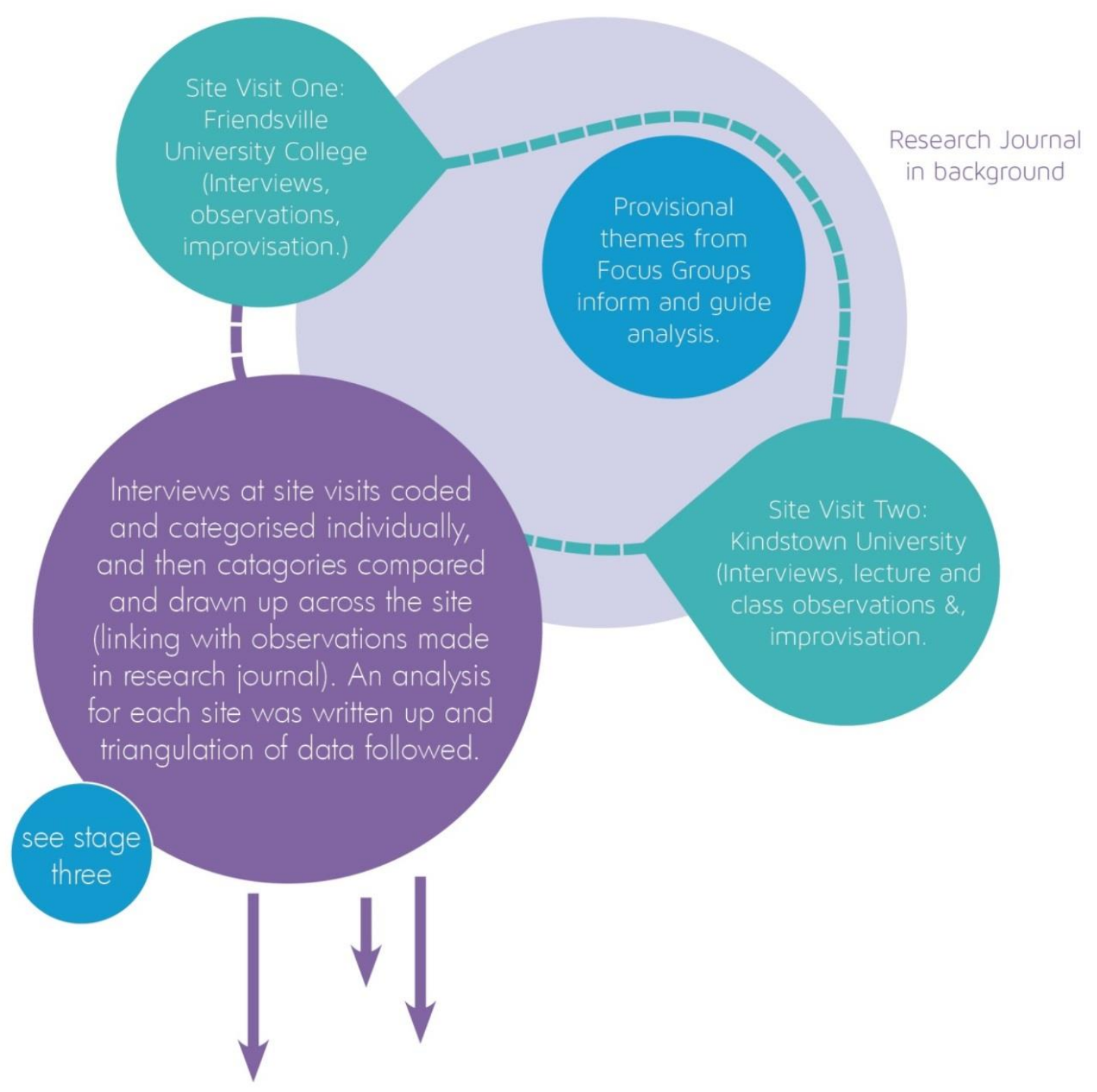

FIGURE 2: MODEL OF STAGE 2 OF STUDY - SITE VISITS 1 AND 2 


\section{b) Second Site Visit to Kindstown University Music Therapy Programme. Over another}

three-day visit nine months later, in another continent, I met three lecturers, one clinical and two research-based, and one external clinical supervisor-researcher, plus two students from this programme. I attended a methodology lecture with first-year students, a professional presentation on employment for students, a research seminar for senior students and external practitioners enrolled for $\mathrm{PhDs}$, and shared a summary improvisation session. Material was documented and analysed as in site visit 1 .

As in Stage One, I continued to document reflections and responses to the research process in my research journal. Documentation and reflection on the improvisations at the end of each site visit was an additional feature of the research journal in Stage Two of the project.

Figure 2 above shows the Stage Two process of conducting each site visit, developing codes and categories, and formulating a provisional analysis for each site. The analyses were influenced in the process by thematic material developed in the focus groups, and ideas derived from the researcher journal.

Appendix 2 contains a list of all the participants' pseudonyms, roles and settings where they were included in this research project. They are listed according to the stages of the research as described above, Focus Group-BA and Group-E, Site Visit FV and Site Visit KT.

3. Stage 3: Integration of Stage 1 and 2 data analyses, and triangulation with researcher's journal

The focus groups and site visits each had a collection of provisional themes. These were reviewed and revised and brought together with the researcher journal, to produce three core themes, focussed in the thesis, Chapters 4-6. My own researcher reflective journal had continued as a growing accompaniment to the process of the research. I kept regular entries prior to enrolment and then onwards through part-time study and finished my commentary in January 2013.

Figure 3 below shows the process of triangulating thematic material from the three main data sources, focus groups, site visits and researcher reflective journal. Although initial codes and categories were developed for the focus groups, reviewing them in the light of thematic material analysed from the Site Visits and raised in the researcher journal at later points was illuminating, and additional material was highlighted and refined, in a circular or spiral process. 


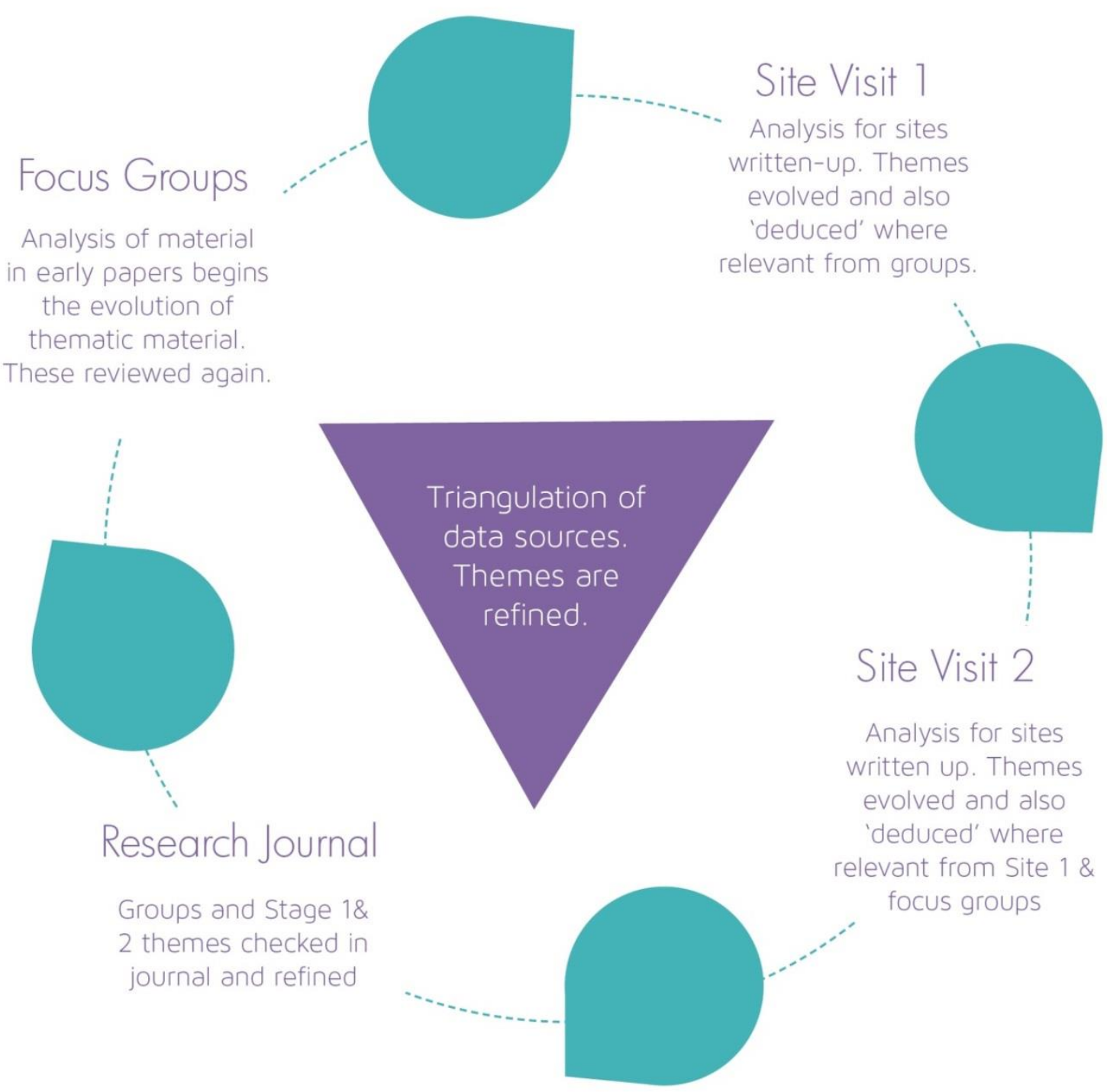

FIGURE 3: MODEL OF STAGE 3 OF STUDY - TRIANGULATION OF DATA SOURCES

\subsection{Ethical Considerations}

The study received ethical approval from the Faculty of Humanities and Social Sciences Human Ethics Sub-committee under delegated authority from the Victoria University Human Ethics Committee (approval \#15689) in July 2008. An ethical analysis of the research framework was made in the first seven months of enrolment, and guidelines for Victoria University and Massey University Human Ethics were observed. In addition the Code of Ethics for the Practice of Music Therapy in 
New Zealand (2012) and the United Kingdom was also part of my consideration as I am a registered music therapist in both countries. The basic principles of ethical research: informed consent, participant rights to confidentiality and access to information about the research, avoidance of harm, consideration of conflicts of interest, cultural considerations and risks of the research versus benefits, and issues of data storage were considered in the ethics application.

In this project there were some ethical issues to which I would like to draw attention, as they had some implications for the participants and issues about which I needed to remain vigilant.

\subsubsection{Informed consent to participate}

In accordance with the ethical code for human subjects of Victoria University of Wellington, participants to the focus groups were invited by email and noticeboard advertisement and sent a full information sheet and consent form following an interested inquiry. Participants then had 10-14 days to decide if they still wished to participate in the focus group. If they were happy to be involved they confirmed by email. Information sheets and consent forms for Focus Group participants are included as Appendices 3 and 4.

Informed consent to participate in Site Visit interviews was arranged in two stages. I first wrote to the programme director and inquired about consent in principle to undertake the research at the programme site. The programme leaders had a free right to refuse and the first programme approached did decline. After agreement had been provided by the director, information sheets were then forwarded to staff and students and they were asked to email me as researcher if they were interested to participate. The programme leader assisting in recruitment helped me avoid contacting staff and students directly and allowed them to 'opt in' to the research if they so wished. An information sheet and consent form for participants in the Site Visits are included as Appendices 5 and 6. I could then accept the first two students, and first four staff members to reply in accordance with the inclusion criteria. If no staff or student members had wanted to be involved, I would have approached another potential site for permission to undertake the research.

\subsubsection{Confidentiality and de-identification of data}

The names of all participants were changed in the write-up of findings, and occasionally specific identifying details were omitted or disguised in the thesis in order to protect privacy of participants. However, in the information sheet, participants were also alerted to the risk that because music therapy is quite small and interconnected as an international discipline, there was a chance that they could be identified in the research. Participants then had the choice to decline participation, or to remove any sensitive details when they checked the transcript. The latter did occur in some instances. 
Participants in focus groups were also asked to keep the confidentiality of their colleagues by not disclosing whom they worked with in the groups.

The names of the music therapy programme 'sites' visited in the course of the study, were changed to the pseudonyms Friendsville University College and Kindstown University. I decided to describe the location of both Site Visits training programmes as the combined fictitious continent of 'Eurostralia' (one being in Europe and the other Australia) as a further measure to protect the identity of the programmes and participants. The number of music therapy programmes in any one country is still relatively small and it seemed a better way to protect privacy to not connect either of the departments to a single country but to note that Australasia and Europe were the continents that were represented.

In reviewing the transcripts with participants, some people indicated that they might have liked to have been identified in the study, but due to the sensitivity of some parts of some interviews, the group nature of the sites, and the usual practice of New Zealand research ethics to de-identify interview data, it seemed preferable to maintain all pseudonyms and keep the focus on the content of the contributions. I was aware at the end of the study, when drawing together the discussion, that providing some contextual issues for programmes and participants, would have made a valuable contribution to answering the research question, but given my ethical choices in the research not to identify locations, I was not at liberty to comment in detail in that area. This is referred to in the study limitations (Chapter 7).

\subsubsection{Avoiding issues of power and vulnerability for students and staff}

I was interested to invite the views of students alongside staff members within this project, but was aware of the challenge for students to speak freely, particularly in focus groups alongside their own staff members. This was of course also a reason for interviewing students other than those involved within my own working environment in a music therapy programme in New Zealand, to avoid conflict of interest with my own students. I therefore also did not include any current students within the focus groups, these were reserved for qualified music therapists at various stages of experience. Students were interviewed individually in the site visits.

I originally invited all participants at the respective sites to attend the voluntary summary improvisation session and play together and to add and further debriefing comments at the end of the respective site visit. However later I realised that there were some sensitivities for participants that I had not anticipated, and which might have made people less willing to engage in this optional session. One of the staff participants observed during the site visit, that she would prefer to not play with students because of how she had reflected on her experience in her interview. Equally this could have been the case for students in the research. The fact that only single participants were able to attend these sessions was perhaps inadvertently a benefit for both students and staff and avoided power 
issues and ones where participants might have felt exposed. This is an area I would be more careful with in any future project planning.

\subsection{Methods and procedures for data collection}

\subsubsection{Overall recruitment strategy}

I aimed to seek perceptions about the topic from a broad range of viewpoints and using different approaches to data collection, given guidance from Mabry (2008) and Smeijsters and Aasgaard (2005) about being alert to the possibilities for richness, depth and complexity in case study research .There were 19 participants in this research study, including 14 registered music therapy professionals, and four enrolled students ( 2 from each of 2 programmes which were the settings for the Site Visits) plus myself as the nineteenth member of the study. My focus in this inquiry about music therapy training, was on Masters' level teaching and learning, and although Bachelors' courses could well have been a topic of interest, I decided to concentrate on Masters' work because the requirement for research, combined with competencies for practice was particularly focussed at this postgraduate level of study. It was also the level of study in which I had had principal experience. Having made this decision, all the participants recruited were involved in learning, teaching or supporting - or had experience themselves - of Masters' level music therapy training.

\subsubsection{Procedures for Focus groups}

Focus group recruitment

For Stage 1 of the research, which included two focus groups, attendance at a World Congress of Music Therapy in 2008 in Buenos Aires, facilitated access to a wide range of music therapy participants (in experience, culture, range of research and practice and teaching expertise), so this was a very suitable arena for the first Focus Group (Group BA). Similarly a visit to Europe in early 2010 also provided opportunity for sourcing international viewpoints for the second European Focus Group (Group E). Across both focus groups, inclusion criteria were that the participants had completed a postgraduate music therapy programme that had included some research as part of the learning and were eligible for registration to practice as a music therapist. I aimed to include music therapists with mixed levels of experience in the focus groups. The first six respondents who met these criteria for each group were invited to take part. (See Appendix 7 for the advertisement for expression of interest in a Focus Group -World Congress Buenos Aires). In the event, the groups were a little smaller than 
might be typical for focus groups in social science research, due to participant availability at the time offered for each group. ${ }^{14}$

Across the two focus groups there were 7 music therapist participants : 1 American, 1 Australian, 1 New Zealand, 1 African, and 3 British music therapists. The ages varied from mid-twenties to midsixties and there were 5 women and 2 men. The music therapists all had some experience of conducting research, not all in music therapy, and some had extensive publications as researchers. All were practitioners and all bar one had experience of tertiary teaching in music therapy. Therefore some rich and diverse experience was represented. As recruitment was located within and alongside training programmes, I acknowledge with hindsight that practitioners who might not have involvement with research but supervise students in the community were likely to have been underrepresented in this recruitment process. See discussion in Chapter 7 section 7.2 on research limitations for further observations on this issue.

\section{Frame for the focus groups}

The arrangements for each focus group followed a pattern. They were conducted in a comfortable space free from interruptions. They were each approximately 90 minutes in length with refreshments provided. In each focus group, participants had replied to an advertisement and had read the information sheets prior to offering to participate. Informed consent was checked at the start of the groups, group members signed the consent forms, and confidentiality amongst members was emphasised.

As the researcher, I facilitated these groups, promoting interaction and development of discussion amongst participants. The participants were invited to introduce themselves and their history/interest in topic. Following this personal introduction, they were encouraged to react to issues and ideas raised by other members. Some prompt questions were available to me as researcher but free-flowing discussion that responded to the participants' contributions was sought where possible. (Focus Group briefing and the prompt questions are noted in Appendix 9).

\section{Member checking of transcripts of groups}

The discussions were transcribed, and focus group members were sent copies of the transcription of the recording of the group conversation interview, and were invited to correct, explain or remove any aspects of their own commentary that seemed misrepresentative. In some cases I highlighted sections of the transcription that were identifying and suggested where I might disguise or omit some information, to protect identity of the participant. In other cases participants also suggested where material might be slightly elaborated. Some participants added details where their comments had not

\footnotetext{
${ }^{14}$ See section 3.2.3 for Krueger and Casey's definition of a typical focus group recommending six to eight participants.
} 
been fully audible. When one participant did not reply after some repeat correspondence, I was careful to remove identifying data, and wrote positively that I presumed the participant was very busy, and would include the commentary unless they objected.

\subsubsection{Procedures for two site visits to educational settings (Europe and Australasia)}

I visited two different educational institutions to capture a picture of members of the department's views on research and practice, and also my own impressions of the curriculum and activity. I was able to witness some taught classes, and seminars, and also to view some of the documents about the programmes. The departments were in the fictitious continent of 'Eurostralia' and were established from:

a) A university training programme based in an allied health department which had strong affiliation with a practice setting in the community serving a range of different client groups (established 20 years). This programme I called 'Friendsville University College' (Site FV for short). It was a newer university and provided education in many applied areas of study. The music therapy programme had become the 'training wing' of a flourishing local music therapy service, which had begun with a mutual contract between the music therapy organisation and the University College. The programme was well-established and had trained several hundred students over 20 years. The programme was the equivalent of two years full-time Masters' study, although the majority of students undertook study over three years part-time. There had been some significant changes to the length and structure and curriculum of the programme, to incorporate regulatory changes and research had developed significantly in that restructure. Models of research from the Health Faculty had been drawn on in the developments to the programme, as well as research methods in music therapy. New staff had become involved in teaching the programme from other health disciplines, and this had had significant impact on the programme. At the time of the visit, the staff team had responded vigorously to these challenges and revised the curriculum to better suit department and student learning needs. It was a time of change, and the conversations in this research study reflected this.

b) A university training programme based in a music department which had been established for over 30 years. This programme was named 'Kindstown University' (Site KT for short). Music therapy had been offered by the university for a substantial time and the programme was well established in the framework of music courses offered by the faculty. It was housed in the music department building on a large city campus, which catered for a wide range of pure and applied disciplinary areas. The programme was just preparing to upgrade in accommodation and to change location. The programme director was very experienced, and there were two 
other key lecturing staff, one full-time one part-time. Other staff at the university offered visiting lectures and there were six $\mathrm{PhD}$ students currently in progress, in addition to the Masters' course, and so research was strongly present in the department. The Masters' programme at Kindstown was a two-year full-time programme with practical and theoretical training in the first year and placements and a small thesis delivered in the second year.

Both programmes were located in the leafy suburbs of cities, and in each case, I visited in the middle of university semesters or terms, when students were in the flow of learning, and usually experiencing placements out in the community. The programmes had 10-15 students in each year group, and more junior students were engaged in basic theories and practice and preparing for research, and the senior students were completing their projects or dissertations. Staff members in both locations included a good balance of lecturer-researchers, clinical teachers and external supervisor-researchers.

\section{$\underline{\text { Site visit recruitment }}$}

In planning recruitment for Stage 2 site visits, I chose a purposeful sample of two music therapy programmes in two different continents (Australasia and Europe or possibly America if European recruitment had been challenging). ${ }^{15} \mathrm{I}$ also aimed to include in the study two music therapy programmes that demonstrated some contrasts in how they were set up as noted above, (including preferably one with more of a clinical tradition and one with more of a university or a research tradition and/or location of the programmes in different faculties or kinds of institution). See Appendix 8 for the letter to each programme director, inviting participation in a site visit. Following agreement in principle for the department to participate, the programme leader then assisted in recruitment of interviewees amongst programme staff and students, using the criteria of recruiting people in different roles (supervisors, researchers, lecturers, and students at different levels of experience) on a first-come-first-served basis.

Within the two site visits, 11 participants were recruited ( 5 interviewees at one and 6 at the other site). Interviewees included 4 students ( 2 at first-year, 2 at second-year level) and 7 staff members ( 5 programme lecturers specialising in either clinical practice or research or both; and 2 clinical supervisors, both of whom had research or teaching experience). These groups comprised 1 male and 10 female participants, ranging in age from their early twenties to mid-sixties.

\footnotetext{
${ }^{15}$ By purposeful sample I mean that a number of training programmes were identified which fitted the criteria of being twoyear masters' programmes, whose graduates had undertaken research, and were based in music or other departments and which had a tradition of being linked to clinical services, or were in a university academic research tradition and approached them one at a time. The intention was to find suitably contrasting settings. I approached one programme at a time, and having secured interest for one, selected some others in another continent which were based in a different tradition and again approached them one at a time, with some other possibilities to allow for programmes to refuse.
} 


\section{Frame for the interviews}

The 11 participants in the two site visits to music therapy departments were invited to a recorded unstructured interview with me as researcher, and encouraged to tell their own story of the experience of research and practice as it seemed relevant to them. The interviews were recorded on an Olympus mini-recorder. I was available to assist interviewees and I invited each participant to say something about themselves and their interest in the topic to begin their account, but in reality the interviews were quite free-flowing and I tended to ask questions related quite specifically to what the person had previously said, if they came to a halt rather than asking other pre-planned questions. I was interested in 'narratives' and the way that each person's account developed, and although narrative analysis would have been a fascinating approach to these interviews, my approach was to use a more broad thematic analysis, that could be applied consistently to each of my data sources. (See Appendix 10 for the briefing for site visit interviews.)

I wrote some field notes during the interviews to supplement the transcripts, and this was particularly helpful with one interview at Site KT, where the Olympus recorder ran out of memory towards the end of the interview, and I then drew on the field notes when writing up the last 10 minutes of interview.

\section{$\underline{\text { Site Visit observations }}$}

I kept field notes of observations at classes that I was able to attend whilst I was present in the department, and this included research lectures, two practical seminar classes supporting placement work and a seminar by external music therapists on issues in employment. I also observed an additional research seminar at one site that was available during the week of study in the participating department. My field notes recorded details of topics and learning conversations that occurred in classes, relevant to the research question, and I was able to cross-reference these with relevant documentation about modules taught on the programmes, which I also made notes on, so that I could see the context of lectures attended.

I reflected on these notes and developed insights and commentary in my research journal (Section 3.6.4) and this was the central way I drew on my site visit observations in the analysis.

\section{$\underline{\text { Site visit summary improvisation sessions }}$}

At the end of each site visit, participants were invited to join me in an improvisation session and reflection to finish the research process. This was practically quite challenging to organise as staff and students were in the department on different days, so it was not possible to find any times that suited all. I decided to just work with whatever was possible, and in both settings only one participant could come. Both were very willing so we did continue with the sessions. 
At Site FV (Friendsville) one clinical lecturer attended and we used a seminar room with piano and diverse tuned and un-tuned percussion. At Site KT (Kindstown), one student attended, and we used tuned and un-tuned percussion in a smaller staff office. I recorded both sessions on the portable Olympus recorder. At Site FV, we did not talk much before the music making, but chose to focus on the topic of combining research and practice and identified instruments we would personally like to play. At Site KT I read a few notes to the student participant about her interview which had been some time earlier before playing together.

At the end of the improvised music we had a 10-minute discussion about experiencing the music and reflected on the topic of my research. This was shared between us, and we both commented on the experience. I later wrote some notes about the music and direct quotations from the recorded discussion in my Research Journal. I also notated a few ideas from the music in notation. Both the improvisations are used in the findings as part of my autoethnographic commentary.

Member-checking of transcripts for interviews and commentary on improvisation

As with the focus groups, individual interviewees were sent copies of the transcription of the recording of the interview for verification, or to remove any details. Sections were again highlighted where participants were identifiable. Interview participants often added clarification to their transcripts or some extra comments for the final version. I also sent the commentary on the music improvisation sessions to the two participants who joined me.

Interesting and often moving feedback was offered back by some interviewed participants, when I returned some analysed material later in the research process, and some examples of this are noted in Appendix 11.

\section{Peer-debriefing with music therapy colleagues}

Two colleagues (one from the New Zealand School of Music, and another local music therapist ) assisted me in providing 'peer-debriefing' which Lincoln and Guba (1985) describe as "a process of exposing oneself to a disinterested peer... for the purpose of exploring aspects of the inquiry that might otherwise remain ... in the inquirer's mind" ( p. 308). My colleagues read examples of transcripts, checked and tested out the original codes, scrutinised categories that were created for individual interviews and then for the whole site visit, and provided feedback about their impressions. In each case they observed features I had missed and queried various aspects of the analysis of a Site, which provided invaluable insights. 


\subsubsection{Reflective research journal}

I kept a reflective research journal from the period of preparation for the research in 2007, and thence forward as the process of the research developed up till its completion in 2013 in a regular way. I began with a handwritten journal in 2007 and as the research developed transferred to an electronic method of recording my thoughts about the research.

The journal offered an opportunity to raise questions to myself about data gathering, ethics, recruitment and practical tasks of the research, but also to grapple with responses to readings, and challenges in thinking and later the process of analysis and synthesis of concepts and themes in the write up of findings. I also found it useful to comment to myself on my own experience as a teacher as the process of the research alongside my work with students developed. It often helped me to understand the data I was working with more fully. As the data analysis progressed and I was writing up the findings I developed more reflexive attitude in my journal entries, and I decided to make use of the journal entries in the write-up of findings employing an autoethnographic style, as discussed in section 3.2.3.

\subsection{Analysis of Data}

\subsubsection{Thematic analysis}

The analysis method used in this study was the broad and flexible technique of thematic analysis, used widely across varied qualitative methodologies by researchers in social sciences and allied health. For example, Australasian music therapy researchers O'Callaghan (2001) and Rickson (2010) have used this genre of analytic approach in their doctoral studies employing respectively grounded theory and action research methodologies . Thematic analysis is defined by Braun and Clarke (2006) as “... a method for identifying, analysing and reporting patterns (themes) within data. It minimally organizes and describes your data set in (rich) detail. However, frequently if goes further than this, and interprets various aspects of the research topic..." (p. 79). The aim in this study was to ground the study clearly in the data but to go beyond the surface and to explore in-depth within the sources, and to find synthesis and differences across the sites and focus groups.

Braun and Clarke observe that thematic analysis, whilst being widely used, has been previously rather poorly delineated in its methodology, and their article provides detailed and helpful guidance on providing clarity and rigour to the analytic process. They give a detailed six-step framework for approaching the discovery and reporting of major themes. This involves in brief: 
1) Familiarising yourself with your data following transcription;

2) Generating initial codes;

3) Searching for themes;

4) Reviewing themes;

5) Defining and naming themes;

6) Producing the scholarly report (including relating back to the research question and selecting vivid extracts to illustrate the findings).

(Braun \& Clarke, 2006, p. 87).

Braun and Clarke emphasise, like Stake (1995), the interpretive approach to case study analysis (section 3.2.2), and that the critical analytic stance begins from the outset of step one, and only concludes with the final opportunity of report writing. In developing the thematic analysis, I also initially drew on McFerran and Grocke's (2007) approach to the microanalysis of text-based sources in music therapy. This was particularly helpful at the start of my study as there have been substantial contributions to the music therapy research literature using phenomenological analysis of text, and this provided models and steps for the analysis of meaning in the focus groups. The process for the analysis therefore included a slightly adapted first stage of Braun and Clarke's 'Familiarising yourself with the data'. In the focus group transcripts I first highlighted key statements through the transcript, and identified these as 'meaning units', for which I then went on to provide initial codes.

Saldaňa (2009) links the process of coding to the Greek root of the word "to discover" and explains that it is a problem-solving strategy that connects data and researcher's concepts or ideas. "Coding is not just labeling (sic), it is linking" (p. 8). The linking then continues from ideas to all the data that relates to those ideas. I used two main levels of coding as defined by Saldaňa and other qualitative researchers, which are described in the following sections. I should also note that these two main levels of coding for each data source were not just sequential. I "cycled back" many times to check and correct the meaning of first level codes, and then compared these to the patterns and categories created. Analytic memos, described after the coding sections below, assisted in the process of reviewing and modifying the different levels of coding.

First level, initial coding

The familiarising process, described above in Braun and Clarke's framework, was important for getting the meaning and feel of the whole transcripts. I listened to the sounds of the voices, their emphases and expressions, and the feel of the interactions in the focus groups and interviews (both 
while transcribing and then reviewing the transcripts). Following the highlighting and marking of the texts for links to the research question, I began the coding. As I was interested in the voices of the participants, the first stage, initial codes I used were a mixture of "In vivo" and "Descriptive" codes. "In vivo" codes are described as "a word or short phrase from the actual language" of the participant, and Saldaňa recommends that they are particularly appropriate for studies that aim "to prioritize and honor the participant's voice" ( p. 74). I was interested in this quality, and this connected across higher levels of coding too, so that two of the findings chapter titles in this study still hold the language of the original participant data. "Descriptive" codes are summaries "in a word or short phrase...the basic topic of a passage" and Saldaňa explains that it is the substance or meaning not just shortened content ( p. 70). As I gained experience coding, it became easier to make short code labels condensing the meaning of the data phrase, and so I used more of a mixture of both sorts of coding. I began coding by hand and then transferred to using the NVivo software package (NVivo 8, QSR International), which was a more flexible way to compare codes across the data sources.

This stage of coding was largely inductive. As Richards (2009) writes, I was aiming to encourage ideas to "come up from the data", rather than applying a frame of ideas to it. Appendix 12 provides some examples of initial coding with in vivo and descriptive codes relating to portions of text, from the first focus group Group-BA (Buenos Aires).

\section{Second level, pattern coding}

For the second level of coding, I used a straightforward process defined as "pattern coding", which Miles and Huberman explain brings together "a lot of material into a more meaningful... unit of analysis" and is a way of grouping "those summaries into a smaller number of sets, themes, or constructs" (as cited in Saldaňa, 2009, p. 152). Pattern coding refers to Braun and Clarke's next three stages, searching for themes, reviewing themes and defining and naming themes. Codes and their text fragments or quotations were compared and contrasted and similar coded phenomena were collected. This process allowed me to sort, group and re-frame the codes to develop core categories, and to collect groups of meaningful units together. For each focus group and site visit, I developed a series of categories, for which I wrote definitions which covered the collection of codes included. Appendix 13 shows the core categories developed as part of the pattern coding process for Group-E (European focus group) plus the definitions attached to the categories. Appendix 16 gives two examples of the individual set of provisional 'themes' collated for two interviewed participants at Friendsville (Site FV), one student and one lecturer.

As I began analysing the second focus group and the subsequent site visits, a process of inductive and deductive analysis took place. A further cycle of pattern coding occurred for the two site visits, when I

\footnotetext{
${ }^{16}$ Chapter 4 "Being on Fire" and Chapter 6 "All these meta-layers" were original in vivo codes.
} 
drew together the sets of interview themes for individual participants and compared and incorporated them into categories or 'provisional themes' for the whole site. Appendices 17 and 18show collated themes respectively for the Friendsville and Kindstown site visits. As I progressed through writing about the provisional themes for each Site, I continued to develop and refine definitions of the themes (relating to Braun and Clarke's step 5 of naming and defining themes).

Analytic memos

Richards (2009) observes that the analysis process is founded on writing and the development of memos "encourages quick and easy documentation of the ideas and the ways ideas grow". She notes that memos are informal records (messages to the self) a kind of "thinking aloud, never as finished research productions" ( p. 80). As such, they build and develop the analysis process. During the course of first and second stage coding of transcripts, I wrote short memos, asking myself questions about the data and where groups of codes might go. As Rickson (2010) notes, the analytic memos were "suggestive, even provocative" and built and linked to material written in the researcher journal ( p. 96). Some examples of analytic memos relating to coding of interviews are included in Appendix 15 , along with short sections of data. (A more extended extract of the same interview data is also included in Appendix 14 for reference, sourced from student Florence's transcript at Site FV.)

I continued to write memos as I collated the analysis for each Site Visit, and wrote a provisional report of the themes. Some examples of the analytic memos written at this level of the thematic analysis are included in Appendices 16 and 17, and give a sense of the questions I asked about how a theme was fitting and where ideas should go. Richards (2009) advises that if you are not sure where to put ideas or codes, you should ask the data, or put them back into the data, which explains the process of cycling back, checking and reframing, that forms an important part of the thematic analysis.

Having outlined the strategies used within the thematic analysis, I shall now provide a brief recapitulation of the analytic stages for each data source.

\subsubsection{Procedures for Stage 1: Analysis of focus groups}

The following steps were taken for the two focus groups which constituted Stage 1 of the research (diagram at 3.4)

- Both focus groups were transcribed verbatim and returned to participants for checking and verification

- 'Ums' and hesitancies were left in the text and some descriptions (e.g. of laughter) though these tended to be removed at the last stage of writing up the findings in order to make quotations clearer 
- Transcripts were read carefully several times and annotated with connections to the research question

- Key statements were highlighted and individual 'meaning units' identified

- Initial coding was developed in NVivo software package and the codes sorted into categories representing the priorities for each focus group.

- Analytic memos were developed and helped to describe the categories (at this stage entries were also made in the research journal)

- For the second focus group (Group-E), I was aware of bringing the categories and provisional themes from the first group (Group-BA) as comparison to the material which developed in the second data source. (So a deductive approach was combined with the new ideas which 'came up from the data' in the second group.)

- Focus group categories were then reviewed and sorted into provisional themes for each group, themes were defined and examples described in draft

- Preliminary summaries of the focus groups were drafted and were then ready for comparison and triangulation with the other data sources

\subsubsection{Procedures for Stage 2: Analysis of the site visits}

The following steps were taken for interviews, field notes and improvisation data in each separate Site Visit to 'Friendsville', and then to 'Kindstown'.

- Individual interviews were transcribed verbatim and returned to participants for checking and verification.

- 'Ums' and hesitancies were left in the text (as for the focus groups) but removed subsequently

- Transcripts were read carefully several times and annotated with connections to the research question

- Key statements were highlighted and individual 'meaning units' identified

- Initial coding was developed by hand for the site visits and a set of provisional 'mini-themes' devised for each participant in an interview.

- The provisional themes from the focus groups also had some bearing on the coding of the site visits. I was aware of looking for particular categories

- Field notes and documentation from the sites were reviewed, and entries made in the research journal. These materials were reviewed along with the provisional themes for the group of participants, and notes were made about shared and distinctive themes for the site on a sheet 
of paper. I preferred to do this part of the analysis by hand, on my study floor with all the participants 'round the room'. ${ }^{17}$

- The improvisations were reviewed, notes made of the conversations and musical features, and I wrote reflections in the research journal

- Site visit categories were then devised and reviewed, and descriptions and definitions were developed as the 'provisional themes' for each Site. (See Appendices 16 and 17 for the provisional themes for Site FV and Site KT)

- There was then a more deductive approach, returning to each interview and 'testing' the provisional themes to check if the Site themes connected with the participant material. (This return to the data was illuminating, as I found material that linked more closely between participants, or just new things I had missed.)

- Key themes for each site were then structured and a provisional summary for each Site prepared as a written draft.

- The two Site visit summaries were offered for peer-debriefing with my colleagues (see section 3.6.3). They offered feedback and suggestions for review of three themes, which significantly developed the analysis

At the end of the second site visit summary, the research journal was also reviewed in the light of themes highlighted in the focus groups and site visits. Notes were made about links between the research journal and the other data sources. Some codes and quotations were identified which linked to research questions and the other data sources for inclusion at pertinent places in the findings.

\subsubsection{Procedures for Stage 3: Triangulation of data sources from Stage 1 and 2 alongside research journal}

A model of the triangulation process for stage three of the thematic analysis was provided in Figure 3 (section 3.8). The following steps were taken for triangulation of the focus group, site visit 1 and site visit 2 data (with background presence of the researcher journal):

- The draft written analyses of themes were colour-coded on computer, printed out and the thematic summaries compared and contrasted. (Red for focus groups, blue for Site FV, green for Site KT and pink for research journal)

- Linked themes were reviewed, definitions compared and reflections were made about collecting the sources into one thematic area, or re-collating new themes. (Appendices 17 and 18 illustrate brief versions of some of the memos which discussed the 'placement' of these themes)

\footnotetext{
${ }^{17}$ Although NVivo software was very useful for the focus groups, I found the wide visual and spatial component much easier for the site visits with the multiple people and documentation.It was partly a wish to have some study away from the computer, but the spatial component also greatly aided my ability to think about the data.
} 
- I re-wrote definitions for the re-developed themes, and collapsed quite a few themes into larger broader areas of meaning

- The process of expanding and collapsing the themes continued until all the key areas of the thematic material identified could be included somewhere in the analysis (referred to by Braun and Clarke (2006) as a kind of "saturation of data")

- I then began to combine the colour-coded texts, and to reposition the shared themes into larger meaning groups. The colour referencing of the text was useful visually, as it allowed me to check the balance of all the different groups of data. (If I observed one area not so well represented I returned to the individual codes and transcripts to refresh my memory. Quite often new insights were raised by re-visiting the original codes and data.)

- Through this cyclic process I finally began to identify a sense of the core themes which developed into the three findings chapters.

As the draft written analysis was completed, I considered possibilities for the form and shaping of the overall thematic presentation. With feedback from my $\mathrm{PhD}$ colleagues and supervisors in the School of Education, I decided on the following musical metaphors which are outlined in this latter section of the chapter.

\subsection{Mapping the Findings}

Chapters 4, 5 and 6 of this thesis are devoted to the presentation of findings. These three chapters represent the central thematic material I have interpreted and triangulated across the three main data sources: (1) focus groups in Buenos Aires, Argentina and Europe; (2) music therapy training programme site visits to Friendsville University College and Kindstown University in 'Eurostralia' (i.e. one in Australasia one in Europe) and (3) my researcher's reflective journal. In each chapter I have outlined the core theme that I deem to sum up the sub-themes in each of the three main areas of the analysis and then have presented each sub-theme in turn.

\subsubsection{Using musical analogies to frame the findings}

Some distinctive musical forms have been identified to assist in the meaningful structure of the thematic analysis (Braun \& Clarke, 2006) and are laid out in the three following findings chapters. The patterning of thematic material is intrinsic to music at all levels of sophistication and there appeared to be good assistance for creating a strategy for telling the tale of these findings in considering how composers and performers organise 'telling the tale' of their music. This has allowed me to continue to think like a musician and to embody the music therapy discipline more fully in this 
study. Aigen (1998), Kenny (2005) and Ledger \& Edwards (2011) amongst other music therapy researchers have continued to remind the music therapy community to consider using the strength of our musician-selves to frame and articulate our work. I was further encouraged by researchers in education and language teaching to find some artistic shape to my research and was excited to read about ScholARTistry. The process of ScholARTistry has been coined by Neilsen (2005) as a way to combine art and scholarship: "to make academic writing an area where virtuosity and clarity are valued, to make educational research an area where the arts are legitimate inquiry, and to infuse scholarship with the spirit of creative connection" (cited in Cahnmann, 2006, p343). In the spirit of Neilsen and Cahnmann's approach I offer a way of employing the thematic structure of music to help articulate my answer to the research question and ground the thesis.

I decided to use a different musical thematic construction for each chapter as the data suggested to me different ways of introducing and developing themes, as will be shown below. This is an autoethnographic device as these musical forms have personal significance for me. They are approaches or 'forms' in which I have sustained particular interest in my own journey with music and music therapy (ground bass, theme and variation, and motif in opera) and had a good fit with the themes in the analysis. Overarching this as a 'container' for the findings of the thesis, I have used the metaphor of moving from improvisation (an 'in-the-moment' spontaneous playing with ideas) to a more considered and refined composition, which is the thesis. As a natural improviser rather than composer, it is interesting how hard it was to fix the 'composition' - I am used to playing, documenting and moving on with ideas for the next engagement (and I return to this in discussion at 7.1.7). However, writing-up the research and communicating the findings in a contained written form is a kind of composition, which is a further process of synthesising, re-working and pinning down the finished form. Despite thematic analysis in qualitative research being essentially a text-based analytic tool, it seemed that musical approaches to the analysis and construction of themes could be potentially productive and illuminating.

The following model provides an example of a particular musical form or process as a 'thematic device' for each chapter. The three major areas of findings are titled as follows:

- Chapter 4: 'Being on Fire'

- Chapter 5: 'Acknowledging and managing change'

- Chapter 6: 'All these meta-layers'

They are contained by a translucent vessel which moves from improvising (a fluid process) to the more stable and refined composition of the final findings. See figure 4 below. 


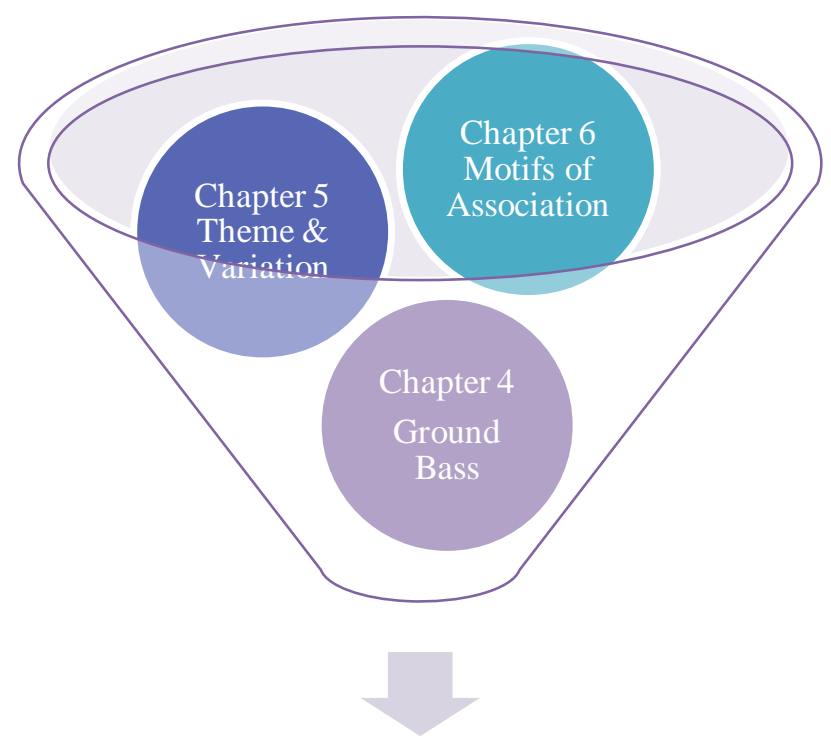

Playing with pattern, meaning and form

in thematic analysis: from 'improvisation'

to 'composition'

FIGURE 4: A MUSICAL MODEL FOR THE THEMATIC ANALYSIS

\subsubsection{The musical forms used as metaphors in the findings}

1) The overall structure - from improvisation to 'composition'

Improvisation is a well-used approach in music therapy practice in Europe. Darnley Smith and Patey (2003) observed the significance of learning improvisation for music therapy students on two training programmes in London. My own experience of music therapy training, practising with children and adults, and of teaching in music therapy during the 1980s and 1990s in London, centred on the use of improvisation as a core technique in my work. ${ }^{18}$ Improvisation is linked in definition by Sloboda (1985) to the process of story-telling as a verbal art:

In a sense, every act of story-telling that is not a verbatim recall is an act of improvisation.

However, such improvisation reaches a peak in feats such as the singing of epic poetry in the Homeric tradition, presented into the twentieth century among the folk singers of

\footnotetext{
${ }^{18}$ The Nordoff-Robbins tradition of 'Creative Music Therapy', Juliette Alvin's 'Free Improvisation Therapy' which I learnt at Guildhall School, (as described by Bruscia) and Mary Priestley's 'Intertherap' were three traditions existing in London during the 1970s and 1980s when I was introduced to and trained in music therapy. Improvisation was central to each of these theoretical models and learning about its use and then practising it had a profound effect on me as a person and a professional therapist.
} 
Yugoslavia.... Parry's observations (Parry 1971) and recordings show that epic singers composed their songs anew on each occasion. No two performances were the same. (p. 141)

As I was engaged in analysis of transcripts of interviews and was looking for patterns in the codes I had made of the texts of focus groups in this research, I was aware of a link between doing this 'search for meaning' in texts and finding meaningful patterns in music improvisations (and also sometimes in the words people used to describe such improvised music) that we might build with people in music therapy. ${ }^{19}$ Inductive analysis - a process of seeing things 'come up' to you (rather than looking for some specific ideas that you have pre-determined - a more deductive approach) feels rather like this free improvisation experience. Of course sometimes improvisations are more precrafted and shaped than this, and one might limit the choices (such as a few pitches on a xylophone or the black notes on the piano) offered to make things easier for a shy music therapy participant. However many times I have just launched in on piano with a probation client on the drum kit who is 'just feeling his way', and we have explored together and seen 'what comes up'. Nachmanovitch (1990) has an interesting description of this kind of 'feeling your way' approach to music describing it like a walk in a new city:

A walk, following your intuitive promptings, down the streets of a foreign city holds rewards far beyond a planned tour of the tried and tested. Such a walk is totally different from random drifting. Leaving your eyes and ears wide open, you allow your likes and dislikes, your conscious and unconscious desires and irritations, your irrational hunches, to guide you whenever there is a choice of turning right or left. You cut a path through the city that is yours alone, which brings you face to face with surprises destined for you alone. .... As the pattern of people and places unfolds, the trip, like an improvised piece of music, reveals its own inner structure and rhythm. Thus you set the stage for fateful encounters. ( p. 19)

Some of the first ideas that emerged for me or 'came up in the data inductively' from the initial coding of the focus groups were to do with curiosity, aliveness, excitement about what you were doing and a questioning and searching (these formed the bulk of Chapter 4 and captured the idea of the ground bass). However, there were other strong ideas that appeared to have meaning in my first examination of data; for example, the importance of participants' history, the struggles people had with timing and balancing learning, the massively complex area that was clinical practice and research. These themes seemed to fit with materials that have formed the substance of Chapters 5 and 6 , with core themes about change and complexity.

I have made use of reflections on two improvised pieces created with two participants (one student one staff member) at each of the site visits Site KT and Site FV, to introduce and close the findings

\footnotetext{
${ }^{19}$ This has been a regular process in documenting music therapy sessions, experienced repeatedly in thirty years of reviewing music therapy sessions.
} 
sections of this thesis. These experiences with the participants were very interesting examples of cocreating meaning - a really fascinating way of 'interviewing' somebody if you like. We held the topic of integrating research and practice in mind, played the music that 'emerged' from being in the room together and then discussed it, and in each case some new insights emerged. So part of the 'composition' of the thesis has been to frame the findings with these improvised musical reflections. In addition, the process of comparing, reflecting, redeveloping, and reorganising and bringing initial ideas back to the data for re-examination, and placing the material in a suitable 'form' seemed more like what the composer does as she or he constructs and articulates the music. This latter approach, refining and crafting the whole also uses elements of a deductive second-stage of thematic analysis when you bring your patterns, shapes and ideas and re-apply, test and form them to synthesise into a whole composed framework.

The following short sections introduce three additional thematic forms, which I have applied to the findings chapters. These are:

\section{2) Chapter 4 - 'Being on Fire': Ground Bass}

This particular complex theme, or collection of ideas, 'being on fire' recurred with unusual frequency across the data sources and was pervasive in each one in varying ways, and over the two and a half year period, which suggested that it should find a significant place in the report of findings. The theme seemed very reminiscent of a ground bass in musical form, repeating quietly and insistently and potentially underpinning everything that happens for researcher-practitioners. As an example of ground bass (or 'chaconne' as it is often also named), I have chosen a well-loved example, Music for $a$ While, a song Purcell composed as part of the incidental music for for the play Oedipus, King of Thebes by the poet Dryden. The Oxford Dictionary of Music's definition of ground bass (It. Basso ostinato, 'obstinate bass') is as follows: "Short thematic motif in bass which is constantly repeated with changing harmonies while upper parts proceed and vary" and this analogy seems to provide a starting point for explaining how this idea developed in the research analysis. In this chapter, participants in both focus groups (the first stage of the data collection) prompted the development of this theme in my analysis, firstly as a collection of 'in vivo' $\operatorname{codes}^{20}$ (such as passion, fire and curiosity) and through the course of further data gathering at the two tertiary sites, the theme developed in scope and connection. The researcher journal refers to this theme periodically throughout the research journey. 'Being on fire' seemed a good descriptor for this core theme - it was coined by one participant in the Site 2 Visit "Kindstown" - as it implied both the igniting of something but also keeping the flame alight, both of which were important characteristics in people's stories about integrating research and practice.

\footnotetext{
${ }^{20} \mathrm{An}$ 'in vivo' code is usually a first-level code, which uses directly the language of the participant. (Richards, 2005)
} 
3) Chapter 5 - Acknowledging and managing change: Theme and Variations

Theme and variation is a musical framework of magnificent utility, being employed by composers throughout the history of music. There are many admired examples of the form, with particularly well known examples in the baroque and classical eras. I have chosen many musicians' favourite example of Bach's Goldberg Variations, as my musical frame for Chapter 5 as will be explained in detail then. However, I also remember vividly the experience as a student youth orchestra violinist playing the orchestral accompaniment to Rachmaninov's Rhapsody on a theme by Paganini, where piano and orchestra explore a series of intricately contrasting variations on Paganini's melody, and being amazed by the building virtuoso of the piano solo as the piece developed.

The challenge of demonstrating different facets and meanings of the music by having the central focus of the original theme, but altering various features singly or in combination seemed to be a helpful metaphor for capturing the change process. In the second core chapter, the idea of the world of therapeutic practice and research being centred on change, seemed to fit well with the metaphor of a central theme which morphed and changed in many different ways. Theme and variations is also a very valuable musical form for music therapists to be aware of and to practise. Music does not have to be the same when repeated.

\section{4) Chapter 6 All these meta-layers - Motifs of Association in a Debussy Opera}

Opera is an art form renowned for its complexity, both in conception for the composer and lyricist, and in execution for singing actors, orchestra, conductor, designers (set, lighting, sound, costume), stage director, managers, and often choreographer and dancers. In Claude Debussy's Pelleas and Melisande (1902), specific motifs are used to colour and highlight different aspects of the drama at varying points. The composer (and in performance also the conductor) can foreground different aspects at different times: "We'd like you to think about this now, Notice this." The metaphor here might link to the educator managing the complexity for the student in training of research and practice. The multiple complex strands are potentially overwhelming, how do we approach it?

Debussy's motifs of association in his opera became the musical form to underpin the last chapter on "all these meta-layers". Musical ways of managing layers, include holding all the layers together in a well-designed web, foregrounding different aspects at a time, and recognising the enjoyment and stimulation of complexity. The sub-themes in the chapter emerged and are highlighted at different moments.

\subsubsection{Text presentation of the findings}

In the write up of the analysis, the focus groups, site visits and researcher journal were triangulated to provide a rich range of perspectives. As I moved through the analysis, coding, re-coding, creating 
categories and grouping the categories across the data sources, the emergent themes seemed to group into three overarching areas (with a few exceptions and extra ideas) which have provided the three main chapters for the findings.

The triangulation of data and consequent write-up of the findings chapters has been approached in the following way. In each chapter the core overarching theme is identified and defined as a starting point to the presentation of findings for that chapter. This is followed by a coloured map of the sub-themes for each chapter and each sub-theme then is explored in turn. As with the core theme for the chapter, sub-themes are defined at the outset in italics, and presented as a synthesis of contributions from the different data sources and interpreted for meaning by me as the researcher. (My own researcher journal is included reflectively at periods, both to observe reactions to the research process, and to indicate developments in my understanding). There is some explanation of the material within each sub-theme, in order to bring together meanings represented across the whole case study. It has been a complex process, and possibly varies in the success of the communication, but the intention was to be faithful to sources, and to hold the various 'positions' and expressions as they indicated responses to the question.

The' look' of the text includes quotations in italics and short names for each data source coded in colour (Red for focus groups Group-BA and Group-E, Blue for the visit to Site FV, Friendsville University College and Green for the visit to Site KT, Kindstown University). Research journal citations are given in Pink, for example: (RJ $3^{\text {rd }}$ April 2009). All material in italics indicates a direct quotation from participants, and longer quotations are referenced with a participant research name and line numbers. The definitions of the sub-themes developed in the analysis. They began as definitions of categories for each relevant Site Visit or focus group, and as I developed higher level coding across sources, the definitions evolved to absorb the meaning from the different sources.

By way of introducing the findings as a whole, and, a brief vignette showing the emergence of some meaningful thematic material for myself and 'Naomi', a student at Kindstown Site visit will be presented next.

\section{A musical vignette: Finding patterns in improvisation with Naomi Student} Site $K T$

In an improvisation with Naomi, first-year student interviewee at Site KT, we sat together in a fairly small room in the afternoon at the end of my visit with a collection of tuned and untuned percussion. I read a few notes out about the interview we had shared earlier in the day, and suggested that we invented a piece together on anything interesting that caught her 
attention from recollecting the interview, or just leave it open with the idea of integrating research and practice (the subject of my research) being the reason for coming together. I didn't have any particular expectations about this music. It was just another space or process to reflect. My brief outline of the field notes highlighted Naomi's process of deciding not to do music for a Bachelors' degree, and then coming back to music therapy, and then choosing her research topic, (choosing between clinical project and a spirituality topic), and her experience as an honours student conducting some undergraduate research.

The resultant piece was in three sections. Naomi checked if it was ok to start, and after a short pause, she began with a tiny motif, exploring the notes on a metallophone (in a kind of mode). The notes were set up in this particular pattern and are illustrated below:

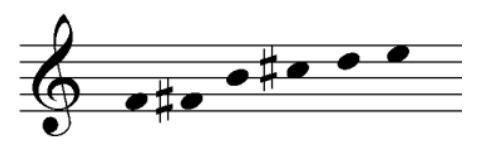

I fitted in the spaces Naomi made with the motif-playing some accompanying off-beat rhythms on a pair of rosewood claves, and later on a cabassa (a metal shaker that you twist). The motif expanded and grew between us, Naomi responded to my rhythmic shaping, and responded to her phrases.
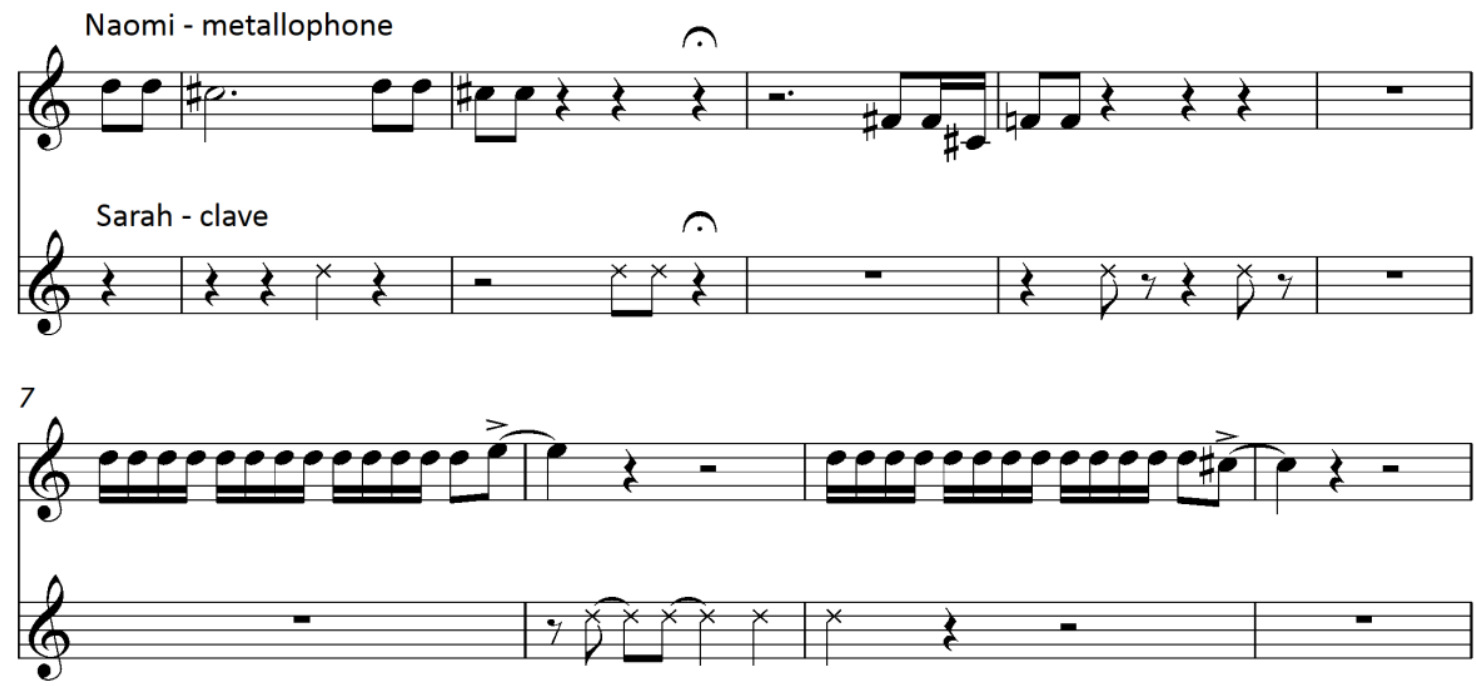

In the middle section we played together on the djembes, and then Naomi returned to the mode and theme on the metallophone and I joined in with voice in a kind of call and echo dialogue. We expanded and 'stretched' the theme, playing it in sequence, using voice as echo. After playing we talked and I said: "It's funny isn't it, playing music with somebody for the first time?" And Naomi said yes and articulated her surprise when she found that the 
metallophone notes were set up in that particular mode, (they weren't in usual diatonic order) and it created a certain sort of feeling in her-it suggested something uncertain. With the first little theme on the metallophone, Naomi said she didn't think about this beforehand. She didn't think: "What am I going to do?" It just came to her. She said: "That mode gave me a sense of indecision" It evoked mysteriousness and something a bit mischievous. As researcher, I found this interesting on reflection and particular in the context of the improvisatory form I had thought about for analysing the study data. Naomi responded to the 'form' of her musical surroundings, the notes in a particular pattern, and an idea just came up and then developed between us in the improvisation.

Naomi then went on to say "When you were reading back to me I saw 'dichotomies' research and practice and my choosing this way or that way". Later she observed that in the middle of the piece, when we were both playing djembes, and there was a dialogue - a kind of conversation between the two instruments and she said she thought: "Ah! These two things can co-exist. I made my own decision - I chose for myself."

So pattern and meaning 'emerged' from the music for Naomi and myself, and the idea of Naomi's choosing - emphasising her curiosity and her interest, and the sense that research and practice can coexist, seemed an appropriate place to step into the next stage of the thesis, the three findings chapters.

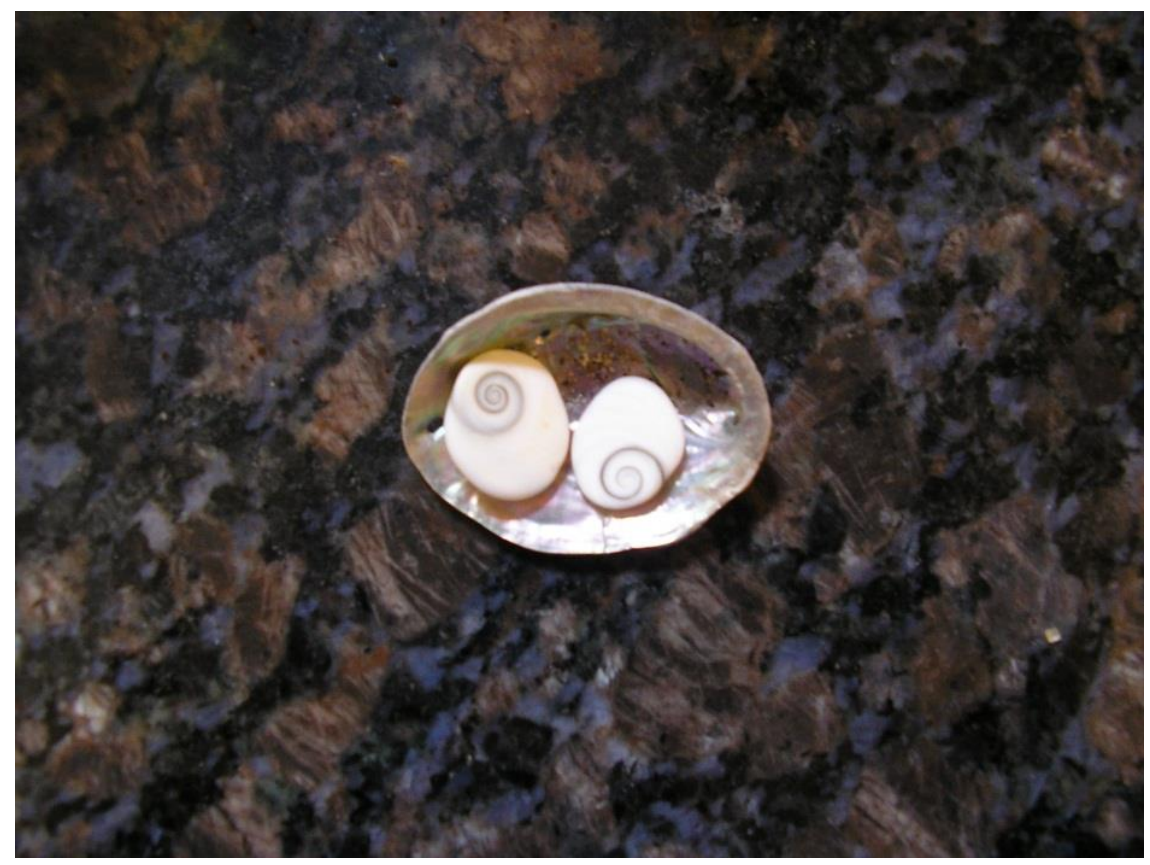

FIGURE 5: KORU PATTERNS ON THE 'CAT'S EYE’ SHELL 


\section{Chapter 4: Stage 1 OF Findings}

\section{'BEING ON FIRE': GROUND BASS}

\section{Introduction}

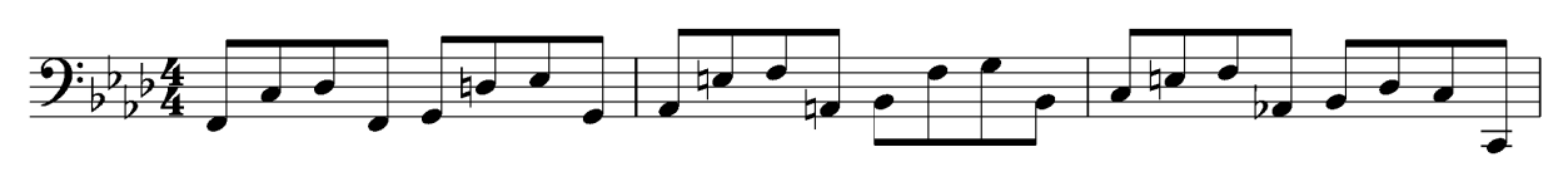

The musical illustration above is the three-bar ground bass of Music for a While, by Henry Purcell, from Oedipus, King of Thebes, by John Dryden. The ground bass provides a stable, cycling underpinning to the exquisite melody setting the words, "Music for a while, shall all your cares beguile". The three-bar bass repeats strictly for the majority of the song, with a short section in the middle where the bass is freer, however the beginning and the end hold the three-bar phrase, as written above. A repeating bass line of this nature works on me as the listener in a stabilising semiconscious way, and countertenor, Andras Scholl's performance notes to his 2011 recording of the song, refer to it as hypnotic, just keeping the music in a steady place and pulling the listener in, while the singer goes on his journey with the melody (Scholl, 2011)..$^{21}$

'Being on Fire' (a phrase coined by one participant at Site KT) is the 'ground bass' to this chapter. The ongoing metaphorical content of this part of the findings is about the energy of illumination. People described the ways in which they might be lit up about researching practice - 'sparks' emerging and being nurtured - and it is such a repeating underpinning to the story of the findings. Participants speculated in various ways about how the spark might be sustained (help from others, good support and supervision, inspiration from varied sources). It became interesting in the course of the analysis to examine what sorts of experience were responsible for enthusing the participants. Enlightening also were participants' recollections about students or as students themselves, and how they saw this having an integrating function for research and practice. The quality of people's speaking voices was also of interest to me, as interviews and focus group discussions developed

\footnotetext{
${ }^{21}$ Andras Scholl sings Music for a while on a 2011 recording O Solitude, solo arias and duets by Purcell. Several recordings of Scholl singing Purcell's song are available on YouTube for quick reference.
} 
(animation, emphasis, reinforcement, and repetition), as it seemed to highlight and embody the 'fiery' process people were describing. I will now move on to outline the thematic material, beginning with a key for identifying data sources, and an overall picture of the themes developed in this core area (Figure 6).

\subsection{Key to identifying the data sources}

As a reminder the following key will be used as appropriate to identify which source generated the material. The colours are intended to assist the reader with identification of the data sources, and were of great use to me as researcher to keep a balance between the different areas of data as I moved through the analysis. Appendix 2 presents a list of all the pseudonyms, settings and roles of each of the 19 research participants, to act as a reminder for where each contributor was based.

\begin{tabular}{|c|c|}
\hline Data Source & Abbreviation \\
\hline $\begin{array}{l}\text { Focus Group } 1 \\
\text { Buenos Aires (conducted at the XII } \\
\text { World Congress of Music Therapy July } \\
2008 \text { ) }\end{array}$ & Group-BA \\
\hline $\begin{array}{l}\text { Focus Group } 2 \\
\text { Europe. (Conducted at the department } \\
\text { office of a music therapy tertiary } \\
\text { programme in Europe. January 2010) }\end{array}$ & Group-E \\
\hline $\begin{array}{l}\text { Site visit 1: Friendsville University } \\
\text { College, Eurostralia. }\end{array}$ & Site FV \\
\hline $\begin{array}{l}\text { Site visit 2: Kindstown University, } \\
\text { Eurostralia }\end{array}$ & Site KT \\
\hline Researcher's Journal & RJ \\
\hline
\end{tabular}




\subsection{Core theme for this chapter: Stage 1: 'Being on fire'}

Description of Core Theme:
The ground bass
In the collected reflections of researching about practice
(or developing connections between the two) participants
demonstrated widespread recognition of an energy or
passion that people discover to go and 'find things out'
about the music therapy field. The awakening of curiosity in
students and practitioners was observed as central - both in
research' and 'creative' practice. The participants talked
about this both within themselves (what has excited them)
and recognizing and nurturing it in students. Participants
linked this directly with the process of practice and of
researching about practice. They recognised that
empowerment and confidence develop through encouraging
this spark and it sustained people through hard work and
difficulty. Some participants noted that personal growth of
the therapist was also harnessed and the idea of the 'quest'
- of going in search of previously unknown territory -
provided an integrating metaphor connecting the planning
and thinking of research with learning journey of a
therapist. 'Not knowing' and searching are integral to both.

\subsubsection{Layout of sub-themes}

This main area in the findings incorporates a number of sub-themes which are pictured in the following map. Each sub-theme will be introduced in turn in the rest of the chapter, beginning with a short description in italics which identifies the material brought together in the respective section, followed by the illustrated expansion of the theme, including quotations from participants and my interpretations of the meaning or significance of the material in relation to the research question. Quotations from participants are shown in italics with line numbers for longer quotes. 


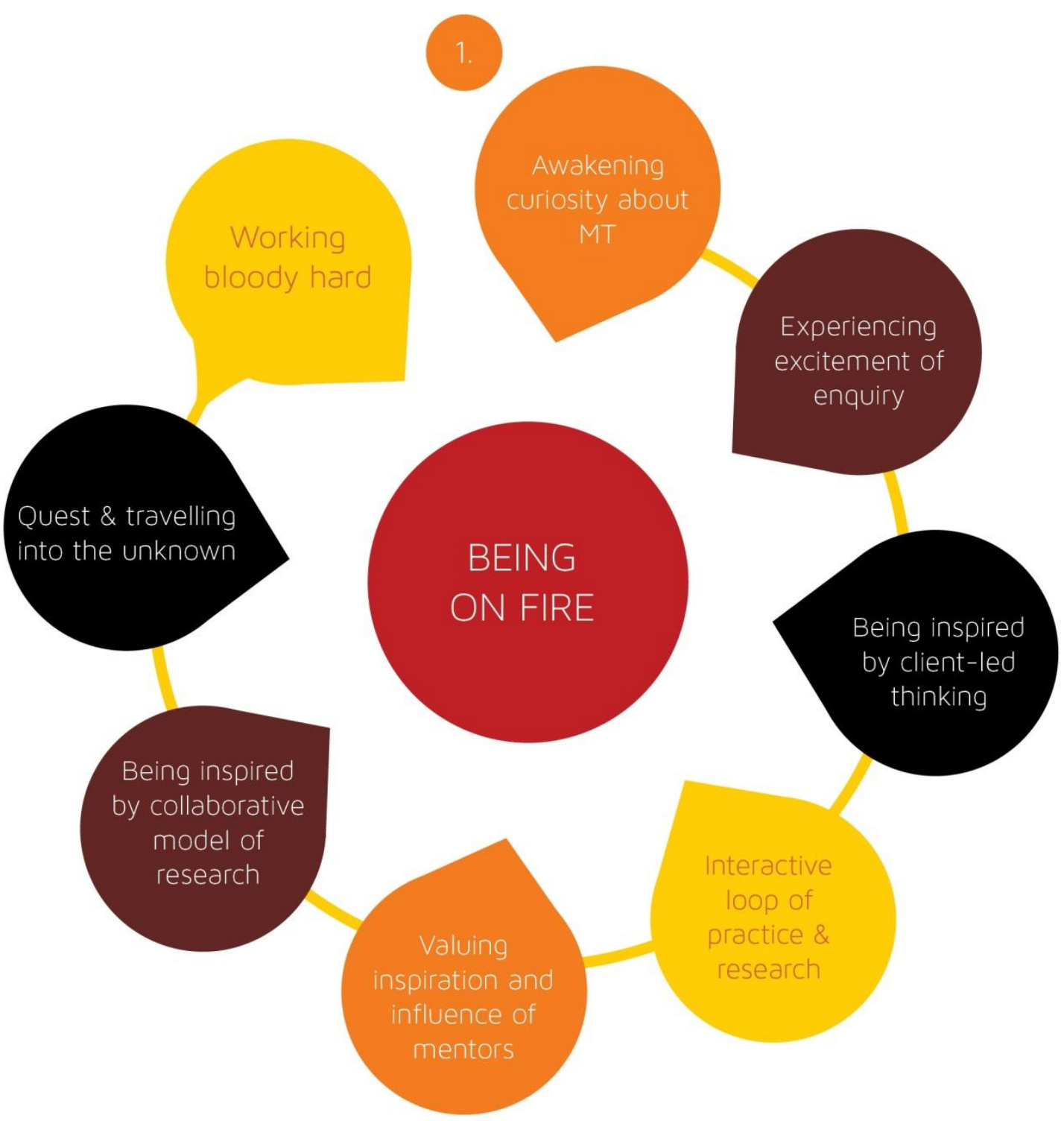

FIGURE 6: MAP OF THEMES FOR CHAPTER 4

\subsubsection{Awakening curiosity about music therapy}

Description of sub-theme:

Participants observed the emerging process of being interested and curious about aspects of music therapy and saw this as a naturally occurring and 'regular' sort of phenomena that could be characteristic of practice and research. In the context of education this included facilitating the spark of interest in students and guiding and framing their interests. Asking questions and reflecting about practice was considered to be a typical way for this to happen. 
In the opening to the focus groups, three lecturer participants (one in Group-BA and two in Group-E) raised the idea of curiosity and being awakened or enlivened by an aspect of learning about, or doing practice in their introductory stories about themselves and their interest in the topic of this research study. Their histories were diverse, but they overlapped in this interest and inquiry about their worlds, as they described their development as music therapists. One of the lecturers in Group-E noticed two different kinds of interests in herself as a combined honours psychology and music student, expressing her joint excitement about numbers, statistics, methodology and 'puzzles to solve' in undergraduate psychology alongside the "kind of curiosity and imagination of my (instrumental/music) teachers", noting the different flavours of the disciplines with the psychology examples being very much in the 'box of research'. Another in Group-BA acknowledged a change in her interests as she developed as a researcher and explored the idea of this "curiosity about patients'experience" in group discussion as the kind of research in which she has become much more interested. The third Group-E lecturer participant almost jumped with excitement describing the discovery of a portfolio of articles by a supervisor, embodying the chapter's ground bass idea of being on fire in the enthusiastic speech:

I read them all night! The sheer intellectual excitement, finally - here is a sense of ideas going together with experience and actually being able to think around my ongoing experiences as a clinician and being able to put them together with the heritage of the ideas and interdisciplinary ideas and thinking from an informed research perspective about that as well. (Eddie: 130-133)

Interestingly each of these participants in two different focus groups evoked a synergy between research and practice in an immediate way, there was a recognition of different processes (problemsolving, thinking. wondering, alongside active music-making and experiencing in therapy) and the enjoyment of bringing them together was expressed. A fourth Group-E participant later in her group then made a more deliberate connection with training students and explicitly picked up her focus group colleague's introductory suggestion of curiosity about patients in research as being a particularly valuable and authorising experience for the new student. It validated and underlined creative thinking and confidence in one's own ideas. This also had particular benefits back into the practical work with patients - the student can make discoveries and test out beliefs but also becomes more vivacious and lively in her own ideas about practice:

I think one of the great benefits of inviting students to do something which we can probablyfor this conversation - call "research" is that if it goes well, it encourages a certain kind of curiosity ('Yes' murmured by others) a sort of aliveness, rather like you're saying, thinking about patients which is very much enhanced I think by having that focus, as well as the kind of curiosity you might express in supervision or somewhere else but actually some sort of 
belief or discovery... "I can really think about this, I can really have my thoughts about this... It might be really useful for me and for my work." (Catherine: 292-299)

As researcher, I should own up to my attraction to this thematic material - and I should be interested in and working hard at disproving it (in the manner of Yin 2009) as I am aware I might be looking for it. A hint came from my research journal Feb 2012:

I recall writing the documents for the Guildhall Music Therapy programme in 1990s.My previous position for 14 years required that I write such materials. I was always concerned to add in the qualities we were looking for in aspiring therapists, firstly that they be passionate communicators, but following this that they would have a 'curious questioning attitude'. Finding these kind of ideas in the focus group data has felt quite confirming, but I have to try to not go overboard with this. (RJ, February 18 2012)

However, I was also intrigued that four experienced trainers from different continents, Australasia, Africa, and Europe spontaneously talked about the importance of arousing and working with natural individual curiosity of each person. The 'repeating bass' acknowledging curiosity and passionate inquiry seemed to be well-established.

The aliveness that lecturer Catherine (Group-BA) felt was particularly valuable above, was also echoed in an elaborated statement by a researcher-lecturer from Group-E, halfway through the discussion group. This researcher-lecturer, Kirsty, was also thinking (like me in the 1990s) about the attitude of the therapy student, when we begin to consider introducing research - that of being really attentive, ears pricked, senses awake and watchful - really noticing detail in the practice, and keen to look back at what it might mean:

So I suppose if we're thinking of research, one of the things that we are keen to establish as an attitude is that right from the word go - one is refle-xive, one is reflec-tive as a practitioner, and that includes being alert and vigilant, to all the possibilities and problems, at any stage of ... the process, and I mean at a kind of macro- as well as on a daily, on-theground level. So if we start thinking about research, the question then is: 'Well ok how does research fit with, or how is it part of all this? (Kirsty: 313-318)

This participant brought in a linking concept that might be part of both practitioner and researcher language and tasks, the notion of reflection widely acknowledged in the training of practitioners, which creates a natural loop from the awakened curiosity about an issue, into idea, new plans, theorising, testing, new practice, and so on - very much the processes of research. In making sure I understood Kirsty's perspective in Group-E, I asked for confirmation, that it might be a real encouraging of questions at every level? It was significant that she corrected me with a reminder that 
the curiosity/questioning is necessarily given a context and a shape by the training programme (it is not just random and 'anything' but contextualised by teaching and supervision).

Sarah: 'So kind of, lots of questions, that become an inherent part of everything you do?

Kirsty: A questioning attitude, but also some kind of frame for making sense of it all.'

(Kirsty \& Sarah: 324-326)

To summarise then: participants observed that curiosity was awakened and encouraged, and was seen to link easily between practice and research, but also might need to be given focus and direction by the lecturers and supervisors.

Asking questions was also highlighted in the initial stories of some lecturer participants in both extended visits to Site FV and Site KT. It was a slightly less prominent feature generally of these two contexts than in the focus groups, but two individuals at the sites specifically identified this kind of inquiring, questioning approach in themselves, and saw it as an urge and a slightly nagging quality that was hard to resist. A Site FV lecturer offered this thought when invited to 'start anywhere' in her experience. She said right from the beginning of her training she always had felt wary about big claims, "I suppose I've always asked questions about how does this work? Why does this work? And wanting to just somehow gain some - evidence for it."(Hope). In a slightly similar way a Site KT participant observed early on in her interview the sceptical and inquiring approach that drove her along, noting that she didn't "ever feel that I have an answer to anything... so it's a hunger for knowledge". In both cases, this provided a backdrop for their own practice-based research pathways. The programme director at Site KT observed that once their music therapy training programme had converted to Masters' some years previously, there was a change in student recruitment towards older people, sometimes already parents, with more experience of music and, as she described: "People were like sponges... It was a big ask, theory and clinical methods... But I think it's working well. My sense is that music therapists are (now) asking more questions. More inquisitive and this adds to clinical skill...” (Beatrice 287-288)

Another researcher-lecturer participant, Quentin, from Group-E also went on to describe how they aimed, within their teaching groups, to cultivate a questioning approach that actively linked between the practice experienced and the research interests of the student. They “... try to establish a culture in our seminars... of being truly inquiring, you know, gently but... pointed. So that really encourages students to actually use the academic seminars as a place to explore something”. This kind of description underlined strongly the potential for integration of processes, as what was described here could easily be thought of a "clinical supervision approach" (where one might encourage the practitioner to ask questions about what they did in a session and to explore potential strategies) but equally this could be a "research approach" as the students may become very interested in why or how they have experienced something with a client, and wish to document this aspect in detail, or to test a 
theory they have about the phenomenon, and develop a pilot study to explore this.

\subsubsection{Experiencing the excitement of search and inquiry about practice}

Description of sub-theme:

Participants communicate clearly (through content of speaking and their quality of voice) an energy and passion for inquiring and finding out new knowledge about practice. The participants talk about this both within themselves (what excited them) and recognizing and nurturing it in students. This is linked directly with the process of research about practice. It enlivens people, awakening something within them. Empowerment and confidence develop through encouraging this spark. Explicitly and implicitly they emphasise going in search of previously unknown territory and not knowing where they are going.

Group-E and Group-BA laid the ground for this aspect of thematic material and a particular dynamic energy is identified that develops in the analysis and which each later Site Visit reveals in abundance. The three lecturer participants in Group-E who are from the same team have just been marking essays and one person strongly expresses the quality of $a$ “...kind of fire/motivation" and elaborates further about students who get engaged in this way can override lack of previous academic experience: "Somebody with - I can only call it fire, it's a fire element - in their mind (let's not even think intellect 'cos we don't know) who may or not be academically strong, will kind of pull together something pretty impressive." (Kirsty 427-429)

This can be equated with the 'aliveness' to which Catherine in Group-BA drew attention. Although they were not particularly explicit about this, both speakers hinted at a creative or imaginative drive in the student music therapist that can be encouraged and harnessed.

Passion, enthusiasm and creative urge for inquiry permeated the stories about research and practice of all five participants at Site FV. It was one of the strongest and most consistently received messages from this data, and I observed this interest to be sustained too by everyone, despite some of the difficulties experienced. One clinical supervisor participant said: "I do like a challenge, very much like a challenge yes I do, I will rise to a challenge" and then observed a little later "in the end ...I used phenomenology... which I got quite fascinated in 'cause it does enable you to find out more about how an experience felt". A senior student participant described herself evangelically as "a born-again music therapist" through the exciting journey of the music therapy learning. She enthused: "Beside thoroughly enjoyed reading papers and researching and reading books and bought dozens and dozens 
myself and write as much as I can about a subject and I ...want to provide evidence that will convince people of its value..." (Florence 49-53)

The junior student spoke about his experience of being drawn to music therapy learning because of the fascination with how people feel about music, and having less focus on what composers intend, as in his previous musicological study. He referred to:

...the catalyst, that sort of thinking or feeling towards music ...I suppose sort of drew me towards it. It was more music therapy in the sense of, well, it's what the person feels, it's what the person's actually doing which is important; more important than what the composer actually wants. (Patrick 356-360)

The fourth (lecturer) participant recorded her view about her research project: "Yeah, yeah. I loved what came out of it. I'm mean it was incredibly stretching, you know, I more or less gave up life for 18 months. Didn't do lots of things and just couldn't put it down..." and while not minimising the struggle with large amounts of data, definitely reminded herself that she would do it again because " $t o$ be able to collaboratively research practice was an amazing thing to be able to do". When I asked the fifth lecturer-researcher participant if she would do another study using similar qualitative methodology she responds with real energy:

Yes I would, I would and I would hope that I would do it better. But what I would be really interested in is how to do the analysis and how to theoretically underpin that. Because I think there is a lot of potential there for bringing in a lot of clinical understanding ...(Anna 199201)

The vitality of people's interest in their own areas of practice inquiry at this site was most fascinating to me, and strengthened the initiative from focus group two, where this was first identified. Some Site FV participants emphasised the challenge and struggle at the same time, but the four who had been engaged in active research, all spoke animatedly about their topic of inquiry, and you could feel the motivation whenever they concentrated on describing their research.

Two lecturers from Site FV identified a particular discovered passion for the careful understanding of ethical issues and I interpret that this particular interest had a special connection between research and practice for practitioner-researchers. The challenge of managing research ethically is of great interest and value to clinicians, and both the participants had particularly sensitive issues to deal with. They were very enthused when talking about giving voice to their clients and managing confidentiality and all the challenges around it. They made a lot of effort to steer the research carefully and seemed to feel that they and the clients were particularly rewarded by the care they took. 
Site KT gave similar witness to the weight of this particular sub-theme - experiencing the excitement of search and inquiry. There were different areas of emphasis to those identified above at Site FV, and the difficulties experienced were less visible perhaps, but the communication embodied a quality that I recognised from the previous visit, passion and energy characterising it again. This sub-theme related to how practitioners had experienced research for themselves, how they anticipated the process as a future or completing researcher (from the student perspective) and how they had considered current music therapy practice that might develop into forthcoming research.

Two staff member researchers amongst the six Site KT participants spoke eloquently about what one described as "extending the knowledge base". They had worked over the years in practice areas where there was "scant literature let alone research". The first researcher drew on individual clinical experience in a new music therapy area and combined this with theoretical frames from other disciplines so this new integration was a pioneering adventure. Commitment was driving her “...because my clinical experiences were convincing me this was valuable work for vulnerable people." (Alex 59-64) The second researcher (identified in the previous sub-theme concerning the importance of evolving questions) emphasised the restless quality of this inquiry and because current frameworks did not adequately explain things, it was urgent work.

I'm on a constant search, there's no doubt that I'm on a constant search for knowledge. Yeah it is kind of hysterical because I don't ever feel that I have an answer to anything and I certainly don't believe most of what I read in some ways either, so it's a hunger for knowledge. (Bella: 122-125)

By looking in new ways at one client group, not previously documented in the music therapy literature, the first participant, found in the early stages of her career that she was challenging orthodoxies in music therapy internationally and locally by pursuing research and practice in different ways to the norm. This participant was compelled by her integrity as a practitioner and she felt - for example - that randomised controlled trials (RCTs) were not suitable in her area of practice but was very enthused to research anyway by "his questing passion to know. So as she says, she and a colleague "were trying to develop a way" (Alex 121-122) and she "started to think in a psychodynamic way for researching music therapy" (Alex 109). The senior student at Site KT identified the increased sense of agency and purposeful role that being involved in research on practice as a student practitioner afforded her and was animated noticeably by this combination:

I think I'm more excited now about being a music therapist knowing that I can do that research as well, and kind of contribute to the body of knowledge that's there, and feel like I can actually be a worthwhile member of the music therapy profession.' (Abby 591-592) 
The second researcher, Bella, also described the research journey of extending our own and others' knowledge as being one where often 'I don't know what I am doing', and while the uncertainty was a challenge, she finds she has often been helped by others, and the rewards are very rich: “...my experience has been a lot of mentorship and a lot of exciting acquisition of new knowledge and how fulfilling that is."(Bella 183-185)

Sometimes these research journeys were experienced as isolating and difficult to sustain leaving one participant "quite alienated in my own music therapy field", but again appropriate mentorship seemed to help preserve esteem and courage as an independent thinker and someone who could "question and challenge and not accept everything."(Alex 365-366) However another viewpoint was highlighted by a further clinical lecturer at Site KT who described the possibility of collaborating with others in the search for something new and outlined the process of bringing people along: "I in-serviced everybody about the project and I got the medical staff on board and we got everyone in. Everyone knew about it.... And this then ...opened some great doors." (Helena 316-320)

Obviously different times, places, personalities and client groups affected the way that individual pioneering adventures or collaborative interdisciplinary projects developed, but it was interesting to see the possibility that the search for the new could send the therapist off on his or her own independent journey, or bring people excitedly on board to support and open up possibilities. Both avenues were possible characteristics of the research-practice experience as described by these interviewees.

As a postlude to this sub-theme, excitement about introducing students to research as part of music therapy training was explored in both focus groups, Group-BA and Group-E. Highlighted here was both the process being stimulating for students but also inspiring for the teachers themselves in enthusing their learners. Participants described with animation various solutions they had to the challenge of introducing students to research. (They also discussed ongoing difficulties, explored in other sections of the findings (e.g. see Chapter 6, section 6.2.7.), but the excitement is relevant here. A programme leader in Group-BA was particularly concerned that the students should be encouraged to find their own value and excitement in the topic, as she felt they were aiming to get something that is:

....meaningful for the students! So you know my big sense with them will be, 'Don't do it because it seems easy, don't do something because it seems unproblematic, do it because you're really interested in it.' And then my job is to work with you and make it feasible, pragmatic you know, 'do-able' within the time period. (Hannah 978-982)

A lecturer and supervisor in the same group had enjoyed having a student on placement who was needing to develop research questions as part of training and valued the fresh spirit that this injected into the workplace while recognising this was also a valuable inherent part of clinical work anyway : 
"I suppose there is something about that capacity to be inquiring and not mind about not knowing the answer and not mind what question you ask, and being able to be sort of excited about that, which absolutely links clinical practice and research..." (Catherine 905-908), and Hannah programme leader, chimed in in agreement. "Research-exactly!"

\subsubsection{Being inspired by client-led thinking as a way into research}

Description of sub-theme:

Many participants identified being led to 'research thinking' through relationship with, work with, or activity that is generated by - a client field or specific clients. Spontaneous specific ideas were generated and developed naturally from activities in music therapy practice.

On a number of occasions at Site FV - as participants were being invited to comment on their stories of linking research and practice - they started to talk about specific client work, their engagement in it and how this had led to a research study. People also returned to it later in their stories. The idea of 'client led-ness' seemed at first to be a large powerful category for this site, and thence to develop into its own theme, which resonated with other data sets in this study. Every participant at Site FV contributed to this theme and there are a number of different aspects to consider, which will be outlined in the following paragraphs.

Two lecturer participants at Site FV evoke the voice of the client in influential ways in their journey towards - and then during - their own research projects, before they start to reflect on student learning and the ways they teach. So for themselves as 'students of research' the clients' voices have had a seminal influence. One of them expresses this with real directness. She was involved with an unusual case, where her client was really urging her to research the work, because she personally had found it so meaningful. Although the methodology was not ultimately participatory action research, it could have been so, with the client's voice and role strongly emphasised.

And my sense of this person, and having worked with her for some time, was... she slightly 'blew me away' as a client, you know, she was extraordinarily eloquent. Anyway, before we ever thought about research... the client, whom I called XXX in my research, she kept saying 'We should research this, we should research this!' So she was encouraging me anyway. (Hope 93-98)

The second lecturer, Anna, responded to the challenge of working with people who have very little voice in society and the research becomes an opportunity to address "very particular and urgent questions about a particular (adult) population who had lived most of their lives in institutional 
care." She observed the special enticing challenge of creating research where a vulnerable group "could be more a position of equals rather than being a researcher with subjects" and she went on to note that she doubted she would ever have considered undertaking a research degree "... had I not been involved in working with that client group". So client voice, fairness and advocacy became intimately involved in the reasons and impetus for research suggesting a strong integration between these areas. For both these participants, a sense of relevance to their client work was emphasised in their story about experiencing research.

Alex, a senior researcher at Site KT, illustrated a similar incidence of intimate connection between the practice and the research and in this case identified a clinical conundrum that supervisor and student therapist were trying to solve. It was a genuine problem of practice that the student raised, and she as supervisor was helping to query, and it developed into a very satisfying research topic using practicebased documenting techniques:
And yeah so of course what happened with that was we started discussing about the differences (between student and supervisor experiences) and it just occurred to me that this was a research question. So the conundrums that sometimes my students bring up, well that people bring up including students, emerge into a research question because I find that that reframing offers a useful and an interesting way to try and find an answer. (Alex 186-191)

In Group-E Quentin, a programme leader and practice researcher noticed how close to research the regular process of reviewing our music therapy practice could be (e.g. documenting notes, and reviewing and indexing recordings):

You sit down, and you listen back. And you spend time, and you have your thoughts and you test them against what you hear,....' And, you know, there is that, sort of, search for meaning between all of them that is, in a sense, research, in a very practical day-by-day way.

(Quentin: 213-216)

Group-E's conversation together revolved for some time around the idea of embedding the research in practice, and this was a potent theme for this focus group. The participants discussed in depth making full use of the ways in which research was a natural part of practice or an extension of normal tasks that occur in music therapy practice with people. These might include processes of documenting, reflecting, questioning, and 'not knowing what to do' and needing to find a solution, asking other staff and practitioners, reading and inquiring. In considering the application to students, this group concentrated on their efforts to find 'embedded' integrated ways to include research learning, and empowering people rather than 'teaching research skills' as a specific skill area.

As indicated, both Group-E and Group-BA debated this issue intensely in different ways - in 
particular what could constitute and be defined as practitioner research. This will be covered later in following chapters. A neat example of the potential for integrating processes was afforded almost unconsciously in a rather passionate explosion by Group-E researcher-lecturer Kirsty, who was capturing the importance of early pioneers doing both jobs of working practically and reflecting on the practice, and she did this in a very musical way. She asserted that it was particularly vital that:

They had also experienced the event themselves. Yes! It's not that there were two people listening to somebody else's work. And there was something very clear and unambiguous about their use of 'their own experience in the room; with those children' [Kirsty tapped her pen in rhythm with the words]:

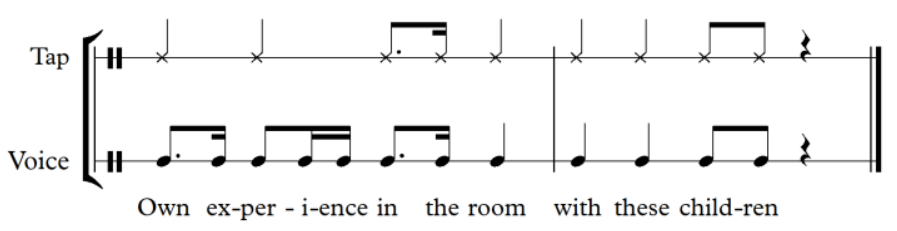

[This] contributed to their thinking about how they were listening and making sense of... So there wasn't a kind of... discreetness... between the experience, and the listening and the thinking ... (Kirsty 225-231)

Returning to Site FV (and their universal adoption of this theme) a senior student Florence, was strongly drawn to case study approaches as a foundation to music therapy research. Although her scientific background emphasised experimental research and randomised controlled trials (RCTs), she found the voice of the client in case studies meaningful and a significant way into research. The junior student on the programme wove a story around encounters with clients and patients. This participant was really keen to talk about his practice. He was on placement in a new area and trying to work things out. His engrossed state was palpable and he showed a strong interest in the clash of cultures between the medical model in rehabilitation and his human-centred music therapy training theories. (This seemed like practiced-based thinking in action.)

I think to actually try and apply some of those (medical rehabilitation) interventions into a musical work, I've found it very dry actually and quite artificial.... And I suppose it made me realise actually it's more important to actually address the relationship and address where that person is and then the rest of it sort of, as you then work with the music, potentially the rest of it sort of begins to fall into place.' (Patrick 102-112) 
Student Patrick admitted that at this stage of training, "Research is long way off in my mind" but was excited by the practice questions and theories. The close relationship between regular practice concerns or real-life cases and any research questions they developed in their studies, for both these students, appeared to be important in how they might value the future research they pursued on their programme. I enjoyed taking part in a supervision support class with other students at Site FV, while I was making the visit. This happened to be a class I could observe and the group was welcoming of a visitor. I asked them a few questions informally at the end of the class, but mostly just observed their regular learning. I made this note in my research journal:
It's very striking observing the clinical seminar classes at Site FV how engaged and curious all the students are in each other's cases. They asked good questions and didn't wait for the lecturers to lead things. Three people took it in turns to be in the hot seat, and then the others 'got in there' after the person had spoken and discussed ideas. They problem-solved together and thought about the difficulties and what the student could do next. The lecturers just guided and punctuated, and didn't say much really. It was great to witness this - I loved their interest and varied perceptions. RJ $3^{\text {rd }}$ February 2010

A clinical supervisor participant at Site FV was surprised about how moved she could be by the learning about patients through research, and how the meaning of her work was intensified. Practicewisdom was definitely increased and some photographic imagery of her project "Hands, old hands on a drum - they were just so meaningful" moved her deeply. The project was commissioned by an agency interested in music and older people, and she emphasised the value of undertaking research that was relevant to the agency and institution - everyone's awareness was raised and new practice could be initiated and trialled. She was also able to transfer her knowledge gained in research with the elderly to a new group work situation with children, quite an unusual and interesting outcome.

Joint ownership of research with their clients was characteristic of the two lecturer-participant stories at Site FV and a strong ethical steer for their work. It seemed there were many opportunities for (iterative) connection between research and practice values in this area; one emphasised how developing the strict boundaries required in research ethics (including care with informed consent and assent) were great teachers for practice ethics and therapeutic boundary setting; another's commitment to client consultation in every step of her research journey overrode her supervisor's wish for a 'cleaner' or simpler methodology for her inquiry. After a rough and humiliating experience on the research journey with another clash of cultures between medical research approaches and arts therapy ones, the participant was reminded to disseminate her study because "the client really wants to publish this'. 
A salutary reminder was offered by a researcher-programme leader from Group-BA that from her perspective, everything reverted back to the practice and people we work with, however much we might enjoy our concepts, theories, teaching or research stance. Students were the first to tell us this:

'But they always say, you know, without any coaching, they all say exactly the same thing.... They learnt what they needed to learn from working in the field.. and that's what I often say to my students. I say 'You can sit in class after class, but who will teach you? Your patients will teach you, your clients will teach you what you really need to know about yourself and your capacities, you know, and this is a kind of preparation. we can't reproduce what you're going to experience. We can help you be somewhat prepared for it. (Hannah 717-723)

Hannah also went on to say that this sort of basis was the ideal starting point for research: “ $\quad .$. that clinical knowing or that clinical wisdom, that is then the best position to start asking questions that develop into research." (Hannah 269-70)

\subsubsection{Being inspired by an interactive loop - the 'back and forth' from research to practice}

Description of sub-theme:

Participants observed that the interaction between research and practice was a free-flowing channel, which could go either way, beginning in a research construct or a practice construct. The inspiration came from the way they fed each other. The impression I observed from many staff participants especially in Group-E and Site KT was that they were comfortable with the 'two way traffic' and that this was part of the appeal of the researchpractice loop. They were closely related and mutually inspiring.

A recent graduate participant in Group-BA initiated the idea of the 'flow-between' the conditions of practice and research in this study. Paloma discovered, apparently with slight surprise, in Group-BA that embarking on student research somehow validated the clinician in her:

I think the research project ... did start to support your own thoughts and "maybe I am actually becoming a clinician", because you could see there was something definitely tangible there about it. (Paloma 471-473)

It was interesting that the research made her feel more solid as a practitioner, reinforcing something, giving some strong ground to work from. 
In reviewing Site FV, I had got used to practice questions being the catalyst for an intriguing research step, and this caught my attention strongly as a key process, (as witnessed in the sub-theme 4.2.4). I was lured into thinking in the analysis that practice was inspiring research - that participants being sparked into research by a practice observation or surprise and that was the way it went. Nevertheless I began to realise during my visit to Site KT there are also numerous examples where a researcher stance is a natural starting point for participants, and in terms of this study - it is interesting, bringing to mind the idea that training in music therapy is not just appealing to people in the 'push for practice' or for working with people but also in the excitement of the theorising or the kinds of questions you might want answered. This sub-theme started as being inspired by research-led thinking, but closer examination emphasised that the flexible movement between the two is what is important in the participant exchanges. ${ }^{22}$

Looking back at conversations in the Focus Groups also confirmed it. I had slightly missed this idea before, where the process was conceived flexibly by many group members. It was particularly obvious in Group-E, where participants were aware, when they trained over ten years ago, of having a training that was slightly thin in terms of theoretical and research stimulation and coming later to theory they realised how much that had affected their way of running the programme now. Also in Group-BA, they started to think about the iterative process while discussing the problem of fitting everything in, and 'isn't two years just too short a time to be including both?' In conversation, they rummage around with thinking that everything relates and has become mutually beneficial in training:

Catherine :...doing some research and reading wakes your mind up and helps you to be a more mature active kind of therapist.

Hannah: So you see it flashing back the other way, potentially? (662-665)

Maturity here, and 'groundedness' (from Paloma at the beginning of this sub-theme) as a therapist could be contributed to by the research journey, and also being more alert and ready to think - these were processes that could be passed back into practice. The participants seemed excited by this flexible reflective movement.

Two participants at Site KT were immediately thinking about research when they first found out about music therapy. The programme leader-researcher read about it in the American JMT, which she found in the seminar room at her University; the junior student, who had already been involved in research with music and people in an undergraduate intermediary honours study, found out about music

\footnotetext{
${ }^{22}$ I am also grateful to a peer-reviewer for re-emphasising for me the two-way flow here. In reviewing some Site FV transcripts and analysis, she noted that participants commented about research often feeding into their confidence and interest in their practice. It was rejuvenating and stimulating in their stories about their work, and she highlighted it strongly in her reading of the materials.
} 
therapy from the careers service, and it was the research element in one of the lecturer's fields of study that attracted her to train. The thought of being a researcher drew her in. This seemed a little ironic to me as I was writing up the analysis, as I realised that when reviewing this student participant's transcript, I wrote a research note (2011) about my own personal pathway to music therapy training.

'I was quite ambivalent about the idea of music therapy in my initial investigations about it (I had the parent models of doctor and nurse in my growing up). Going to a music therapy conference in London UK in 1979 where research was part of it, made me think, this is a worthwhile profession after all! (RJ $5^{\text {th }}$ April 2011)

I had forgotten my own focus on the importance of research to balance practice knowledge, and my own respect for this in my twenties.

A lecturer-researcher at Site FV was especially motivated by the reflexive quality of participatory action research and emphasised that her own major study both made her able to conduct a research project that fitted with her values as a clinician, but it also helped her in teaching practice concepts to students. ${ }^{23}$ She gave examples of how the nature of boundaries that are important in research could reinforce therapeutic boundaries such as clarity of timing and protection for confidentiality. Also, processes such as seeking informed consent were spelt out very clearly in research ethics. This informed the student clinician very effectively and reinforced practice boundaries. She also noted how critical thinking could be developed flexibly through both domains of research and practice, the one informing the other. The significance of critical thinking as a pivotal process between both domains was also highlighted by a programme leader in Group-E, who explained that being able to take a stance and critically defend the concepts that accompany this theoretical position were really valuable processes to practitioners. It helps them be aware of their choices and to be clear to others about what they do. Research and academic frameworks assist this critical process, but ultimately authorise students as practitioners, in the face of other approaches and disciplines. In the accounts of both these participants, one could hear clearly that research ideas and concepts inspired and motivated understanding of practice.

A Site KT researcher-lecturer also attested to the value of thinking and articulating ideas that develop from research processes (the critical thinking mentioned above) and bringing this back to the practice environment, but she also underlined the extent of the challenge faced by students and indeed experienced practitioners because as she said "you're not thinking when you're making music are you?" Nevertheless, she emphasised that experiencing this challenge was such a valuable growth

\footnotetext{
${ }^{23}$ Daphne Rickson and I developed student projects with action research in some of the earlier examples of Masters' projects. Our later work involved secondary analysis of practice data as this was lower risk ethically for students to undertake.
} 
process for the student: "To go into a discussion about that without making up bullshit as though you're achieving miracles and but also without ...being terrified to explain what you're doing..." (Bella 489-491)

These, the researcher-lecturer claimed, were magnificent contributions to the complexity and difficulty of the discipline, and actually what needed to be learnt by students, in her opinion. Other approaches would be naïve and missing important responsibilities for the growth of the knowledge base.

A recent graduate and an experienced practitioner-lecturer in Group-BA both indicated a slightly longer reflective cycle in their experiences of research and practice. The practitioner-lecturer began her professional career as a researching music scholar and then embraced the experience of being a clinician with an in-depth psychodynamic focus over many years, and research was not a particular central concern. At the time of the focus group she was beginning to feel the excitement and possibility of a new research approach in music therapy practice. The new graduate in Group BA said she had been exhausted by her experience of Masters' research, but after a couple of years as a practitioner she surprised herself by the thought: "I'll go buy that book, ...to start my own interest in exploring my own work again, perhaps leading on to research, now I mention it! Ha ha". (Paloma 814-816)

An experienced researcher in Group-E summed up the concept here that there was comfortable and natural pivoting between the frames of research and practice in music therapy if we cared to concentrate on it:

.... another layer of that, which I think goes into the reflective practice, merging almost like there is... no barrier between them, but there is a merging into a research attitude which is a questioning attitude and I think that can accommodate... a time of flux. (Eddie: 364-366)

This participant's comment linked this chapter to the major theme of Chapter 5 - the constant change that research and practice are required to accommodate and respond to. Eddie suggested that integration of research and practice, and flexible 'ducking and diving' between the two and maintaining a questioning attitude helped the profession manage resourcefully at times of flux. It is obviously one stance, one opinion, but one which resonated in other people's perspectives in the data. (This will be pursued further in Chapter 5.) 


\subsubsection{Valuing the inspiration and influence of mentors}

Description of sub-theme:

The mentorship of key people from interviewees' histories was referred to specifically, and influences were described and noted by participants. Sometimes this included having practices and processes modelled by the teacher/mentor; sometimes it involved specific teaching or advice given that the interviewee would not have thought of, or was unsure about. Dynamic experience was often captured in the research conversations, including the receiving of energy and inspiration from the mentor's way of being, acting and demonstrating. Relationship and trust were emphasised. People could also 'act against' participants' projects or aspirations - and this got in the way of integrating practice and research in some stories recounted by participants.

Instances of the role of inspiring people; teachers, mentors and other professionals abounded in the interviews I shared at Site KT. I did not initially ask any specific questions about this (e.g. "Who was important to you?") but spontaneously in the participants' stories of research and practice, examples emerged. I think you would expect this in the development of all professionals (as in the old car sticker "If you can read this, thank a teacher") but it was pertinent to be reminded of the impact and significance of the research mentors and clinical supervisors, and also other sympathetic professionals (sometimes just for fleeting and key moments) who shared the journey of learning. At times the participants also indicated the satisfaction of knowing that they themselves had made a difference in music therapists' careers, and helped with guidance and inspiration or steering somebody's direction in research and practice, but this was often in relation to noting how much they had valued support and advice themselves. It was also woven in to the other Site FV, and was hinted at within the conversations about other issues in the focus groups but was slightly less overt, and appeared later when the data was reviewed in the light of Site KT themes that I developed. It was interesting to go back and notice the allusions to help given when I looked again.

One participant observed with admiration the ongoing effect on students of her colleagues' sustained modelling of work as researcher-practitioners. She said they were: “...excellent researchers, I mean absolutely prolific and excited about it still" (Helena 696-7). One of the student participants commented that 'there's a lot of people that do both' (i.e. research and practice) and thus thinks "I'll always try and maintain the two" (Abby 68-69), having experienced the culture of professionals and teachers maintaining both arms. Answering the current research question 'how can research be integrated....?', this idea seemed very relevant. It seemed likely that there could be a responsibility when involved in training for (at least some) staff to model doing both, if students are to feel that the two can work together and you are not just 'one thing or the other' a researcher or a practitioner. This 
added to this student Abby's belief that "the two are quite strongly linked" and that it is realistic and desirable that music therapists do both things. It was also interesting that this particular participant did not imagine that research would be 'her thing' before training. Performing music had been her background in the Bachelors' degree and it was therefore quite a surprise, in beginning her training process, that research was an integral part:

Research was something that I'd never really considered all that much.... I think that was because I didn't really know anything about it, I didn't know how it worked (pause) and really how anyone would go about it, and I think I considered that you either kind of practiced as a music therapist or you do research, I think I had an idea that they were probably quite separate. (Abby 45-50)

The exposure to the modelling during training and "the fact that we have to do research in the course probably (pause), I guess that (research) becomes a reality for us while we're doing the course. "(6567).

Inspiration could happen both from teaching/supervision conversations and from the writing and research of mentors. The way in which this might be shared and passed on by music therapy teachers was recognised in various ways by participants. The students noticed this quite specifically.... (the senior and junior student at Site KT both noted respectively the collaboration with the supervisor, and having read her studies before training). The experienced therapists remember both the teaching and writings of their own mentors “....my professor was a very good teacher. I had a very, very solid introduction to research methodology with him"(Beatrice 43-45). In returning to Group BA, I remembered then that researcher-lecturer Zelda had enthused that her own inspiring professor had "taught a way of thinking" and inspired her whole career and that of others with this learning. These lecturers acknowledged that their own contributions of sharing the journey and giving something to students that is both useful and inspiring, was a particularly satisfying part of their job in research and practice. For example researcher Alex from Site KT observed: "Because it was a journey that we shared together and I think the way I've affected students has been probably a lot through my writing as much as my clinical supervision and the way I suppose I've introduced students ... to my writings." (Alex 273-276)

This same participant valued highly her mentor from a previous clinical training in a related field and observed the consistent impact and influence of this exciting teacher 'Professor Ann X' so much that a puzzle or interest that the teacher had been intrigued by in clinical research remained with my participant and much of her career developed and pursued this interest:

I had this amazing ...tutor ... who would be one of the most, if not the most eminent practitioner/researchers (in a related field) now in Eurostralia. She talked about process 
notes being a font of knowledge, that wouldn't it be wonderful if we could work out how to research (this) to integrate that into the knowledge base.' (Alex 243-47)

Later in the interview having observed her own development she noted: "And that started me thinking: Alex you're starting to answer Ann's question, you're starting to discover a method for being able to research this." (281-283)

It occurred to me this was something of the chaconne or 'insistent bass' - the repeating underpinning motif - for participant Alex, which continued to circle throughout her career. (It also resonated with senior researchers, Zelda Group-BA and Beatrice Site KT.) The answering of a question that the supervisor was perplexed by, but perhaps was not able to pursue, was significant. Alex treasured that idea and found her own way to pursue it. She was also genuinely inspired by it, and followed it in a committed way. The idea that you might be asking and answering your mentor/supervisor's question was of great interest and surprise to me in another way as the researcher:

In a discussion with my friend who has worked for many years in social care and health administration, we shared notes about research and how it is developed in different fields. My friend Jiff mentioned a young relative who was excited about her new research degree, which was working on one aspect of her supervisor's study. I asked if the young relative minded that it wasn't her own topic,_and Jiff commented that you wouldn't really expect that in the sciences. You apprentice to the supervisor, and that is how you learn and develop as a researcher.' (RJ 18 April 2012)

My own experience of arts and humanities research is that a lone researcher 'goes off to the ivory tower' on their own and pursues their original topic. Of course science research has always been conducted in large varied teams, with apprentices learning by involvement or research fellows or assistants doing different aspects of the study, and why not music therapy? This might be especially true when studies are large, or mixed-methods in approach, and externally-funded. Site KT exemplified some of those opportunities and the interesting possibilities for research-led teaching in the future of music therapy.

Another researcher-lecturer at Site KT recollected that in her own experience as a student choosing research approaches, her supervisory team persuaded and influenced the redirection of the research topic, specifically into an area that she probably would not have considered and did not imagine she would be so confident at; that is, some in-depth musical analysis. The supervisors had a sense that this was new ground, profitable territory to which the research student would develop important original contributions, but she cannot anticipate this: 
(They) were agitating I think the profession internationally to start analysing the music more effectively... because it wasn't documented, it really wasn't and ... my supervisors would have known that it was a wave that was happening across the profession but I obviously didn't know that. Both would have known that I'm sure. (Bella 89-90 \& 107-110)

She could nevertheless appreciate their intervention retrospectively and was very grateful to have been nudged in a new direction.

However, conversely, the productive mutual two-way relationship of research supervision was again highlighted by another participant, who persuaded the supervisor this time to allow the pursuit of a topic of passionate interest:

And I can remember (my supervisor) saying "Well why would this be research? And it's obvious isn't it?" And I said "Well I don't think it's ever been done before!" I could remember that clearly! And he said "Well that's true - it hasn't been done before".

(Beatrice 39-42)

Beatrice from Site KT emphasised chance and timing with development, but also the relevance of long-term relationships with some of her key people, and that these were ongoing; she kept coming back to people who had supported and 'mentored' her, and they continued to assist in the journey of developing the research and the discipline.

Sarah: I was just thinking about the relationships (with your music and music therapy professors)... (Beatrice Yeah!) That people... (Beatrice Yeah!) ... sort of place things and...'

Beatrice: 'Come into your life and then go out... and come back. All of that ....

(Beatrice 39-41)

This feature was also observed by others across the data sources.

People could also hinder or obstruct the process and although this appears to be the opposite thread to what was previously discussed, it does serve to highlight the importance of who supports the practitioner-researcher and indeed how they do it. Easily courage and initiatives get squashed if those who are managing the process do not wish to develop it, or do not know how to. A clinical lecturer at Site KT working on community research in a hospital environment described her struggle in getting a project to work as follows:

'The ...unit manager there was a difficult woman (laughter) who...was a 'no' person and she hummed and hawed for a while about whether it would be best for me to come in and run a pilot project ...to make sure that it was safe. So I was thinking "How can you not want to, 
how can you not want me here?" ... We eventually decided that I should run a small research project there and I would trial the use of a method that I would use as part of my programme and we'd just see how it goes. And I'm not sure whether she really was trying to put me off thinking that if she made a research project I might just quietly go away 'cause it was all too hard, or whether she was genuine. (Helena: 46-70)

It is interesting to review the clinical lecturer's comments, for as a result of the 'NO Person' she became more definite, strategic and determined to make the project work, so in fact the hindrance acted like an extra catalyst to try really hard and see it through. However her relief at the contrast when the unit manager left and a new positive excited manager arrived, was captured very strongly in her narrative. She was so excited: “...the unit manager left so that was also a wonderful time. (laughter) Isn't that wonderful, we were like: 'Oh she's going' And the new ... unit manager's [approach was]... 'Oh this is wonderful, yes do what you like'”' (Helena 153-157).

The ground bass of 'being on fire', coined by clinical lecturer Helena, was expressed again strongly here. Other related examples were offered in Site FV of supervisors outside the department, who were not particularly involved in, nor trained in music therapy, but who brought research expertise, providing quite limited and sometimes actively unhelpful supervision. Undue focus was given to methodology by such supervisors, and very little attention to analysis or processing of content of clinical or musical material, which two participants in this research and reportedly other student researchers found frustrating and discouraging. Certainly some participants commented on developing less positive attitudes to research and feeling less confidence as contributors to the discipline at Site FV following this experience.

\subsubsection{Being inspired and held by a collaborative model of research.}

Description of sub-theme:

Lecturers, supervisors and students identified the value of collaboration with others in their experience of research. In a number of cases, this was a kind of saviour/protector of their research integrity, and created support and motivation for the progress of the projects. There were different sorts of collaboration, including music therapy clients \& practitioners, researchers and practitioners, students and supervisors, teams of music therapists and interdisciplinary teams. 
This theme was one of the last to write and I was grateful to a peer reviewer for reminding me of its importance in her review of interview transcripts, codes and analysis. ${ }^{24}$ Witnessing the collaborative conversations between participants in Group-BA and Group-E, provided the initial impetus for considering this sub-theme, but it seemed more an issue of research process that attracted my attention, rather than a theme in itself. However, as the following journal note suggests, it gradually appeared to be the kind of idea that wove throughout the data, and linked things together across the chapters, and as such will be revisited in the discussion (Chapter 7, section 7.1.6)

I reflected about being inspired by collaborative work in the case study on a walk today. I remember being so excited about the focus groups' activities as collaborators in a 90 minute conversation, both a well- established team (Group-E), and a new team of thinkers (Group$B A)$, with different objectives and experiences, people attending a conference. But also there were many levels of collaboration perceived both in passing and quite deliberately at the site visits, with supervisors, with multi-disciplinary team members. The levels of collaboration seemed to be these: a) Researchers sharing ideas and results with patients and with team members; (Site FV); b) New researchers getting together and sharing their data analysis and students getting together and sharing the excitement and hardship of research-practice experiences (Site FV \& Site KT ); c) Examples of supervisor and research student collaboration (Site KT); d) music therapists brain storming with a joint focus (Group-BA \& Group-E) (RJ Nov 13 2012)

A: Researchers sharing designs and results with patients and team members:

Across both the sites (FV and KT) practitioner-lecturers gave examples of research design and reporting that was shared with their community partners, both patients/clients and professional team members. The collaboration was observed in both quantitative and qualitative research design (a point which interested me) and four participants at the two sites raised the issue. A clinical supervisor participant new to research at Site FV, who took up a project later in her practice career, (discussed in Chapter 5 section 5.1.7), was particularly enthusiastic about giving the research back to her team, noting that "the more I talk about this, the more I think I should get this published 'cos it might be of help to other people." It was interesting that she talked about returning the research learning to the community of practitioners (rather than external academic context or international journals) as she recognised that dissemination was important for fellow practitioners. Another participant, in a similar way, noted that her institution of practice was especially interested in her findings, and she told me

\footnotetext{
${ }^{24}$ My Te Kōkī, NZSM colleague re-awakened my awareness of 'collaboration' in reviewing transcript and analysis. This theme had been placed and reformed a number of times in the research analysis, as it seemed to relate to or exist within other themes but finally found its place here.
} 
with pride and pleasure: "they are just completely absorbed with what came out of it...I had that feedback at the residential setting as well. People ...were really interested in what the findings were saying. "(Hope 272-274)

This reinforced that there is, of course, huge practical value of research for practice itself, but sometimes in a university, you become absorbed in the process of research for the benefit of academia and the 'discipline of thought'. These practitioners could see the relevance and immediate interest for a supportive team. They also described the benefits going straight back into the work.

\section{B: New researchers}

At Site FV, the jovial reflection of clinical supervisor Hilly of herself and her new-researcher colleagues getting together and being supported, and then actually inspired by conversations about data analysis gave palpable evidence that practitioners can be drawn in to enjoyment of their research, given the right conditions.

I can remember, when you mentioned Sarah about bringing it all together with the data and stuff, I can remember one afternoon, one Saturday afternoon in August, having all these bits of paper all over the floor trying to put them all together into sort of groups of what common threads and things, thinking: "God this is going to drive me round the bend." I can remember meeting Hope and Dave for coffee and one morning [afterwards when ]...we discussed data analysis. She said "Hilly's a good friend of mine we've known each other for many years...can you believe that we're here discussing data analysis?" (Laughter).

(Hilly 288-298)

The camaraderie and support of Hilly with her fellow mature Masters' students was an important factor in sustaining them in confused moments and in the wish to solve problems. In our interview, Hilly and I both enjoyed the surprise: how could it be that they could get excited by data analysis? Well, they did and carried each other along with the enthusiasm. An analytic memo here observed that the collaboration with fellows emphasised the process of research rather than the goal and outcome, and this linked back to my research journal comment in the previous section (4.2.6) about lone researching. Working with a team allows you to share your process, and music therapists are familiar with the value of 'process'. In this example, Hilly's experience meeting colleagues after the thought that the analysis was going to drive her mad, combatted the isolation and may have helped the group sort out their ideas.

\section{C: Student practitioner-researcher and supervisor collaboration:}

A researcher-clinical supervisor at Site FV highlighted a particularly creative experience she had with a supervised student placement, where in a 'student-led way' the trainee practitioner became 
interested in the clinical notes being generated at placement, and how these could become a central research topic. The collaboration that is emphasised here appeared particularly rich from the supervisor-participant perspective, because both partners (student and supervisor) stimulated and supported each other's thinking, but both had a valuable part to play in the process. The student practised and documented and together they developed a two-level research project, one for the student masters' project, and second as a pioneering a technique for research about practice.

She created it for herself, so we had more creative possibilities in what we could share in that sort of student supervisory 'research potential' mode. ... I really encourage people to question and sometimes they become research questions... I think that my clinical experience profoundly affects the way I supervise the postgrad students I've had. (Alex 632-638)

There are two levels in which this connects to the research question, first, that the collaborative process enhanced and inspired the research, but second that a 'practice way of supervising' also supported research supervision. So integration of research and practice are observed fluently in this example.

Two further participants at Site KT (student and research supervisor) commented directly on collaborating in the supervisor's research, how this affected student progress. The supervisor participant observed how they were able to discuss analysis of results in an equal and open way (Bella) and the particular student involved sees that as surprising and positive. The student also recorded the reduction in stress and anxiety of taking part in a previously established project (Abby). The supervisor influencing the student by creating a boundary and limiting the project choices (a point highlighted by lecturer Anna at Site FV, is recognised as an important influence by a student here). The anxiety for a student of trying to choose options and to consider the pragmatics of participants, ethics, timeframes for her project, when everything is new, was perplexing and she noted 'I've thought of some topics so I'm not so lost anymore in terms of what I'd like to study!' (Naomi Site KT) and then goes on to say that the supervisor helps her choose by reminding her of the time limitations, that this is a small dissertation, and that a large complex project can be left for a $\mathrm{PhD}$.

As you walked in the room I was actually talking to (my supervisor) asking her advice ... I think it's just for the amount of time, the short amount of time we have with this (dissertation) and the hoops that I might have to jump through for the ethics, and also the work load. I'm just thinking very practically in terms of next year and in terms of I know the placement, the placement subject will be huge ... (Naomi 238-242).

As researcher I was reminded again of the complex and challenging learning that clinical research demands. 


\section{D: Music therapists brainstorming in Group-BA and Group-E}

There were numerous examples in Group-BA of stimulating collaborative debate about research and practice, and I sensed how shared exploration of the meaning and complexity of aspects of this topic were enhanced by discussion in an engaged group. In Group E they were more used to conversations together, and similarly to Group BA they shared together in animated fashion. Sometimes within the 90 minutes this happened in a fast surge, when lots of ideas came together, and at other times a participant returned to something said earlier by another person, because there had been time for the thought to sink in. Two examples will serve to illustrate the collaborative process for Group-BA.

First the swift elaboration on an idea was captured in a discussion between a clinical lecturer Catherine, and programme leader Hannah. ${ }^{25}$ The participants discussed the choosing of research questions, and these two lecturers identified the potential linkage of the personal growth of students and the research journey, but also the way that trainees might avoid issues. They observed that there is a possibility of harnessing both together, but it could be a tricky process for supervisors, they needed to be alert, sensitive to students. Catherine led the conversation:

We're asking people to think about doing a piece of research, and there is something very delicate to work with in these students about their choice of topic. Because I think very often people choose to write about something they want to work through, actually themselves.

Hannah: Yes! And so I...that's what I sometimes feel... the dilemma in teaching something that in a way could be a haven for certain students - that they hide in their sort of intellectual capacity. Catherine: They can objectify something...? Hannah: Yes and something gets hidden in the research process. (405-409)

The second example was educator and student perspectives being shared on one idea. (The participants did not know each other and came from different programmes.) Lecturer, Hannah and new graduate from another country, Paloma, made a connection about the stress and 'blur' students might experience in developing and writing research about their clinical work. The new graduate was remembering being a student and Hannah responded from the perspective of educator. Paloma characterised her experience of the research and thesis writing as being challenging and stressful. "Oh...It made my brain very grey, 'mush-like" and it was "a lot of work to juggle the hours". However she observed that although "it's taken quite a long time since me being out of it ... looking back I found it very beneficial" (167). The conversation moved on and lecturer Hannah responded a little later (after talking about her own individual development as a clinician and researcher) with

\footnotetext{
${ }^{25}$ A further illustration of Group BA's swift engaged discussion appears in section 5.2.3 about an evolving definition of research.
} 
concern and a sense of responsibility about what teachers might expect of students in the researchpractice combination:

I resonate with Paloma's comment earlier about ...this blur for the student. As a teacher for so many years [I have been] ... particularly committed to students coming out of the university with a good idea of how to use research ... But [I am] a little anxious that what I am actually doing is putting students through this traumatic experience from which they emerge with an amount of 'blur' around research and sort of hopefulness around their capacities as a clinician, but a real blur and kind of dissociation around the topic of research.

(Hannah 245-255)

It seemed useful to group members to explore the role of student and educator in this conversation without it being your own student or your own teacher. The lecturer was able to think - there may be some different ways to do this, and the student could reassure that in retrospect it was beneficial, despite finding the process quite difficult. Group-E also gave many animated examples of their joint vision of research and practice, and a typical example of their shared dialogue is given in the following section 4.2.9, where two members discussed the 'hard work' of their pioneers.

The process of this emergence of 'ideas-in-action' within both groups was intriguing, and was an unexpected bonus of this research approach. As researcher and therapist with substantial experience in group work in my earlier years as a practitioner in the probation service, I was particularly interested to see how research and practice came together in my own research in focus groups. What had started as a seemingly efficient and energizing way to gain a broad picture from a range of people about my topic, progressed to being an inspiring journey of co-created knowledge, with participants sharing their creativity in connecting and elaborating on other peoples' ideas.

\subsubsection{The quest and travelling into the unknown}

Description of sub-theme:

Personal growth of the therapist was also harnessed by the participants, and the idea of the quest - of going in search of previously unknown territory - provided an integrating metaphor. This travelling metaphor connected the energy for planning and execution of research with the learning journey of a therapist. ('Not knowing' and searching are integral to both.)

In this penultimate sub-theme for this chapter, the idea of the quest and traversing new territory was rather startlingly captured by one researcher participant at Site KT: 
.... I think it was exciting to have traversed territory that wasn't well known... So I think that what I got from that was this learning, this realisation that I could conquer knowledge that I didn't have and that you could find a temporary answer to a question that was really exciting and that just led to more and more questions. (Bella 158 \& 169-173)

So for this participant - and this seemed very characteristic of others too - the hard work, journeying and mastery (albeit mastery as a 'temporary answer') of practice-based research, were highly stimulating and a strong reinforcement for continued pursuit of the music therapy 'quest'. In addition these words strongly evoked creative process and it was interesting for me to be reminded of the connection of research with creativity as well as the more obvious artistic, musical part of music therapy practice. It was significant to hear, as it created an active imaginative connection point between research and practice and another area of potential integration. The process that this participant captured here had something of the feeling of improvisation, (the idea of travelling somewhere, and of finding temporary 'patterns' or answers that shape the practitioner-researcher's understanding).

Participants in the Group-BA focus group drew attention at several points in their group conversation to the kind of personal quest and internal journey experienced on music therapy courses. The experience of personal change and learning and how this might be managed in training was of concern to the participants midway through the group. This was particularly emphasised where a training programme had a specific psychodynamic focus as its theoretical approach, but also when students were learning to work with complicated psychiatric conditions. Researcher-lecturer Zelda considered that the American model of a three-year undergraduate degree, followed by a two-year post-graduate degree when research was undertaken in the later postgraduate period, presented certain advantages here, as this potentially allowed more growth time for the person and clinician. She was concerned about Paloma's experience (in Group-BA) of too much to manage, with research and practice tasks. Hannah (lecturer-researcher) in this group observed that though she now taught research as an integral part of the two-year programme, she herself had been really focussed on her clinical learning about psychosis in her own student days and was very grateful for the immersion. She subtly communicated that she doubted she would have had so good or strong a clinical experience of learning, if she had been tackling research at the same time. She wryly observed the paradox - as she was now involved fully in research, leading projects and advocating for good research teaching. However a researcher-lecturer in Group-E also highlighted that an academic and personal journey were clearly both part of training experience and that they could have potential to sit alongside each other: "...the progress in the kind of programme we are doing there is not just intellectual progress and equally it's not just personal process. It 's quite an interesting animal I think." (Eddie 468-469) 
Group-BA returned to their discussion of the issue of this kind of mirrored 'journey' of research and practice towards the end of the group. They shared some important further insights about "not knowing' in both research and therapeutic learning, and how students might process and absorb this. The focus was on a 'learning journey' and all four participants (lecturers and a new graduate) discussed the stripping down of self, which students often have to do. Programme leader Hannah emphasised the unpredictability of the clinical practice environment: “... when you respond to the patient, you don't know what's going to happen next, and that's what creates the anxiety, the sense of the unknown." (Hannah 834-836)

Supervisor-lecturer Catherine referred more to documenting or writing about the clinical work:

....people are struggling with that having to give up something of the selves they brought in. (I remember that when I trained actually)....I suppose something about writing in particular is very interesting in that respect. That people suddenly revert to being about sixteen, worrying about handing their essay in on time. (Paloma: Yeh!) Whether it got $60 \%$ or $61 \%$. And there is something about the regressed state that a lot of people are in, (which is actually part of the anxiety I think), and I'm not quite sure where this thought ends, but it is something to do with: however excellent you've been at something else, you're a beginner. (Catherine 862-873)

This idea about research was specifically echoed also by the Site KT participant at the opening of this theme, who talked about managing uncertainty particularly in the research journey, and tolerating not knowing what she was doing.

Group-BA concluded that the parallel processes, if carefully supported and understood by supervisors and lecturers, could usefully dovetail research and practice and create really interesting journeys or quests.

A clinical lecturer participant at the same site observed how important it was for students to be fully engaged in the placement experience and to support them to find a placement in their "really burning interest" area (Helena 442) to provide and fuel this interest and excitement in the research pathway they went on to do. Giving students choice about this and where possible involving them in helping to set up a new placement added to the sense of commitment. She further commented that if you "really love to work" (458) in an area of practice, this really "carries you through the process". I was struck, when listening to Helena, by her 'fiery' language and the energy she conveyed (linking back to subtheme 4.2.3) sensing that one needed personal strength to sustain oneself through the challenging journey of practice-research. There were similarities of tone and 'feel' in other participants' accounts. For example, Site FT researcher-supervisor Alex vividly captured the effort she needed to make to manage the struggle to make new connections and to forge new paths in her practice research; hunger for information is described in animated ways by Site FV clinical lecturer Hope and Site KT 
researcher lecturer Bella (as described in section 4.2.2) in their constant need for asking and answering questions; and metaphors of conquering and mastering were articulated by Site FV supervisor Hilly and Site KT programme director Beatrice. It was interesting that what united them was a kind of energy characteristic of 'fire', hence the title of this theme and chapter, and the idea of the ground bass underpinning. It was also easy to identify urgency and excitement in their voices as they described their experience which further emphasised fiery passion and aliveness.

\subsubsection{Working bloody hard}

Description of sub-theme:

The rigour and systematic nature of inquiry into complex real life environments was acknowledged in this theme. Research about practice involved really looking in depth at what you do. It required really scrutinising it, working at the materials, going back again and again to seek answers and not leaping to conclusions. This idea linked the huge effort and investment of pioneers as practitioner music therapists with current requirements for rigorous research work.

There was real recognition across participants in all site visits and focus groups that the tasks and process of researching practice (as student or qualified practitioner) involve a huge amount of 'bloody hard work'. The sub-theme was evoked in various ways, with reminders of being stressed as students, and exhaustion and sometimes confusion in the researcher role, through the fascination and absorption and slightly obsessive qualities self-observed, to the satisfaction of 'job-well-done' and excitement and creativity of getting to the end of a major and difficult task.

Quentin and Eddie, lecturer-researchers in Group-E launched the idea of this theme in the analysis, by exploring the topic with specific reference to pioneer music therapists who embarked on early music therapy practice with research qualities and values implicit in everything they did. Within the focus group these two participants mirrored language and ideas, expressed at slightly different times in the conversation. The 'hard work' was captured in the carrying around of equipment, and making sure that work was recorded, and then sitting down for review, making notes, and returning to the material and listening again. This linked strongly, for the two participants, with music therapists' work with a supervisor (maybe clinical and/or research supervisor) returning to the material, sitting down and 'researching' for understanding, meaning or information. If you did not understand, you would go back and listen again. The participants shared the idea that this came directly out of practice-driven values, it was the desire to explain and make sense of what they were doing inside the music therapy work with patients. But it also had a natural extension into what was needed for research. 
Virtually every participant at the two in-depth site visits identified the sustained engagement required to develop and complete research both as a professional and as a student in training. This was particularly graphically drawn by Beatrice at Site KT who recounted an image that appeared during a Guided Imagery and Music session around her pioneer work developing the music therapy discipline through research and teaching, alongside another area of psychotherapeutic practice in which she was also passionately interested.

I was ploughing through brown earth with my elbows and I created these two absolutely parallel ditches along this brown earth as if I was going to plant seeds....it's really all of your body is in it. I suppose I could have done it with my feet or my knees or something. But it's the elbow grease! That's what it is (more laughter). It's the hard work!

(Beatrice 211-214 \& 235-7)

In her story, research came at the very start of her encounters with music therapy, alongside all the other professional disciplinary development and I really got the sense from her interview, that it was because she was constantly curious and researching, and because it absorbed her entirely, that she gained the reward for the 'furrowing' and elbow grease. ${ }^{26}$

In her consideration of students in training, another lecturer-researcher participant identified that the benefit for the hard work was that the new researchers got invested and empowered. This was not just a teaching exercise; they could feel part of a bigger process and that they could contribute effectively and truly achieve something worthwhile:

I think that that is the great plus is that they get to ask a question and find out how hard it is to answer it, but ultimately to answer it. It's wonderful, to know that you can do that from my own perspective and my own experiences...That is what I think really just about justifies the huge amount of time they have to spend in doing it... (Bella 276-280)

One of the students retains her sense of value and involvement in what she is doing by thinking how practically relevant her project can be. She is ergonomic, hates waste, and sees that if there is practical value to somebody else in her topic, that the research can be applied, it will become meaningful and worth the effort. So the integration of research and the idea of practice in her imagination adds value to the process because "in terms of research topics I'm very much one for researching so it has a practical impact ...research for research's sake is also good, but if it has a practical use or it can be applied in practice, ...I find it more worthwhile doing .." (Naomi 205-209). The other student actively

\footnotetext{
${ }^{26}$ See Appendix 10 for Beatrice's feedback about this example.
} 
accounts for the value of her training as a researcher as part of her music therapy journey in that it contributes to her sense of professional identity:

I think I'm more excited now about being a music therapist knowing that I can do that research as well, and kind of contribute to the body of knowledge that's there, and feel like I can actually be a worthwhile member of the music therapy profession. (Abby 591-592)

An inspiring and significant 'mythic' kind of explanation for why people might go on battling with the difficult topics and complex interrelationships was provided by one participant in passing:

I think that at my core is the desire to foster connections, you know, both intellectually and personally connections and patterns are the things that really intrigue me. And in my professional work it's my networking and my learning from other people which is, I think, my strength. (Bella 214-218)

This might be an emblem for any person who is interested in the communicative musicality ( $\mathrm{S}$. Malloch \& Trevarthen, 2009) and desire for contact that embodies music therapy internationally - as professional researchers and practitioners we are looking for connection pattern and meaning. Looked at from this perspective, there is no incongruity, no difficulty no lack of fit between being research and practitioner.

\subsection{Concluding comments}

How does this coding analysis relate to research and practice at student level? What it evokes for me as researcher is that on each participant's account of their journey from student to professional, has been aspects of the experience of passion, of not-knowing, of curiosity and seeking for pattern, of others giving help, clues, guidance, interest and support, of difficulty and real hard work, of isolation and of collaboration with others, of excitement, of the significance of contributing to new knowledge and the development of the discipline. In planning our programmes of study it behoves us to account for these things, to frame, expect and provide for these experiences, to guide and to leave free. 


\section{Chapter 5: Stage 2 OF FindingS \\ ACKNOWLEDGing AND MANAGING CHANGE: \\ THEME AND VARIATIONS}

\section{Introduction}

In March 2012, I attended a live performance of The Goldberg Variations by Johann Sebastian Bach in Wellington, performed by Michael Houston, New Zealand pianist and concert soloist. This work for keyboard encompasses an opening aria in $\mathrm{G}$ major, followed by thirty variations based on the opening 'theme' and ending with a re-statement of the theme to finish the piece. The first eight bars of the aria appear in the following extract:
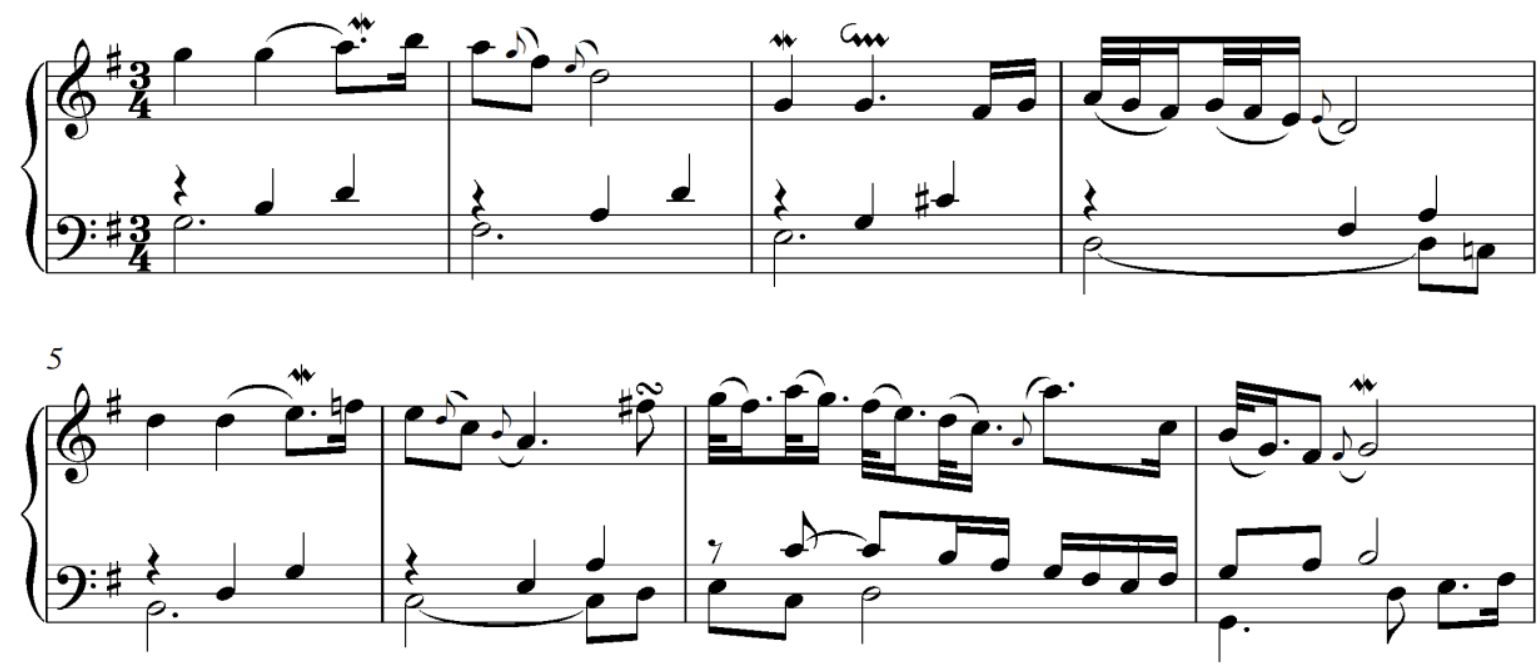

It was the first time I had heard this music live in entirety and was a most interesting and uplifting experience, as the sheer physical effort of the flow of variations and concentration offered by the pianist was monumental. In fact the audience really concentrated too, so it was a superb shared experience. I also heard the piece very differently from any recordings I have listened to, mainly because I have tended to listen to a section, and then absorbed further variations in a background way, while cooking or writing. I have also particularly played and practised a few variations for my own 
satisfaction a few years ago which was different again, providing a focus on one particular aspect of the theme-variations process.

What it made me think was a notion of difference and sameness being brought together in every variation. I know the aria or central theme quite well so I could hold in mind the core musical material, but the variations took the audience to such different places and emphasised very different sensuous, musical, intellectual or spiritual experiences as they unfolded, and we really felt we were taken on a journey of life, so many and varied were the garments, adornments, shapes and colours of the thirty variations. For particular variations it was as if I had never heard them before, so specially did Houston play them and in addition so differently from my own conception through listening or playing.

So the purpose of adopting the musical form of theme and variations for this chapter, was to emphasise a metaphor of change and evolution, while also being in the presence of something steadfast at the core of the experience. Within the method of thematic analysis, this highlights a particular use or transformation of thematic material, which seemed pertinent to the topic of the chapter. In a somewhat paradoxical way the 'aria' for this chapter is that everything is in a state of flux and continues to change.

\subsection{Core theme for this chapter: Stage 2: 'Acknowledging and managing change'}

The following is a condensed description of the core theme for this chapter. The core theme is divided into seven sub-themes, articulated in the next section. These will be expanded and illustrated by turn, in a similar way to Chapter 4 , as this chapter progresses. 


\section{Description of Core Theme \\ (the Aria for this section of the findings)}

The process of change and evolution within the profession was regularly alluded to by participants. Individual and group discussions revealed how professionals and students were aware of how their own ideas develop over time, how language they and others used for their work developed, and how music therapy training itself was an important period of transformation and change for students. Participants observed that student practitioners need to be ready and responsive to the way that theories change (intra-disciplinary and interdisciplinary processes). Preparation for this in their training programme, allowed graduates to begin to take their own place in the evolving field, being adaptable and confident enough to contribute. Music therapy practice aims to create changes in people's experience and relationships in order to restore health or to alleviate distress. Research in itself contributes to change (developing the theoretical base) but also documents and acknowledges changes and advances in the discipline. The idea of change was seen as an integrative concept for both practice and research.

\subsubsection{Layout of sub-themes for the chapter}

This second main area of findings incorporates seven sub-themes (or 'variations' to capture the metaphor of the chapter) which are pictured in the following map. In a similar way to Chapter 4 , each sub-theme will be introduced in turn in the rest of the chapter, beginning with a short description in italics which identifies the material brought together in the respective section, followed by the illustrated expansion of the theme including quotations from participants and my interpretations of the meaning or significance of the material in relation to the research question.Quotations from participants are shown in italics with line numbers for longer quotes. As a reminder, Appendix 2 provides a list of all participants and their roles and location in the research for the reader's reference. 


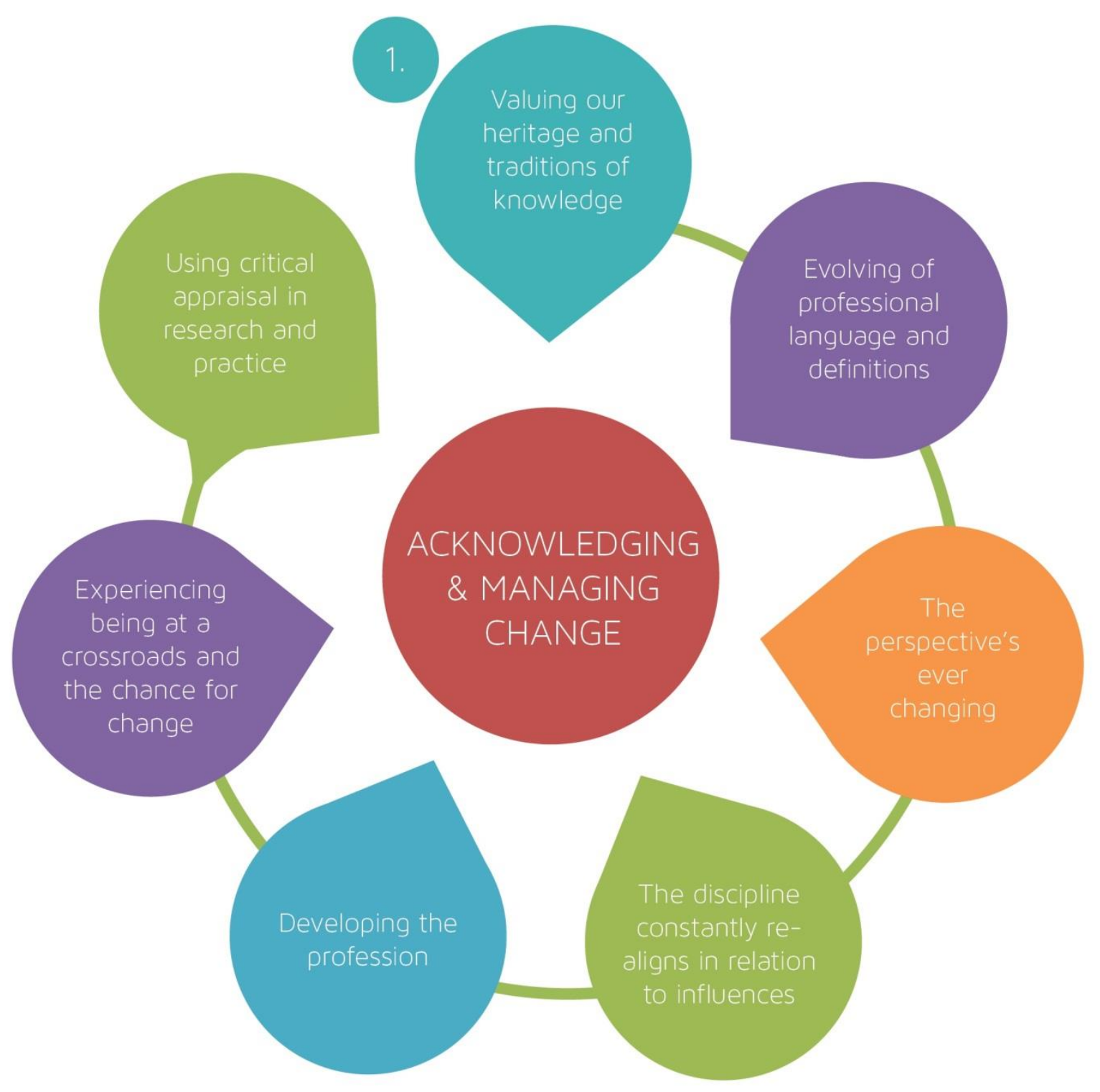

FIGURE 7: MAP OF THEMES FOR CHAPTER 5

\subsubsection{Valuing our heritage and traditions of knowledge}

Description of sub-theme:

In considering evolution and change it was important to acknowledge where we began and to consider our roots and influences. Participants each shared by invitation something about their individual history in interviews and focus groups and in part were led by the research interviewing to consider the relevance of history. However it was also an idea that was pursued independently in the discussion and progress of interviews - what background of training people had, and what influences on thinking and practice were experienced. 
Genealogy and history is particularly relevant to New Zealand and to Māori life: research conducted in NZ needs to be aware of this.

The sub-theme has particularly important connection to the metaphor of 'theme and variations' employed for this chapter, as our roots and individual heritage can be seen as the starting 'aria' from which we depart, but to which we can always relate and return, (it is Shakespeare's Sonnet's "everfixed mark" ). The diversity in roots and heritage of this research study's 19 participants is wide and reflects the broad base of the discipline and variations in approaches to training world-wide. Original undergraduate training for those interviewed involved music most often, but a Bachelors' degree in music therapy itself, psychology, social work, medicine, teaching and humanities were also represented.

A particularly strong emphasis is afforded to this sub-theme by European Group-E, participants for whom the same training heritage was shared. A good proportion of their discussion together concentrated on the nature and importance of their training philosophy and the foundational ideas of pioneers. Although they observed the changing world around them and the importance of new ideas and theory, they also emphasised a commitment to their background. One participant Eddie observed this in a particular way and noted that in his tradition there had been a particular valuing of experience and documentation of live music therapy. Philosophically this has involved a commitment to "raise your thinking to the level of your experience". He described everything he had done since training has followed this principle. He had: “... always tried to keep an active contact with the phenomenon itself" and theory was tested by this real life engagement. Other participants in Group-E supported this, talking about the practical documenting, the day-by-day reporting, and the theorising which results from this. They went on to remind that 'it's not just a tradition of practice' but that thinking and doing were closely combined. The group's summary of their heritage involved a deep commitment to the integration of research and practice.

An interestingly contrasting feature of a number of researcher histories in the other site visits and focus group, was that they themselves had not engaged in clinical/practitioner research as part of their initial music therapy degree. Two of them (Group-BA and Site FV) saw this as a specific advantage as they had been focussing on learning to be safe and beneficial practitioners at this time. They came to research later, when they were particularly keen and interested. Another distinguished researcher was exposed to research strategies and training, at undergraduate and Masters' level, but did no clinical research until engaged in a PhD study. Requirements were different at that time, but she acknowledged the value of the rigour of her early experiences, "the way of thinking that we learned as part of the research training there" (Zelda 329/330) that this established a firm foundation with the materials of research for her and for other programme leaders in her country. This approach to learning had had significant influence on the direction of the music therapy discipline in her country. 
A considerable number of senior music therapy researchers and programme directors trained at this school.

Some other examples across the data sources showed the varied foundations that participants recognised as significant and these stretch across own experience of parents and different levels of education and training. A Site KT participant identified the place of her parents in the profession of teaching as providing a profound influence on her experience of learning now as a music therapist. She said they had a "really strong influence on my expectations of constant learning". Two other participants at Site FV and Site KT observed that previous experience of vocational training respectively in science and social work had profound reaches with their growing engagement and learning within music therapy. The science participant had grown up with evidence-based practice, and paradoxically both a commitment to EBP and arguments against its application in music therapy, shaped her perspective. The social work participant was aware of the valuable teaching and research approaches that she learnt in social work and was deeply committed to the interesting crossovers she has discovered in both disciplines. Dual-training had become an excitingly rich fusion. The research musicologist in Group-BA noted that she was particularly keen to be fully engaged as a practitioner and supervisor when she retrained in music therapy as a mature person: "I trained in an institution that had a very psychodynamic model and I was immensely liberated by that" (Catherine). However the influence of her earlier experiences was now resurfacing and though she commented on the difficulty of keeping the balance with research and practice in her current lecturer job, she found herself interested in pursuing research again. "I am struggling with that in myself, although I have come full circle and I am now rather interested in being a researcher again!" (Catherine 69-71)

My personal experience as the child of a doctor and a nurse similarly shaped my expectations and providing a backdrop to a subsequent career as a music therapist. A note in my research journal during the research process observes a double influence, which has affected me throughout my music therapy career: "I have a strong sense of the responsibilities of healthcare and of providing 'helpful outcomes' for service users, alongside a commitment to the ephemeral and 'quality of life liberation' that musical experience has provided me with throughout my life" (RJ $15^{\text {th }}$ September 2012)

So music therapist participants in this study were shaped by their environments, both as young people growing up in their homes and social experiences, and also as absorbers of music therapy and other culture in training backgrounds. Participants acknowledged specifically how they return to their heritage, but also use the frame as something to react against, and to pursue tangents and explore differences. Of course these 'cultures' were all very different and I observed how very non-uniform music therapy could be. What was consistent was that my participants and I were strongly affected and shaped by the past. 


\subsubsection{The 'perspective's ever changing'}

Description of sub-theme:

The process of change is central to student experience in music therapy. The professional world is evolving and growing as students are learning concepts and building their understanding but participants comment(ed) repeatedly that students are also undergoing substantial personal growth and change as they learn to be sensitive therapists. They observe(d) the challenges and subtleties of the education process, meeting personal needs of students but also capturing the professional environment when ideas and theories change. Debates arise/arose about whether research and practice can work together to enhance the understanding of issues or whether obstacles are created.

A feeling of the necessity of responsiveness to change and the idea that the profession is in constant development, was expressed strongly by participants at Site FV. It was notable that both a student and a lecturer chose to articulate this clearly, and in the process of learning about music therapy (both as practitioner and researcher) they believed, one needed continually to be responsive to this. The lecturer Anna got involved in thinking about different levels of change that create an interface between research and practice. She said first: 'in therapy and research it is about change and particularly in research it is how to bring about social change' and thus she found a strong ideological connection which sits comfortably with her thinking. She went on to explore this further when prompted by my request for clarification. I asked Anna if she was thinking about monitoring change, being aware of it, or being open to it.

Yes or believing in it! Change as a value. Although not change for its own sake-noticing whether it would actually be better if things did change ... And change might be possible even if someone believes it's not. And then a student might believe that, (and) a client might believe that." (Anna: 304-307)

So change seemed to resonate here as a kind of hub or pivot between the two and Anna said that within the process of research the student may change their idea of themselves: "a student might believe that they can't write very well, or they may not be able to do research because they just feel uncomfortable with the whole". She implied then in the process they might experience themselves differently - so the research itself becomes a developmental journey, akin to personal or therapeutic development.

The student participant, Patrick characterised this on a more personal and practice level, and observed that he had learnt to view people through different lenses compared to his previous work in 
healthcare, and to suspend judgment. It was his words which prompted the title for this theme, becoming aware of how things are in flux, how he himself had changed, and how we have to learn to identify, manage and somehow synthesise perspectives in a changing landscape: he said: “...I think somewhere along this training I've found that I view people in a different way and accepting them for who they are really without having to sort of make judgements on them". (Patrick 252-254)

Experienced therapist/educators across the data sources elaborated at various points on the transformation, growth in self and personal challenge experienced in practitioner training, highlighted by student Patrick, and debated whether simultaneous learning about research can support this. Site FV lecturer participant Anna had some concerns

I have got reservations about it being part of an MA - research - because I think that really all the time could be well spent on just developing being a clinician and that almost it can take away some of that very detailed focus. ... I think if someone is really struggling with their own personal development and they are being side-tracked (they get very focused on for example getting research methods right, and get very anxious about that) ...I think then the balance or the emphasis is not right for them.' (Anna 234-236 \& 258-261)

Catherine a lecturer-supervisor in Group-BA described the idea of the personal journey as a necessary 'disturbance of the self' essential to learning and growth for a therapist, and observed the need for careful management of the place of researching as there is a possibility of entanglement or 'escapism'. Catherine began talking about this with a number of confirmatory interjections by Hannah (a programme leader from another country)

Catherine: I think that many students' experience of training is actually as a time of tremendous disturbance (Hannah: Yes!) ... and that's quite right, that people are quite rightly disturbed and they're addressing, meeting in their patients disturbing material which has all kinds of resonances with them... Because I think very often people choose to write about something they want to work through, actually themselves.... And there is something about helping people to recognize the objective worth of their research, but also to recognize where their motivation is for doing what they do.

Hannah: Yes! And so I...that's what I sometimes feel... the dilemma in teaching something that in a way could be a haven for certain students - that they hide in their sort of intellectual capacity (Catherine: They can objectify something...?) Yes and something gets hidden in the research process. (Catherine \& Hannah 399-437) 
This idea was supported and complemented by other participants in the two site visits, who approach the issue from the other side, articulating the way they had experienced challenging changes (as students or professionals) in the process of their research. Sometimes painful hindrances were noticed in the management of research about practice. Alternatively a number of examples were given of the way in which they have used research creatively to address things that were personally valuable to them on their learning journey. Personal learning had thus been enhanced by being a researcher. (This is addressed more fully in the 5.2.6.)

Group-E participants described using the conceptual and reflective processes of their approach to training (which is identified by one as using the "research, the academic effort of the course") to explore specific practical problems students might be encountering in their music therapy placements. This was an intriguing example of research and practice hand-in-hand and demonstrated the effort of the lecturers to engage the students' personal learning at the same time as developing practice wisdom or research skills. As an educator I certainly recognised the regular problems that students and professionals encounter out in the community, trying to secure rooms, and quiet space in busy school or hospital environments, and to encourage regular contact with their children or clients:

So it often has to do with, you know, 'not having a room', or 'being interrupted' or you know 'not knowing if anyone's ever going to come back ever again'. All those kind of things which are the reality of life, particularly in an institution with its own life which isn't dictated by how music therapists think music therapy should be conducted ... are things that they use the research, the academic effort, of the course to explore. (Quentin 342-348)

So a number of participants saw the possibilities of parallels between student's personal learning about self and others and their learning through a research approach. Possible avoidance of deep engagement in personal learning was raised by some participants, deflecting to the reasoning skills needed for research, but others saw the potential of real life problem-solving (i.e. answering questions that are one's own practice 'problems' in a research-led way) to be genuinely integrating. The personal reflection required for qualitative research (discussed by Alex Site KT) and strategies like action research in particular (as raised by Anna Site FV) were are highlighted as methodologies and approaches that married practice and research in the field in comfortable ways. These particular approaches embraced and accommodated change and growth of the protagonist/researcher, mirrored the reflective process undertaken by practitioners in their notes and journaling, and were noted as particularly integrating processes. 


\subsubsection{The evolving of professional language and definitions in music therapy}

Description of sub-theme:

Participants contributed ideas about the way that professional language in music therapy had evolved in their experience of the discipline. It was observed that language in MT and other disciplines is changing and evolving all the time. It was noted how language could shape thinking and the value of making this process transparent was highlighted in one area of the data. In particular, definitions of 'research' weree offered and critiqued particularly in relation to the kind of research undertaken as part of training. What kind of research was considered valuable for students to pursue? This question was debated widely across the groups and sites.

Evolution in language could be considered as a kind of barometer of the process of change in a discipline (as evidenced in this study). Participants observed this in explicit and more subtle ways in the groups and sites and it was an important area of discussion between people in both focus groups. Focus Group-E brought the idea of language centre-stage in this research process. One lecturer participant was thinking about it in a very deliberate way as she introduced herself, particularly when considering teaching students, by emphasising how collections of terms relate to theories and ideologies of work (explicitly and covertly). She described a process of consciousness-raising:

...getting students to consider the kind of language that they are using, and what frame that language comes from, and the kind of ideology and - in a way - the 'oppression', behind it, you know that it can really limit how we think and how we speak, and how that influences what we do. (Kirsty 88-90)

This kind of exploration of language became an important way to reveal and compare different theoretical approaches to music therapy for Group-E. The participants illustrated ways they have evolved in their teaching programme to help students become familiar with different terminologies and how they relate to traditions of practice. My own thinking also evolved as a result of this interaction in the focus group. I was aware of being rather naïve previously, and looking back over interview transcripts, I became much more consciously aware of how different participants identified their theoretical position and practice approach through the language they used. A psychodynamic background was indicated by use of such terms as 'disturbance of self' and 'schizoid split', a social constructionist position by 'power relationships between therapist and client' and interest in 'reflexivity' and a more positivist research training was suggested by the term 'taking data' and 
developing hypotheses about practice. I had registered this before, but it was valuable to think specifically about the language:

As researcher I had a very interesting personal reaction to this a little later in Group-E, when I was talking about clinical practice and clinical seminars for students where work on placements is reviewed and discussed. Kirsty raised my awareness of the use of 'clinical' which has become a training habit for me. We talked about being clinicians and being practitioners and I realised that I had used them interchangeably and tended to refer to 'clinicians' specifically when I was considering training issues. Our supervision groups at the Guildhall school were called 'Clinical Seminar and I realised how - by default - I was using a medical model for the language, whereas my own practice had gradually become more influenced over the years by humanistic and psychodynamic thinking. Maybe I had evolved in my own thinking, whilst my institutional language stayed the same. It was fascinating to be made more aware. I made a conscious choice to change my research title to educating practitioners/from educating clinicians. Here was language evolving before my eyes. (RJ 30 $0^{\text {th }}$ Jan 2010)

I cross-reference here a point made by Bella at Site FV about student's acquiring of language (see section 6.2.5 'Finding confidence'). This lecturer observed that students' own personal use of research language grows in their learning on a music therapy programme. They have more vocabulary and thus they change in their ability to articulate and perceive the work they are doing. This is a complementary observation made to Kirsty's earlier in this section where lecturers might familiarise students with the different 'language' of theories, and giving confidence to use and interpret such theories.

The term 'research' itself sparked an ongoing debate between group members in the two focus groups, and then continued on in the specific site visits. This felt to me as researcher, a very pertinent aspect of observing the evolution of language and concepts for a discipline - particularly in the context of the present study concerning the involvement of students in research activity. The way that research is conceived in music therapy has clearly changed in recent years, according to participants, and how this applies to students was raised on a number of levels.

Site KT researcher participant Alex noted the change in the kinds of research she could practically be funded to undertake over the years, and was relieved and proud that her own contributions might have contributed to growing acceptance of qualitative methods for vulnerable participants. Alex and lecturer-researcher Anna (Site FV) both pointed out examples in their interviews of where the language of qualitative research fitted easily with student's work in practice settings. They both talked (in slightly different ways) about reflection and developing practice wisdom as being a strong part of their own research journeys and their understanding and personal conception of research as applied to 
student work seemed centred around these concepts. Site KT researcher-lecturer Bella's fascination with 'pattern and meaning' also seemed to link clearly with qualitative research concepts.

All the Group-BA participants alluded to the definition of research in the way they articulated their experiences. Some group members demonstrated powerful change in themselves in a most interesting exchange. This began with experienced researcher Zelda's story where she reflected on her own thinking about research and noticed that she began her career trying to 'really make it more strict and then now I'm in this ... more "loose" or flexible definition of research'. Initially she never thought of 'taking data' as being anything other than clinical evaluation, but now had changed her thinking somewhat to be able to redefine such activity (the taking of data) as a kind of pre-experimental design although she expressed the observation that she 'continues to feel quite confused' (104-152).

However Zelda also expressed frustration that people could try to describe almost anything they did to document their work as 'research', which she felt had an undermining effect on the quality of studies attributed to the discipline. She said "that really makes me crazy because I think then we never raise our standards for what we are really talking about" and in this way, too loose a definition of research had its problems for her. Recent graduate Paloma responded to the expression of confusion about how research is defined in the music therapy field. She described the experience of writing her masters' thesis vividly (as noted in the previous chapter section 4.2.7) : it 'made my brain very grey ... mushlike' and later echoed the colour metaphor, saying 'research as a word is very grey and I could not define it, like you say, so many people coming with different definitions... It's quite confusing..." (160-177). Lecturer-researcher, Hannah made a more specific association with the way her ideas about what constituted research have changed over the years of being a clinician and researcher:

I think what Zelda said really resonated with me... how does it link with clinical practice? Because actually I did many evaluations of my clinical practice before I ever started researching - that I never would have called research. They were just evaluation they were part of your responsibilities as a clinician to really understand if you've set these goals and objectives - if you think you are doing this - are you actually doing it? But later, I've reflected on and thought actually - that's foundational to research. (Hannah 220-226)

Hannah further elaborated on "this idea of this curiosity about patients' experience" as the kind of research in which she has become much more interested. ${ }^{27}$ Finally Catherine, lecturer participant picked up this thread at a slightly later point in discussion by articulating that (from the discussion) there might be two ways that research can be understood.

On one level we are talking about the need for research... to demonstrate something about efficacy or good practice ... in other words how we might present research to the world, and

${ }^{27}$ The idea of curiosity is also discussed in Chapter 4, Section 4.2.2. 
the other is something about the relationship within the clinician between research and practice. [The process of students researching] ... encourages a certain kind of curiosity (Hannah murmurs 'Yes')... a sort of aliveness ... which is very much enhanced I think by having that focus'. (Catherine 289-297)

Group-E members played with the idea of the term 'research' perhaps not being very helpful as applied to student training, with one person wondering "is research too broad a term?" In discussion together they suggested that - for the purposes of student learning - a day-to-day practice-linked definition could encompass instead the 'search for meaning' combining curiosity and reflection on placement experiences. Alongside this there might be a more external process of learning about 'Research Methodology'. In this way, perhaps Group-E's ideas were allied to those summarised by the Group-BA lecturers above. Certainly they identified a kind of practical researching process that appeared to resonate with lecturer Catherine's curiosity and aliveness. They described having abandoned the time of a formal written thesis as the research requirement on their programme. They now used a more varied collection of research-related tasks, which were not isolated as the 'research component' but built into and extending from practice documentation and analysis. In this way they recognised that bringing in research was not just importing this 'thing' - the thesis, nor embarking on completely separate activity - undertaking the research skills work, but building and weaving it into the structure of practitioner learning. For this department, integration of research and practice seemed to be established comfortably through these steps.

It was interesting that further questioning of whether "research is the right word?" for what it is that students did (raised in Group-BA), continued at Site FV. The senior student participant who asked this went on to observe a disparity between being a very effective clinician and "having the academic and research side" - perhaps suggesting in her narrative that possibly they were being forced together in the programme? Terms as part of, or instead of 'research' that came up a lot in the language of this site during my visit were 'evaluation and audit' and the same student participant said:

I think it's important for everybody to be able to present music therapy on an evidential basis cause we've got to compete for money, [That] is the bottom line. And that needs to be convincing and [have] reasoned and balanced arguments. So I think ...evaluating, efficacy and effectiveness ...should be part of everyone's practice and then understanding the different methods for different aspects of that. (Florence 979-984)

This raised an inevitable question about the definitions we use for 'research' when incorporating research activities and learning in training programmes, as identified in the literature review and in focus Group-BA). Language and definition may act as a barrier or as something divisive or challenging. What the music therapy department means by 'research' at one site may be identified differently by another health department. In received documentation, the language of one of the 
modules - Research Methodologies - which Site FV music therapy department borrowed from another area of health and social science research (when outlining critical appraisal skills to be gained by students, mentioned in section 5.2.7) appeared to echo the hierarchy of evidence in EBP (see literature review).

- Evaluating intervention research (experimental and quasi-experimental research; randomised controlled trials; action research; descriptive and inferential statistics including both parametric and non-parametric approaches)

- Evaluating survey research

- Evaluating qualitative research (open interviews, discourse and content analysis, observational research)

- Evaluation criteria: reliability, validity; issues of corroboration; triangulation

And so the context in which research was being considered seemed to start from the medical model of intervention. Qualitative research, in the third bullet point, does not have a consideration of the arts or arts process in its examples - of course there is no particular reason why it should - but by various participant reports, the shared modules were experienced as particularly problematic by the department.

\subsubsection{The discipline constantly re-aligns in relation to various contextual influences}

Description of sub-theme:

Participants observed the way that the discipline repositioned and accommodated to the needs of the time and to the challenges of socio-political change. These changes could be internal or external to the discipline (for example the sense of aligning research to more qualitative or musical concerns; or the wider external needs of evidence-based practice) or a mixture of both. Practices in education and research were both observed to need to respond to these stimuli and challenges, and students were by default affected by changes in professional climate. Therapists interviewed saw advantages and disadvantages to the process of re-alignment but the need to engage with this was seen to be imperative for all parties. On a micro-level this fitted also with how students change and grow; as they develop they can then take their place in the evolution of the profession and know that their work contributes.

Lecturer researcher participant Eddie in Group-E identified the title for this sub-theme, in his reflections that the music therapy discipline has chosen, or been required, to make some moves and 
choices in relation to how it allies itself to various movements in the professional world. This seemed to refer both to strategic change initiated by therapists aware of wishing to realign the discipline in particular directions, changes that become necessary for the discipline to respond to, and also gradual

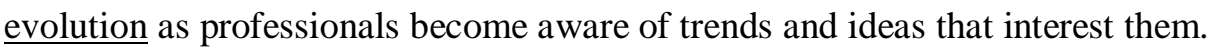

Eddie and Kirsty (also lecturer-researcher) gave some examples of how this had been happening in their recent experience. Eddie noted how fast the landscape had changed for example in the funding of the arts in healthcare in the last seven years and this obviously had affected the decisions that different groups of music therapists have made about their research, teaching and employment. He was interested in reading an American article which was relocating music therapy and the discipline of 'Music Medicine'. Previously the latter had been the province of people other than music therapists '... who are increasingly then using medical epistemologies and medical methodologies on musical phenomena. ' However the article he referred to noted that, in 2010, music therapists in the USA and elsewhere in the world were increasingly placing themselves within Music Medicine - thus observing the disciplinary world changing before our eyes

'...there is a re-alignment happening in terms of music therapy and music and health. As we speak now, you know, people are realigning it, and that will have far-reaching consequences about education and research. (Kirsty: And practice!) And practice (laughs) - yeah mainly practice actually!' (Eddie 277-280)

His observation about this realignment was that it was making music therapists more 'plural' in their possibilities for research and practice "and positioning themselves within integrative medicine, with which then you can go all ways..." The result of this change in positioning of the discipline was that there was an experience of uncertainty and flux (but perhaps excitement at possibilities as well) "as the boxes that we previously had were quite neat for 25 years - are far from neat anymore".

Kirsty added to the discussion about the change in one of the 'boxes' or frames that might have more traditionally been used in international music therapy. She indicated that it is the work of both practice and theory (led by research we might assume) that creates the possibilities for re-framing, and the implication in her words is that there is a flexible relationship between the two (practitioners do things, theorists observe and frame, and practitioners then put the frame into practice and add to it, and onwards in a spiral development).

You know in the old days when I trained, it was 'what you did at the piano with a child'. That was music therapy! Everything else was 'leading up to doing music therapy' and consequently what happened afterwards. I suppose - partly as a result of - well - the work that practitioners have started to do, which doesn't take place a) at the piano or b) necessarily in a closed room, or indeed with children, but might take place in very open 
spaces, partly a result of that, partly a result of disciplinary thinking that started to drift in toward -, or being hauled in by some of us to - part of music therapy thinking, there is a reframing of what music therapy work really is. (Kirsty 301-309)

Site FV Lecturer-researcher Anna's interest in action research and her explanation of how the process fitted with practitioner and client involvement in a redistribution of power provided an interesting example of more gradual re-alignment of professional values and practices. Anna demonstrated how she as an individual music therapist became aware, through discussion with manager, reading and her own research of a particularly valuable movement for change crossing over a number of different disciplinary fields.

...what it offered was an alternative ...relationship with the research ... as more a position of equals, rather than being a researcher with 'subjects'. There was an alternative frame. A way of doing participatory research where people ....particularly as I was very interested in working with this vulnerable group, where they themselves could influence the research and it was... extremely challenging and therefore very enticing for me. (Anna 80-84)

My own colleague, Daphne Rickson's practice and research documenting music therapy and inclusion in New Zealand has had an impact on my ideas and values as a researcher/educator in music therapy, and also our colleagues in Australia. I note in this RJ entry last year how the NZ music therapy profession has gradually been influenced by a social constructionist approach (somewhat akin to that described by Anna above) through Daphne's action research. Our students in New Zealand have also been affected by the theories and ideas presented discussed and modelled by my fellow teacher:

Daphne's StarJam research project has been a most interesting part of our research conference this month (Nov 2011). This has grown out of her PhD project which has been undertaken between 2004-2010... music therapy as a consultancy role for schools, particularly as it might affect possibilities for practice in NZ. This work has also been part of the growth in community music therapy worldwide. (Through this association) ...I have become more aware of social constructionist thinking - the role of advocacy for participants' voices in research and also client voices in music therapy. My own research role has been studying teaching of students researching, but it is interesting how ideas have rubbed off on me. I have certainly become much more familiar with the inclusion agenda in education in NZ as a result of my team work with my colleague. This work also challenges us to think in NZ and internationally about how we might practice music therapy, how we might change our practice from working with children to working with the adult teachers and professionals who support the children. (RJ 25 November 2011) 
Expressing some similarities with the above examples, two researchers at Site KT Bella and Alex showed their own observations of disciplinary re-alignment. Alex demonstrated how bringing a frame for psychological assessment with adults from another allied health discipline for consideration to the music therapy professional association in her country created a change in how the national body viewed this process. As a result she was asked to join the committee and develop how this approach might be used nationally. So she herself contributed to the realignment of practice for adults. As evidenced elsewhere, lecturer-researcher Bella observed her supervisors helping her realign her own research topic towards a music-centred, improvisation analysis approach at a time when this work was emerging in the discipline. The supervisors could see this beginning to happen and thought that Bella would make an active and serious contribution to this initiative. They could see the profession redefining itself and were responding to changes in the field.

The imperative for music therapy as a discipline to 're-align' with the requirements of evidence-based practice was an obvious topic to emerge in the research findings, and this may have partly come about because I was alert to it, and was prepared questions to ask (particularly the focus groups) about it. Florence Site FV as a science graduate discussed how she personally responded to the potential realignment music therapy has needed to make. She said: "I got quite het up about it because Ifelt it was using wrong methods to study the effects of music therapy and I'd seen evidence based practice as a spectrum. Depending on what you're looking at you've got to use the right tool for the right information. I don't think that that is implied in the hierarchy of evidence. " (95-100)

Group E made a number of comments about EBP and the way that music therapy was needing to respond and 're-align' its processes. One researcher-lecturer talked about the way that the language of EBP was "filtering through to the AHPs (Allied Health Professions)" and noted the growing impetus amongst the profession to think: "How are we going to respond to this culture?" Eddie and other members of the group discussed how the different organisations were galvanising themselves to respond and adapt to the framework that would be demanding for the new students going out into the workplace.

However, returning to the metaphor of Bach's aria and variations, Eddie also reviewed the importance of maintaining core steady values amidst all this change. It was as if there was a central 'theme' that would help 'ground' people when all was shifting around them. He said "... the touchstone of what I think I'm trying to provide for the students, or lead them towards, or help them get to, is ....quite clear, and quite unchanging. So however the research culture changes around us... I think that what I have my eye on, ... what we are essentially doing, is quite similar." (Eddie 144-147) 


\subsubsection{Developing the profession}

\section{Description of sub-theme:}

Participants referred to the tendency observed in themselves and others towards moving the profession forward. Knowledge about practice constantly changes, through a research-led approach. Research anticipates and creates change, and practice in therapy is about 'change' in its definition. What we know morphs and adapts and this sub-theme encompassed participants' observations about how research and practice contributed to change and the growth of knowledge.

Some of the sub-themes outlined here feature in other chapters, indicating some dove-tailing of the main themes, but in each case they feature the idea of participants acknowledging how contributions are made to helping the discipline grow, change and build on its work.

One aspect of this topic was alluded to several times by a researcher participant in Site KT who showed how another profession's traditions and 'materials' might be used and adapted for music therapy's disciplinary gain. She was dual-trained, coming to music therapy from another allied health discipline and gave a number of examples of tools she had borrowed and developed over a career of 2 to 3 decades. A source of pleasure was how that had meant that she could contribute back to her own original discipline from music therapy after her exploration of the tools in music therapy and now published in journals in that area. This was an obvious example of interdisciplinary growth and development and how each discipline could benefit from the advances of the other. She also acknowledged that that her original discipline gave some frameworks and approaches that allowed her to question approaches in music therapy, which added rigour or weight to her inquiry:

(My original profession) taught me to kind of look at theory,(it).... taught me to look beyond music therapy. It gave me the strength to be able to question fundamental premises like (one particular approach being)... the only way for music therapy. (Alex 342-345)

The student participants at Site KT noticed how current issues being discussed in the professional field could be topics of interest to them for their research studies on the programme, suggesting that they already had a sense that they could contribute to the developing landscape of professional thought. An example of this was the more junior student who was just working on selecting a topic and although the clinical placement opportunities were attractive for her research, different attitudes to spirituality highlighted at a conference, and then followed up in the literature, had really grabbed her attention and would probably be more manageable as a Masters' topic. She had recently found an article which identified some controversy and thought this would something of value for her to follow up: 
Spirituality ... it's a topic that we skirt around and we don't really talk about it and (the author) said that 'cos she teaches this,... she would always avoid talking about it in class and wouldn't understand why anyone would bring spirituality into it. But then she had sort of changed her opinion on it throughout her years and said actually it is something we must acknowledge as therapists and teachers. Just to accept the diversity of the range of religions and spiritualities and also reflect on how it affects our practice. I think personally that that's important. (Naomi 187-193)

She noted her own place in the topic - it had a personal relevance and in her interview went on to elaborate why in some depth. This participant had already undertaken research at honours level, and perhaps had experience and belief that research could contribute new knowledge, and by identifying gaps in professional understanding she could begin to develop a way of making a contribution herself.

The senior student saw herself as a contributor to a team of researchers, by working in an assigned area of a bigger project. She did her part of the analysis and then checked things out with the lead researcher, her supervisor, and in doing this she was learning research skills and being guided, but also providing very useful input to the project and knew that she was making a difference.

I've been sort of working on the data and then emailing it through to (my supervisor) and saying, "What do you think?" And then she'd provide a second opinion, and we kind of have conversations about it like that. So really it's (pause), I guess we've been working on it together.... I think you learn a lot more that way too, because a lot of times she'd give me feedback and I'd think, "Oh, I hadn't thought of it quite like that." And then I can actually take it to the next level. (Abby 301-312).

Later she went on to affirm this more strongly and particularly noticed that it was having research involved in her conception of her practitioner career that added to her sense of purpose and achievement (as noted in the previous chapter, section 4.2.9)

The clinical practice lecturer participant at Site KT firmly believed that being interested and willing to develop research in a hospital setting, and the evidence-based approach that she adopted had had a significant impact on the hospital team's respect and enthusiasm for including music therapy as part of their services. Interestingly to me, she began with a research study in a new area of the hospital, and it was definitely the research that develops the practice in this case:

I had no clinical experience to base it on, other than all the reading I'd done. So, what was good about the project - we didn't get significant results - but what was wonderful is that.... everyone knew about it, they got used to seeing me around, we ran the project for a couple of months and then I in-serviced and presented all the results. (Helena 95-101). 
This moved the discipline forward in practical ways. More staff members were employed and new programmes developed. The willingness to engage in research as a practitioner took its toll on the participant's time, but she grew her department rapidly and with the goodwill of the team.

Already noted earlier in section 4.2.6, one lecturer-researcher participant indicated how her supervisors anticipated a future trend in the discipline towards examining the music more centrally in the evaluation of music therapy process, and they guided the participant (when a student researcher) towards doing a music-centred study. This was another part of observing a gap in knowledge, and trusting the supervisor's greater sense of where the discipline is heading as she says ' it wasn't documented, it really wasn't and ... my supervisors would have known that it was a wave that was happening across the profession but I obviously didn't know that." (Bella 107-109) The idea of engaging the student in real contributions to the discipline, and in the supervisor recognising a student's potential, were all significant factors in the process of building a profession's knowledge base. Getting students engaged in topical or timely conversations for the discipline from an early point would seem to enrich the meaning of their work and give a sense of belonging and ownership. Students at both sites exemplified this in the conversations. For this to work, mutual trust with student and supervisor was necessary, and supervisors being well-informed and interested in current international trends. Sometimes it was the student who informs the supervisor, as where Beatrice's noted her supervisor's willingness to be persuaded about something she wishes to inquire about. "And he said 'Well that's true - it hasn't been done before." (Beatrice 41-42). So she embarked on her new area of practice investigation.

An example of how practitioner research approaches develop and grow over time was given in passing by Alex, who observed the radical changes in research ethics' approval process which were now part-and-parcel of any music therapy project with vulnerable participants. In her early research studies three decades earlier,

...in some of these places, well at XXX Hospital I started doing the work that I described with the people with advanced illnesses, there wasn't even an ethics committee, let alone be thinking in terms of research. Like we weren't using those constructs at the time.

(Alex 299-303)

She reflected that her approach to the people in these early studies was particularly careful because of clinical ethical responsibilities in her practitioner training and that had prepared her well for the current very stringent requirements when researching with such a vulnerable group. There was an implication here in both site visits that the learning about ethics has enormous potential for crossfertilisation, through understanding both practitioner and researcher responsibilities, and perhaps one of the strongest arguments for integrated teaching about both I have yet found. Because of the strong 
ethical code for practice of music therapy in international settings, there was potential for valuable contributions to debates about research ethics, similarly experience with research ethics could teach practitioners elegantly about the dilemmas that might remain covert in practice settings; research made the issues more explicit.

All the participants in this site were female and I observed interesting commentary from two staff participants differentiating how men and women might progress disciplines, or at least how gender politics might indicate the different roles. From my Research Journal reflecting on attending a class at Site KT on research methods, I commented that one of the lecturers:

.... notes in passing in her lecture on the development of an area of research investigation, and laughing as she spoke, that 'men tend to need to make their mark' on the discipline and put their name to something. (This comes up because she is referring to all the many different versions of the research method that have been referenced.) It was interesting for me, as someone who would tend to 'play down' gender politics more than emphasise them, to have this articulated. (R J. $2^{\text {nd }}$ October 2010)

It did have an impact on my thinking, so in another interview on this site later in the visit, the issue arose again (and I suppose I was trying to work out what a 'female' approach might be) I mentioned it to the interviewee, researcher-lecturer Bella, in response to the comment she made about fostering connections (section 4.2.9) I observed:

Sarah: ....I guess I'm sort of picking up a bit of a theme from Beatrice when she was lecturing the other day and she was saying the male way would be to sort of 'put your mark on things' and.. (for you) It's actually building on the things that other people have made and making it so that it's more understandable, ... Bella: Oh absolutely and I definitely have taken that from her without question, it's not a desire to put my name to anything. '(245-246)

The ethos that emerged to me from this site was one of collaboration and sharing roles and each clinical and research supervisor talked about either working with students (Bella, Alex), working with colleagues in varied ways in their research about practice (Beatrice, Helena) and in practice roles which have potential to develop into research (Alex, Helena). The students also discussed this. Researcher-supervisor Alex summed up the value of this mutuality, particularly in how it affected and developed the capacity of students:

And it's been very gratifying to see one of those students refer to this work in her own articles and chapters in her own far more advanced research... and see that work I think affect her future career path overseas. in fact some of the, I think the greatest satisfaction I have is in watching that, in watching the careers develop. (Alex 145-148 \&166-8) 


\subsubsection{Experiencing being at a crossroads: the opportunity for change}

\section{Description of sub-theme:}

Moving into research-mode had the sense of entering a crossroads or junction in people's careers when they were established professional clinicians. Uncertainty and hiatus was sometimes part of the experience and opportunity and creativity also linked to it. Research itself might create the crossroads and 'critical thinking' could be part of this-it was required at the cross roads.

This theme was expressed most explicitly by a clinical supervisor participant at Site FV where she described her move into research from practice occurring at a time of major change. The step into research is experienced as an opportunity for change in work direction and in level of thinking. She says the research degree came about because her managerial role in a clinical team ceased when her organisation disbanded:

... actually it was a good thing for me and I mean hindsight's a wonderful thing, but it was a good thing for me and I think it's probably opened up more avenues actually for me since then. (Hilly: 82-85)

It was clearly a personal challenge and a real crossroads in her career. As she says "I did find the whole thing terrifying, I felt completely out of my depth to begin with and many, many times I thought of giving up" (221-223). However somehow the creativity and interest did hold her steady and she clarified at the end of the interview, the value that she attached to her change of direction and the project she undertook:

'I do have to bring myself back to that and realise just how much it has informed my work' and she notes that 'the more I talk about this more I think I should get this published 'cause it might be of help to other people.' (Hilly 570-574).

Such a crossroads in a working life is underlined at least as strongly in another lecturer's story at Site FV. Anna equated her change in pathway to research with specific personal development. It occurred alongside parenthood, change in client group in a new post and a new temporary supervisor in another therapy discipline who introduced her to a research approach that sparks interest. She noted 'that my research development also took place in parallel with this quite ... rapid acceleration in personal development too. Particularly becoming a parent. '(Anna 73-74). It is as if the change in circumstances created a space for thinking differently for both participants, it allowed one to step back, and perhaps reflect and analyse, which makes way for research. The junior student also alluded to personal development through dynamic experience on the training programme in his story which considered research and practice. Although there wass not specific reference to research at this point, 
he was reflecting on his learning and how he was going to be a confident professional. My hunch as researcher here was that he didn't know what to expect, but he thought this might be relevant to consider. His lecturer was looking back and saw that personal development steps could go hand in hand with research steps. Within the context of this site visit, the two are imagined together.

Another instance of the change and challenge aspect of this theme (in slightly different context) was the senior student's new direction in music therapy from the medical sciences. Her experience of a 'crossroads' was from the worlds both of medical science, and music teaching, and she came to a music therapy entrance interview looking for a challenge and a way of working with both strands of interest. Her attempts to link the humanities and her "rigorous scientific training" was not always easily achieved, and she also embodied the clash of cultures in her learning and wanted to challenge the orthodoxy of EBM and the hierarchy of research evidence. She was aware that evidence could be perceived differently by different professional groups: she said "if you're actually presenting evidence to a group of psychotherapists it is very different than presenting it to a group of neuro-scientists." (Florence 183-184)

On a finer more detailed level, the research process itself often seemed to bring about crossroads in thinking for participants - and the three staff participants at Site FV all expressed this in significant ways. One described the surprise of herself and her good friends sitting sharing research : "we've known each other for many years, and she said, "Can you believe that we're here discussing data analysis?" (laughter) (Hilly 249-250). A second person emphasised that she has changed her own approach to sustaining her practice thinking and where she gained inspiration:

'I have learned to look at research - and I head for the journals all the time, - nothing to do with music therapy - so and it's given me a way of being able to read them which before I wasn't doing and so I feel I am more in touch with literature that I've ever been ...'

(Hope 580-583)

Another observed that 'my own learning was just so enormous' and it made her aware of both her limitations in knowledge and the potentialities for new steps. Engagement in research allowed the possibility for a new pathway (extending the metaphor and taking a particular new turn at the crossroads) and lecturer Anna began new activities: 'it's provided a gateway to things like being a peer reviewer for articles in music therapy journals ....and book reviews. ...also now teaching research to music therapists on a masters' course' (Anna 112-115) 


\subsubsection{Using critical appraisal in research and practice}

\section{Description of sub-theme:}

Critical thinking was identified specifically in three data sources as a process that allied research and practice. Learning to think in a clear analytic way had potential for training capable research-orientated music therapists, but also assisted students in some of the challenges faced in the complex demands of practical placements.

This section seemed a useful place to conclude this chapter, as it brings us clearly back to a crucial process for Masters' students; that is, the development of the capacity for critical thinking. Although it was not discussed in a lengthy way, the references made were resonant in each of three data sources . Researcher-programme leader Zelda's reference in section 4.2.6 to her professor teaching "a way of thinking" in Group-BA affirmed a particular sort of practice that was particularly effective in encouraging researchers. Zelda noted how many people who had absorbed this style of learning, with her professor as mentor, had gone on to lead research teams and to be able to inspire students themselves. I had the sense from Zelda's way of speaking that her mentor had been particularly passionate as a communicator (linking with the 'fire' theme of Chapter 4).

In analysing Site FV data, the crossroads sub-theme (5.1.7) was identified early on, and originally the following material was connected in that thematic area, as a 'micro-version' of the crossroads. I saw being able to manage a "crossroads in thinking" and be able to hold a number of options in mind or tolerate complexity whilst one works things out, as being linked there. However in moving back from this data and looking across the case study, it seemed that this special kind of thinking, observed by a Site FV participant as "critical appraisal" was deserving of its own sub-theme. Lecturer-researcher Anna identified and highlighted this area as one of the most integrative components common to both research and practice in her interview:

Being prepared to rethink ideas and rethink /unpick intuitions and dealing with the complexity of a situation, acknowledging there may be a number of different perspectives that need to be balanced. All those I think are common to clinical practice and research practice. So the more capacity a person has for flexible thinking for the ability to re-frame and to underpin any kind of argument with appropriate reference, understanding their reading in a deep way rather than just patching a lot of references together - [the better for their development]. I mean I think that is common to both areas.(Anna 270-276)

In my research journal during the Site FV visit, I thought about this excitedly in response to Anna, while interviewing later participants.... 
Yes - critical thinking as a skill is so helpfully shared between the research and practice pathway! You get very nice links to flexible thinking, reframing, considering different meanings and underpinning arguments with good background, so that people have read, and thought and practiced and then linked everything together. This is the province of both disciplines. $\quad$ (Research Journal $2^{\text {nd }}$ February 2010)

Critical thinking is seen as a key component of generic Masters' or postgraduate level work and identifying this (as this participant does) as a core music therapy practice skill as well as a research one, is an interesting way to make a bridge between the processes. The implication of this participant's idea was that experience of critical reflection on practice may assist and feed into the research process. Stimulating critical thinking in both areas could be a strongly integrating strand.

A Group-E participant's perception on this topic was first alluded to in section 4.2.5, and he expanded on Anna's practice-focussed argument in the following quotation. This programme leader reinforced how important it was for students to learn to think independently when on placement:

I think we seem to inculcate critical thinking at Masters' level, and trying to get people not to just say 'I'm training to be a music therapist. Tell me what to do and I'll do it', but rather for them to say 'Well look, here are the issues. This is what's puzzling. This doesn't seem to make sense'. And to gain the skills to go away and look things up, and on a very small scale, to go and talk to people and gather information and to do the kind of things that are directly and immediately useful to them as, ... 'practitioners'. (Quentin 400-404)

He suggested that critical thinking is a training ground for later research: "Yes there is this option of a further leap, ... actually doing some reformulating yourself, which is another step." So it would be particularly valuable for students to practice these skills for that larger, more serious research step, but equally, he considered that research-minded work also helped them in their day-to-day practice. So this reflexive movement of practice experience where you work out critical thoughts doubling back to assist your future research, and preparation for research (critical thinking) helping out the practicebased problem-solving provided a rich emblem for integrative practice.

\subsection{Concluding comments}

Allowing for change, creating the environment where change can happen, and evaluating change were processes that participants in this research observed as being strongly common to research and practice. Having a solid foundation, and knowing where our values lie and 'where we come from' was presented as an important precursor for change, and it was noted by participants that we were 
profoundly affected in our learning by our heritage. The two sub-themes of the chapter which involved (a) change and evolution of professional language and (b) the cyclic practice-research development of the discipline, were obvious, but enlightening topics of reflection for participants. Interviewees seemed to be illuminated and excited by seeing these connections. Particular focus was given to participants observing their music therapy worlds growing and changing as a result of research. The new practices that resulted were exciting both for individuals involved in their own change, and for participants observing new disciplinary trends building and developing before their eyes.

As researcher, I noticed considerable reference to the personal change and growth that accompanies music therapy students' progress through their training. Many student and lecturer participants made connections between this idea of the student's growing awareness and enlightenment and the way that 'personal research' and an interest in reflection might contribute positively to a researching attitude. There were concerns that too much focus on academic research might risk taking students away from their personal learning (allowing a place to 'hide'), but some participants saw excellent potential for growing critical and personal awareness together. Embarking on research was often seen as a very stimulating time by participants, and provided opportunities for making new directions and changes in their thinking. From this perspective, personal growth seemed to be facilitated by a research journey, and being a researcher appeared to create helpful changes in therapists' approaches and practices. For a number of participants this process contributed strongly to changes in their thinking, and stimulation and development of critical thinking was identified as the last sub-theme in the chapter. Critical thinking and its' attention to multi-level, complex processes seems a good place to end this chapter on change and to transition into the final section of the findings, devoted to the management of complexity. 


\section{Chapter 6: Stage 3 OF FindingS \\ 'ALL THESE META-LAYERS': \\ DEBUSSY'S USE OF MOTIFS OF ASSOCIATION}

\section{Introduction}

This chapter is concerned with a collection of sub-themes about the complexity of the process of integrating research and practice in music therapy education. The sub-themes focus on a range of areas which relate to this complexity and how music therapists, students and educators in this study understand and 'manage' it. The themes explore roles and tasks of lecturers, supervisors and students, and also how emotional (and musical) responses to complex experiences can illuminate learning. The sub-themes which follow are perceptions of the participants across all the data sources, in a similar format to those presented in the previous two findings chapters beginning with an autoethnographic experience of place to introduce the frame for the chapter. The last sub-theme (2.1.8) gives a musical and reflective exploration of one particular experience of complexity, drawn from research journal notes and transcription from a music improvisation and discussion with one participant at the close of Site FV. 


\subsection{Introducing Debussy's use of 'motifs of association'}

\section{A personal experience of landscape, space and music-drama}

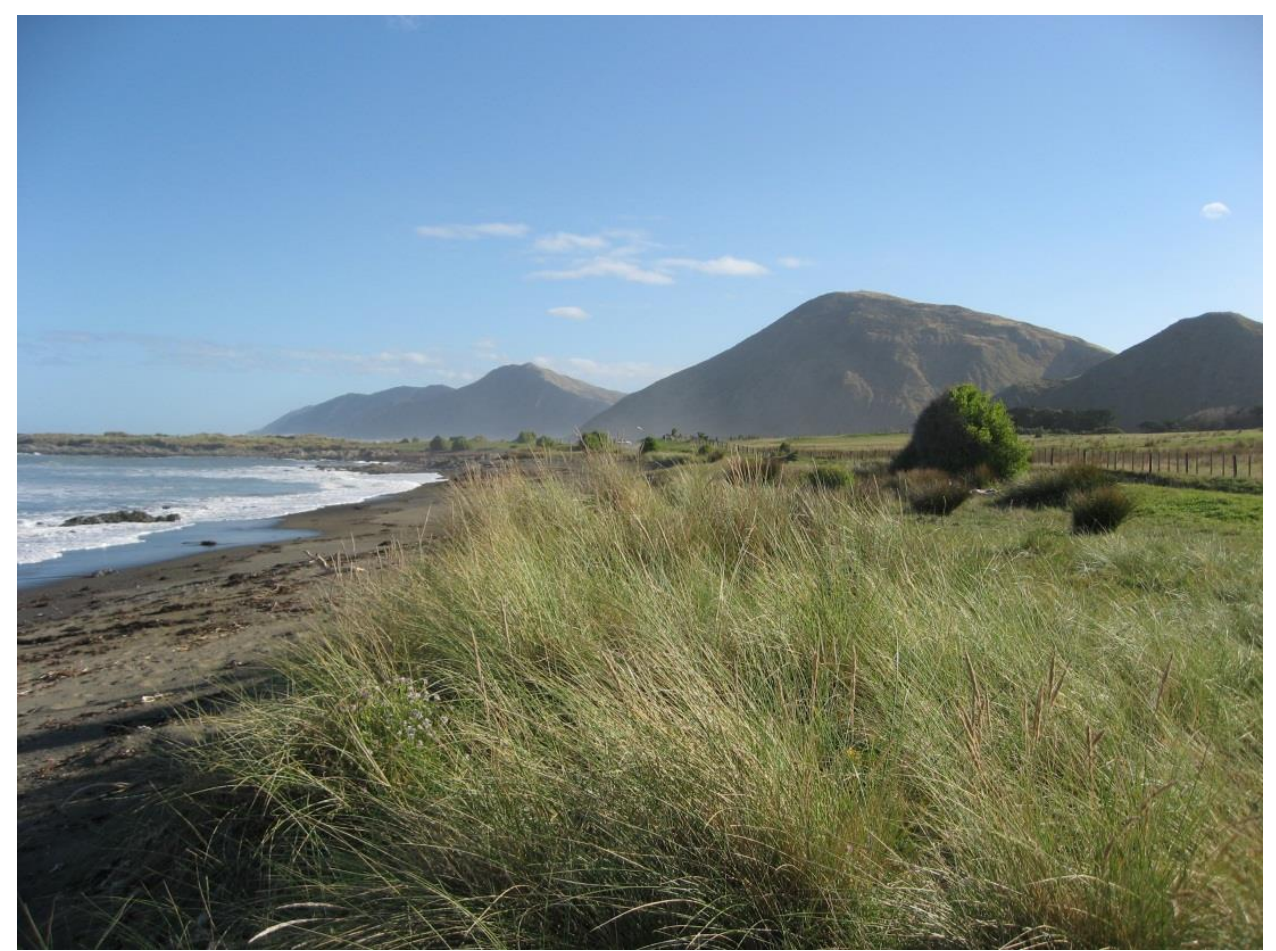

FIGURE 8: PHOTO OF THE SOUTH WAIRARAPA LANDSCAPE: AN IMPRESSIONIST VIEWPOINT

A post-Easter family holiday break on the Tora Coast, South Wairarapa, New Zealand in April 2012. This is a majestic place, where the natural world is beautiful and unavoidable; for example, the dew on the grass in the mornings, the colony of elegant brown seals disguising themselves as similar-hued rocks, the variations in light and fast-moving clouds in North Island windy gusts - all delightful and inspiring. (RJ April 20, 2012)

I had brought my research journal and draft of the analysis of the second site visit, and my husband Julian some composition on this short break and we both had a productive, stimulating time away from our usual home environment. I also took a new DVD recording of Debussy's Pelleas \& Melisande, and we watched it one evening. We had previously both seen two productions of the opera in London \& Birmingham very spread apart, in 1978 when students, at English National Opera, and then in 1992, a magnificent production directed by Peter Stein and conducted by Pierre Boulez, which was memorably affecting musically and emotionally. I had also much enjoyed being taught a course 
in French song by Roger Nichols, a Debussy expert, at university, and so revisiting the piece over Easter with Julian (a late-1970s Birmingham University fellow student) was a joy.

That day, I had just been writing something about complexity in the research-practice field as a Site KT theme, and was connecting it with an improvisation at Site FV in which we observed how complex and multi-layered the practice-research connection was in music therapy. Listening to the thematic unfolding of Pelleas was a revelation, Debussy (and the production's conductor) handled their 'complexity of material' in masterful ways - what could I use of this inspiration? As I looked back at the photos I took of the location, some images suggested impressionist paintings (such as Figure 8 above) in the use of the natural world, the wind blurring the colour of the grass, the slight mist in the background. I had a love of Debussy and Satie as a young pianist. I realise now this was a powerful part of my musical and cultural history. I spoke French and had been on exchanges in my teens and visited many times as an adult, enjoying galleries, cooking and musical culture.
Julian and I discussed the inspired presentation of the music and drama of this French production of 'Pelleas \& Melisande'. There was something striking about how the musical and dramatic material was so effectively held together and the meaning of different characters' feelings and motivations conveyed in subtle and powerful ways. Julian described his experience of the conductor employing 'skilful shepherding' of the musical thematic material, really working with the orchestra to colour moments in the drama while the singers told their stories. I thought of how, for me, that 'spotlighted', or put into the foreground, particular feelings or themes in the drama, perhaps while other things were also being presented on stage, but were for the moment receding into a background, as suddenly one's attention was drawn to this special reminder. Perhaps this is a bit convoluted, but we were excited to think how Debussy's music manages this process. Debussy (and the conductor) keeps the whole thing going in the flow of the music, but theme or motif can be emphasised and explored in the forefront, while other aspects sit quietly awaiting their time for consideration. There is also wondrous use of silence, almost as a theme in itself, which frames key moments in the drama. RJ April 212012

In a further conversation in October, we discussed Debussy's process further, considering the use of themes as a particular sort of "economy - a vocabulary for the composer to be able to keep the listener informed about the whole" RJ April 21 2012. Nichols, in his musical synopsis of the opera, writes about Debussy using 'motifs of association' (an interesting phrase for me in the context of this chapter) to provide ongoing commentary on the story and relationships between characters, but he also suggests how subtle is this usage. Unlike Wagner's methodical and very wide use of themes (Wagner "motivised everything that moved or had its being"). Nichols suggests Debussy is quite selective and not especially definite about the themes, there are hints and uncertainties, but the 
listeners are signalled by connection between themes in the music and events on stage (Nichols, 1982, p. 13). Some examples of themes that occur along with appearances of the characters and location are as follows:

Melisande has a short wistful fragment, often on oboe.

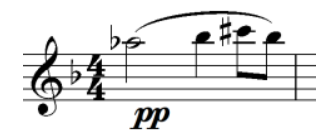

Golaud is accompanied by a more extended idea, with rhythmic urgency (hinting at his agitation and jealousy of Melisande's attention to Pelleas).

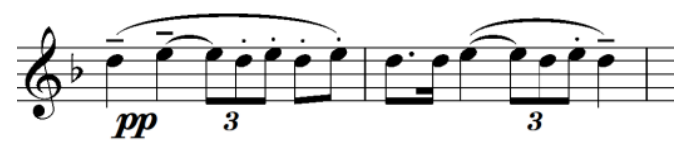

'The Forest' has an austere and solemn low-register theme that opens the opera.

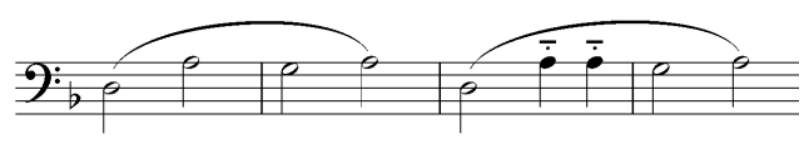

$p p$

Pelleas links with a quiet animated little melody outlining the interval of a third and then a fourth.

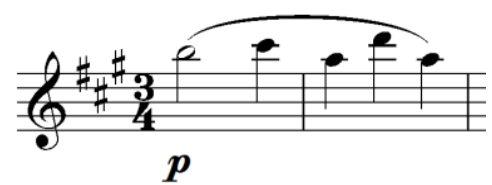

The listener/observer has to make up his or her own mind about significance, but the music plays out relationships and connections of importance.

So how does this relate to the current chapter? At a simple level, the combination of practice and research in the music therapy is acknowledged by all this case study's participants as being highly complex. One lecturer-researcher said "It's so complex we barely know what we are doing” (Bella Site KT) and this is echoed in many conversations I had through the course of the research, (see 1.1.3). The metaphor of Debussy's opera being held together by skilful shepherding and planning of the music and 'motifs of association' that punctuate and provide meaning to aspects of the experience seems a promising musical analogy for how educators might be approaching the challenge of managing such complexity. The themes I have selected in this chapter also are somewhat tentative and fragile, perhaps a little indefinite in quality, which also seemed to capture the spirit of Debussy's 
music. The rest of the chapter is devoted to outlining aspects of the complex layers observed in the sub-themes and also noting the ideas and responses of educators, researchers and students in the field to how the complexity is managed in their environment. In the manner of the opera, the motifs which have been developed from the thematic analysis in this chapter help me to understand the complexity, and to keep a sense of the multiple layers of knowledge and understanding to be fathomed by students in training. The motifs developed, from the data, involve feeling responses (anxiety, excitement, confidence) musical process, strategies to organise and 'balance', and a sense of the whole. Keeping close to music - the mistress of multiple layers - seemed a good way to hold the whole in mind.

\subsection{Core theme for this chapter: Stage 3: 'All these meta-layers'}

The following is a condensed description of the core theme for this chapter. The core theme is divided into sub-themes, articulated in the next section. These will be expanded and illustrated by turn, in a similar way to the previous presentations of findings, as this chapter progresses.

\section{Core theme: All these meta-layers}

Debussy's motifs of association

This theme was concerned with participants' perceptions of the complex layers of understanding that make up learning about the music therapy discipline and bringing research and practice together. Participants alluded both to the anxiety surrounding this complexity for students and others, and the excitement that involvement in such a rich environment brought. Finding confidence (for oneself and in the work) was a needed process to survive difficulties. Providing time and strategies to absorb and manage the complexity was noted, and participants observed the modelling of tolerance and coordination of such diverse strands by mentors. While complexity was strongly acknowledged, simplicity where it could be found was valued. 


\subsubsection{Layout of sub-themes}

This third and final section of findings incorporates seven sub-themes (or 'motifs' to use the Debussy analogy) which are pictured in the following map. In a similar way to Chapter 4 and Chapter 5, each sub-theme will be introduced in turn in the rest of the chapter, beginning with a short description in italics which identifies the material brought together in the respective section, followed by the illustrated expansion of the theme including quotations from participants and my interpretations of the meaning or significance of the material in relation to the research question. Quotations from participants are shown in italics with line numbers for longer quotes. As a reminder, Appendix 2 provides a list of all participants and their roles and location in the research for the reader's reference.

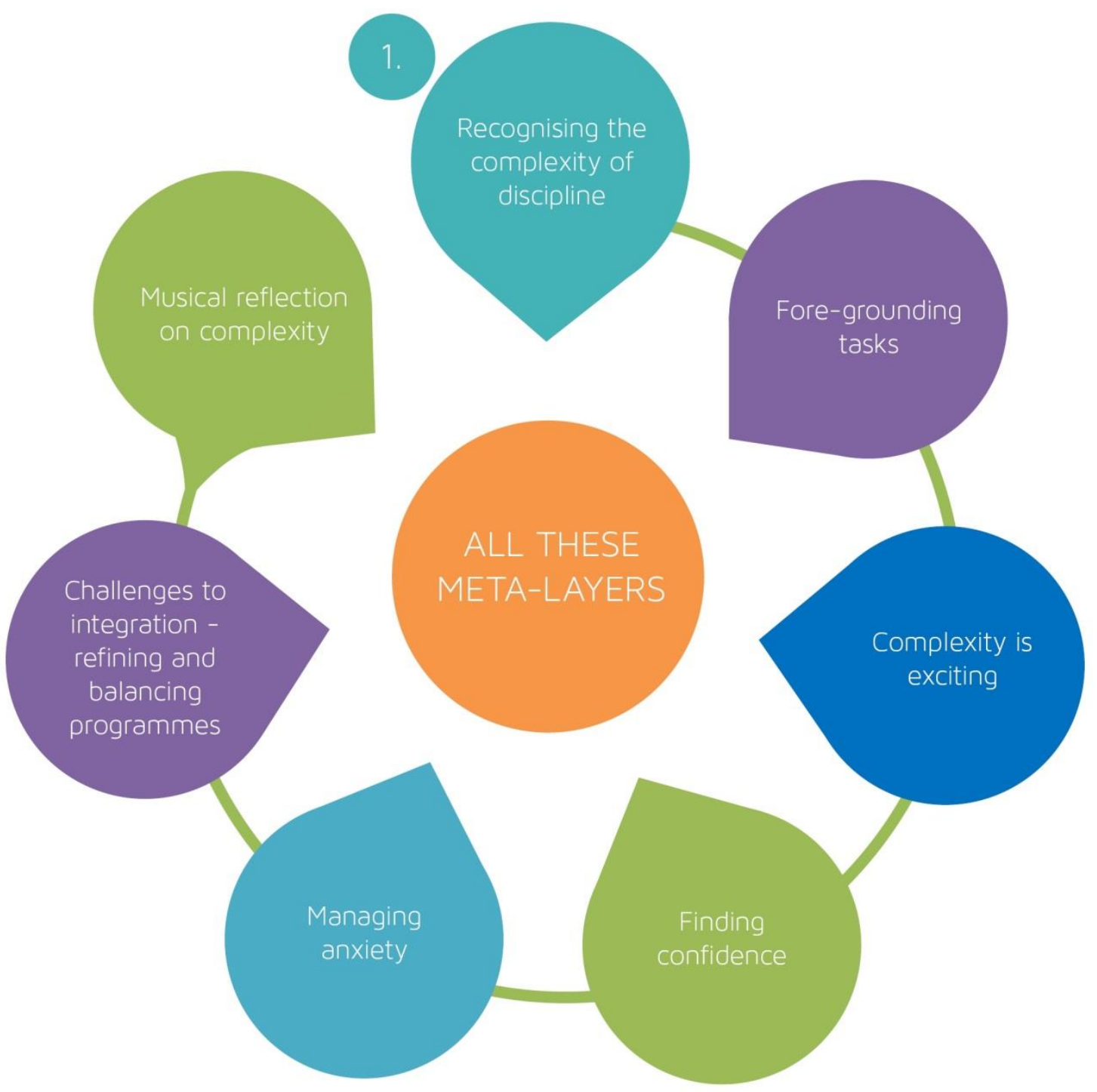

FIGURE 9: MAP OF THEMES FOR CHAPTER 6 


\subsubsection{Recognising the complexity of the discipline ('many layers')}

Description of sub-theme

This sub-theme was concerned with participants' perceptions of and reactions to the complex layers of understanding that made up (learning about) the music therapy discipline and bringing research and practice into connection. Student participants reflected on the challenges of keeping the many different skills for practice and research 'together', and lecturers on how very difficult it was to understand the complexity of patient work, together with myriad meanings of 'research'. Paring down tasks, simplifying responsibilities was a valued role of lecturers and supervisors. Being able to make connections (parallels) within and between the complex worlds of research and practice was perceived as helpful by some participants. While complexity was strongly acknowledged, simplicity where it can be found was valued.

To keep the chapter's metaphor in mind - the analogy of the opera with a complex web of motifs , orchestra, text, dramatic story, characters - this sub-theme presents the 'whole opera', the participants' awareness of the complex whole that makes up education about the discipline.

A junior student at Site FV, and three lecturer/researchers in Group-BA acknowledged the way that students uncovered and have to learn about the complications of music therapy practice. The Site FV student had had experience as a care worker for adults with special needs, but training in music therapy revealed new layers of understanding of the complex issues he was dealing with: “...the more I move through this course I begin to realise that there is actually a lot of hidden... stuff underneath. And again it's stuff that people may not actually... have awareness of." (Patrick 226-229)

The three Group-BA three lecturer-researchers had an animated and often amusing conversation about the challenges of combining research with this many-layered learning about practice. The conversation reached a cadence with a kind of explosive revelation from one programme director about the level of complexity practitioners work with, and that students are thus expected to relate to:

But you're asking the students to do two things at the same time, like to know that they're in this profession - they're learning about how to become something, at the same time, they're learning about how this profession is researched.... Not just the doing of the work, the relating to the client, which is exceptionally difficult in music therapy! .... It's exceptionally ... it's, it's, ....I mean I can't say it's hard, but its difficulty is around its complexity. You 
know when I'm meeting people at the conference, ${ }^{28}$ and you ask: 'Well who do you work with?' No one works with just easy people (strong laughter from Group-BA). People work with such difficult people and one woman the other day said 'I used to work with these extremely difficult people ... and then I realized, they're just extremely difficult so now I work with these people' ... and I now I thought - They're extremely difficult too ...!

(Hannah 371-385)

Awareness of the complicated web of work that people were involved in teaching and learning about music therapy (practice and research) came through in subtle ways in the participant communications shared during my visit to Site KT. I sensed people's commitment and enjoyment of their work at all levels, and essentially the team was involved in the challenge of getting things done in manageable systematic ways. Nevertheless periodically in passing there were perceptions that students and staff were involved in an intricate jigsaw puzzle of learning, and sometimes there were feelings of frustration or uncertainty communicated about how best to tackle this. There was also 'relish' and enjoyment of it, which comes a little later in 6.2.4. (I think I needed to be cautious about the first interpretation, the struggle to manage the complexity, I would tend to empathise with this position and so I am aware of trying not to force the data in this direction.)

Towards the end of her interview, the senior student observed that there are "so many parts that you need to be thinking about" as a music therapist in training, and dividing your time the number one challenge to which she and her class mates had to respond. She relished the later possibility of $\mathrm{PhD}$ study when she might be able to focus just on one area and "really get absorbed in that":

...you've kind of got your research going on, which feels very different to going home and learning songs that you're going to sing with the kids the next day at placement, or, you know, all those sorts of things, I do feel like we have to jump between a lot of different skills that we're learning all at the same time... (Abby 784-788)

In my research journal 2008, I experienced a vivid example of student's urgent wish to focus on one thing, but this time it is the clinical practice she wanted to spend time with. She was fairly exhausted by the rigour of research studies and could not wait to get back to the simplicity and personal focus of music therapy practice at the end of the Masters' degree.

At the beginning of a supervision with $G$, she just let out a little 'cris de coeur'. This was really unusual for her because she has been very focussed on her research and worked hard in an uncomplaining way. It was something to the effect of 'I've spent so much time thinking and planning this research, ethics, literature, writing up that I've got very little left for concentrating on the practice'. I think she meant something about losing touch with it-

\footnotetext{
${ }^{28}$ XII World Congress of Music Therapy, Buenos Aires, Argentina.
} 
academic process had taken her too far away. ... Conceptualising and musical practice can seem like different processes. G certainly feels this currently.' (RJ $8^{\text {th }}$ December 2008)

The junior student at Site KT appreciated having been able to choose a simpler cleaner study for her final Masters' dissertation, where her role was less complicated and more defined. Her supervisor helped her focus on the important skills she needed to learn at this time in a supportive way. She did not need to do everything at once, and this opportunity allowed her to concentrate on her research task, not trying to conduct clinical work as well. The supervisor suggested that she save her clinical topic for a later $\mathrm{PhD}$ subject when there would be more time for ethics applications, complex arrangements with placements etc. This paring down of the task, highlighting the important elements of learning for this student at this time seemed to be a really crucial part of the supervisor-teacher role:

...the short amount of time we have with this (dissertation) and the hoops that I might have to jump through for the ethics, and also the workload. I'm just thinking very practically in terms of next year and in terms of I know the placement, the placement subject will be huge at the hospital. You have to do a minimum of thirty days um placement and also the final placement has got to be an independent placement for me, so that's going to be a lot of work for me too. So I'm kind of thinking in terms of juggling everything that spirituality topic will probably be an easier one to conduct... (Naomi 239-246)

When I was involved in the music improvisation session with Naomi as the only Site KT participant available to attend (musical vignette at the close of Chapter 3) we had some fascinating reflections on choice- making, and her experience of feeling empowered to make good choices for herself. The music- making focussed her on making active choices in music and in research. She noticed that she was not being persuaded by the team, she was finding her way. But perhaps what was communicated by some students in this study was how to choose your focus, how to keep the tasks in manageable order while you learn? And how would lecturers and the course structure assist?

One lecturer at Site FV had an interesting way of presenting the complexity with a different idea about how it might be experienced. Instead of the 'many layers' being a problem, she saw the complementarity. She emphasised the ability of being able to work between and across the layers as being shared processes in clinical practice and in research (certainly qualitative research). If you learnt to analyse and reflect and evaluate in music therapy practice, you could transfer this to your research.

I think being prepared to rethink ideas and rethink /unpick intuitions and dealing with the complexity of a situation, acknowledging there may be a number of different perspectives that 
need to be balanced. All those I think are common to clinical practice and research practice. ${ }^{29}$ (Anna 270-273)

\title{
6.2.3 Foregrounding tasks (as in Debussy's motifs of association) as a strategy for dealing with complexity
}

Description of sub-theme:

\begin{abstract}
Participants identified how certain tasks were brought into the foreground at different periods in music therapy Masters' education to assist learning and to help manage the complex practice-research environment. This theme had a particular relevance to the function of motifs in the opera outlined at the outset of the chapter. Educators chose to put into the foreground some aspect, and give space from others (as in Debussy's score where we become especially aware of a particular motif, texture, colour and sound from the orchestra to emphasise meaning). A variety of strategies for 'foregrounding' were described by the music therapists and students in the study.
\end{abstract}

The simplifying of the tasks, and foregrounding of one thing at a time was a strategy observed and highlighted by the senior student at Site KT. She reported on a conversation with a supervisor where the staff member has said "Oh, so now you're a real researcher 'cause you're not doing the music therapy as well," and she suddenly realised that it was helpful that her role was simplified: "...and I was like, "Oh yeah, I'd never really considered that it can be quite beneficial to come in and just sort of step into that researcher role rather than have to grapple with the complexities of 'these are also your clients." (Abby 527-529)

Two programme directors in Group-BA from Europe and USA identified two different strategies for bringing to the foreground particular processes in research-practice learning. One of these was to offer a research learning assignment where the students developed a project and research proposal based on a hypothetical topic (but that could happen in real life practice) so they went through all the necessary processes and developed their thinking and concepts, but did not undertake the study. The practice was in the background at this point. Both lecturers had tried this, and found it useful to prepare students for following 'real' projects. A second strategy was to focus a final research assignment very particularly on the process of writing for journals, and the task of presenting work for publication, (rather than the process of writing up a thesis for the university)

... the way they write it up, that's not a thesis, they choose a journal and they prepare, their findings as a journal paper. And then they submit it to the journal, so that along the way we

\footnotetext{
${ }^{29}$ This quotation is also referred to in section 5.2.7, with regard to critical thinking.
} 
teach them a whole process of how to read the journals, and how to understand what a refereed journal is, how to present to a refereed journal, what you might get back and then how to respond to that....' (Hannah 348-352)

Perhaps this was a different sort of 'spotlighting' but it created a strong connection with what students read (and how to base their research within a body of knowledge) and what they produced in their university assignments had a real-life practice relevance and the traditional focus of a Masters' thesis (the usual research stepping stone in most disciplines) was in the background or superseded. This was an example also of a specific integrating strategy on the part of the educator, devising a task that brings the allied health practice world and the learning process about research into close association.

Reviewing documentation of course modules at Site FV and interviews with clinical and research lecturers revealed some interesting 'highlighting' strategies to particular research and practice skills that fitted with the particular strength of location within a health research rather than music department. One particular module discussed by the team concentrated on 'evaluation of clinical practice', and included various approaches to audit of clinical work, developing evaluation strategies which could then lead to research. The module was building on a generic first-year module for the health faculty on evidence-based practice, and provided students with example strategies for creating 'evidence'. One lecturer said:

...what we have done is try to reduce the scope so that the people will produce primarily evaluative studies. People actually aren 't doing research on the Masters' now they are doing evaluations, service evaluations, which is much more practically relevant and may be very useful in job creation. (Anna 349-351)

The modules were still being refined and worked on at the time of my visit in 2010, but students that year were undertaking two assignments for the module, one a critical appraisal of a method to evaluate their practice, and second a musical analysis of work drawn from practice. In each case the work related directly to their experience with patients, but isolated a particular evaluation task, rather than engaging in a full research project. The complexity was thus reduced and one aspect could be examined and 'rehearsed'. It was notable here as in Group-BA that lecturers had an eye on making the assignments relevant to future work as registered practitioners, by encouraging familiarity with clinical audit. Integration of research and practice was observed in both examples.

Another different way of actively simplifying the work that students didwas described in detail by another Site KT researcher \& clinical supervisor. Instead of taking away the clinical component, the student and supervisor worked together on building clinical record-keeping which became a form of research, dovetailing the clinical and research activities into one thing. (In the Pelleas opera analogy, this could be seen as both motifs being superimposed or 'played together'.) This streamlined the work 
done on placement and used it as a basis for the research activity. The supervisor noted that she had to find a willing student who was interested in this but how valuable that joint process became, for building clinical understanding and research-wise for finding a really relevant research tool for them both as practitioners.

...when we thought of writing this, there were prongs to how we thought it could contribute, or at least in my mind and the student agreed. And one prong was looking at (a clinical challenge - how to behave on placement), the other prong was a method, a research method and what was emerging for me was ways of thinking about how research practice was done. ... that is, you can research your own practice and you can also be working as partners - in researcher/practitioner partnerships - where you help the practitioner to research (their own work) ...' (Alex 578-585)

(This example was also coded as an example of the inspiration of collaborative practice in section 4.2.7)

The approach described above from Site KT was complemented by another process initiated in Group-E, which could be considered as a kind of integrating attitude to the whole curriculum. As in the previous example, linked to the musical frame of Pelleas, it could be a kind of superimposing of motifs) Group-E's interesting variation on the integration of teaching approaches in practice and research, here viewed them as one and the same thing. One of the researcher-lecturers outlined their approach not to teach 'research skills' so specifically as a module, but weaving the idea of a curious or researching approach to practice throughout the courses taught from the outset of training:

[We try to have] ... let's call it a principle of reflective, integrative practice that then refracts through the different skill-sets. So that might be personal assimilation, that actually you know how as a person with your own tendencies and qualities, that you've changed how you see yourself and how you're able to engage in the total work (working with people, working with music, working with ideas, working with critical thinking)- how that goes? Then, in terms of tacit practices that are involved with each of those. Then involved with actual specific thinking skills, and how that is one ongoing flow, really (Eddie 446-452)

Lecturer Quentin added to this by emphasising that the aim was to really encourage students to "actually use the academic seminars as a place to explore something".

There were some other solutions that this team demonstrated, for example:

a) Organising the order of the curriculum so that something was in the foreground for a period. (Bella, Helena, Beatrice) 
b) Making the research assignment shorter, more focussed and timing it not to coincide with other (clinical) elements too much (Beatrice and Helena)

However the senior student also noticed that perhaps it was valuable to practise negotiating the multiple layers:

I guess if it's part of the profession then probably having a course that makes you do that sets you up really well to do it. We're probably, by the end of the course we'll probably just be used to doing all those different bits and pieces that probably are part of music therapy work anyway, so. (Abby797-801)

She also recognised that her lecturers modelled the management of this complexity with their energy and interest. (If they were managing it with excitement, why not the student?) What the staff members were passionate about created a particular focus and a starting point and "...you just kind of hook onto that enthusiasm I guess". (Abby 941-2)

\subsubsection{Complexity is exciting.}

\section{Description of sub-theme}

Participants often emphasised the complexity of tasks undertaken in the descriptions of the content of projects that they had chosen but did so in animated ways (including interest and detail and tone of voice). They mentioned the multiple layers and rewards together, and it seemed as if the complexity was what intrigued them and kept them involved. It also seemed to be a particularly significant aspect of the choice of topic or project for participants.

I found it compelling and stimulating to observe that perhaps paradoxically for particular members of the staff team at Site KT and at Site FV it was (at least in part) the complexity that really intrigued them about the music therapy discipline and particularly their attitudes and approaches to research. There was so much to find out about and there would always be a place to contribute to knowledge. The passion that was captured here also related this theme back to the content of Chapter 4 'Being on Fire'. As noted at the beginning of this chapter, one Site KT researcher-lecturer said with both intense seriousness and pleasure: “... what we do is so complex that we barely understand it..." and this created a huge focussed imperative for the discipline as a whole: "to at least explain why you think you're doing what you're doing." (Bella 489-491)

I think this latter idea is the heart of the chapter's theme. Trying to negotiate our responsibility around this essential feature and 'predicament' of the discipline, both as individual members of a profession, and as mentors for students, remains the central puzzle of my thesis. 
What I find inspiring about the journey of this research is that there are all manner of creative solutions to the mosaic of complex strands, and teachers find ways that are suitable for particular students for particular client groups, for particular institutions, and build strategies that work to steer a path through the jungle. The other data sources (focus groups/site visit one) have alternative solutions equally plausible. (RJ $2^{\text {nd }}$ June 2012)

One very experienced lecturer participant at Site KT described in a specially animated way the indepth complex full-time study of her first student internship (three months intensively on a long term ward and three months in a therapeutic community), and her delight at coming to music therapy through a research interest, (Beatrice 62-65). Another clinical teacher at Site KT, who anticipated she would be undertaking a PhD study in the future said with relish “... it's got to be a really humdinger question" and one that "really engages me on a lot of levels" (Helena 492). It was important that it would be thoroughly absorbing and so she would wait to find the right topic. With a similar spirit in mind, a lecturer at Site FV reflected on her own project and her tendency to go for challenging issues, as that was what she has found stimulating.

If something's difficult and it's a challenge then I do tend to get a bit hooked into that. So I was quite excited at the idea of looking at whether non-verbal people could also directly influence the research. Or the complexity around that... (Anna 180-183)

I sensed that there was a strong creative drive for these experienced professionals, they were not just giving themselves a hard time, but genuinely inspired by the unsolved questions, the challenging topic and the uncovering of something new. Two other clinical supervisor/lecturers at Site FV also emphasised a similar sense of tenacity and involvement in their research experiences. One (also referred to in 4.2.3) recounted the value of being 'stretched' to her limits and managing something that took all of her focus as being a very stimulating experience for her and the other relished her sense of 'enjoyment of a challenge'.

Researcher Eddie in Group-E linked his own excited devouring of reading material and input about a new and stimulating research topic as a young researcher with his account of the animated unfolding of pioneers' work in the music therapy field, developing and documenting practice. It seemed that there was a connecting drive (for pioneers and for himself) to explore the theory in conjunction with the practice, and I sensed from him a regret that perhaps the strands could easily get separated in the current evolution of the discipline. The role of researcher-educators, in Eddie's perspective, could be to model the two strands and to keep them in close connection.

Site FV lecturer-researcher Anna spoke in a vibrant way about revealing to students the excitement of their multi-levelled thinking. She was discussing more mature students who don't necessarily have much confidence in their academic capabilities, - their attention was focussed on the placement 
documentation, "where their intelligence is very focused and it's not particularly conscious or worked out" and she observed that, with supervisor support, they find this exciting way to embrace theoretical and conceptual work.

So in a way, maybe with both clinical supervision and research - teaching it's trying to make people aware of the value of the complexity of their thoughts, and that they can actually break them down and articulate them. And integrate - not necessarily break the original sense down (41:46) um either do that and bring them back together again, re-integrate them, or just find a way of showing the different levels of understanding that they're working with. So I think it's often there in the person. (Anna 377-382)

\subsubsection{Finding Confidence}

\section{Description of sub-theme}

Participants talked about the ways they gained confidence and the abilities required to go forward with conviction and manage the complex environment of research and practice. The process of establishing self-belief and a sense that the idea or project was worth pursuing, carried the person through periods of challenge and difficulty. The underpinning from supervisors/ mentors was implied or explicitly mentioned by participants.

The imperative to instil confidence and the experience of gaining confidence was referred to across a number of participants as they describe the experience of negotiating research and practice. The Site KT students gave active examples how it was for them experiencing being at a mid-point in training; for example of finding their feet in the research world and the clinical placement. One student brought together the idea that research was very challenging but she was enjoying it because it was supported.

...I do think it's very demanding but I've really been enjoying it. Especially having that oneon-one time with [my supervisor] and learning actually in-depth how to ...go about doing some research. (Abby 256-258)

The newer student at Site KT identified that confidence to engage in research was greatly assisted by her previous research experience as an honours student, where she conducted a related study about people's experience of music in everyday life. Previous training and knowledge clearly increased this student's ability to engage with the research component of the degree. (Increased input to research in undergraduate courses seemed to increase student preparedness for research at masters' level perhaps). 
A senior researcher in Group-BA reflected on her experience of teaching with a two-tier level of music therapy education, 4-year Bachelor of Music Therapy as entrance to the profession and 2- year Masters' (and then on to $\mathrm{PhD}$ ) to develop higher research skills. While she was listening to the recent graduate in Group-BA struggling to come to terms with the huge time and absorption challenge of a 2--year entry level Masters' - she felt that more time enabled students to be just more clinically confident.

A researcher-lecturer at Site KT connected the growth in confidence to the analogy of learning a new language - it includes the acquisition of vocabulary and familiarity with the 'grammar' of research. When students acquire these basics, hopefully they can go ahead into the new 'country' and make themselves understood and do things independently for themselves. Another lecturer, Helena (this time of clinical practice) also noted the importance of enough time spent in the clinical/practice space. She acknowledged that the required number of practice days was regulated by the professional body and national registration authority, but thought that the level was rather low and observed slightly wryly that she kept "bringing up the fact that I don't think it's enough" and the students who happened to add an extra twenty days (160 practice hours) to their total had:

... just another layer of confidence going out into the workforce. They're a little bit more comfortable with their skills and they're a little bit more grounded in their clinical work. (Helena 536-538).

For this participant "it is a juggle" to manage the integrity of the training programme - "I've got the integrity of their clinical experience foremost for me" and her colleagues had "also got the quality of their research experience in mind as well". She acknowledged that they had to experiment to try to maintain the balance between the two, and so "we tweak" she confessed.

A fellow participant added another layer to this dilemma. The aim as teachers was to send students out informed and aware, and we discussed the issues raised by including research in some detail. As observed above, she was on a mission to help students acquire the research language and success gaining a Masters' qualification also enforced this. She was clear that the research was essential, however she was worried that perhaps it was only the strongest students who gain confidence. She was wishing it would be for everyone when she began teaching, but experience left her with a few nagging doubts:

'...they're really proud of having the Masters'. I think that gives them confidence which is what I wanted to come back to before what I was thinking about, was that really a phenomenon which I perceive in our ... part of the world in music therapy training, is that people come out kind of not as confident as I would like them to come out. And my aim, one of 
my early aims when I came here was to address that, but I see that it's not actually that easy to do...' (Bella 405-411)

This built on another concern she had monitored earlier in the interview, observing that she really appreciated students' research literacy that was developed by the inclusion of research in the curriculum 'but the thing I don't like is how stressed students get by it. (Bella 361-363)

One answer was provided by another Site KT researcher-clinical supervisor in quite a pragmatic way. She acknowledged readily the value of her mentor who encouraged her "to be an independent thinker" but she ultimately thought that it was the beauty of doing the work itself that made the difference. We are all pioneers she said, those of us who "stick at it". The confidence came from doing it regularly and being inspired by what music does:

...it's the work. It's the day-to-day being out there and seeing what music does that has kept me at it and kept me wanting students to know and to learn and to think and to be creative in their thinking... (Alex 392-395)

A similar inspiration through practice was observed strongly at Site FV (as noted in Chapter 4).

Paloma, recent graduate in Group-BA indicated that her confidence was aided by the physical object of her Masters' thesis, which she could return to as a completed achievement and 'offering' to the profession, which connected with Bella's viewpoint above about student pride in the Masters' degree:

...when I got to the end, I had this book and I could hand it over and I could feel like I contributed something. And I think that part of the research is really important for ... emerging and to becoming a professional. (Paloma 474-476).

\subsubsection{Managing anxiety}

Description of sub-theme

The management of anxiety was discussed in varied ways by the participants in all data sources. The variety encompassed 'becoming a therapist' and managing the uncertainty involved with this; the challenges to having enough time and to keep focussed for students; and the 'student' anxiety about performing and delivering their assignments (and of course, a combination of all these issues in the student experience). The debate also touched on normal life-giving anxiety felt prior to making a decision, and neurotic 'stuck' anxiety, which prevented you doing anything. 
Group-BA developed an extended discussion about the anxiety students have about the pursuit of practice and research, and various strategies to promote confidence explored by different programmes in music therapy were shared. Zelda, researcher-lecturer in this group did however observe that anxiety was probably a natural state of the student therapist and really to be expected in the training process. She focussed on anxiety about the clinical practice as an example, but reminded that confidence to manage the anxiety and strategies seemed to be an important skill to gain on the training journey. The junior student at Site FV embodied the idea that Zelda raised, describing his own learning and experience and his hopes for the future alongside managing his doubts:

\section{There are aspects of me that really want to make a huge difference and actually offer a} contribution that will change perspectives. But at the same time I think it is what you've said. It's actually having doubts on my own capability I suppose actually to be able to do that competently. (Patrick 330-334)

Site KT senior student Abby talked about shared anxiety amongst her own student cohort, particularly experiencing this towards the end of the second year of training when dissertation deadlines loomed. She expressed her group's shared impression of the need to reduce and limit what they do (they do not quite know how, as everything is important). This topic was explored amongst the other sub-themes of Chapter 6 where the complexity of learning is identified and analysed by participants.

Finally, a delightful irony was captured by one interviewee, suggesting in one-and-the-same-sentence both that she was confident, and that her confidence was eroded, and I wondered if this was a really interesting feature of therapy courses, that actually our professional confidence comes when we 'sort of know' that we do not have it all neatly packaged and clear. When we are paradoxically less confident about what we 'know' we are more able freely to acknowledge ambivalence and uncertainty? One could observe this as a truly reflexive comment.

I was confident, I was always confident, I was shattered by the course though, when I left the course it took me two years to come back to practice because I was so kind of, my confidence was so destroyed at that point. (Bella 508-510)

\subsubsection{Challenges to integration - refining and balancing programmes}

Description of sub-theme

Participants identified a variety of issues that challenged research and practice working smoothly alongside each other. The question of how much time should be spent with particular areas of the curriculum and how attention and time could be balanced fairly 
across essential tasks and areas of knowledge was explored across all the data sources. Some difficult experiences were shared and it was acknowledged by participants that the institutional context can inhibit or affect the ways that research and practice co-habit.

The reality of the effort to bring research and practice alongside clearly at times brought challenges and problems to the programmes that participants were involved with. My prejudice as a researcher was to assume that the integration of research and practice must be a good thing. It was embedded deeply in my research title. However there was important and interesting data collected during the research process that indicated that the coexistence of the two within a single programme could at times be problematic. Almost all participants had something to contribute about potential challenges.

Clinical lecturer Helena from Site KT who acknowledged that she and her colleagues were in a regular process of 'tweaking' their programme to allow for practice alongside the research (in section 6.2.5, about finding confidence) expressed a concern that was repeated a number of times in GroupBA. The three experienced lecturer participants in this first focus group acknowledged that in their own histories, they had fully concentrated on practice first, and this had allowed them to grow and develop their therapist understanding. Introducing research had the potential to take significant time away from that development. Another Site KT lecturer recognised that there were always practical challenges about developing good experiences out in the clinical placements, and that poor relationships with supervisors could affect people's progress there. She was frank about the difficulty in creating good matches:

...so it's not always good, in fact I'd say in less than $50 \%$ of the time those second year placements where you're starting to assert yourself and your personality, the chances of that matching with your supervisor in the second year are fairly small... (Bella 623-626)

If the student was engaged in research about this placement, there was extra potential stress for developing ideas and concepts about the work, and Bella recognised the challenges for students and staff. A further instance of student stress was raised by new graduate in Group-BA (discussed in section 4.2.7). Paloma drew attention to the stress she and her colleagues experienced with preparing ethics applications for their research, and this developed discussion amongst the focus group participants about how relationships need to be developed carefully with ethics committees and the time this takes, but also the value gained.

During the Site FV visit I felt privileged as a researcher to be allowed to talk with members of the programme team at a time of change and difficulty and was grateful for their openness. One could sense the 'trial by fire' experiences that had affected the department, in the introduction of new research modules using very different approaches to usual learning practice for the department. There had been excitement about sharing skills in an interdisciplinary way, but the teaching was also being 
borrowed for expediency and economy from another discipline (under some management pressure) and this was not necessarily a good fit.

Previous analysis of the data indicated a clash of culture between a medical approach and psychological therapeutic approach to treatment and research, and one participant identified differences in what 'medical' and arts therapies' researchers would look for in student work. She cited examples where 'intelligence and creativity' were not understood in a project and were thus ignored:

... if somebody is able to produce some kind of very complex hypertext which may have some visual content and some auditory content which illustrates complex relationships very beautifully and very clearly and that is somehow disregarded by a marker who is not familiar with that kind of text, then that seems to be wrong...' (Anna 475-478)

Two other participants indicated that they experienced low confidence about the pursuit of research, one in anticipation of a future project, and one in retrospect about a completed project. For the first, research was associated with academia and with a sense that relationships with people was a personal strength and but that research was outside his natural skills. For the second person, the hindrances and problems with delivery of the research modules in the previous year (noted earlier) left her feeling that her own research, which initially enthused and excited her, was a dangerous and fraught area. It was still something "I would do again" - but her confidence had been eroded. She was also realistic, but I had the feeling that more supportive supervision would have helped on many levels

... if I think about it. I was trying to do something too big and too complicated. And because I was in it, emotionally in it, it was very difficult to come out of that and so I would be saying.... 'simplify, simplify simplify'. (Hope 346-348)

Other points not observed elsewhere in the findings regarding the challenges are as follows:

Group E also noted inconsistencies about how the range of students managed their studies in the integrated programme they had developed. One lecturer-researcher suspected that some students with strong academic skills did not always engage fully with their own personal development and suggested that "somebody with fantastically impressive academic letters, [could produce] something pretty dead really" (Kirsty 429). A lecturer at Site KT also shared honestly that her team was continuing to ask questions and trying to balance between how they managed research and practice. She was open about her doubts regarding current practice and felt they needed to keep open to review. Finally, a Site FV lecturer observed the steps her department had made to manage the "clash of cultures' they had experienced with different stances on research teaching. She observed: "The new modules have been re-written and students have tried them and they've been able to make more of it. And we've been able to incorporate and appreciate people's creativity more that way. There are huge 
cultural issues about being seated in this faculty where there are no other creative arts represented, but a lot of understanding about health and social care." (Anna 406-410). Their experience had been harsh, but she felt the benefit of reviewing and reflecting honestly.

\subsubsection{Musical reflection on the complexity of research about practice}

Description of sub-theme

In a musical improvisation and discussion at the end of the Site Visit at Friendsville, one lecturer participant and I as researcher shared an experience of the multiple layers that are created in music therapy training including research. The musical experience itself was also multi-layered and subsequent discussion between us identified features of the music, its instrumentation and expression, and how we felt about working together recollecting research, practice, teaching and learning in music therapy. The 'holding together of diverse elements' was notable to participant Hope and researcher Sarah.

'All these meta-layers'

The title for this chapter comes from a quotation from music therapy lecturer and practitioner, Hope about the music we made in an improvisation session at the end of Site visit FV. The resonance created for us, two music therapists - reflecting musically on the experience of developing research ideas about practice - is offered here as a particular illustration of how music provided Hope and I with a way to 'hold the whole in mind' i.e. the experience of music itself creating integration. There are themes that develop together in our music that could be considered like Debussy's motifs, kind of fragile and delicate, with a range of possible meanings. Although this was all improvised, there is something about the 'elasticity' of music that allows many layers and holds sensuous, purely music, memory based or associative possibilities together in one whole. Of course music can also be experienced as fragmentary and chaotic, but my experience here is linked to the operatic form of the Debussy. It also linked to Debussy's opera in that the music shifted and changed; Hope and I slipped roles between student and researcher and therapist, things were in the foreground and background (as described above).

So, the following vignette is taken almost verbatim from my research journal. I made two entries (as I thought I had mislaid the first) within a few days of each other, between $3^{\text {rd }}$ and $6^{\text {th }}$ February 2010. I fused the two entries as they had emphasised slightly different aspects of the event. 


\section{Vignette:}

\section{Experiencing the cycle of music-practice-student-client-music-therapist- research}

\section{It was extraordinary! It took me right back into the research, the layers in the improvisation. ....the realisation that you were in the research on the same journey I have just completed.... All these meta-layers!'.}

So says Hope as we begin to talk after a sonorous end and long, quiet (15 second) pause to our improvisation together at the completion of Site FV.

We were the only people available to do this music-making at the end of the Site Visit. Everyone had challenges to staying on, and at least one member of staff was a bit dubious about sharing such a group with current students, as it could be quite inhibiting. However the room with instruments was only free at the end of day, and so I agreed that I would still offer the slot in case anyone was available to come. (It was possible that two people might have been free, so seemed worth it). As it stood, Hope observed that she was relieved not to be working with students, as this had been very emotive material we had discussed, having implications for her place and role in the institution and vulnerability around this.

We created a piece for piano, metallophone and temple blocks, and in thinking about what we would do, we were both quite clear about making choices... not vague, or deferential. I moved the piano stool from one side of room over to the piano, and Hope offered that she would like to play the piano once I had done this. A large metallophone initially caught my eye and I suggested that I would also like to play a set of temple blocks, which reminded me of improvisation classes at the Guildhall School, London with Professor Alfred Nieman in 1980 s - the temple blocks were always one of my favourite choices. I suppose I was recalling being a student. We were both keen to explore the idea of a musical reflection on our interview experience.

Hope and I talked briefly, and I suggested that we might take the theme of 'Research and Practice and their integration', but was happy to leave it open if Hope preferred. She thought the title was ok and we just went into music from there. We needed to finish our session within 30 minutes so I had suggested that we play for 10 minutes, then could talk for a further 10, and then round off our time. From my perspective the music was easy to 'fall into'. I wasn't really thinking consciously about the title, but just concentrating on sound moment by moment. I think I started after a pause together, playing a simple interval (a major $7^{\text {th }}$ on metallophone), and Hope responded gently with a right hand chord after a second repeat of the 7 th. It felt straight forward and natural. Hope then weaved a little figure in her right 
hand, a yearning sigh, F natural falling to E. I picked up on this and raised to $G$. The piece flowed and built and as it became more energetic I moved to temple blocks and voice. It ended back where it began with metallophone and piano, Hope a steady presence throughout.

Hope noted - with surprise afterwards I remember - that the music had a very specific correspondence to her research experience. Piano and metallophone had been the instruments of choice in the music she analysed as the central part of her study, so the sound world we made was very evocative of the practice and the research. Various things also reminded her as she was playing and she seemed very engaged and knowing what she wanted to do throughout. I had quite vivid experience of really enjoying the mutual sounds we made as music therapists. I didn't feel particularly responsible for holding the sound together (as music therapist might) and noted to myself the easy flow. Two particular ideas occurred to me in my own experience of the music:

1) It was lovely to play supported by Hope's piano playing. Around 15 years previously I had been her examiner. But here she was now a most capable experienced music therapy improviser and I really recognised how skilful she was in her music.

2) It was also funny to go back to the idea of Alfred Nieman at this moment. Hope was reminded of being a therapist, while I was plunged into being the student! I remember Alfred enthusing to us how important group improvisation was as a tooI was a bit sceptical at his claims at the time, whilst having a very inspiring and memorable time in his classes. I think I was a little bit scared of how observant he was to be truthful. I was twenty, out of the egg, with a lot to learn. He probably knew a bit too much about us from our music.

However this was also powerful for us both, as Hope's description of her research experience during the interview had been very painful (maybe her choice of topic had been too ambitious/ the supervisor hadn't given suitable support, the examiners didn't understand musical process so her findings were not considered at all in the marking she had felt). So this 'revisiting' in the music had proved profound... we discussed this afterwards in our reflection.

The experience during the day with Hope was moving for me - she was very trusting and open, but the reflection during the day was profound and upsetting - she was revisiting traumatic experiences, and that felt a big responsibility. I had wondered if this topic was rather dry and unemotional and perhaps unfitting for qualitative research. My experience with Hope was profoundly opposite to this! I think I was drawing on my 'therapy self' in the interview earlier in the day as Hope reflected on being a student, but then we were kind of revisiting Hope being the therapist in her piano playing and me being the student. I was 
undertaking research in my meetings with Hope, and she was undertaking her reflections about research, and we had been sharing the parallels. No wonder Hope talked about 'all these layers'.

\subsection{Concluding Comments}

This chapter introduced and reviewed the core theme of complexity and multiple strands that characterised the landscape of combining research and practice in music therapy. Complexity was seen by participants as a challenge but also as an exciting process, creating puzzles to solve. They saw considerable satisfaction being gained for the student by managing the difficulties and working them through. Such puzzles could become problematic for students but careful management and support from teachers and supervisors made for worthwhile journeys. It was noted that musicians and artists have particular skills and qualities for managing and holding complexity and here qualitative research methods and artistic process using 'themes' seemed to come together. Foregrounding or spotlighting particular themes at various points in the education process was valued by participants, much as a composer might use motifs in large-scale musical works. Using the medium of music actively to inform and inspire learning within this complex landscape was one personal solution I espoused as researcher in this project. 


\section{ChAPTER 7 \\ DISCUSSION}

\section{Introduction and overview of chapter}

Chapter 6 ended with a musical reflection on complexity and how the strands of experience were held together through music in my researcher thinking. The central task of this discussion chapter of the thesis is to draw together and interpret - in relation to the research question - the thematic strands from the three previous chapters, highlighted and developed from music therapy learners', researchers' and teachers' experience of their masters' educational programmes combining practice and research. The research question and sub-questions were:

How can research be integrated into the practitioner education of music therapists at Masters' level?

- What are music therapy practitioners', educators' and researchers' experiences of, and ideas about, combining research and clinical practice?

- How do members of two contrasting international music therapy training programmes (with varied roles and responsibilities in the programme) tell their stories about research and practice?

- How do the researcher's ideas and perceptions about the topic of integrating research and practice develop and change over the process of the research project?

The major themes and areas of focus concerning participants' perceptions, and the experiences and recollections they shared in their stories focussed on:

- Keeping student practitioner-researchers 'on fire' and engaged in their work by harnessing their curiosity, passion and enthusiasm

- Embodying in teaching and learning, the continual process of change and realignment that is experienced in the music therapy discipline

- Embracing complexity, and considering ways to manage the multiple layers for learning new practitioner-researchers

Reviewing these three chapters and considering what has been surprising and illuminating in the reexamination, I have identified some overarching themes which link two or more of the chapters and also have highlighted a number of additional issues which (have inspired new thoughts) and which 
make some additional connections to topics in the wider literature. These are presented in the following sections 7.1.1 to 7.1.7 as a contribution to knowledge about learning and teaching in the music therapy field and also on a personal level as provision of some overall meaning and sense to my research journey. I also aim to show where there appear to be multiple or complex 'answers' to the question of integrating research and practice, as learning along the way has reinforced the complexity or multiple layers intrinsic to this topic. Links are made to the literature review Chapter 2, and also to additional texts and readings which have been suggested or sourced since completing the findings. The connecting and overarching themes are as follows:

- Creating varied and unique research-practice pathways in the differing programme contexts: 'Research learning' is many different things that vary between contexts; what are the factors and reasons for these differences and how do these relate to developments in the $21^{\text {st }}$-century university and healthcare environments?

- Developing creative solutions and strategies for integrating research and practice: How have educators developed the Masters' curriculum to aid and support the integration of research and practice and to move beyond the competency framework?

- Integrating practice and research learning through an ethical lens

- Valuing and aiming for engaged scholarship: Maintaining confidence and engagement as learners and linking emotional engagement and critical thinking.

- Linking research and practice with creativity: the use of the arts and therapeutic learning as core to research learning.

- Valuing collaboration for students, supervisors, lecturers and outside partners: the notion of practice-research as social rather than solitary endeavour

- Developing an integrated working model for curriculum based on the 'many ways' observed in the research process.

This will be followed by a review of the research approach (section 7.2), including identifying limits of the research method. I end the discussion with a section considering my own learning in this $\mathrm{PhD}$ thesis (section 7.3). Certainly I have been changed by my research, in reflexive connection with Chapter 5, and I have come to a place I did not know or expect at the beginning of the journey, so the surprises seemed a good place from which to embark and my own place in the research a suitable way to end. Kamler (2001) and Lichtman (2013), distinguished qualitative researchers and writers, provide confirmation and encouragement for the critical use of the personal in research, so I am encouraged to include this viewpoint at the end of the study. The summary of my personal learning being engaged on the research journey includes: 
- Being an improvising researcher - is there a place for this?

- Connections with traditional stories and myth. Metaphors for creative endeavour and the growth of skills resources and maturity, which are particularly relevant to the arts therapist .

- Creativity and Quest: The connection between travelling to the unknown (the quest) with the journey of the artist/therapist and with the journey of the researcher. Creativity is invoked here, and this seems a highly most relevant connection between music therapy practice and research.

- The place of reflective and reflexive thinking in integrating research and practice. I did not set out on a reflexive path, but increasingly felt drawn towards it.

\subsection{Overarching themes for review}

\subsubsection{Creating varied and unique research-practice pathways}

One of the central lessons of the findings has been that there are many ways to respond to the challenge of absorbing and weaving research into the frame of practitioner learning, and moreover many ways that lead to satisfying outcomes for students and for the discipline. A broad range of difficulties have nevertheless also been observed by all participants in terms of strains on the programming and length of the training, on the variable resilience of students, on the benefits and disadvantages of working alongside other departments with different disciplinary pressures to music therapy, how departments work with external supervisors who may have different expectations of students, and on the time and skills of staff. It is interesting to speculate how and why it is that different sites represented by the participants in this study have found their particular and contrasting solutions, and how their strategies are helping to develop teaching and learning of practice-withresearch. Also it is valuable to step back and consider how music therapy as an international discipline is responding to the challenges faced by the modern university and neo-liberal influences on education, articulated powerfully by commentators in higher education (Barnacle \& Dall'Alba, 2011; Barnett, 2005), where departments have to be:

- productive in research outputs

- accountable (in terms of performance reviews, increased administration and audit of research)

- responsive to industry-led research and the economic management of research

These factors can challenge considerably the values that educators may have about styles of teaching and about education for the 'professions'. For example, meeting health profession ethical codes where "acting in the best interests of the patient" (MThNZ, 2012, p. 1) may be compromised by a different 
set of 'research-led' requirements. However at the same time, insights about growing students in research-based practice and practice-led research gained from this study may also provide evidence to demonstrate how departments might be productive, accountable and responsive to the modern university environment and integrate practice and research processes.

It could be argued that some settings for music therapy programmes appeared to provide a better understanding of the complex framework of support needed for music therapy practice and research and better allowed for integration. Certainly where music therapist educators were freer to make informed 'music therapy-centred' choices about the curriculum, integration seemed more advanced and more possible. In Setting 2 (Music Therapy Centre) and 5 (Cultural \& Ethnomusicology Dept) for example, the programme leaders had been able to lead the curriculum reasonably independently of Faculty pressures. In the following section it is my task to identify some of the strands that enhanced the possibilities for integration in the programmes considered in this study and to look towards building teaching and learning frameworks for music therapy and other graduate practitioner professions in this area. Being able to consider both agreed values and the variety of constraints experienced leads towards the expression of some theoretical principles.

What has become interesting to consider in reviewing the different strategies described by participants and their programmes in the research is that the strategies have 'grown from somewhere'. They have depended on the culture and context of the hosting institution, on the values and theories of the programme directors, and importantly on the client groups that students are trained alongside. The rich mixture of possibilities has been inspiring to witness and I come away from this study with much wider resources and some shared experience and knowledge of great benefit to our own programme planning in New Zealand. I anticipate that they could also be of use to other educators.

The two figures below Figure 10 (Contexts for Seven Masters' Programmes) and Figure 11 (Contexts and Strategies) outline a number of instances, reflected on by the participants, of the environments for Masters' programmes. In Figure 10, key challenges they experienced are highlighted, and in Figure 11 , strategies for learning and integrating practice and research were outlined for the participants' particular institutions. I was not so concerned with capturing the very specific details in the figures, but to characterise people's experiences of their programmes and outlines of the settings, and the supports and constraints to building their approach. I was struck by the differences in frame, and how often the factors of the setting caused certain sets of decisions, which were then responded to or adapted by the team involved. Obviously the framework is modest; one which reflects on six different institutions offering Masters' programmes (and one offering both Bachelors' and Masters') offered by participants in focus groups and sites, but it was good to see them collected together as I found the differences were encouragingly refreshing. Given the complexity of the challenges faced by staff on these programmes, programme leaders had made confident choices that reflected the strengths of their 
environments, but also tried to keep a balance between practice and research issues. So there was not 'the best way' that I could glean from my explorations, but good fits for various approaches at various times in various places. Nevertheless, some hosting environments did provide limits to the amount of integration possible, and this would need careful consideration in any recommendations made about future practice in the field.

In a general way, reviewing the whole findings evoked the subtitle of Lather's (2006) illuminating article arguing for the necessary breadth of paradigms which have relevance in teaching research in education - as she puts it - 'teaching research in education as a wild profusion' (p. 35). Lather's argument centres on the need for multiple approaches for developing knowledge in such a complex world and the participants in this study seemed to exemplify this - they were getting on with a range of methodologies and approaches that suited placements and varied expertise of supervisors, and the values and interests of students. This is underlined by Lather as a particularly persuasive way of creating 'evidence', specifically as a response to the resurgence of predictive positivist research in medicine and education.

Facing the problem of doing research in this historical time, between the no longer and the not yet, the task is to produce different knowledge and produce knowledge differently... Across the paradigms, students so trained in the philosophical, ethical and political values that undergird knowledge production will be able to negotiate the constantly changing landscape of educational research far beyond the application of technical methods and procedures. Layering complexity, foregrounding problems, thinking outside easy intelligibility and transparent understanding, the goal is to move educational research in many different directions in the hope that more interesting and useful ways of knowing will emerge. (pp. 52-53) 


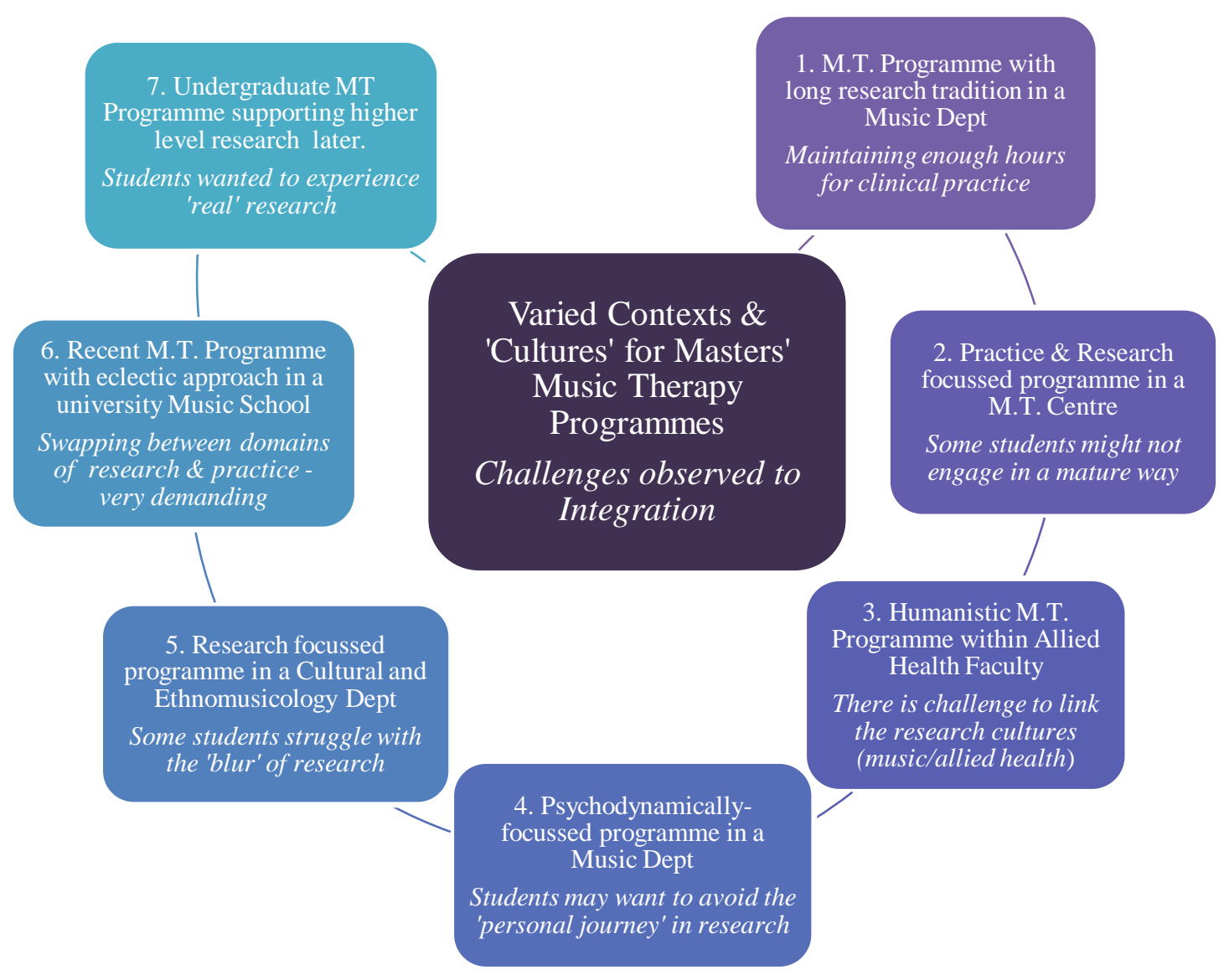

FIGURE 10: CONTEXTS FOR SEVEN MUSIC THERAPY PROGRAMMES AND THE CHALLENGES FOR INTEGRATION

Managing tensions and constraints in the varied institutional settings

Section 6.2.7 of the findings acknowledged the tensions that participants shared in their efforts to combine research and practice for Masters' students and this affected the level of integration that was possible in particular environments hosting music therapy programmes. In Setting 1 (Programme with a long research tradition), difficulties were observed with maintaining enough time for practice alongside the research assignment. This was echoed with a slightly different emphasis in Setting 6 (a newer programme in a music school) where there were challenges also to 'juggle' the research-hat and the practice-hat and to manage the load of clinical practice and dissertation. In both these settings the Universities emphasised the 'thesis' as the research process of choice. This was a regulation that the programmes were required to (or chose to) work with, but possibly is a difficult framework for staff and students to negotiate in clinical disciplines, where students are out in the field.

The research culture of Setting 3, developed in health and social care, was different to the other institutions based in arts or humanities faculties. The programme staff and students were adapting 
their approach at the time of data gathering for this project, following difficult experiences with a research style based in another disciplinary culture of research. It was interesting to observe that this had not been explicit at first, and educators discovered through experience that the disciplines needed different approaches to research to fulfil the requirements of their own professions. In particular, understanding of artistic form and content in the findings of student research raised real challenges of agreement. Music therapy research was not well understood by other faculty members, and methodologies were subtly different. The university setting was heavily influenced by the requirements of EBP and the artist's voice in that context was not easy to articulate.

Setting 1 and Setting 6 (both environments where research was well-established) shared concerns about the 'blur' and anxiety that some students could experience on their research journey. The impression given was a fear that some typical students enrolled in Master of Music Therapy programmes get overwhelmed and sometimes alienated in the research environment and this sometimes jeopardises success and confidence as music therapists. Vulnerable students are a concern for any learning environment but the departments shared some genuine wish to engage and 'hold on to' people who did not naturally take to research, and were prepared to consider that more thinking was needed to respond to the challenge.

\section{Collaboration with external placements, allied health research departments and human ethics} committees

Fruitful collaborative work between the programme and practice institutions (hospitals/centres) was highlighted in Setting 1 (Programme with long research tradition) in Figure 10, significantly in a clinical supervisor/ student joint project reviewing and analysing clinical notes, and in a scheme to pilot practice through a research RCT, through which research a medical team were enthused about the value of the practice. Bringing in expertise from the outside settings of placements as part of the developing research culture of Setting 1, was clearly a sustainable way of expanding the personnel for support of the student study, and building the 'practice relevance' of research undertaken. A common observation about the gap between research and practice in many health professions is that much clinical research does not seem relevant to practitioners, as discussed in chapter two (Stewart, et al., 2012; Teachman, et al., 2012; Welch \& Dawson, 2006). By promoting relevant practice-based research at student level, or, as in a further example in Setting 1 involving a student in a small contributing part of a large scale project of the supervisor, educators may be able to guard against such a perceived gap developing. Lecturers in Setting 3 (based in an Allied Health Faculty) also drew attention to the relevance of their own research conducted in outside practice settings (hospitals, hospices and rest homes) as part of their own research degrees and emphasised the value attributed to it by staff in the practice settings themselves. These features indicate that building research networks, collaboration and support between university departments and external health and education settings 
are a vital part of extending and developing research capacity for music therapy programmes. It also helps practice settings welcome and encourage research and contributes to the requirement for evidence-based approaches in the healthcare or education settings themselves. It is notable that Gilroy (2011a), in the sister profession of art therapy, recently observed the significance of collaboration and liaison in an overview of a selection of research projects reflecting on art therapy practice with children. Gilroy and research contributor Stirling emphasised that such collaboration needs time and careful management to be built, because professionals have different aims which may not be explicit. However, 'when good, effective liaison is established early on and the working practices of all are properly understood' there is good acceptance both of new services, and (by implication) of helpful research reflecting on such a service ( p. 112).

Using the research strengths of other related health departments was featured in Setting 3 in the Allied Health Faculty. Being able to share the resources and research expertise of other related disciplines in the allied health faculty was potentially of great advantage to a typically small music therapy department, and opportunities for interdisciplinary understanding and for saving staff time were highlighted. Nevertheless caveats were also made - perhaps a little similarly to the art therapy example above (Stirling, 2011) - where time and understanding were needed to build collaboration and mutuality. Lecturers and supervisors in this setting carefully drew attention to difficulties experienced by attempting to marry the different 'research cultures'; the real diversity of research practice as exemplified in music-centred studies and other arts-based research required openmindedness and expertise. There was specific knowledge, highly specialised in music, that Setting 3 considered pre-requisite for supervising or examining music, therapy research at Masters' level. A strong recommendation was made for registered music therapists to be responsible for both.

The other widely shared collaborative endeavour featured across the three findings chapters (check) was the building of relationships and shared thinking with Human Ethics Committees of Universities that hosted programmes, and Health and Disability Ethics Committees. This was featured in the planning and execution of the curriculum in Settings 5 (Cultural \& Ethnomusicology), Setting 6 (New Programme in Music School) and 7 (Undergraduate Programme supporting later Masters'), where ethics templates for lower risk clinical research had been or were being established, particularly where there were no active client participants in the research, and students were involved in reviewing case study data, process notes, or undertaking clinical evaluation studies. Participants across the sites and focus groups highlighted that the experience of these collaborations had had mutual and unexpected benefits to programmes, students and the ethics committee members themselves: for example in students learning clearer articulation of their research studies, understanding assent for vulnerable participants, research committees building knowledge of the constraints and interests of music therapy departments (often shared by education and counselling/psychotherapy departments) and the reinforcing of learning about boundaries and limits both as researchers and practitioners. Becoming a 
member of the university ethics committee (a lecturer in Allied Health Setting 3) was a natural and valued development of building understanding of ethical perspectives in music therapy research.

\section{Extended time and reflection provided on undergraduate music therapy programmes}

It was helpful to be reminded of the place of the undergraduate music therapy training (at Setting 7 ) as this emphasised where foundational work with concepts about research, or allowing more time to develop practitioner skills might be focussed. In effect, undergraduate courses followed by a Masters course featuring research provide the benefit of a long period (five years) of dedicated music therapy focus. Also in this framework of dedicated training, it seems that there is less need to be 'integrated' as the separate strands of research and practice can be taught in separate modules, and there is less pressure to be an active researcher as an undergraduate. Just having more time and space to mature the skills of research and practice clearly have special benefits. European and Australasian traditions where music therapy is now most often a postgraduate training can lose out on this benefit in selecting mature personalities who have a regular music degree or other graduate qualification, but have not had the extra opportunity to explore music therapy practice (or be introduced to music therapy research approaches) in a Bachelors' degree.

Significantly AMTA, the American registration body for music therapy is investigating the possibility of Masters' becoming the degree which qualifies graduates to register as practitioners - rather than Bachelors' which has to-date been the qualifying degree (Ferrer, 2012) - so in the future there will perhaps be more compatibility of level in entrant music therapists across the world. European and Australasian courses may wish to explore how the Bachelor's degree might develop aspects of the research and practice skills if Bachelor of Music Therapy is not the pre-qualifying entrance.

\section{Summary of contribution to knowledge in this section}

The evidence of the findings chapters and the discussion of the diverse approaches to combining research and practice at Masters' level point to the following issues:

1. Departments hosting music therapy programmes have particular advantages and constraints when faced with integrating research and practice. Participants in this study observed that music and arts faculties \& departments share an understanding of the place of the art form, but from a disciplinary perspective may expect more individualised approaches to study; allied health departments may be focussed much more strongly on an evidence-based approach to research, which can compromise artistic or qualitative values of music therapy practitioners, but may have a much more established practice of collaborative inquiry, and a familiarity with the ethical responsibilities for vulnerable participants. 
2. Lecturer participants from this study showed that they needed to be prepared to adapt and use the strengths of their institutional setting, whilst also protecting disciplinary values.

\subsubsection{Developing creative solutions and strategies for integrating research and practice}

From my personal perspective, I have found that I shifted my ground considerably, and extended my thinking about valuable student-learning over the course of this study by being exposed to different teaching practices. The contexts reported on and observed in the research pointed to creative and adaptive strategies by individual programme leaders and teams managing the challenges of their own settings. Moreover, the integrative approaches to developing the researcher and the practitioner at one and the same time appeared to have enhanced the value and meaning of a researching/inquiring focus, and to raise staff and students' esteem about undertaking both together. However, I also noticed that radically different standpoints could create successful synthesis of research and practice and how important it is to keep an open mind in the university environment. Sometimes this involved direct 'practice-centred research' focussing on case study or experimental approaches; sometimes it meant historical or theoretical exploration of an 'issue' for music therapy as a discipline (such as 'spirituality' in one student participant's case); or student joining supervisor in conducting one section of their wider-funded study; or qualitative examination of therapist perceptions. At other locations it could involve a music-centred study of case work in a previous placement; or surveying registered therapists' attitudes. Another approach again could involve creating a research proposal on a hypothetical topic; or indeed becoming research-literate rather than being an active researcher. All participants seemed also to be focussed and aware about the necessity for concern with practice issues and care for musical flexibility and deep therapeutic learning. They also seemed alert to reducing or managing the choices so that students' time and confidence might be protected. Participants were honest about the difficulties experienced and how students could become overwhelmed if the time or choices were not managed carefully. Through the conversations, I personally have become more aware simultaneously of the problems and advantages of linking our patients/clients/students into research. 
Context for Music Therapy Programme
Strategies \& Approaches to Research-Practice Curriculum
Long research tradition of

MT within music dept of university

\section{Practice \& research-}

2 focused programme in centre for MT practice

Practice-focused

3 humanistic tradition within

allied health dept of university

Psychodynamicfocused

4 MT programme within

music dept of university

Research-focused

5 programme within a cultural \& ethnomusicology dept

Recent Masters

6 programme in a university

music school with eclectic

theoretical approach

Undergraduate programme

7 (preparation for research

offered, supporting later higher level research
- Broad range of qualitative + other research methodologies

- Large studies with multiple sites, coordinated with external MTs

- Some challenges with sufficient time on placements

- Students take small roles in bigger projects, and work alongside a supervisor

- Integrated assignments created, emphasising critical thinking

- Challenges in practice become questions for research

- Supervisors guide by framing with theory and basic principles

- Research skills not taught separately but woven into curriculum

- Modules on EBP and clinical evaluation taught

- Qualitative and music-centred methods used

- Using other disciplinary research resources, while maintaining vigilance for relevance to music/arts

- Learning about ethics provided valuable integration of practice \& research

- Research methods module introduced in 1st year

- Building the learning of the therapist into research topic

- Challenging student not to escape personal learning

- 'Curiosity \& aliveness'

- Introducing a research-oriented approach early on, and creating relevant hypothetical research tasks in training

- Aligning assignments to professional writing tasks (journals)

- Recognition of clinical evaluation as a kind of research

- An ethics framework negotiated for evaluation studies

- Practice-based research emphasised, majority of qualitative studies

- Research learning focussed on tutor's project - taking students through the process

- Integrated thesis balancing practice and research

- An ethics template developed for low-risk studies

- Framing a proposal as a hypothetical research study

- Opportunity to undertake the study in later Masters' degree

- More leisurely time frame for learning about \& integrating research

- More time for practice and apprenticeship into profession

- Strong relationship developed with ethics committee

\section{FIGURE 11: SUMMARY OF SEVEN PROGRAMME CONTEXTS AND CURRICULUM STRATEGIES FOR INTEGRATION OF RESEARCH AND PRACTICE}


It was interesting how the strengths of the different institutions and length of time in situ had been used by the programme directors to shape approaches to teaching and research, and how programmes had learnt to bend and adapt the challenging frameworks that did not serve so well. The programme leaders in Settings 2 (Programme in a Music Therapy Centre), 3 (Allied Health Faculty) and 5 (in a Cultural \& Ethnomusicology Dept) in Figure 11 discussed at some length how the idea of the 'research thesis' - a really significant marker of traditional university output for research degrees had been abandoned in favour of learning that was embedded in a number of shorter more focussed research tasks. These programme leaders and lecturers argued strongly for how important this change was for contributing to practitioner understanding of the production of research outside in the professional healthcare and education worlds and that this had far more relevance to the professional requirements of the music therapist. Also the respective faculty committees of their universities had been prepared to accept the relinquishment of the traditional research thesis for arts and/or practitioner research education and they themselves had been persuasive advocates of such a change. These respective universities perhaps were used to the Arts Faculties having different needs and traditions in research culture, and some of the arguments for varying the standard assessments had been well laid by sympathetic faculty colleagues and by the effective advocacy of the programme leaders themselves. A willingness to be flexible or to embrace change in the university approach is strongly supported by commentators such as Barnett (2005) who has argued that university leadership of the $21^{\text {st }}$ century needs to be increasingly ready for diversity and plural or local knowledges in policy development and strategy, and as he articulates, "to live with 'strangeness"'(p. 785). Sometimes it may seem that the university systems are too inflexible and focussed on one particular research 'identity', lamented by many of us in the arts and also in applied, person-centred disciplines. Sparkes (2007) gives one particularly heart-felt challenge in a piece of narrative research from the discipline of education, that indicates how single-tracked University attitudes can be, and how disempowering can be the experience of staff and student researchers. However the evidence of the current study indicates that arts, health and education-related programmes can be proactive and create different pathways and six years on from Sparkes' research, and as a result of such political action, different attitudes are emerging.

\section{Creative assessment design integrating research and practice}

Specific examples of creative adaptation of assessment tasks were provided by Settings 2 (MT Centre), 3 (Allied Health Faculty) and 5 (Cultural \& Ethnomusicology Dept) and judging by the animation of focus group participants when they became involved in discussing these respective developments in the course of this study, I imagine such debate and sharing of ideas would be valuable to a wider circle of educators, who might be inspired to develop future curricula for 
professional education of practitioners (Hoskyns, 2011). ${ }^{30}$ An instance of the research and practice being particularly integrated in the programme assessment was provided in Setting 2 (MT Centre), where students were actively encouraged to notice the challenges of their practice and ethnographic documentation of the experience of managing the challenge became a small-scale research assignment. A second instance of such integration involved using the recorded and notated music of previous case work in a focussed music-centred research assignment (developed in Setting 3 Allied Health Faculty and 6, new Music Therapy Programme in Music School). Setting 5 (Cultural \& Ethnomusicology Dept) demonstrated a programme leader and University management team being particularly resourceful about preparing students for practice-based research in professional life. In this setting, the final research assessment was to produce a journal article rather than a dissertation, and part of the process included having to research which journals would be a suitable destination and using their author/text guidelines in preparing the written work. Furthermore, after the assessment had been marked, the students would have a journal article 'ready-to-go' - which could be of great advantage to university departments all in need of research outputs for their staff and students. Real efficiency was demonstrated here and practical relevance. Lather (2006) and Barnett (2005)'s challenge for plural approaches to research development are demonstrated in a University Faculty supporting such an approach to research assessment.

\section{Making the 'thesis' relevant}

However conversely, in another pair of examples - Setting 1 (MT Programme with long research tradition) and 6 (new MT programme) illustrated in Figure 10 - a shorter research dissertation (the more traditional university stalwart) was successfully being retained, and both supervisors and student/graduate music therapists interviewed from these two settings in this study advocated for the value of the experience of writing such a dissertation or minor thesis. Setting 1 gave illustration of the thesis being focussed around one aspect of a supervisor's project but still provided a personal and highly-valued study for the student. Setting 6 demonstrated (from the perspective of a graduate) that the 'journey of the thesis' continued to be experienced as a significant personal achievement that was intensely satisfying in completion. Nevertheless in both these instances, the programme staff had worked hard to modify and shorten the thesis to suit the time constraints on student practitioners who also had to spend significant periods gaining placement experience and expertise.

\section{Creating meaning for student practitioner-researchers and moving beyond competency}

In a comparative study of personality types of music therapists and music educators, Steele \& Young (2011) establish the personal characteristics of music therapists (compared to music educators) as

\footnotetext{
${ }^{30}$ I was interested to note how engaged music therapist participants became in a collaborative focus group discussion and recognised the good fit there was with focus group methodology and therapeutic group work training and experience. Also, music therapists are often used to multi- or trans-disciplinary team work in practice settings and thus collaborative development of ideas is natural and to be relished.
} 
identified in the American Music Therapy Association (AMTA) handbook. They emphasise the genuine interest in people and caring for, relating to and empowering of others. Also quoted are the following: "Empathy, patience, creativity, imagination, openness to new ideas, and understanding of oneself..." which are considered important defining qualities of registered music therapists (p. 56). The evidence of the perceptions of participants gained through this study was that they too were focussed on developing these attributes in student professionals, and that they were concerned to balance the learning experiences in their programmes, so that such attributes could be nurtured. Setting 4 (Fig 10) in particular emphasised thoughtful work in supervision on research questions that would both encourage 'curiosity and aliveness' and assist the student in building understanding of self, in the progress of their research study.

So in a general way there emerged, in review of the seven settings of Figure 10, a deep interest in promoting meaningful experience, imaginative understanding and self-growth in both research and practice, and I observed many more layers beyond the 'research competencies' which, for example are quoted in the competency and 'standards of proficiency' schedules outlined in the following table Figure 12 (sourced from the American Music Therapy Association, the Health and Care Professions Council UK, and the Australian Music Therapy Association): 


\begin{tabular}{|c|c|c|c|}
\hline Source & $\begin{array}{l}\text { American Music Therapy } \\
\text { Association }\end{array}$ & $\begin{array}{l}\text { Health \& Care Professions } \\
\text { Council, UK }\end{array}$ & $\begin{array}{l}\text { The Australian Music } \\
\text { Therapy Association }\end{array}$ \\
\hline 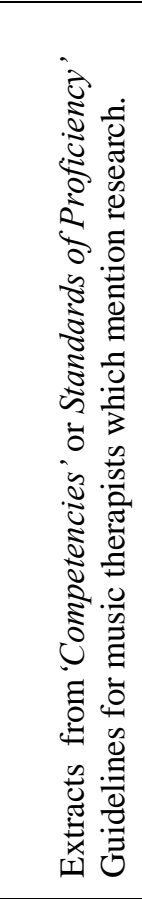 & 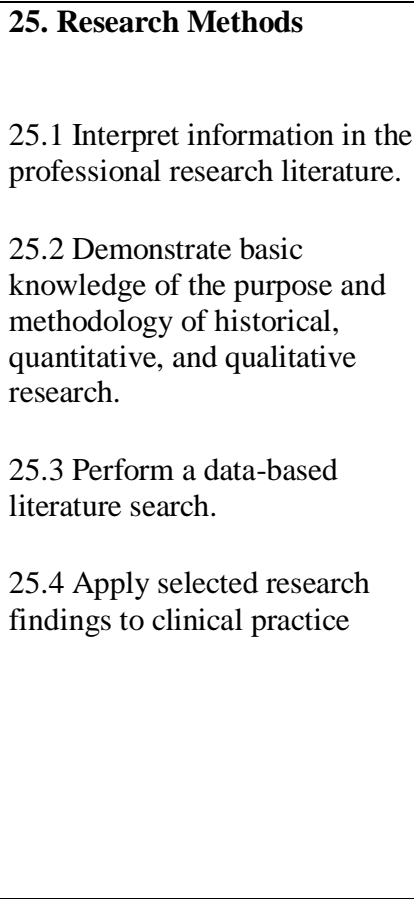 & $\begin{array}{l}\text { 2b.1 Registrant art therapists } \\
\text { must be able to use research, } \\
\text { reasoning and problem-solving } \\
\text { skills to determine appropriate } \\
\text { actions } \\
\text { - recognise the value of research } \\
\text { to the critical evaluation of } \\
\text { practice } \\
\text { - be able to engage in evidence- } \\
\text { based practice, evaluate practice } \\
\text { systematically and participate in } \\
\text { audit procedures } \\
\text { - be aware of a range of research } \\
\text { methodologies } \\
\text { - be able to demonstrate a logical } \\
\text { and systematic approach to } \\
\text { problem solving } \\
\text { - be able to evaluate research and } \\
\text { other evidence to inform their } \\
\text { own practice }\end{array}$ & $\begin{array}{l}\text { 3. Understands music therapy } \\
\text { research: } \\
\text { 3.1 Can prepare and present } \\
\text { literature reviews on aspects of } \\
\text { music therapy } \\
\text { 3.2 Can identify most suitable } \\
\text { research methods to be applied to } \\
\text { research questions in music therapy } \\
\text { 3.3 Can identify and describe the } \\
\text { differences between qualitative and } \\
\text { quantitative research methods and } \\
\text { their applications in music therapy } \\
\text { research } \\
\text { 3.4 Understands the application of } \\
\text { statistical methods in quantitative } \\
\text { music therapy research }\end{array}$ \\
\hline Reference & $\begin{array}{l}\text { AMTA Professional } \\
\text { Competencies } \\
\text { http://www.musictherapy.org/ }\end{array}$ & $\begin{array}{l}\text { HCPC-UK Standards of } \\
\text { Proficiency - Arts Therapists } \\
\text { http://www.hpc-uk.org/ }\end{array}$ & $\begin{array}{l}\text { Competency Standards in Music } \\
\text { Therapy } \\
\text { http://www.austmta.org.au/ }\end{array}$ \\
\hline
\end{tabular}

\section{FIGURE 12: TABLE OF COMPETENCIES FOR RESEARCH FOR QUALIFIED MUSIC THERAPISTS IN THREE COUNTRIES}

The standards and competencies table presents a very functional picture for what is required for registered professionals and research process. There is not much that is active or involved about the competencies - you acquire skills, demonstrate them and tick the boxes. It was fascinating to compare what I heard from participants about engagement and interest in clients, hard work and complexity, the building of theory, a feeling for constant change - a curiosity about the client's perspective, and research enlivening understanding. What is presented in our standards of proficiency is in the measureable 'learning outcome' area - completely worthy and important and meeting the requirements of outside institutions. However, what the participants described was in large part holistic, using self, embodied, visceral, critical and creative, exciting, difficult. So a key issue here is what professionals and students said about 'good research' integrated with practice in our field. It searches and changes the landscape, it looks in depth at the practice, it requires energy and collaboration. It also requires discipline and knowledge, and these are part of the competencies, of course. Nevertheless a substantial part of what experienced researchers and lecturers commented on regarding the development of quality research was not necessarily reflected in the competencies, and I 
would suggest that, so far, it is the competency frameworks that have been driving what we require of our training programmes. In contrast to the competency framework, which has largely been adopted by the professional bodies for music therapy, it may in future, in the light of these findings, be more appropriate to develop an approach more in line with the "capabilities" approach to Higher Education described by Lozano, Bono, Peris and Hueso (2012). I am grateful to Professor Kenny for introducing me to the concept of "capabilities" in the late stages of the review of this research, and am very interested to explore this further in subsequent study.

Some participants also observed that perhaps not everyone should be required to be engaged in active research - and maybe what is needed from entry-level music therapists (and we could substitute arts therapists/teachers/counsellors here) is just to be 'research-minded' or research 'literate' and certainly this seems to be the flavour of the competencies presented in Figure 12. Nursing Professor, Pam Smith (1997) creates an impressive rationale for this kind of approach in the training of nurses as discussed in the literature review. However the entry level under discussion here is Masters' not Bachelors', and many music therapists in Europe in the 1990s and new millennium fought hard for the right to develop music therapy at postgraduate level, (founded on a undergraduate degree in a relevant area) because the value was to develop mature professionals and to uphold the standards of the discipline and the focus on research as part of the learning.

So I do not think there is a choice merely to advocate for research-mindedness or research literacy. If we value the status and funding of research degrees, and wish to educate students to be invested and creative about the discipline, then the responsibility is to be resourceful and have research hand-inhand with practice. If programme staff are alert and responsive and embed research principles within the learning, demonstrate and involve students in projects, while still preserving the integrity of the practice and the qualities and values articulated by the AMTA handbook, challenging of course, then there is a good chance of being very successful (as witnessed in the seven programmes pictured in Figure 10). Ironically, alongside this, there is also a need to argue the case for various forms of practice-based research in the arts (or research-led practice) not to be considered just a rather lowlevel, messy, disciplinary activity (rather akin to professional development) and the 'real research' to be esoteric, pure, clean, high-level academic scholarship. I was reminded rather pointedly of this in a meeting attended by some members of the senior leadership team at my University in 2013, and in reading a collegial account of collaborative action research in an education department in the UK (Houston, et al., 2010) where what was deemed 'worthwhile research' which will be published in high-ranking journals and attracting substantial public/private grants, may still be quite far out of the regular reach of practitioner departments. So it seems this debate is still work-in-progress both for the 
music therapy and other practitioner disciplines, and for the Tertiary Education Commissions, ${ }^{31}$ or equivalent authorised bodies in other countries who set standards for what is considered significant research.

As noted earlier, Lather (2006) anticipated that more interesting and useful ways of knowing might emerge if universities are open to diverse research approaches, and it is important to remember that the arts can contribute so significantly to different and exciting new ways to know about the world (Leavy, 2009). Music therapy programmes and supervisors might be cautious about plunging fully into arts-based research opportunities, because of the need to develop the simple competencies. However, using the artistic process as the means of research could be one of the most powerful ways to create meaningful learning for student researcher-practitioners. A beautiful example of artsfocussed practice and research in education is given by Cahnmann (2006) who used 'scholARTistry' in her teaching of bi-lingual children (see Method 3.8.1 for Neilsen's definition). Cahnmann, language teacher, researcher and creative writer delivers her findings on interviews with Latino youth as a lyrical poem, and then discusses the poem and reflections in a published article. Austin and Forinash (2005) describe the emergence of arts-based music therapy research and discuss examples where the form and process of the arts have added substantially to knowledge in the discipline. Ledger and Edwards (2012) have since speculated why there is not more arts-based research developing in the music therapy field, giving excellent examples of non-verbal knowing being a highly effective communication of ideas and concepts in their review. For example, Ledger's $2010 \mathrm{PhD}$ research used narrative methodology, story-telling and poetry in presenting the findings. In my years of teaching music therapists, poems, stories, and songs relating to practice have had great capacity to draw music therapy students into a personal experience in the classroom. Cornforth (2011) also reinforces the attraction to practitioners of disseminating 'peopled stories' about practice, but which also valuably serve the dual purpose making "a strong impact on those who read them" and accumulating evidence for informing strategy and policy in healthcare (p. 84).

Though one would need confident modelling and supervision and quality examples of such forms as research, one could anticipate students' excitement and potential for expertise if their musical/artistic training was used more fully in their research. This kind of approach is considerably more in keeping with the "capabilities" approach to Higher Education than one of competencies (advocated by Lozano et al. (2012) noted above).

\footnotetext{
${ }^{31}$ The TEC is the New Zealand body for evaluating the quality and advocating overall standards for research in New Zealand universities. Other countries are managed by equivalent regulatory bodies.
} 
The evidence of the findings chapters and the discussion of the diverse approaches to combining research and practice at Masters' level point to the following issues:

1. Departments hosting music therapy programmes have particular advantages and constraints when faced with integrating research and practice. Music and arts faculties \& departments share an understanding of the place of the art form, but from a disciplinary perspective may expect more individualised approaches to study; allied health departments may be focussed much more strongly on an evidence-based approach to research, which can compromise artistic or qualitative values of music therapy practitioners, but may have a much more established practice of collaborative inquiry, and a familiarity with the ethical responsibilities for vulnerable participants. From this case study evidence, it seems that programme leaders are advantaged if they are prepared to adapt and use the strengths of their institutional setting, whilst also protecting disciplinary values.

2. Educators with more than a decade of experiencing the combination of research and practice in Masters' level programmes showed in this study that have developed varied and creative ways of weaving the strands of practice and research. They have managed in many cases to develop a capacity for 'research with meaning', or 'research with heart' whereby students enhance understanding of practice through research endeavour, and also build student capacity and confidence in making creative contributions to the discipline.

3. From the evidence of the participants, it seems that research 'competency' could be reviewed in the music therapy core proficiency standards and competencies for practitioners internationally to reflect (in addition) the need to build meaningful inquiry, to respect connections between research and practice ethics, to use research to enhance the clinical practice and artistic interests of practitioners, and to encourage and enhance a creative approach to the building of knowledge (i.e. not just ticking boxes).

\subsubsection{Integrating practice and research learning through an ethical lens}

The understanding and embracing of an ethical framework - both in practice and in research - in the music therapist's learning, was commented on in important ways by a number of participants in this study. It emerged in various themes in the findings (section 4.2.3 excitement of search and inquiry and 4.2.4 client-led thinking; Chapter 5's sub-theme 5.2.5 'developing the profession' and pervades chapter 6 - the complexity of the discipline). In many ways, understanding ethics in research and practice could find a pivotal place, and under certain circumstances could lead the research teaching as students learn to negotiate their questions and curiosity alongside the rights and interests of their 
client-participants in music therapy practice. As was observed in section 7.1.1, the learning and relationships developed with human ethics committees was a specially valuable alliance for three or more participants in the study. They saw it as a collaborative investment of ongoing importance, and that it required time and commitment.

In the cases of three participants in this study, an approach to the ethical principles of their practice drove the way that they developed their research, particularly in their role as student researchers (at Masters' and at $\mathrm{PhD}$ level). What was fascinating about these examples was that in each case the practitioner-researcher was using the ethical framework to learn something significant about the nature of practice. One participant was inspired by her client to initiate the very existence of the research - by indicating how important the work felt to her as the receiver of the service. It needed to be researched because the client wanted it documented and disseminated. Music therapist and client were jointly engaged in the research process from this perspective. Another participant was motivated by participatory action research as part of her own values as a music therapist, and became creatively engaged in finding ways to include non-verbal clients as active participants. Facilitating the voice of vulnerable participants is a vital topic for ethics committees, and this research embodied the challenge. The third participant used her practitioner ethical code to direct a powerful ethical approach to the nature of research that she and her clients could accommodate. This participant started to advocate for the relevance of qualitative research as a much more appropriate methodology for her client group as a result of her study, and began to change the landscape of understanding for such approaches in areas of healthcare where people are at particularly stressful times in their lives. Modelling this approach to students felt a very important contribution for the participant, and underpinned learning valuable lessons about practice ethics too. There is only so much people can tolerate - is it appropriate to ask for patients to undertake this inquiry? Such questions also underpin decisions about treatment or intervention - learning about the ethics of the research underpin and consolidate the learning about practice.

Cornforth articulates the humanity and relational basis of research ethics, in a chapter encouraging counsellors to understand research ethics as a complementary extension to the ethical code for counselling practice. Like the participants in this study, she observes the potential for research centred on practice to become 'one way of expressing core counselling values, particularly social justice' (Cornforth, 2011, p. 83). In this way the integrated learning for students becomes a very strong feature, dovetailing and reinforcing messages about informed consent, acting in clients' best interests, avoiding abuse of power, developing culturally informed processes, sharing and collaborating, understanding and improving services. The evidence of the current study points to the resourcefulness of learning and teaching about ethical thinking in the integration of practice and research. 
The recent text guiding student music therapists through ethical processes in their research 'Towards Ethical Research' provides a timely introduction and emphasis on ethical thinking that will assist students and educators to make this integrating link with research and practice (Farrant, Pavlicevic, \& Tsiris, 2011).

\section{Summary of contribution to knowledge}

1. Participants in this study found that when research is approached as an ongoing engagement with ethical thinking, learning about practice and research are enhanced, and a natural integration ensues.

2. This case study indicates that the requirement to consider ethical issues in research reinforces and upholds the high ethical requirements for practice and revises and enhances the reasons for taking care in these areas.

3. Participants suggested that fostering strong relationships with university and health education ethics committees was important in the development of integrated practice and research.

\subsubsection{The value of aiming for engaged scholarship}

Meaningful research experiences that connect with the learning that matters to music therapy students (about music, about people well-being and health, about understanding of relating and communicating, and cultural awareness) are helpful connecting points to this section which considers creating an environment for emotional engagement in the classroom, research setting and placement. In Chapter 4, the participants reflected fully on people have a 'burning interest' in their areas of practice and research; in chapter 6 they considered the excitement of complexity - practitioners were stimulated by the intricateness and complications of the challenges to research their work. So returning to the research question - 'How can research be integrated into the practitioner education of music therapists at Masters level? - there seems to be a significant place for thinking about how students can become involved enthused and passionate about learning in these combined areas.

Kenny (1998), when Associate Professor of First Nations' Education at Simon Fraser University) preempted the comments of the participants in this study in her perspective on the importance of a personal, whole-hearted investment in music therapy research study.

Initially research begins with a burning question (Kenny 1989). Good research is timeconsuming, so it helps to have a passion for your question. An intense intellectual engagement can sustain you through many hours of data analysis and interpretation. You need to really care about your study (p. 208). 
In the same year, Madsen (1998), Professor and coordinator of Music Education and Music Therapy at Florida State University made a passionate statement about introducing his students to research and observed that "I want my students to develop a love affair with research in music education. I want them doing research right away - the earlier, the better, so that having once tasted it, they can appreciate it, value it, and go on to design and carry out their own studies" (p. 39).

A student (in section 5.2.5) discussed the development of her topic, and a lecturer also reflected on the importance of delicate handling of the areas that students explore in their research (section D of 4.2.7). Sensitive supervision can really engage students in a valuable and meaningful area, both for their intellectual and personal-therapeutic growth. McFerran (2006) suggests a similar understanding about the hidden meaning of research questions, and how we might explore material that is valuable for holistic growth as well as achieving the research task .

Education professor and writer bell hooks challenges teachers and academics in her radical texts, to provide an environment that nurtures whole learners. ${ }^{32}$ She makes specific critique of the academy in the 1990s that tended to value the 'academic' or thinking skills as separate from experience in life, feelings and spiritual values (hooks, 1994). Chapter 4 of this study's findings specifically referred to such themes as being inspired by (people and processes), the learning with others rather than solitary endeavour, and some of the varied feelings of anxiety, and then developing confidence. Alongside this was captured the need to be committed to the project and the labour and hard work that might be involved. Chapter 5 emphasised the management of changing processes, and changing theories and the joint importance in research and practice of critical thinking. There is real relevance in hooks' writing to the challenge of applying thinking and conceptualising to lived experience, and how sometimes the university environment can work against the development of trust, collaboration and exciting learning. So how do educators develop good processes for active practice skills and the ability to think critically about them?

Two core texts, 'Teaching to Transgress'(1994) and 'Critical Thinking' (2010) by bell hooks made a call to university teachers to use the tertiary classroom as a laboratory of exploration where the process of conceptualising and working out of thoughts is modelled and played out within the learning group. The ability to question and defend ideas can be practised safely, and the lecturer/supervisor supports and models (hooks, 1994). The lecturer also takes risks, exposes herself to mistakes and shows how problems might be solved. hooks emphasises working with the whole student, a topic familiar to therapist training, but it was interesting to observe the attention given to students' feeling lives and personal histories in the establishment of engaged critical thinking. So in practice-based professions (like education, counselling and arts therapies) students learn to think through exploring

\footnotetext{
${ }^{32}$ bell hooks chooses to use lower case letters for her name.
} 
and embodying the experiences of practice, and then examining them critically, reflecting, discussing and writing about them (hooks, 2010).

Music therapy researcher, Baker's (2007) findings about using clinical work as a focus for developing students' abilities to reason and think about practice, and music therapy lecturer Watson's (2005) observations about personal growth and change and the way such processes might be handled in music therapy student learning provide strong reference points here. Both commentators indicate respectively that there is value in concentrating on clinical experience (Baker) and personal responses to training (Watson) in an engaged and involved way in the classroom, and reflection on both, in their place can be used to develop reasoning (Baker) and personal and therapeutic insight (Watson). As noted in Chapter 2, these authors also comment that little has been written or researched about pedagogical approaches to music therapy curriculum, and that research has been focussed most substantially on the clinical placement learning, rather than building of personal insight or conceptual capacity .

Hadley (2006), emphasising a feminist approach to learning in the music therapy curriculum, provides additional experience about collaboration and support in the therapy classroom. She advocates for embodied knowledge, rather than the focus on academic scholarly outcomes, which often pervade university curricula. She reflects:

My philosophy of education is that people learn by doing and that it has a longer-lasting impact if people enjoy it and it is meaningful. The music therapy classes that had the most lasting impact on me were those that were experiential in nature, those that integrated theory, practice and personal experiences. (p. 397).

She also notes that the awareness of the impact of oneself as a many-layered person needs to be accounted for and thus a framework of building understanding in students on many levels is imperative to their learning in a $21^{\text {st }}$-century world. Hahna's (2011) PhD research emphasises similar complex and multi-levelled qualities. These authors' use of feminist theory encourages the interaction of our ideas with our experience of people, understanding our conflicts and influences, and enjoying our active experience of learning. This approach appears not only practical for a female-rich, active profession needing to 'learn to be' in the world, but also necessary to one which thinks critically, asks questions and researches its actions.

Baker, Watson and Hadley write about teaching music therapy students within group contexts at entry level of the profession, but an additional point noted by Wigram (2009) in supervising research at higher doctoral level has increased importance for new Masters' practitioner-researchers. Wigram notes that the supervisor provides significant experience and guidance to limiting and focussing the tasks of the researcher. Such a role is essential to creating manageable research tasks within the 
complexity of practice-based research and this is especially true when previous research training at Bachelors' level may be limited. Lecturer-participant Hope in section 6.2.7 had significant distress, in trying to manage the expanse and complexity of practice-based research, and the role of the supervisor in creating helpful limits might have made all the difference. In this regard, Wigram and Wheeler (2005b) both emphasise the care needed from supervisors helping the student to manage the limits and implications of the research question.

Therefore reflection on the findings of this study point to these issues: that emotional engagement students' whole-hearted investment in their study - is a crucial kernel and significant starting point/embracing centre piece to the process of integrating practice and research. Critical thinking which connects with and intersects with it allows us to discriminate, make choices and plans, 'weed', refine and apply comparisons and talk about or present our 'theories' is a vital second step. Integrated researcher-practitioners need support from their teachers and supervisors to develop both steps handin-hand, creating enthusiastic involved learners with safe limits provided from experienced cotravellers and guides. Obvious perhaps, but it is interesting that the values of practice are again underpinned in the needs for research.

In the following figure 13, emotional engagement has a central lively position, boundaried by the critical thinking modelled by supervisors and encouraged in the student group.

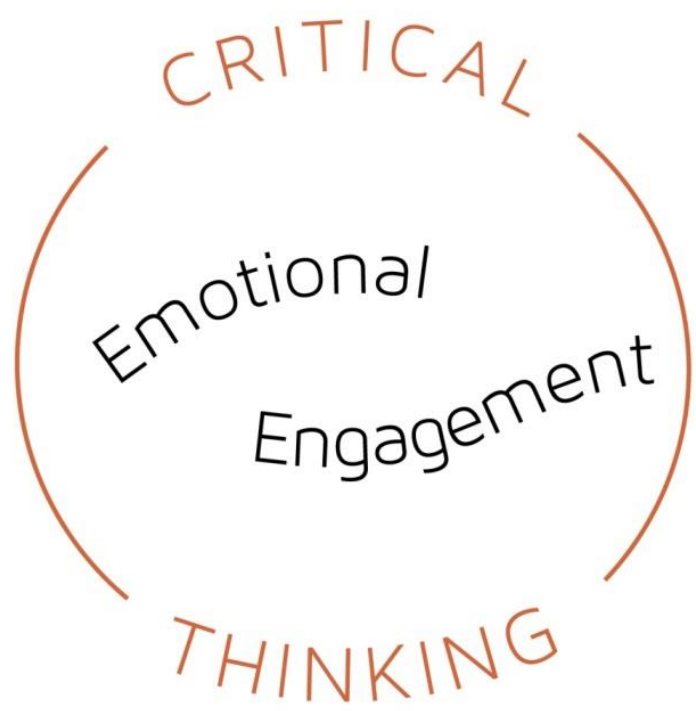

FIGURE 13: INTERACTION BETWEEN EMOTIONAL ENGAGEMENT AND CRITICAL THINKING - PARALLELS IN RESEARCH AND PRACTICE 
1. From the evidence of many participants and linking with music therapy authors above, it appears that students do develop concepts and questions through engagement of their experience and other personal 'ways of knowing'. In some cases these may lead to research. This seems appropriate to student therapists, who need to develop understanding of feelings and thoughts together.

2. This study suggests that students' research benefits by engaged connection with their practice and with their artistic, personal selves.

3. Participants observed that critical thinking can be developed from this engaged base and is necessary to provide limits and to develop theorising as students unfold their learning.

\subsubsection{Linking research and practice to creativity.}

There were some specific processes highlighted by participants captured across the findings chapters, which, on reflection, indicated a strong relationship with creativity in the building of research within a practice discipline. For example, in Chapter 4, sub-themes featured excitement and passion for exploration, the 'journey' into unknown places, and the intense hard-working focus; in Chapter 5, the emphasis was on constant dynamic change and growth. In Chapter 6 amongst the many aspects of complexity raised, researcher Alex emphasised the creative sharing between student and supervisor when a student invented her own particular way of researching her notes.

Craft, Claxton \& Gardner (2008), in recent research and collaboration on creativity, emphasise ethical responsibility and sustainable approaches to developing creative practice, described as 'wisdom' and 'trusteeship' in their joint text. Their varied chapters in this book create a platform for therapists and educators engaged in work which fosters community, health and the artistry of others. In particular the collaboration of students and supervisors described in section 4.2 .7 of the findings, generating new ways to look at wellbeing and education, distinctly evoked this kind of approach to creative practice.

This came as something of a surprise in standing back and reviewing the findings and I have wondered why I was surprised. Possibly it had something to do with where this research project started, in the 'problem' or challenge of bringing and weaving a research focus into a practice discipline which I was configuring as 'intuitive, sensitive, artistic and person-centred'. ${ }^{33}$ Research was - in this framing - 'scholarly, planned, cognitive, rigorous' and I for one was struggling with how to marry the two. Figure 14 demonstrates the boxed-in and quite restrictive way I was viewing

\footnotetext{
${ }^{33}$ I am aware at other times of the many other aspects of practice, which include reviewing, thinking, theorising and documenting, but the musical artistic parts of the work felt to me the most compromised in trying to achieve a blend of research and practice.
} 
research as balancing with practice, which I presented as part of a paper to the World Congress in Buenos Aires 2008 (and which featured in my research journal in the introduction to the thesis, p. 4).

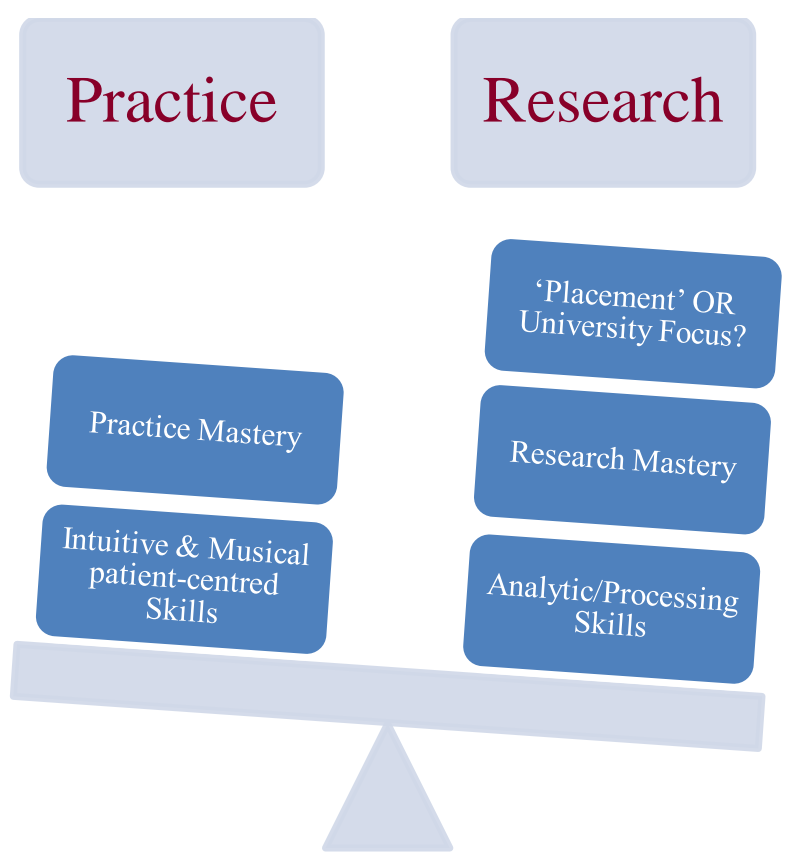

FIGURE 14: BALANCING RESEARCH AND PRACTICE AT THE OUTSET OF THE STUDY

Returning furthermore to the research competencies frameworks of Figure 12, one can also see how as a profession (in three countries for example) the focus is on the 'scholarly, methodological and rigorous' in what we are 'counting' within the research competency area (evaluating evidence, developing the ability to understand methodologies, developing literature reviews, understanding statistical analysis, distinguishing qualitative and quantitative approaches and so on.)

However, considering the arguments of the previous sections, and the evidence of this study, it seems that if the areas of research and practice are combined, and for example that we can be allowed to be intuitive and musical in the research as well as the practice, whilst also remembering that practice also involves some significant documenting, analysing and reasoning processes, the balance might work better. So the journey of the research for me has been one of linking back of research to creative practice. I have always thought of music as discovery, research in this project has been a kind of unfurling - a koru opening up. Emphasising the connection with research and creativity and music exploration seems to be a productive integration. The participants expanded on creative processes, both currently in their work and in their earlier student research. The students in the project often found this too. 


\section{Summary of contribution to knowledge}

It was the case in this study that creativity could be located by the participants in the practice and in the research. Making efforts to not separate the two, and finding appropriate ways to highlight researcher creativity (using student strengths in the arts) was a positive finding for a number of the participants.

\subsubsection{Valuing collaboration and community between students and staff}

The evidence of this study giving high value to the collaborative and shared qualities of the researching process was surprising and delightful to discover. Through such negotiation, research can echo the work of clinical practice teams, which is common in mental health and in special education. Music therapy in my experience in Europe in the 1980s and 90s was often-pioneer based, and a music therapist was a reasonably unusual presence in an education, health or probation team. Research, even more so, was something usually to be undertaken alone (the sole music therapist in a university or conservatoire music department), and although supervisors were a great support, and inspiring, the bulk of the work involved considerable determination and motivation to drive the project, and to find out what you need to know for yourself. My experience of music therapy's research history has often been an 'on your own' thing. However, departments at Universities of Aalborg, Herdecke, Bergen, Temple, Florida State, New York, Melbourne, and Jyvaskyla (and of course many others) have gradually established larger teams of $\mathrm{PhD}$ researchers amongst teaching teams. Growing from some of these centres, the principle of shared research teams establishing systematic reviews for the Cochrane Library and the focus on collaboration has made meeting the needs of evidence-based practice easier. A student (in section 4.2.3) saw how she could begin to contribute to developing the profession through research and practice, and how valuable it seemed to music therapy that students could be part of this experience.

Two doctoral research projects examining pedagogical approaches in music therapy have attached high value to collaborative learning style. Luce's research (2001) subsequently published in the Journal of Music Therapy (2008) emphasised group learning and collaboration as a way to marry and connect the developmental and learning needs of undergraduate students. Although at an earlier stage in the tertiary system, with possibly less independent research capability required, the principle of holistic learning in collaborative learning consensus groups with peers was generally valued by students as they moved through the process . Conclusions of Hahna's (2011) doctoral study using phenomenological methodology also observed that a feminist approach, explored by her participants, valued a collaborative egalitarian learning style, where tutor and student peers problem-solve and share together in a holistic way. 
Angela Brew's $(2001,2012)$ work at University of Sydney with undergraduate research uses students in team projects from an early stage. This became increasingly evident in my data analysis, and fits with observations about growing collaborative projects internationally with research. My personal sense is that in a female rich profession, there is potential for really productive collaboration. The experience of working in focus groups as a research method was that these were great arenas for sharing ideas - a practical "kitchen table approach" (Kamberelis \& Dimitriadis, 2005). I was surprised and excited by the co-creation of knowledge. Curtis' (2013) and Edwards'(2013) recent contributions to the Voices Journal and Forum emphasise how feminist approaches to music therapy specifically focus on and value team negotiation and collaboration and clearly interest in this viewpoint is gathering strength in the discipline.

Communities of practice is also clearly an important reference point here (Wenger, 1998). Many of the actions of participants in this study reflect the significance of their collaborations with colleagues, both as practitioners and researchers. Stige (2011) emphasises the growing appreciation for Wenger's theories in reflections on the development of 'community theories' in music therapy, and in our debt as a music therapy community to the work of Tony Wigram who died in 2011.Wigram was, throughout his career, an inspiring model of integrating practice and research both as practitioner and teacher of students and indeed my own first encounter with a music therapist.

\section{Summary of contribution to knowledge}

1. Participants in this study found that maximising on collaborative approaches to research endeavour seemed to reduce isolation and increase students' confidence as practitionerresearcher.

2. Findings in this study indicated feminist approaches, and understanding of communities of practice could enhance the Masters' curriculum.

\subsubsection{A working model for integrating practice and research in Masters' training}

Bringing together some of the principles and choices listed in Figure 11, I sought to develop a holistic model that expressed some of the issues that seemed important to the participants in the integration of research and practice in the training programmes. It seemed that a matrix which considered 'insideoutside' the university or conservatory programme, and both individual and collaborative activity could be captured. Within this matrix, I have attempted to focus on the key areas which participants highlighted as significant, in their attempts to integrate practice and research. So Figure 15 presents four sections of the model - two inside the programme and two outside the programme. Across this are set individual processes and collaborative processes. The boundaries between each of the four quarters are permeable, and processes could certainly be shared across the four quarters (wide reading 
is mentioned twice anyway as it clearly features as an inside and an outside process). I think the key features within each box could be altered or refined, but they seem to illustrate what people told me and how I have also experienced things over my years of teaching in two continents. My proposal is that successful integration of research and practice happens when three of the boxes in the model are engaged. Hopefully we might use all of them, but at least three of the areas could be a target for our programmes. The choice of these might be more individually focussed or collaboratively focussed; more outside the programme or more within the programme, depending on our strengths and resources. However I would contend that a balance across the areas is needed, and reviewing the areas highlighted might remind us of what there is to consider, as observed by a range of experienced educators and their students. 

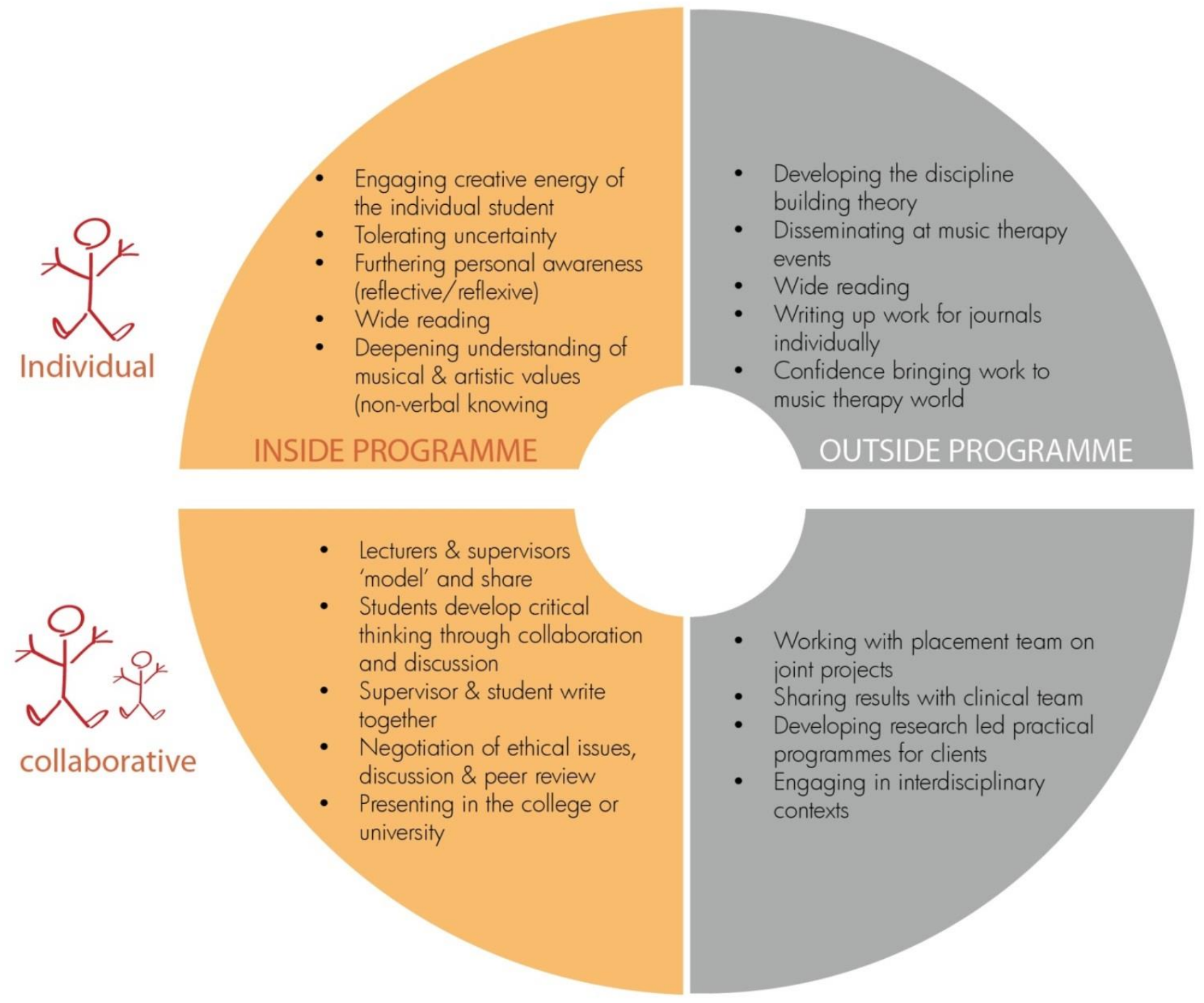

\section{FIGURE 15: MATRIX OF PROCESSES INTEGRATING RESEARCH AND PRACTICE (INSIDE-OUTSIDE; COLLABORATIVE- INDIVIDUAL)}

The idea for this model sprang from reading Rusinko's (2010) article on integrating concepts of sustainability in higher education. She was similarly aiming to investigate the possibilities for embedding and integrating some particular values and approaches at tertiary level (in that case sustainability), and I was intrigued by the parallel process. I notice on reflection the relationship with other conceptual models in music therapy, based in the integrating holistic frameworks of Wilber (2000), such as Abram's (2010) work considering an evidence basis for qualitative research in music therapy and Ole Bonde's (2011) model of health musicing. However the central meaning of this model was sustained by absorption in the research data, and trying to capture an overview of colleagues' values. 


\subsection{Review of the research method and limitations of this study}

The nature of this topic, the integration of practice and research has lent itself comfortably to a qualitative case study. I have discovered much about qualitative research strategies in the course of this inquiry that have assisted understanding of music therapy practice, and the findings of the $\mathrm{PhD}$ have identified a number of them directly. These included valuable work with clinical notes as sources of data, critical thinking as a technique for both areas, and the learning gained from thinking about research and practice through ethical approaches. Students and staff interviewed in the course of the study had also often found qualitative research a complementary parallel to their clinical work.

I remember embarking on this journey and having ambitious expectations of what could be my inquiry. My hope had been to develop a mixed methods study as I had begun experience of research in 1981-2 with an experimental study, and gradually built descriptive research and more qualitative inquiry from then onwards. Mixed methods attracted me because I respected the need to develop clear focussed studies and to test theories about our practice. Having different lenses to the work also attracted me from a constructivist perspective. However, limiting the study to qualitative inquiry was a particularly helpful step, as I would have needed greater experience to absorb the expertise of multiple research approaches. Moreover, focussing on qualitative depth encouraged the more detailed use of 'researcher voice' which has been a valuable contribution to the process of qualitative analysis.

I had originally designed the framework of a survey to circulate to a much broader group of participants, but on reflection it seemed beyond the scope of this focussed study. I valued the depth that I was able to bring to the analysis by keeping the attention to the site visits and focus groups, but recognise it would be timely in future to inquire about research practices from educators in a broader group of Masters' programmes through such a survey. In developing the recruitment process for this study, I focussed on interviewing professionals and students who were actively involved in student training. I recognise that through this focus, the recruitment strategy tended to favour the viewpoints of those more involved in, and sympathetic to, research. Although there were voices (including my own) that presented doubts or ambivalence about the experience of integrating research with clinical practice, there were not many participants who were active in their disagreement. In future research it could be important to canvas the viewpoints of clinicians who have not engaged with research following their professional training to provide more balance from a more discursive range of professionals.

Working on and developing a case study methodology has been a fascinating process and I think certain aspects of the inquiry have been highly illuminating. Ethical frameworks for research in New Zealand led me towards inquiry which did not identify the sites I visited and I aimed not to disclose 
identifying issues for participants. I recognise that in not negotiating to have a more open exploration with the two sites or participants, I was then not able to comment on or explore the particular quality and nature of the contexts I visited in much depth, because I was avoiding identifying them. Any other approaches would have invited some very different ethical thinking, but might have provided a richer opportunity to look closely at contextual aspects of the educational settings, and to explore this detail more fully with participants.

It could have been valuable to make more detailed use of documentation in this study, as I used it only to provide supplementary information about the participants' interviews and perspectives. The analysis of a wider range of materials in relation to curriculum planning could be productive future research, particularly where the documents were analysed in a more rigorous and detailed way.

Finally, using improvisation as a kind of 'interviewing' technique (inviting therapists to reflect on ideas and issues) proved to be a really interesting way to work with two of the participants in this study. It was a small and fascinating part of my work, but it seemed to have potential as a style of artsbased 'interviewing'. I would recommend that other music therapy researchers consider ways of using it as a reflective tool in future projects.

\subsection{My own learning in the PhD}

\section{The 'Improviser-Researcher' as a model for consideration}

In the process of learning about my own limits and possibilities as a researcher through the course of this $\mathrm{PhD}$, a strong thought occurred to me about my own experiences with research. I have an inevitable perverse streak, so when working in a music conservatoire, I worked hard to emphasise the possibilities of research as part of learning. Now working in a university I want to preserve the qualities of practice for students, because research is well-catered for and the times to emphasise practice are more scarce or have to be fought for. However my concern has I think really been about balance between the two, the see-saw needs to be well-founded, and to allow for both ends of the balance, and to give both a turn in smooth flow.

An experience of a staff development research project in co-mentoring raised the idea for me and my colleagues of trying to "teach in the mode of the art form" - in that case, teaching music musically, but also teaching music therapy in the "mode of music therapy". Of course this can mean many things to music therapists, but for me this included having an improvisatory approach to teaching and learning. 
Edmund de Waal (2011) introduced an interesting quality of the scholar-researcher in his biographical account of his ancestor, Charles Ephrussi, an art collector and scholar of Dürer in the late $19^{\text {th }}$ century. De Waal pictures his ancestor's work documenting and researching artefacts, but also suggests that he needed to be a detective and work his imagination in the pursuit of his research. He also connects it reflexively to his own biographical research with his family and Charles' collection of Japanese figures 'Netsuke'. De Waal writes that Charles Ephrussi was searching for lost Dürer drawings in a process that his ancestor called 'vagabonding'.

Vagabonding was his phrase. It sounds recreational rather than diligent or professional. As an extremely rich Jewish mondain, it would have been contrary to social practice to be seen to work. He was an 'amateur de l'art', an art lover and his phrase is carefully selfdeprecating. But it does get the pleasure of the searching right, the way you lose your sense of time when you are researching, are pulled on by whims as much by intent. It makes me think of the rummaging that I am doing through his life... I vagabond in libraries, trace where he went and why. I follow the leads of whom he knew, whom he wrote about, whose pictures he bought... I find that as the months pass I have a strangely increased sensitivity to the quality of paper..... And I find that I have fallen for Charles. He is a passionate scholar. He is well dressed and good at art history and dogged in research. (pp. 72-73)

The capturing of this personal passion of Charles, and the need to take intuitive leaps, and stay connected and sensitive to all nuances of your topic was a very affirming description of the research process. It connects with the creative and curious, whilst also needing the dogged and the sustaining features. It made me think that 'improvising' has a necessary place, and can be part of the researcher's armoury.

My experience in this project has reinforced the value of improvisation, both as a reflective tool in the site visits, and in the contribution to the process of analysis, particularly the inductive stage exploring the meaning of data. I also recognise the limits of improvisation and the necessity to formalise, shape and define the process of researching for students. I have appreciated the role of supervisors in providing this for me in my own research process.

\section{Reflection or reflexivity}

As I worked on the constructivist path using the more cognitive concepts of Schön (1987) in reflective practice (see Chapter 2), I gradually realised the draw for me as a therapist-researcher to 'bend back on myself' and bring insights from my experience into my research analysis. This seems more truly 'reflexive' now, and I acknowledge that it is sometimes quite difficult to disentangle the terms. 
Etherington (2004) writes about her own experience of research on practice, and notes that research can "...open opportunities for creative and personal transformations" and has strong concerns that "the cost of separating research from professional training is the widening of the research-practice gap..." (p. 17). Her own experience demonstrated that reflexivity was the process that brought the two areas into close connection, and I consider, in retrospect, that this is also my experience. One of my most valuable therapeutic skills has been to be able to step inside and outside my 'practice', to be involved and to observe, and this has been exciting to discover as a useful strategy in qualitative research.

I would like to think that students could be drawn into using this process as they work in practice and research (as discussed in section 5.2.7), but I also think that it takes time and experience to be able to work effectively with these skills. Maturity in the field and supervision develops such expertise, and perhaps it would be better to allow more concentrated time with clinical practice to hone these skills and come to research later (as Group BA lecturers reported of themselves in section 4.2.8). My reality-principle tells me that we do not really have this luxury in $21^{\text {st }}$-century professional training, and if we are skilful as educators, perhaps we can do just as lecturers described in the section on critical thinking and develop strategies to allow reflexivity to be a core process that really brings research and practice together. It will be a fruitful future area for consideration and research.

\section{The link with ideas in this study with a traditional pattern in stories and myth}

It has been intriguing and surprising to discover parallels in the findings of this study with traditional stories and some of the literature about myth. As I worked through the emerging themes for Chapter 4 'Being on Fire' it seemed that the pattern was rather a familiar one, and echoed the idea of 'The Hero' and his/her adventures as discussed by Jung and Joseph Campbell, renowned and also variably criticised mythologists of the $20^{\text {th }}$ century (Ellwood, 1999). The pattern of sub-themes - awakening curiosity, asking questions, the excitement of enquiry, the inspiration of wise mentors, the importance of helpers and collaborators, travelling into the unknown, and toil, labour and probably bravery in the face of difficulty - all these evoked the parallel with Jung and Campbell's overall shape of the Hero's Journey (Campbell \& Moyers, 1988; Jung \& Von Franz, 1964). There are also some links to the later chapters in the emphasis on change and personal growth (Chapter 5) and in confronting complex challenges, and having the flexibility or ingenuity to persist (Chapter 6). In discussion with storytelling friends, I have also been alerted to the connection with traditional stories of the young person going on a journey. For example from Scandinavia there are a number of tales of the Ash Lad in a collection of Norwegian Folk Tales (Asbjørnsen \& Moe, 1960). I am aware that this has not really been my style in the past and I have rather resisted engaging in imagery and music together in my music therapy practice, ${ }^{34}$ and left it to other colleagues to explore, although I have always loved

\footnotetext{
${ }^{34}$ I have not yet taken advantage of training in Guided Imagery and Music (GIM) despite working alongside friends and colleagues very committed to its use, and being intrigued yet resistant!
} 
stories and metaphors in my experience as a student of literature. ${ }^{35}$ Finding connection with story and myth in this research has therefore been unusual and surprising for me. I also wondered about my female-rich profession. Most of my participants were female, my 'heroes' were generally women articulating something of the pattern of an outgoing journey of discovery. (One of the criticisms of Jung and Campbell has been the male predominance in their telling of the hero myth.)

Some further inquiry revealed of course that others have made associations with research - and also with the different stages of education - and journey metaphors or archetypal processes in learning. Willig (2001)began an introduction to qualitative research with the call to adventure and noted the distinction between her early experience of learning about research which she describes as following recipes and the use of the self as excitement and experience of the journey into unknown territory (also captured by Bella in Chapters 4 \& 6). Mayes (2005) makes an interesting association for the educational process, tertiary learning, and the need for the student to be open to the process of the journey of learning. He/she has to put aside a previous life, and be prepared to enter new realms. This is a psychological challenge for the student and the role of the teacher in archetypal terms becomes the wiser old man or woman.

In a seminal article on the development of research in the music therapy discipline at the end of the last millennium (see Chapter 2), Kenny (1998) draws attention to therapist curiosity as an essential driver in the process of effective research about practice . Kedge and Appleby (2009) make a similar point about the nursing profession. I found a funny lateral-thinking jump to student training in a Norwegian story about 'The Ash-lad', who is a sort of archetype of the young inexperienced person who has to go and 'find himself 'on a journey (Asbjørnsen \& Moe, 1960). The Ash-lad is characterised as a young boy who stays in the Viking house, raking out the ashes, looking after the fire, listening to people around, but has no experience of the world. He suddenly finds himself drawn to the task of marrying the princess (his curiosity?) and has to go on a series of trials and adventures where he will be really tested. In the process the young person willingly (and with full trust) picks up others, who are slightly strange but with unique skills who want to come with him. He just does this in a friendly welcoming way (he is used to being alongside others and likes company). Of course when he undertakes his trials, all these people help him, and his trust is richly rewarded. He wins the princess and comes back home to live in a rich and active and 'grown-up' way.

Campbell highlights the 'Hero of a thousand faces' in his writings and interviews and regards it as a highly significant myth (Campbell \& Moyers, 1988). He observes the pervasiveness of this myth in the stories about youth and growth across cultures. In popular culture at the time of co-authoring The Power of Myth, he emphasised the popularity of the Star Wars cycle of films and more recently we might note the excitement and investment internationally about New Zealand's own Lord of the Rings

\footnotetext{
${ }^{35}$ I was a Combined Honours student in my Bachelor degree (Music and English were my subjects).
} 
directed by Peter Jackson, and of course the popularity of Harry Potter for my children's generation of story-readers. What these myths emphasise is the endless retelling of the idea of the growing person (the student-in-training here) going out into the unknown and developing knowledge and experience for herself and her community. The process involves trials and labours (the hard work) that must be passed through. The requirement on the young person is (for example in the story The Ash Lad and the good helpers) (Asbjørnsen \& Moe, 1960, pp. 170-177):

- to have the interest, energy and bravery to go out into the world

- to develop wit and resourcefulness (find skills in yourself you didn't know you had)

- to do things step by step (the stories tend to emphasise repetition and stage by stage process)

- to invite or being willing to accept the help of others

- to come back home and share your new knowledge

The way that participants revealed their experiences of research about practice in their core training as music therapists and in following research degrees identifies a markedly similar process to this journeying out to discovery, enduring trials and bringing back your knowledge to benefit the discipline. Margaret Attwood (2000) observes the need for a journey or a surprise or 'something of the unknown' to make a story. He or she sets out on a journey, or perhaps a stranger came to town. There is no story if there is no unknown. We need to encounter things outside ourselves, and what we do not know. "In Paradise there are no stories, because there are no journeys. It's loss and regret and misery and yearning that drive the story forward, along its twisted road." (p. 518). It is also the journey of education - towards knowledge and maturity - we need some adversity some challenge, to help us gain awareness and skills, also to provide excitement drive and energy.

\section{Research Journal entry $23^{\text {rd }}$ September 2012}

A small 'spark moment' came to me this morning. A little tune came to my head, a really favourite children's hymn I played regularly on the piano for my Church of England primary school assemblies when I was about nine years old. It is called 'When a knight won his spurs' and it is in the children's section of the 'Songs of Praise' hymnal. I also remember choosing it as a hymn for my wedding slightly obstinately: "This is my favourite hymn from childhood". As a child I first loved the tune and the way it had been simply harmonised. It was an English traditional melody, and I have since been reminded that it was harmonised in 'Songs of Praise' by Vaughan Williams. I've often wondered why I have loved it, and the words are interesting in respect to the Hero's Adventure. (Below in Fig 16, the first verse is notated to give an idea of the tune, and the two other verses follow.)

There are dragons in the old days and the knight had to fight them boldly and bravely. But now the process is figurative, he doesn't have a horse and a sword, but there are still battles and 
adventures to be had. So he still needs to be on fire ('Let me set free with the sword of my youth'); he needs the protection of faith and joy to endure 'the castle of darkness'. If he works through it all he will be richly satisfied with the 'power of the truth'. There is nothing postmodern about this knight!

It's really funny though - it's the simplicity of the melody that drew me first, the words were just there and I have never before thought why I liked the message. I know this research project is all about a journey of discovery for me - this little hymn from my childhood is a clue, something that has journeyed with me most of my life.

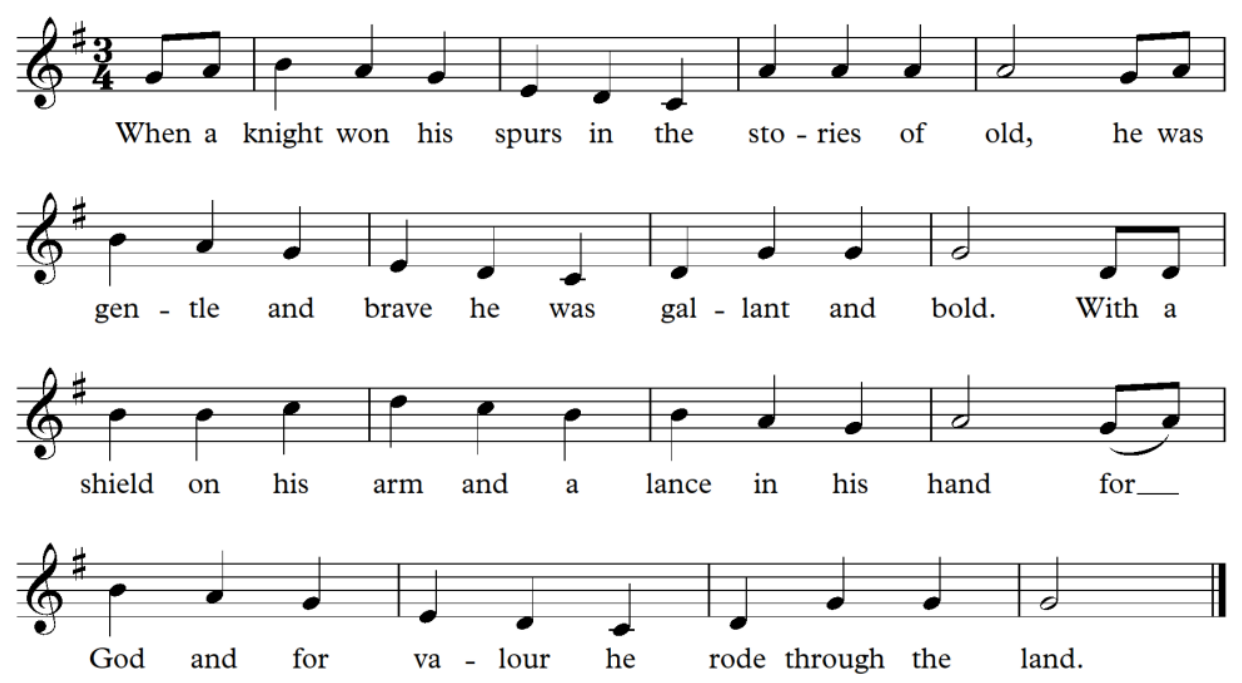

FIGURE 16: WHEN A KNIGHT WON HIS SPURS

Tune: Stowey (from an English traditional melody). Words: Jan Struther

No charger have I, and no sword by my side,

Yet still to adventure and battle I ride,

Though back into storyland giants have fled,

And the knights are no more and the dragons are dead.

Let faith be my shield and let joy be my steed

'Gainst the dragons of anger, the ogres of greed;

And let me set free, with the sword of my youth,

From the castle of darkness the power of the truth. 
I have been an "Ash-Lad" on this research adventure and have been tested to discover how to marry the heart and head, the personal and the conceptual and how to bring myself into writing so it feels authentic, but also allows critical reflection. It is hard when you are making meaning to not be drawn by your own trends and interests, your own wish to make things fit your own patterns. However I think I have also learnt a pattern or two from others and most of all the value of collaboration in thinking, writing and researching. 


\section{CHAPTER 8 \\ CONCLUSIONS}

\section{Closing Thoughts}

\subsection{Summary of research}

This thesis set out to find how research can be integrated into the practitioner training of music therapists at Masters' level. Within the thesis I explored the perceptions of a range of practitioner, researcher and educator music therapists about this issue and further investigated music therapists' (including student) stories about their experiences of the process. I also considered how my perceptions changed over the course of the project.

Participants in this research project indicated in my findings, through their contributions to discussions and interviews, that three key concepts lie at the heart of how such a synthesis might be achieved and these are the importance of:

- Fire and curiosity

- Change

- Complexity

Curriculum planning for the inclusion of research by educators, together with participants' own experience of learning as research students, was reflected on deeply in the course of the project. The following overarching issues I gained from my individual colleagues' commentaries, my own experience and the community of participants across the case study. Although in a qualitative study the sample of participants is relatively small, I hope that educators might respond to the meaning and lived experience of these synthesised findings and find valuable contribution to the dialogue and future planning for integrated research and practice. The summary identifies:

- the value of diverse approaches to learning about research and practice, to suit the contrasting environments and political cultures of institutions which support music therapy Masters' programmes

- the potential to craft specialised assessments which create an unique blend of practice and research processes and which can be specifically designed to suit the tertiary environment which houses the music therapy programme 
- the harnessing of engaged and personalised learning to capture the interest and imagination of students in their clinical practice and their own 'journeys' and which can make research concepts real and alive

- the essential core of 'ethical practice' as a fundamental pivot between research and therapy work and the need to keep it centre stage in student learning

- the importance of supervision to guide and exercise limits

- the value of the supervisor's experience in recognising creative opportunity and theorybuilding potential in student work

- the vital role of the community of learners and teachers who can collaborate, support, inspire, motivate and provide necessary containment for the process (and also share the ferocious workload that research and practice generate). However collaboration takes time and willingness and institutions may have different values about where team members can give their emphasis.

- the maintenance of research as creative practice, as something to hearten, challenge, enthuse and consolidate music therapy as a growing discipline. Students are owed the opportunity of this experience to lift Masters' research above a set of skills, or prescribed competencies to be achieved and then stored away or forgotten.

Finally I developed an integrative model of inside-outside, individual-collaborative as a recommended research-practice framework in higher education. I suggested that educators might explore working with this model to assist the integration of research and practice.

\subsection{Future steps}

Inevitably these concepts are not generalisable, and are only representative of some music therapists' viewpoints at a snapshot in time. However I was surprised by the strength of some of the core beliefs and related perceptions of these 19 experienced participants, who were mostly unconnected across their institutions. I hope that others might recognise some complementary understanding and find connections with their own experience in the synthesis of viewpoints expressed. Others might also be inspired to take the ideas forward and I too could explore in new directions. I was particularly interested in the artistry of participants' story-telling during this project and in the use of improvisation as an interviewing technique in our field. I would look forward to developing further learning and expertise with these areas as research approaches.

Further qualitative research in the field of Masters' education could explore the specific ethical challenges of practice-based work for students, as has been started by Farrant and colleagues (2011) 
in London, and also possibilities for developing communities of research and practice, which involve student apprentices. In-depth research on the curriculum and styles of teaching practice could refine and develop areas highlighted in the current inquiry. There might also be opportunities to survey larger groups of educators about their attitudes and practice with regard to research, including chosen methodologies, ethical approaches and styles of assessment. Students themselves could be more fully involved as participants in a variety of future topics, including mixed methods or quantitative studies.

\subsection{Coda}

I return to the metaphor of 'Improvising to Composition' introduced in section 3.8, where I outlined the map of the findings. In a research journal entry, I captured some conversations with composers:

Talking with my friends and composer colleagues Dave Lisik and John Psathas, as we waited at two different photocopiers in the Te Kōkī NZSM offices recently, I was grateful for some thoughts they shared with me about the difference between improvisation and composition. I have acknowledged being more improviser than composer, and here I needed to find the ending of this piece of writing, which is clearly 'composed'. Dave observed reassuringly that improvisation to composition could be considered as a continuum, particularly as jazz continues to include improvisation for performers within the composed music. So rather than 'one thing or another' they are related, and compositions can be positioned differently along the continuum according to your viewpoint as composer.

A distinction I found helpful was John's thought that the improviser is focussed very strongly in the immediate moment (which I would certainly understand) but calls on a bank of experiences and materials while concentrating on that moment. Composers, he reflected, are thinking quite differently of the past and the future when they craft the composition. They are thinking of where they have come from and where is their destination. My husband clarifies this too, suggesting that the piece really only exists in the imagination until it is performed. It is written down - sure - but the music is held in performance, so there is always a 'future' imagined by the composer. Perhaps that is true for the reader of a thesis too?

(RJ $9^{\text {th }}$ April 2013)

My hope is that music therapists can continue to honour the requirement to plan, execute and complete their research, whilst also maintaining a 'vagabonding' or improvisational stance, which often characterises music therapy work. This speaks to me in a personal way of the integration of research and practice. 
Throughout the research, I have made a conscious effort to help my understanding through links with varied arts media, and I leave the thesis with a drawing in keeping with the spirit of my topic: the curious practitioner who may also be a researcher.

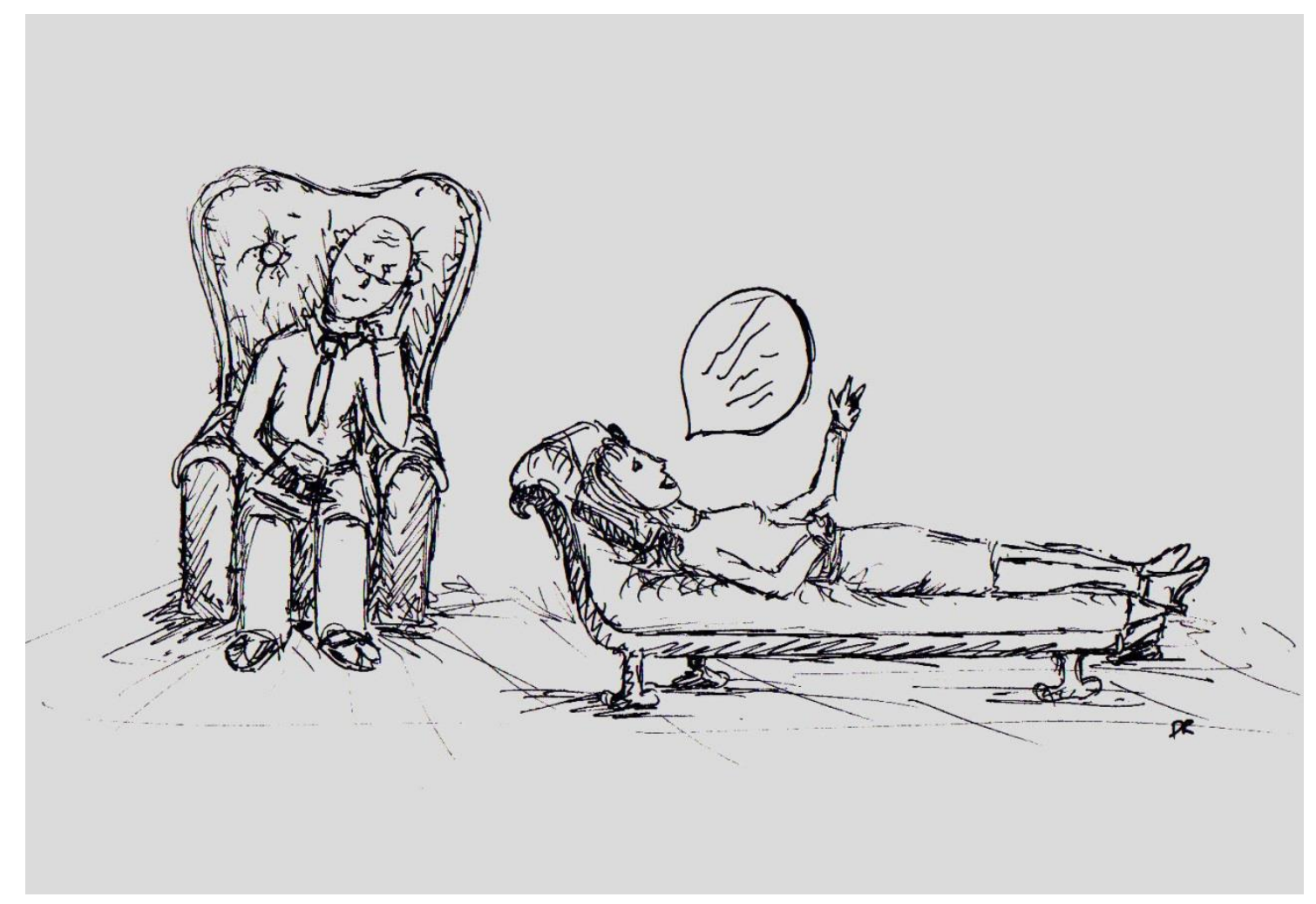

FIGURE 17: "EVERY ANALYST WHO IS AWAKE WHILST WORKING IS ENGAGING IN RESEARCH" - AFTER WINNICOTT (DOROTHY RAPHAEL) 


\section{References}

Abrams, B. (2010). Evidence-based music therapy practice: An integral understanding. Journal of Music Therapy, 47(4), 351-379.

Aigen, K. (1991). The roots of music therapy: Towards an indigenous research paradigm. Unpublished Doctoral Dissertation, New York University, New York.

Aigen, K. (1996). The role of values in qualitative music therapy research. In M. Langenberg, K. Aigen \& J. Frommer (Eds.), Qualitative music therapy research: beginning dialogues (pp. 933). Gilsum, NH: Barcelona Publishers.

Aigen, K. (1998). Creativity in qualitative music therapy research. Journal of Music Therapy, $X X X V(3), 150-175$.

Aigen, K. (2005). Music-centred music therapy. Gilsum, NH: Barcelona Publishers.

Aldridge, D. (1990). The development of a research strategy for music therapists in a hospital setting. The Arts in Psychotherapy, 17(3), 231-237.

Aldridge, D. (Ed.) (2005). Case study designs in music therapy. London: Jessica Kingsley Publishers.

Alvin, J. (1975). Music therapy. London: Hutchinson.

American Music Therapy Association (March 2009). AMTA Professional Competencies. Silver Spring, MD: AMTA.

Amir, D. (1992). Awakening and expanding the self: Meaningful moments in the music therapy process as experienced and described by music therapists and music therapy clients. Unpublished Doctoral Dissertation, New York University, New York.

Ansdell, G., \& Pavlicevic, M. (2001). Beginning research in the arts therapies: a practical guide. London: Jessica Kingsley.

Ansdell, G., \& Pavlicevic, M. (2004). Community music therapy. London: Jessica Kingsley.

Ansdell, G., \& Pavlicevic, M. (2010). Practicing "gentle empiricism"- the Nordoff Robbins research heritage. Music Therapy Perspectives, 28(2), 131-139.

Ansdell, G., Davidson, J., Magee, W. L., Meehan, J., \& Procter, S. (2010). From "This F***ing life" to "that's better" ... in four minutes: an interdisciplinary study of music therapy's "present moments" and their potential for affect modulation. Nordic Journal of Music Therapy, 19, 3

Asbjørnsen, P., \& Moe, J. (1960). Norwegian folk tales (C. Norman \& P. Shaw Iversen, Trans.). Oslo: Dreyers Forlag.

Association of Professional Music Therapists (2001). A career in music therapy. London: APMT UK (Now British Association for Music Therapy BAMT). 
Attwood, M. (2000). The blind assassin. New York: Random House.

Austin, D., \& Forinash, M. (2005). Arts-based research. In B. Wheeler (Ed.), Music therapy research (2nd Ed.) (pp. 458-471). Gilsum, NH: Barcelona Publishers.

Australian Music Therapy Association (2004). Competency standards in music therapy. Malvern, Victoria: Australian Music Therapy Association.

Baker, F. (2007). Enhancing the clinical reasoning skills of music therapy students through problem based learning. Nordic Journal of Music Therapy, 16(1), 28-41.

Baker, F., \& Krout, R. E. (2011). Collaborative peer lyric writing during music therapy training: a tool for facilitating students' reflections about clinical practicum experiences. Nordic Journal of Music Therapy, 20(1), 62-89.

Barbour, R. (2007). Doing focus groups. London: Sage Publications Ltd.

Barnacle, R., \& Dall'Alba, G. (2011). Research degrees as professional education. Studies in Higher Education, 36(4), 459-470.

Barnett, R. (2005). Recapturing the universal in the university. Educational Philosophy and Theory, 37(6), 785-797.

Barry, P., \& O'Callaghan, C. (2008). Reflexive journal writing: A tool for music therapy clinical practice development. Nordic Journal of Music Therapy, 17(1), 55-66.

Barry, P., \& O'Callaghan, C. (2009). Music therapists' practice-based research in cancer and palliative care: creative methods and situated findings. Voices: A World Forum For Music Therapy, 9(1). Retrieved from https://normt.uib.no/index.php/voices/article/view/53/255

Bell, J. (2010). Doing your research project : a guide for first-time researchers in education, health and social science. Maidenhead: McGraw-Hill Open University Press.

Bergstrøm-Nielsen, C. Graphic notation in music therapy: a discussion of what to notate in graphic notation, and how. Approaches: Music Therapy \& Special Music Education, 1(2), 72-92.

Bilsker, D., \& Goldner, E. M. (2000). Teaching evidence-based practice in mental health. Research on Social Work Practice, 10(5), 664-669.

Bonde, L. O. (2011). Health musicing - music therapy or music and health? A model, empirical examples and personal reflections. Music and Arts in Action, 3(2), 120-140.

Bradt, J., Dileo, C., Grocke, D., \& Magill, L. (2011). Music interventions for improving psychological and physical outcomes in cancer patients. Cochrane Database of Systematic Reviews (Online) 8(Cochrane AN: CD006911; PMID: 21833957

Braun, V., \& Clarke, V. (2006). Using thematic analysis in psychology. Qualitative Research in Psychology, 3, 77-101. 
Brew, A. (2001). Conceptions of research: a phenomenographic study. Studies in Higher Education, $26(2), 271-285$.

Brew, A. (2012). Teaching and research: New relationships and their implications for inquiry-based teaching and learning in higher education. Higher Education Research \& Development, 31(1), 101-114.

Brew, A., \& Ginns, P. (2008). The relationship between engagement in the scholarship of teaching and learning and students' course experiences. Assessment \& Evaluation in Higher Education, $33,535-545$.

Brown, S. (1997) Supervision in context: a balancing act. British Journal of Music Therapy, 11(1).Bruscia, K. (1989). The content of music therapy education at undergraduate and graduate levels. Music Therapy Perspectives, 7(1), 83-87.

Bruscia, K. (1998a). Defining music therapy (2nd ed.). Gilsum, NH: Barcelona Publishers.

Bruscia, K. (1998b). Standards of integrity for qualitative music therapy research. Journal of Music Therapy, $X X X V(3), 176-200$.

Bruscia, K. (2005a). Data analysis in qualitative research. In B. Wheeler (Ed.), Music therapy research (pp. 179-186). Gilsum, NH: Barcelona Publishers.

Bruscia, K. (2005b). Research topics and questions in music therapy. In B. Wheeler (Ed.), Music therapy research. Gilsum, NH: Barcelona Publishers.

Bunt, L. (1994). Music therapy: an art beyond words. London: Routledge.

Bunt, L., \& Hoskyns, S. (Eds.). (2002). The handbook of music therapy. London: Brunner-Routledge.

Burr, V. (2004). Constructivism. In M. S. Lewis-Beck, A. Bryman \& T. F. Liao (Eds.), The Sage Encyclopedia of Social Science Research Methods. London: Sage Publications Ltd.

Cahnmann, M. (2006). Reading, living, and writing bilingual peotry as ScholARTistry in the language arts classroom. Language Arts, 83(4), 342-352.

Campbell, J., \& Moyers, B. (1988). The power of myth. New York: Anchor Books.

Cleverly, D. (2003). Implementing inquiry-based learning in nursing. London: Routledge.

Cochran-Smith, M., \& Lytle, S. L. (1993). Inside/outside : teacher research and knowledge: New York : Teachers College Press, c1993.

Cochran-Smith, M., \& Lytle, S. L. (2009). Inquiry as stance: practitioner research for the next generation. New York: Teachers College Press. 
Cornforth, S. (2011). Ethics for research and publication. In K. Crocket, M. Agee \& S. Cornforth (Eds.), Ethics in practice: a guide for counsellors (pp. 80-92). Wellington: Dunmore Publishing Ltd.

Craft, A., Gardner, H., \& Claxton, G. (Eds.). (2008). Creativity, wisdom, and trusteeship: exploring the role of education. Thousand Oaks: Corwin Press, SAGE Publications.

Crotty, M. (1998). The foundations of social research: meaning and perspective in the research process. St Leonards, NSW: Allen \& Unwin.

Curtis Jenkins, G. (2002). Good money after bad? The justification for the expansion of counselling services in primary health care. In C. Feltham (Ed.), What's the good of counselling \& psychotherapy? The benefits explained. (pp. 196-210). London/Thousand Oaks: Sage Publications.

Curtis, S. (2013). Sorry it has taken so long: continuing feminist dialogues in music therapy. Voices: $a$ World Forum for Music therapy, 13(1). Retrieved from https://normt.uib.no/index.php/voices/article/view/688/572

Darnley-Smith, R., \& Patey, H. (2003). Music therapy. London: Sage Publications.

Davis, W. B., Gfeller, K. E., \& Thaut, M. H. (2008). An introduction to music therapy: theory and practice (3rd ed.). Silver Spring, Maryland: The American Music Therapy Association, Inc.

De Vaal, E. (2011). The hare with amber eyes: a hidden inheritance. London: Vintage Books.

Denzin, N. K., \& Lincoln, Y. (2005a). Introduction: The discipline and practice of qualitative research. In N. K. Denzin \& Y. Lincoln (Eds.), The Sage handbook of qualitative research (3rd ed., pp. 1-32). Thousand Oaks: Sage Publications.

Denzin, N. K., \& Lincoln, Y. (2005b). The Sage handbook of qualitative research (3rd ed.). Thousand Oaks: Sage Publications.

Dileo Maranto, C., \& Bruscia, K. (Eds.). (1987). Perspectives on music therapy education and training (Vol. 1). Philadelphia: Temple University, Esther Boyer College of Music.

Dileo Maranto, C., \& Bruscia, K. (Eds.). (1988). Methods of teaching and training the music therapist (Vol. 2). Philadelphia: Temple University, Esther Boyer College of Music.

Duerkson, G. (1994). Prologue (Reprinted Comment from 1968 Journal). In J. Standley \& C. Prickett (Eds.), Research in music therapy: a tradition of excellence. Outstanding reprints from the Journal of Music Therapy 1964-1993. Silver Spring MD: National Association for Music Therapy.

Edwards, J. (2002). Using the Evidence Based Medicine framework to support music therapy posts in healthcare settings. British Journal of Music Therapy, 16(1), 29-34.

Edwards, J. (2005a). Developments and issues in music therapy research. In B. Wheeler (Ed.), Music therapy research. Gilsum, NH: Barcelona Publishers. 
Edwards, J. (2005b). Possibilities and problems for evidence-based practice in music therapy. The Arts in Psychotherapy, 32(4), 293-301.

Edwards, J. (2006). Thresholds between practice and research - thinking about Susan Melrose's notion of the 'signature practitioner'. Voices: a World Forum for Music therapy. Retrieved from http://testvoices.uib.no/?q=coledwards300106

Edwards, J. (Ed.). (2007). Music: promoting health and creating community in healthcare contexts. Newcastle: Cambridge Scholars Publishing.

Edwards, J. (2013). Universities, Music Therapy, and Change Advocacy. Voices: a World Forum for Music therapy. Retrieved from http://testvoices.uib.no/?q=fortnightly-columns/2013universities-music-therapy-and-change-advocacy

Ellwood, R. (1999). The politics of myth: a study of C.G. Jung, Mircea Eliade and Joseph Campbell. Albany: State University of New York Press.

Epstein, I. (2001). Using available clinical information in practice-based research. In I. Epstein \& S. Blumenfield (Eds.), Clinical data-mining in practice-based research. Binghampton NY: Haworth Social Work Practice Press.

Esterhuizen, P., Freshwater, D., \& Sherwood, G. (2008). Developing a reflective curriculum. In D. Freshwater, B. J. Taylor \& G. Sherwood (Eds.), International textbook of reflective practice in nursing (pp. 177-195). Chichester: Wiley-Blackwell.

Etherington, K. (2004). Becoming a reflexive researcher: using our selves in research. London: Jessica Kingsley.

Evans, D. (2003). Hierarchy of evidence: a framework for ranking evidence evaluating healthcare interventions. Journal of Clinical Nursing, 12, 17-84.

Farrant, C., Pavlicevic, M., \& Tsiris, G. (2011). Towards ethical research: a guide for music therapy and music and health practitioners, researchers and students. London: Nordoff-Robbins.

Ferrer, A. E. (2012). Music therapy profession: current status, priorities and possible future directions. Unpublished PhD Thesis, Ohio State University, Ohio.

Flower, C., Hoskyns, S., \& Purcell, S. (2004). The value of a co-mentor process for music therapist teachers and clinicians. Paper presented at the 6th European Music Therapy Congress, Jyvaskyla Finland, June 2004.

Forinash, M. (1999). The phenomenology of music therapy with the teminally ill. Unpublished Doctoral Dissertation, New York University, New York.

Forinash, M. (Ed.). (2001). Music therapy supervision. Gilsum, NH: Barcelona Publishers.

Freshwater, D. (2008). Developing an evidence-based approach to clinical practice. In D. Freshwater, B. J. Taylor \& G. Sherwood (Eds.), International textbook of reflective practice in nursing (pp. 53-70). Chichester: Wiley-Blackwell. 
Freshwater, D., Taylor, B. J., \& Sherwood, G. (Eds.). (2008). International textbook of reflective practice in nursing. Chichester: Wiley-Blackwell.

Fry, J., Klages, C., \& Venneman, S. (2013). Using a written journal technique to enhance inquirybased reflection about teaching. Reading Improvement, 50, 54-60.

Gardner Stelómethet, E. B. (2008). Iyómex, Éyqwlha, Yú: Wqwlha, Language as musical space: an aesthetic approach to research. Voices: a World Forum for Music therapy, 8(3). Retrieved from https://normt.uib.no/index.php/voices/article/view/412/336

Gentleman Byers, J. J., \& Forinash, M. (Eds.). (2004). Educators, therapists, artists on reflective practice. New York: Lang.

Gfeller, K. E. (1995). The status of music therapy research. In B. Wheeler (Ed.), Music therapy research: quantitative and qualitative perspectives (1st ed., pp. 29-63). Gilsum, NH: Barcelona Publishers.

Gilroy, A. (2006). Art therapy, research and evidence-based practice. London: Sage.

Gilroy, A. (2011a). Commentary: art therapy with children. In A. Gilroy (Ed.), Art therapy research in practice. Oxford: Peter Lang.

Gilroy, A. (Ed.). (2011b). Art therapy research in practice. Oxford: Peter Lang.

Goldfried, M. R. (2010). The future of psychotherapy integration: closing the gap between research and practice. Journal of Psychotherapy Integration, 20(4), 386-396.

Goodman, K. (2011). Music therapy education and training: from theory to practice. Springfield, Illinois: Charles C. Thomas.

Goodman, N. (1978). Ways of Worldmaking. Hassocks, Sussex: Harvester Press.

Grocke, D. (2009). Music therapy research and the mental health-well-being continuum. Australian Journal of Music Therapy, 20(Special Issue), 6-15.

Grocke, D. (1999). A phenomenological study of pivotal moments in GIM therapy. Unpublished Doctoral Dissertation, University of Melbourne, Melbourne.

Guba, E. G., \& Lincoln, Y. S. (1994). Competing paradigms in qualitative research. In N. K. Denzin \& Y. S. Lincoln (Eds.), Handbook of qualitative research (pp. 105-117). Thousand Oaks, CA: Sage Publications.

Guba, E. G., \& Lincoln, Y. S. (2005). Paradigmatic controversies, contradictions and emerging confluences. In N. K. Denzin \& Y. S. Lincoln (Eds.), The Sage handbook of qualitative research (3rd ed., pp. 91-215). Thousand Oaks: Sage Publications.

Hadley, S. (2006). Developing a feminist pedagogical approach in music therapy. In S. Hadley (Ed.), Feminist perspectives in music therapy. Gilsum NH: Barcelona Publishers. 
Hadley, S. (2013). Experiencing race as a music therapist: personal narratives. Gilsum, NH: Barcelona Publishers.

Hahna, N. D. (2011). Conversations from the Classroom: Reflections on Feminist Music Therapy Pedagogy in Teaching Music Therapy. Unpublished Doctoral Dissertation, Lesley University.

Hahna, N. D., \& Schwantes, M. (2011). Feminist music therapy pedagogy: a survey of music therapy educators. Journal of Music Therapy, 48(3), 289-316.

Halkier, B. (2010). Focus groups as social enactments: integrating interaction and content in the analysis of focus group data. Qualitative Research, 10(1), 71-89.

Hanser, S., Butterfield-Whitcomb, J., Kawata, M., \& Collins, B. (2011). Home-based music strategies with individuals who have dementia and their family caregivers. Journal of Music Therapy, $48(1), 2-27$.

Hanser, S., \& Madsen, C. K. (1972). Comparisons of graduate and undergraduate research in music therapy. Journal of Music Therapy, 9(2), 88-93.

Hanser, S. (1999). The new music therapist's handbook. Boston: Berklee Press.

Healey, M. (2006). Linking discipline-based research with teaching to benefit student learning. Paper presented at the HERSDA Seminar, Victoria University of Wellington, New Zealand.

Heaton, J. (2004). What is secondary analysis? Reworking qualitative data. London, UK: SAGE Publications Ltd.

Henton, I. (2012). Practice-based research and counselling psychology: a critical review and proposal. Counselling Psychology Review, 27(3), 11-28.

Hepburn, A. (2006). Constructionism. . In J. Victor (Ed.), The SAGE Dictionary of Social Research Methods. London: Sage Publications.

Higgins, R. (1996). Approaches to research: a handbook for those writing a dissertation. London: Jessica Kingsley.

hooks, b. (1994). Teaching to transgress. New York: Routledge-Taylor Francis.

hooks, b. (2010). Teaching critical thinking: practice wisdom. New York \& Abingdon: Routledge/Taylor Francis.

Hoskyns, S. (1988). Studying group music therapy with offenders: research in progress. Psychology of Music, 16(1), 25-40.

Hoskyns, S. (2005). Co-mentoring in music therapy education: reflections on practice in the UK and opportunities for New Zealand. New Zealand Journal of Music Therapy, 3(1), 36-66. 
Hoskyns, S. (2011). Collaborative conversations in focus group research: music therapists reflect on combining research and practice. New Zealand Journal of Music Therapy, 9.

Hoskyns, Sarah (2012). Learning about ethical research practice: with students and with human ethics committees. Voices Resources. Retrieved October 24, 2013, from https://voices.no/community/?q=columnists

Houston, N., Ross, H., Robinson, J., \& Malcolm, H. (2010). Inside research, inside ourselves: teacher educators take stock of their research practice. Educational Action Research, 18(4), 555-569.

HPC-UK (2012). Standards of Proficiency: arts therapists. London: Health \& Care Professions Council www.hcpc-uk.org.

Johns, C. (2009). Becoming a reflective practitioner. (3rd ed.). Chichester: Wiley-Blackwell.

Jung, C., \& Von Franz, M. L. (Eds.). (1964). Man and his symbols. London: Aldus Books \& Jupiter Books.

Kahui, D. (2009). A cultural approach to music therapy in New Zealand: a cultural perspective. Unpublished Masters' Thesis, A joint award of Victoria and Massey Universities, Wellington.

Kamberelis, G., \& Dimitriadis, G. (2005). Focus groups: strategic articulations of pedagogy, politics, and inquiry. In N. K. Denzin \& Y. S. Lincoln (Eds.), The Sage Handbook of Qualitative Research (3rd Edition) (pp. 887-907). Thousand Oaks: Sage Publications.

Kamler, B. (2001). Relocating the personal: a critical writing pedagogy. Albany: State University of New York.

Kamler, B., \& Thomson, P. (2006). Reconsidering the personal. In B. Kamler \& P. Thomson (Eds.), Helping doctoral students write: pedagogies for supervision. (pp. 59-80). London: Routledge.

Karkou, V., \& Sanderson, P. (2006). Arts therapies: a research based map of the field. London: Elsevier/Churchill Livingstone.

Kedge, S., \& Appleby, B. (2009). Promoting a culture of curiosity within nursing practice. British Journal of Nursing (BJN), 18(10), 635-637.

Kelly, G. (1955). The psychology of personal constructs. NY: W.W.Norton.

Kenny, C. (1989). The field of play: a guide for the theory and practice of music therapy. Atascadero, CA: Ridgeview Publishing Co.

Kenny, C. (1998). Embracing complexity: the creation of a comprehensive research culture in music therapy. Journal of Music Therapy, $X X X V(3), 201-217$.

Kenny, C. (2002). Making sense out of culture. (Fortnightly Column). Voices: a World Forum for Music therapy. Retrieved from http://www.voices.no/?q=fortnightly-columns/2002-makingsense-out-culture 
Kenny, C. (2004). A holistic framework for aboriginal policy research. Ottawa, Ontario Canada: Status of Women Canada.Unpublished manuscript, Ottawa, Ontario, Canada.

Kenny, C. (2005). Reflections on music as knowledge. Voices: A World Forum for Music Therapy. Retrieved from http://testvoices.uib.no/?q=fortnightly-columns/2005-reflections-musicknowledge

Kitzinger, J. (1994). The methodology of focus groups: the importance of interaction between research participants. Sociology of Health and Illness, 16(1), 103-121.

Kitzinger, J., \& Barbour, R. S. (1999). Introduction: The challenge and promise of focus groups. In J. Kitzinger \& R. S. Barbour (Eds.), Developing focus group research: politics, theory and practice (pp. 156-172). London: Sage.

Kronos Quartet (Artist). (2013). La Sidounak Sayyada (Souleyman arr. Garchik) [Performance].

Krout, R. E. (2003). A Kiwi odyssey: music therapy university training in New Zealand takes flight. Voices: a World Forum for Music therapy, 3(1). Retrieved from https://normt.uib.no/index.php/voices/article/view/114/90

Krueger, R., \& Casey, M. (2000). Focus groups: a practical guide for applied research (3rd ed.). Thousand Oaks, CA: Sage Publications.

Kuper, A., Reeves, S., \& Levinson, W. (2008). Qualitative Research: An introduction to reading and appraising qualitative research. British Medical Journal, 337(16 August 2008), 404-409.

Langenberg, M., Aigen, K., \& Frommer, J. (Eds.). (1996). Qualitative music therapy research: beginning dialogues. Gilsum, NH: Barcelona Publishers.

Lather, P. (2006). Paradigm proliferation as a good thing to think with: teaching research in education as a wild profusion. International Journal of Qualitative Studies in Education, 19(1), 35-57.

Lathom, W. B. (1982). Survey of current functions of a music therapist. Journal of Music Therapy, 19(1), 2-27.

Lattas, J. (2009). Inquiry-Based Learning: a Tertiary Perspective. Agora, 44(1), 12-16.

Leavy, P. (Ed.). (2009). Method meets art: arts-based research practice. New York: Guildford Press.

Ledger, A., \& Edwards, J. (2011). Arts-based research practices in music therapy research: existing and potential developments. The Arts in Psychotherapy, 38, 312-317.

Lee, C. A. (2003). The architecture of aesthetic music therapy. Gilsum, NH: Barcelona Publishers.

Lichtman, M. (2013). Qualitative research in education: a user's guide (3rd ed.). Thousand Oaks: Sage Publications.

Lincoln, Y., \& Guba, E. (1985). Naturalistic inquiry. Newbury Park, CA: Sage Publications. 
Loades, R. (2005a). Bologna Accord Challenges European Universities to Make Changes beneath the Surface. Graduate Management News, March-April 2005, N.PAG. Retrieved from http://www.gmac.com/why-gmac/gmac-news/gmnews/2005/march-april/bologna-accordchallenges-european-universities-to-make-changes-beneath-the-surface.aspx

Loades, R. (2005b). The Bologna Accord: A European Revolution with Global Implications. Graduate Management News, Jan-Feb 2005. Retrieved from http://www.gmac.com/whygmac/gmac-news/gmnews/2005/january-february/the-bologna-accord-a-european-revolutionwith-global-implications.aspx

Lozano, J., Bono, A., Peris, J., \& Hueso, A. (2012). Competencies in higher education: a critical analysis from the capabilities approach. Journal of Philosophy of Education, 46(1), 132-147.

Luce, D. W. (2001). Collaborative learning in music therapy education as experienced in a course in the foundations and principles of music therapy. Unpublished $\mathrm{PhD}$ Thesis, Michigan State University.

Luce, D. W. (2008). Epistemological development and collaborative learning: a hermeneutic analysis of music therapy students' experience. [Article]. Journal of Music Therapy, 45(1), 21-51.

Lytle, S. L., \& Cochran-Smith, M. (1992). Teacher research as a way of knowing. Harvard Educational Review, 62(4), 447-474.

Mabry, L. (2008). Case study in social research. In P. Alasuutari, L. Bickman \& J. Brannen (Eds.), The Sage handbook of social research methods (pp. 214-227). London/Thousand Oaks: Sage Publications

Madsen, C. K., \& Furman, C. E. (1984). Graduate versus undergraduate scholarship: research acquisition and dissemination. Journal of Music Therapy, 21, 170-176.

Madsen, C. K., LeBlanc, A., Flowers, P., Radocy, R. E., Webster, P., \& Yarbrough, C. (1998). A passion for research. Teaching Music, 6(2), 38-40.

Malloch, S., Shoemark, H., Crncek, R., Newnham, C., Campbell, P., Prior, M., et al. (2012). Music therapy with hospitalized infants - the art and science of communicative musicality. Infant Mental Health Journal, 33(4), 386-399.

Malloch, S., \& Trevarthen, C. (2009). Communicative musicality: exploring the basis of human companionship. Oxford: Oxford University Press.

Mayes, C. (2005). Jung and education: elements of an archetypal pedagogy. Lanham, Maryland: Rowman \& Littlefield Education.

McAllister, L., Paterson, M., Higgs, J., \& Bithell, C. (Eds.). (2010). Innovations in allied health fieldwork education : a critical appraisal. . Rotterdam: Sense Publishers.

McCormack, B. (2009). Practitioner research. In S. Hardy, A. Titchen, B. McCormack \& K. Manley (Eds.), Revealing nursing expertise through practitioner inquiry (pp. 31-54). Chichester: Wiley-Blackwell. 
McCormack, B. (2011). Engaged scholarship and research impact:integrating the doing and using of research in practice. Journal of Research in Nursing, 16(2), 111-127.

McFerran, K. (2006). Hidden and Professional Questions in Music Therapy Research Voices: A World Forum for Music Therapy. Retrieved from http://testvoices.uib.no/?q=colmcferran270306

McFerran, K., \& Grocke, D. (2007). Understanding music therapy experiences through interviewing: a phenomenological microanalysis. In T. Wosch \& T. Wigram (Eds.), Microanalysis in music therapy (pp. 273-284). London: Jessica Kingsley Publishers.

McLeod, J. (2001). Qualitative research in counselling and psychotherapy. London/ Thousand Oaks: Sage Publications.

McLeod, J. (2002a). Case studies and practitioner research: building knowledge through systematic inquiry into individual cases. Counselling and Psychotherapy Research, 2(4), 265-268.

McLeod, J. (2002b). Research in person-centred, experiential and humanistic counselling and psychotherapy: meeting new challenges. Counselling and Psychotherapy Research, 2(4), 259262.

McLeod, J. (2004). Changing the landscape through research: what you can do to make a difference. Healthcare Counselling and Psychotherapy Journal, 4(4), 4-6.

McLeod, J. (2010). Case study research in counselling and psychotherapy. London/Thousand Oaks: Sage Publications.

McNamara, O. (2002). Evidence-based practice through practice-based evidence. In O. McNamara (Ed.), Becoming an evidence-based practitioner: a framework for teacher-researchers. London: Routledge/Falmer.

Michel, D. E., \& Madsen, C. K. (1969). Examples of research in music therapy as a function of undergraduate education. Journal of Music Therapy, 6(1), 22-25.

MThNZ (2012). Code of ethical conduct for music therapists registered in New Zealand (pp. 4). Wellington, NZ: Music Therapy New Zealand.

Nachmanovitch, S. (1990). Improvisation in life and art. New York: Putnam.

Naubert-Riser, C. (1988). Klee. London: Studio Editions Ltd.

Nichols, R. (1982). A musical synopsis. In N. John (Ed.), Pelleas \& Melisande: opera guide 9 (pp. 13-22). London: John Calder (in association with English National Opera and The Royal Opera).

O'Callaghan, C. (2001). Music therapy's relevance in a cancer hospital researched through a constructivist lens. Unpublished $\mathrm{PhD}$ thesis, University of Melbourne, Melbourne. 
O'Callaghan, C. (2005). Qualitative data-mining through reflexive journal analysis: implications for music therapy practice development. [research]. Journal of Social work Research and Evaluation 6(2), 219-231.

O'Callaghan, C. (2009). Objectivist and constructivist music therapy resarch in oncology and palliative care: an overview and reflection. Music and Medicine, 1(1), 41-60.

O'Callaghan, C., \& Magill, L. (2009). Effect of music therapy on oncologic staff bystanders: a substantive grounded theory. Palliative \& Supportive Care, 7(2), 219-228.

Odell-Miller, H., \& Sandford, S. (2009). Update on music therapy in the United Kingdom. Voices: $a$ World Forum for Music Therapy. Retrieved from http://testvoices.uib.no/?q=country/monthuk_march2009

Osterman, K. F., \& Kottcamp, R. B. (1993). Reflective practice for educators: improving schooling through professional development. California: Corwin Press/ Sage Publications.

Pavlicevic, M., Ansdell, G., Procter, S., \& Hickey, S. (2009). Presenting the Evidence (2nd Edition), the up to date guide for music therapists responding to demands for clinical effectiveness and evidence-based practice. Available from http://www.nordoffrobbins.org.uk/musicTherapy/research/index.html

Pettifer, M. (2004). Editorial: Looking backwards ... looking forwards. Healthcare Counselling and Psychotherapy Journal, 4(4), 2.

Piaget, J. (1953). The origin of intelligence in the child. London: Routledge \& Kegan Paul.

Piaget, J. (1955). The language and thought of the child. New York: World.

Price, B. (2003). Studying nursing using problem-based \& enquiry-based learning. Basingstoke, Hampshire: Palgrave-MacMillan.

Psathas, J. (2010). The New Zeibekiko. Wellington: Promethean Editions.

Pugsley, L. (2008). Expectation and experience: dissonances between novice and expert perceptions in medical education research. Medical Education, 42(9), 866-871.

Ratcliffe, M., Bartholomew, H., Hames, V., Hind, A., Leach, J., Millar, R., et al. (2005). Evidencebased practice in science education : the researcher-user interface. Research Papers in Education., 20(2), 169-186.

Richards, L. (2009). Handling qualitative data: a practical guide (2nd ed.). London: Sage Publications Ltd.

Rickson, D. J. (2010). The development of a music therapy school consultation protocol for students with high or very high special education needs. Unpublished $\mathrm{PhD}$ Thesis, Massey University \& Victoria University of Wellington, Wellington.

Robb, S. L. (2012). Gratitude for a complex profession: The importance of theory-based research in music therapy. Journal of Music Therapy, 49(1), 2-6. 
Rolvsjord, R., Gold, C., \& Stige, B. (2005). Research rigour and therapeutic flexibility: rationale for a therapy manual developed for a randomised controlled trial. Nordic Journal of Music Therapy, 14(1), 15-32.

Rubin, K. (2005). Standardizing European Higher Education. International Educator (Washington, D.C.), 14(3), 7-8.

Rusinko, C. (2010). Integrating sustainability in higher education: a generic matrix. International Journal of Sustainability in Higher Education, 11(3), 250-259.

Ruud, E. (1998). Science as Metacritique. [Reflections on research]. Journal of Music Therapy, $X X X V(3), 218-224$.

Ruud, E. (2005). Philosophy and theory of science. In B. Wheeler (Ed.), Music therapy research. (pp. 33-44). Gilsum, NH: Barcelona Publishers.

Ruud, E. (2010). Music Therapy: a perspective from the humanities. Gilsum, NH: Barcelona Publishers.

Saldaňa, J. (2009). The coding manual for qualitative researchers. London/Thousand Oaks: Sage Publications.

Schlosser, R.W., Wendt, O. \& Sigafoos, J. (2007). Not all systematic reviews are created equal: Considerations for appraisal. Evidence-Based Communication Assessment and Intervention. $1,138-150$.

Scholl, A. (2011). Music for a while. From: Solitude: songs and arias by Henry Purcell 1659-1695. (Recorded) Bagnacavallo, Italy: Decca Music Group Ltd.

Schön, D. A. (1987). Educating the reflective practitioner. San Francisco: Jossey-Bass/Wiley.

Schwartzberg, E. T., \& Silverman, M. (2011). Categorization by competency of studies involving music therapy students in the Journal of Music Therapy 1964-2008. Music Therapy Perspectives, 29, 50-64.

Shapiro, N. (2005). Sounds in the world: Multicultural influences in music therapy in clinical practice and training. Music Therapy Perspectives, 23, 29-35.

Shoemark, H. (2006). Response to Jane Edwards article 'Thresholds between practice and research '. Voices: a World Forum for Music therapy. Retrieved from http://voices.no/?q=content/response-jane-edwards-column-thresholds-between-practice-andresearch

Shoemark, H. (2011). Translating 'infant directed singing' into a strategy for the hospitalized family. In J. Edwards (Ed.), Music therapy and parent-infant bonding (pp. 161-178). Oxford: Oxford University Press.

Sigafoos, J. (2009) Systematic reviews in evidence-based educational practice. Conference paper. $2^{\text {nd }}$ Educational Psychology Forum. Victoria University of Wellington. $16^{\text {th }}$ November 2009. 
Sloboda, J. A. (1985). The musical mind. Oxford: Clarendon Press.

Smeijsters, H. (1997). Multiple perspectives: a guide to qualitative research in music therapy. Gilsum NH: Barcelona Publishers.

Smeijsters, H., \& Aasgaard, T. (2005). Qualitative case study research. In B. Wheeler (Ed.), Music therapy research (2nd ed.). Gilsum NH: Barcelona Publishers.

Smith, P. (Ed.). (1997). Research mindedness for practice; an interactive approach for nursing and health care. Edinburgh: Churchill Livingstone.

Somerville, M. (2011). Body/place journal writing. In M. Somerville, B. Davies, K. Power \& P. De Carteret (Eds.), Place pedagogy change (pp. 15-28). Rotterdam: Sense Publishers.

Sparkes, A. C. (2007). Embodiment, academics, and the audit culture: a story seeking consideration. Qualitative Research, 7(7), 521-550.

Stake, R. (1995). The art of case study research. Thousand Oaks: Sage Publications.

Stake, R. (2005). Qualitative case studies. In N. K. Denzin \& Y. S. Lincoln (Eds.), The Sage handbook of qualitative research (3rd ed., pp. 443-466). Thousand Oaks: Sage Publications.

Standley, J., \& Prickett, C. (Eds.). (1994). Research in music therapy: a tradition of excellence. Outstanding reprints from the Journal of Music Therapy 1964-1993. Silver Spring MD: National Association for Music Therapy.

Steele, A. L., \& Young, S. (2011). A descriptive study of Myers-Briggs personality types of professional music educators and music therapists with comparisons to undergraduate majors. Journal of Music Therapy, 48(1), 55-73.

Stewart, R. E., Wiltsey Stirman, S., \& Chambless, B. (2012). A qualitative investigation of practicing psychologists' attitudes toward research-informed practice: implications for dissemination strategies. Professional Psychology: Research and Practice, 43(2), 100-109.

Stige, B. (2002). Culture-centred music therapy. Gilsum NH: Barcelona.

Stige, B. (2011). Reflections on Tony Wigram's contribution to Nordic music therapy. Voices: a World Forum for Music therapy. Retrieved from http://testvoices.uib.no/?q=fortnightlycolumns/2012-reflections-tony-wigram-s-contribution-nordic-music-therapy

Stige, B., Ansdell, G., Elefant, C., \& Pavlicevic, M. (Eds.). (2010). Where music helps: community music therapy in action and reflection. Farnham: Ashgate Publishing.

Stirling, E. (2011). Collaboration, education, frustration: integrating art therapy into the school setting. In A. Gilroy (Ed.), Art therapy research in practice. Oxford: Peter Lang.

Taylor, B. J. (2006) Reflective practice: A guide for nurses and midwives, $\left(2^{\text {nd }}\right.$ ed.). Milton Keynes: Open University Press. 
Taylor, B. J. (2008). Reflexivity: using reflection as an approach to research. In D. Freshwater, Taylor, B.J. \& Sherwood, G. (Ed.), International textbook of reflective practice in nursing. Chichester: Wiley-Blackwell.

Teachman, B. A., Drabick, D. A. G., Hershenberg, R., Vivian, D., Wolfe, B. E., \& Goldfried, M. R. (2012). Bridging the gap between clinical research and clinical practice: introduction to the special section. [Introduction ]. Psychotherapy, 49(2), 97-100.

Tremain, R. (2010). Trespass. London: Chatto \& Windus.

Tuhiwai Smith, L. (2005). On tricky ground: researching the native in the age of uncertainty. In N. K. Denzin \& Y. Lincoln (Eds.), The Sage handbook of qualitative research (pp. 85-108). Thousand Oaks: Sage Publications.

Warr, D. (2005). 'It was fun... but we don't usually talk about these things': analyzing sociable interaction in focus groups. Qualitative Inquiry, 11, 200-225.

Wallace, B. (2008a). The early seedbed of the growth of TASC: Thinking actively in a social context. In B. Wallace (Ed.), TASC International: Thinking actively in a social context: theory and practice (pp. 7-21). Bicester, Oxon: AB Academic Publishers.

Wallace, B. (Ed.) (2008b). TASC international. Thinking actively in a social context: theory and practice. Bicester, Oxon: AB Academic Publishers.

Wallace, B., Bernadelli, A., Molyneux, C., \& Farrell, C. (2012). TASC: Thinking actively in a social context. A universal prolem-solving process: a powerful tool to promote differentiated learning experiences. Gifted Education International, 28, 58-83.

Watson, T. (2005). Steering a path through change: observations on the process of training. British Journal of Music Therapy, 19(1), 9-15.

Welch, A., \& Dawson, P. (2006). Closing the gap: collaborative learning as a strategy to embed evidence within occupational therapy practice. Journal of Evaluation in Clinical Practice, 12(2), 227-238.

Wells, M., Maschi, T., \& Yoder Slater, G. (2012). Integration of research and practice: innovations and challenges in social work programs. [Survey research]. Social Work Education: The International Journal, 31(3), 331-346.

Wenger, E. (1998). Communities of practice: learning, meaning and identity. Cambridge: Cambridge University Press.

Wheeler, B. (2005a). Overview of music therapy research. In B. Wheeler (Ed.), Music therapy research (pp. 3-19). Gilsum, NH: Barcelona.

Wheeler, B. (Ed.). (2005b). Music therapy research (2nd ed.). Gilsum, NH: Barcelona Publishers.

Wheeler, B., \& Kenny, C. (2005). Principles of qualitative research. In B. Wheeler (Ed.), Music therapy research (2nd ed.). Gilsum, NH: Barcelona Publishers. 
Wheeler, B., Shultis, C., \& Polen, D. (2005). Clinical training guide for the student music therapist. Gilsum NH: Barcelona Publishers.

Wheeler, B. (2008). Personal communication.

Wheeler, S., \& Elliott, R. (2008). What do counsellors and psychotherapists need to know about research. Counselling and Psychotherapy Research, 8(2), 133-135.

Whitehead, J. (2008). How can we use TASC to develop out talents in the gifts we create? How can TASC help us as we account for our lives in our living educational theories? Gifted Education International, 24(2/3), 179-189.

Wigram, T. (1993). Music therapy research to meet the demands of health and educational services: research and literature analysis. In M. Heal \& T. Wigram (Eds.), Music therapy in health and education (pp. 137-152). London: Jessica Kingsley Publishers.

Wigram, T. (2002). Indications in music therapy: evidence from assessment that can identify the expectations of music therapy as a treatment for autistic spectrum disorder(ASD); meeting the challenge of Evidence Based Practice. British Journal of Music Therapy, 16(1), 11-28.

Wigram, T. (2005) Music and sound vibration: testing hypotheses as a series of case studies. In D. Aldridge (Ed.) Case study designs in music therapy. London: Jessica Kingsley Publishers.

Wigram, T. (2009). Supervision of PhD doctoral research. In H. Odell-Miller \& E. Richards (Eds.), Supervision of music therapy: a theoretical and practical handbook (pp. 173-191). London \& New York: Routledge.

Wigram, T., De Backer, J., \& Van Camp, J. (1999). Music therapy training: a process to develop the musical and therapeutic identity of the music therapist. In T. Wigram \& J. De Backer (Eds.), Clinical applications of music therapy in developmental disability, paediatrics and neurology (pp. 282-297). London: Jessica Kingsley.

Wigram, T., Nygaard Pedersen, I., \& Bonde, L. O. (2002). A comprehensive guide to music therapy: theory, clinical practice, research and training. London: Jessica Kingsley.

Wilber, K. (2000). A brief history of everything. Boston, Massachusetts: Shambhala Publications.

Willig, C. (2001). Introducing qualitative research in psychology: adventures in theory and method. Buckingham \& Philadelphia: Open University Press.

Wolfe, B. E. (2012). Healing the research-practice split: let's start with me. Psychotherapy, 49(2), 101-108.

World Federation of Music Therapy (1997). Bulletin 1: WFMT.

Wosch, T. \& Wigram, T. (Eds.) (2008). Microanalysis in music therapy. London: Jessica Kingsley.

Yin, R. K. (2009). Case study research: design and methods (4th ed.). Thousand Oaks, CA: Sage. 


\section{Appendices}

\subsection{Appendix 1: Pilot Work for PhD Proposal}

Summary of Interviews and student commentary. Keynote Address: Music

Therapy New Zealand Annual Conference, University of Otago Sept 2006

\begin{tabular}{|c|c|}
\hline $\begin{array}{l}\text { Professor and UK Programme Leader } \\
\text { Interviewed } 6^{\text {th }} \text { July } 2006\end{array}$ & $\begin{array}{l}\text { Professor and UK Programme Leader } \\
\text { Interviewed } 12^{\text {th }} \text { July } 2006\end{array}$ \\
\hline $\begin{array}{l}\text { - Experience of research and practice } \\
\text { Influence and inspiration of other } \\
\text { clinical researchers, basis in clinical } \\
\text { practice; } \\
\text { 31 MA projects developed with } \\
\text { strong clinical focus related to } \\
\text { employment (subject areas - autism, } \\
\text { older people, learning disabilities, } \\
\text { mental health; generic ones; } \\
\text { - Research an exciting developmental } \\
\text { process or a 'huge chore'; } \\
\text { - Innovation in student projects; } \\
\text { Idea of 'Scrutiny' - learning more } \\
\text { than you solve! } \\
\text { Developing 'methods' teaching; } \\
\text { - Contrasting approaches in clinical } \\
\text { and research supervision; } \\
\text { Two-year Masters' - two streams: } \\
\text { case-based (critically evaluated); set } \\
\text { up clinical research; } \\
\text { Link with humanities research. }\end{array}$ & $\begin{array}{l}\text { Experience of research and practice } \\
\text { - Influence of early research background, } \\
\text { wanting to bring this new approach to } \\
\text { training course; } \\
\text { - Reflects later on 'pushing the research } \\
\text { agenda', returns PgDip to experiential } \\
\text { learning and a final clinical project; } \\
\text { - Inspiration examining Art Therapy MA } \\
\text { (very experienced clinicians) } \\
\text { - Curiosity - explore a theme; } \\
\text { - Innovation in student projects; } \\
\text { Emphasis in supervision on reducing } \\
\text { scale finding simple questions; } \\
\text { Developing a research methods module } \\
\text { across Health Faculty } \\
\text { Two- year Masters' - two streams: } \\
\text { clinical presentation, shorter writing } \\
\text { (critically evaluated); rigorous research } \\
\text { Link with art and design research. }\end{array}$ \\
\hline
\end{tabular}


Students commented informally on their experience of practice and research in a class reflection, New Zealand School of Music 2006.

Keynote Address: Music Therapy New Zealand Annual Conference,

University of Otago Sept 2006

\begin{tabular}{|c|c|}
\hline $\begin{array}{l}\text { What was challenging about including } \\
\text { research alongside practice? }\end{array}$ & $\begin{array}{l}\text { What was helpful about including research } \\
\text { alongside practice? }\end{array}$ \\
\hline $\begin{array}{l}\text { - Surprised when I found out [that } \\
\text { research was involved in training]; } \\
\text { - Very daunting; } \\
\text { - Thought it would be more focussed } \\
\text { on practice; } \\
\text { - Good but daunting; } \\
\text { - I am finding case studies, practicum } \\
\text { and research difficult to balance; } \\
\text { - Each morning a different bit to think } \\
\text { about - very difficult (swapping } \\
\text { between); } \\
\text { - Getting a mark at the end of the year } \\
\text { - hard (practicum is pass-fail) }\end{array}$ & $\begin{array}{l}\text { - It's very important, if [research] not in } \\
\text { Masters' I might never do it! } \\
\text { Research is more substantial - upheld by } \\
\text { a different standard; } \\
\text { Ethical process important - it's 'official' } \\
\text { and adds weight; } \\
\text { Ethical approval puts things into the } \\
\text { public domain (safety, standards and peer } \\
\text { approval) } \\
\text { - Not just this 'fluffy course'; } \\
\text { - I understand [my work] more than } \\
\text { previously - initially thought 'I'm not } \\
\text { doing much here'; } \\
\text { It makes me think about stuff - having to } \\
\text { go to a database and see what others have } \\
\text { done }\end{array}$ \\
\hline
\end{tabular}




\title{
10.2 Appendix 2: List of Participants in the Research: Settings and Roles
}

\author{
Focus Group Buenos Aires
}

Zelda: $\quad$ Senior Researcher, Programme Leader and Lecturer, USA

Hannah: $\quad$ Senior Researcher, Programme Leader and Lecturer, Europe

Catherine: $\quad$ Senior Clinical Lecturer, Practitioner, Europe

Paloma: $\quad$ Recent Graduate, Practitioner, Australasia

Focus Group Europe

Quentin: $\quad$ Programme Leader, PhD Researcher

Kirsty: $\quad$ Senior Researcher, Research Supervisor, Previous Programme Leader

Eddie: $\quad$ Research Director, Senior Lecturer, Research Supervisor

\section{Site Visit FV: Friendsville University College}

Florence: $\quad$ (Senior) $2^{\text {nd }}$ year Masters' Student

Patrick: $\quad$ (Junior) $1^{\text {st }}$ year Masters' Student

Hope: $\quad$ Clinical Lecturer and Placement Coordinator, Music Therapy Practice Tutor, Practitioner

Anna: $\quad$ Lecturer, Music Therapy Practice Tutor, Research Supervisor

Hilly: $\quad$ Community Clinical Placement Supervisor, Practitioner

(NB: The Programme Leader for Site FV provided information and documentation but was not a research participant.)

\section{Site Visit KT: Kindstown University}
Abby: $\quad$ (Senior) $2^{\text {nd }}$ year Masters' Student
Naomi: $\quad$ (Junior) $1^{\text {st }}$ year Masters' Student
Beatrice: $\quad$ Programme Leader and Lecturer, Senior Researcher, Research Supervisor
Bella: $\quad$ Lecturer and Research Supervisor, Senior Researcher
Helena: Clinical Lecturer and Placement Coordinator, Music Therapy Practice Tutor
Alex: $\quad$ Community Clinical Placement Supervisor, Senior Researcher, Practitioner

Research Journal

Sarah

Researcher: Programme Leader, Lecturer and Research Supervisor, Visiting Placement Supervisor, PhD Researcher. 


\subsection{Appendix 3: Example of Information Sheet for a Focus Group}

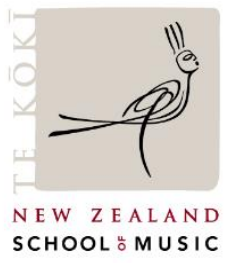

\section{INFORMATION SHEET FOR PROSPECTIVE MEMBERS OF A FOCUS GROUP OF INTERNATIONAL MUSIC THERAPISTS}

Title of research: Perceptions on the integration of research and practice in the education of music therapists at Masters' level

Dear Prospective Participant,

This research study is being prepared for a PhD Degree at Te Kōkī, New Zealand School of Music, Wellington and is being undertaken by:

\begin{tabular}{|l|l|}
\hline Researcher & Supervisory Team \\
Sarah Hoskyns & $\begin{array}{l}\text { Prof Donald Maurice (Administrative } \\
\text { Supervisor) }\end{array}$ \\
$\begin{array}{l}\text { Director of Master of Music therapy } \\
\text { Programme, Te Kōkī, NZSM, PO Box } \\
\text { 2332, } 6140 \text { Wellington }\end{array}$ & $\begin{array}{l}\text { Te Kōkī ,NZSM, PO Box 2332, } \\
\text { Wellington, 6140. Email: } \\
\text { donald.maurice@nzsm.ac.nz }\end{array}$ \\
Email: $\underline{\text { sarah.hoskyns@nzsm.ac.nz }}$ & $\begin{array}{l}\text { Prof Leslie Bunt } \\
\text { University of the West of England } \\
\text { Tel: 0064- (0)4-801-5799 x } 6410\end{array}$ \\
& $\begin{array}{l}\text { Associate Prof Sue Cornforth } \\
\text { Department of Education Studies, VUW. }\end{array}$ \\
\end{tabular}

Introduction

This research aims to find out how the music therapy profession - practitioners, educators and researchers - views the integration of clinical practice and research study within the training of music therapy students. For this part of the project, I would like to recruit a group of music therapy graduates (approximately 6 participants), to discuss their experiences of, and ideas about, the inclusion of research in their clinical training. Victoria and Massey Universities, parent institutions of Te Kōkī, NZSM, require that ethical approval be obtained for research projects involving human participants.

If you agree to participate, you will be invited to take part in a focus group, which the researcher will facilitate, for no longer than $1 \frac{1}{2}$ hours. Refreshments will be provided, and any travel expenses reimbursed as needed. The group will be convened at (venue to be confirmed), at a time convenient to the group of participants, probably on a weekday evening. During the meeting the aim will be to develop a free-flowing interactive discussion in which you can develop ideas together about the integration of research within clinical training, and to identify strengths and dilemmas in the process of learning and teaching according to your experience and personal view. As researcher, I will ask an opening 
question to start off discussion, and occasionally prompt if needed, but otherwise it is up to group members to choose the emphasis and direction of the conversation.

The focus group will be recorded and a written transcript will be prepared by the researcher. The transcript will be returned to you for verification and for correction of any specific details if necessary. The transcript will then be analysed for themes and units of meaning, and a summary will be prepared for inclusion in the research thesis. Every effort will be made to protect your privacy and confidentiality as a participant: for example pseudonyms will be used and identifying information disguised. However I should remind you that the music therapy community is reasonably small and it may be possible that you could be identified in this research. During the process of the research, raw data will be stored in a locked cupboard at the school where the research is being conducted. At the end of the study all raw data relating to the study will be stored securely at the New Zealand School of Music for a period of five years before it is destroyed.

If you would like to take part and you can meet the inclusion criteria below, please contact the researcher, Sarah Hoskyns, by email at the address at the top of this information sheet by (date to be inserted)

\section{Inclusion criteria for recruitment of participants:}

- You will have completed a postgraduate music therapy programme that has included some research as part of the learning.

- You will have graduated with your degree/diploma and be eligible for registration to practice as a music therapist.

I will aim to include music therapists with mixed levels of experience in the focus group: ideally this will be two people with five+ years' experience of practice, two people with onefour years' experience and two new graduates. The first six respondents who meet these criteria will be invited to take part.

\section{Your rights as a participant:}

During the process of participating in this research you have the right:

- To decline to participate

- To withdraw from the activity at any time (up to verification of the focus group transcript)

- To receive a transcript of the focus group for checking and verification

- To have your privacy protected

- To ask that the researcher turns off the mini-disk recorder at any time

- To ask questions about the research at any time

- To receive appropriate information about the research project

- To request a summary copy of the results of this stage of the project.

As the research is part of a larger $\mathrm{PhD}$ thesis, it may take some time for all the research to be written up. However, I would like to take opportunities to publish aspects of the work where appropriate and if participants would like to see a copy of ongoing results, please tick the relevant section on the consent form. If you have any questions about the study, please contact the researcher and/or the administrative supervisor, contact details at the top of this sheet. 
This project has been reviewed and approved the Victoria University of Wellington Human Ethics Committee (application no: 15689). If you have any questions or concerns about the study at any time, please contact the researcher or supervisors (email addresses supplied at the top of this information sheet). 


\subsection{Appendix 4: Example of a Consent Form for a Focus Group}

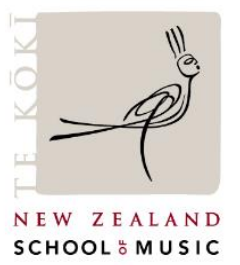

\section{CONSENT FORM FOR PARTICIPATION IN A RESEARCH PROJECT FOCUS GROUP}

This consent form will be held for a period of five years

Title of Research Project: Perceptions on the integration of research and practice in the education of music therapists at Masters' level

I have read the Information Sheet and have had the details of the study explained to me.

My questions have been answered to my satisfaction, and I understand that I may ask further questions at any time.

I agree to the focus group being audio-taped.

I understand that any information I provide will be kept confidential to the researcher and supervisor, the results will not use my name, and that no opinions will be attributed to me in any way that will identify me.

I understand that I can ask for the recording device to be switched off at any time.

I understand that I will have an opportunity to check the transcripts of the focus group before publication.

I understand that the recording and transcript of the focus group will be stored securely by the researcher during the course of the study and on completion of the study be kept in a locked cupboard at Te Kōkī, NZSM for a period of five years. After this they will be destroyed.

I understand that I can access the results of the research when the thesis is completed.

I agree to keep confidential any personal or identifying material discussed in the focus group.

I would like to request a copy of any interim publications from the researcher.

Therefore, I agree to participate in this study under the conditions set out in the Information Sheet.

Signature: Date:

Full Name Printed 


\subsection{Appendix 5: Example of an Information Sheet for Interviewees at Site Visits}

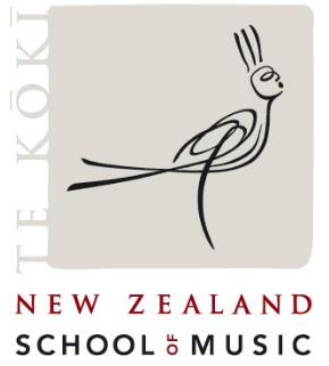

\section{INFORMATION SHEET FOR PARTICIPANTS IN A CASE STUDY OF MUSIC THERAPY RESEARCH AND PRACTICE}

Title of research: Perceptions on the integration of research and practice in the education of music therapy students at Masters' level

This research study is being prepared for a PhD Degree at Te Kōkī, New Zealand School of Music, Wellington and is being undertaken by:

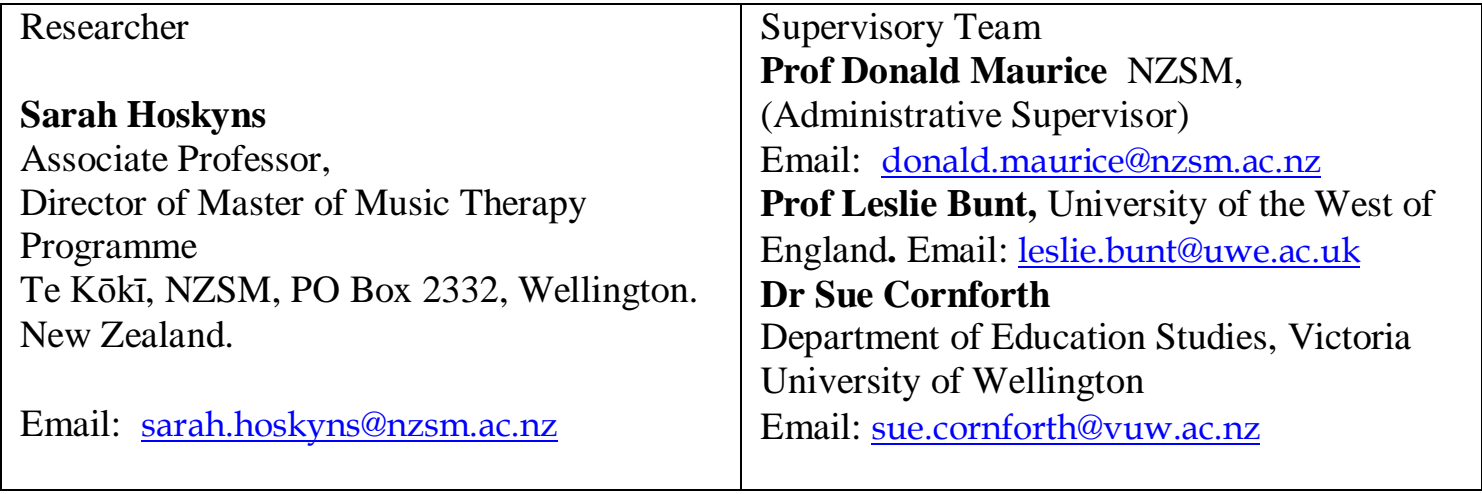

\section{Introduction}

This research aims to find out how the music therapy profession - practitioners, educators, researchers and students - views the integration of clinical practice and research study within the training of music therapy students. I would like to involve your music therapy training department in an in-depth group 'case study' that portrays the perspectives and stories of different members of your community about the experiences of research and practice working together. I aim to recruit 4-6 people who have been involved in both clinical practice and research at a range of levels of experience (for example a teacher, a clinical supervisor, a student, a research fellow, a senior manager, and so on) who are affiliated to, or employed by, your Centre. As researcher I will aim to assist you and other participants to develop your own 'narratives' about experiences in this area. This will be one of two case studies in different international settings for music therapy training. Massey University and Victoria University of Wellington, parent institutions of Te Kōkì ,NZSM, require that ethical approval be obtained for research projects involving human participants.

What will it involve for you as participant?

If you agree to participate, you will be invited to an interview with me as the researcher for approximately 1 hour at the Centre where the case study will be based - and at a time convenient to you - in the week when I am in attendance. During our meeting, I will aim to facilitate you to tell your story about researching and practicing clinically within the training process (at whatever level you are involved). This will be individual and personal to you and my role is to help you 'tell' it. I 
will ask an opening question to start off your thoughts, and occasionally prompt or talk with you if needed, but otherwise it will be your choice about how the direction of your narrative develops.

The session will be recorded and a written transcript of your interview will be prepared by me as the researcher. The transcript will be returned to you - by email or in hard copy if you prefer - for verification and for correction of any specific details. You will then be invited to develop or add to the narrative if you would like, in writing, and to send this back to me. Your story will then be brought together with other stories of participants in the case study and your ideas, perspectives and feelings will be highlighted and synthesised within this part of the thesis. Every effort will be made to protect your privacy and confidentiality as a participant: for example pseudonyms will be used and identifying information about the training location and about you personally will be disguised. However, training institutions are specialist and often distinctive settings and it is important that I warn you that it may be possible that you could be identified in this research.

\section{A debriefing group for participants}

At the end of the period I am in attendance at your Centre I would also like to invite you to a debriefing group with other participants in the case study, to reflect on your experiences and to share ideas and to improvise some music together. I will record and write up this session as part of my own researching 'story'. There is no obligation to attend this group, and it will not affect your participation in the earlier narrative inquiry.

If you would like to take part and you can meet the inclusion criteria below, please contact your Programme Head(specify name) and myself as researcher by email at the address at the top of this information sheet to express interest by (date to be inserted following Head of Dept agreement to be involved)

Inclusion criteria for recruitment of participants:

You will be involved in teaching, learning, clinical practice, research or management at the (Name of Programme) either as a student, or as employee or associate to the Programme. I will aim to include participants with a range of roles at the centre, including at least one current student, one lecturer/teacher, one clinical supervisor (and a balance other senior staff, practitioners or researchers). I will choose four- six respondents based on the criteria above and in the order in which they offer to be involved.

Your rights as a participant:

During the process of participating in this research you have the right :

- To decline to participate

- To withdraw from the activity at any time (up to verification and completion of your narrative)

- To receive a transcript of the narrative, and to correct and develop it in any way appropriate to you, and then to verify it for return to the researcher

- To have your privacy protected

- To ask that the researcher turns off the mini-disk recorder at any time

- To ask questions about the research at any time

- To receive appropriate information about the research project

- To request a copy of any publications relating to this stage of the project.

As the research is part of a larger $\mathrm{PhD}$ thesis, it may take some time for all the research to be written up. However, I would like to take opportunities to publish aspects of the work where appropriate and if as participant, you would like to see a copy of any publications relating to this stage of the project, please tick the relevant section on the consent form. This project has been reviewed and approved the Victoria University of Wellington Human Ethics Committee,( application no: 15689). If you have any questions or concerns about the study at any time, please contact the researcher or her supervisors (email addresses supplied at the top of this information sheet). 


\subsection{Appendix 6: Example of Consent Form for Interviewees at Site Visits}

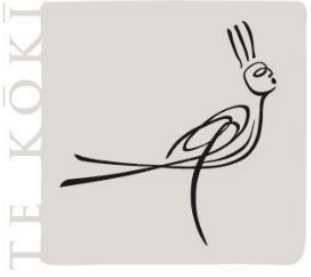

N E W Z E A L A N D

SCHOOL

\section{CONSENT FORM FOR PARTICIPATION IN A CASE STUDY ON MUSIC THERAPY RESEARCH \& PRACTICE}

This consent form will be held for a period of five years

Title of Research Project: Perceptions on the integration of research and practice in the education of music therapists at Masters' level

I have read the Information Sheet and have had the details of the study explained to me.

My questions have been answered to my satisfaction, and I understand that I may ask further questions at any time.

I agree to my narrative being audio-taped.

I understand that any information I provide will be kept confidential to the researcher and supervisor, the results will not use my name, and that no opinions will be attributed to me in any way that will identify me.

I understand that I can ask for the recording device to be switched off at any time.

I understand that I will have an opportunity to check the transcripts of my narrative and to develop or add to it if I would like to.

I understand that the recording of my narrative will be stored in a secure cupboard at the Te Kōkī, NZSM for a period of five years. After this it will be destroyed.

I understand that I can access the results of the research when the thesis is completed.

I would like to request a copy of any interim publications from the researcher.

Therefore, I agree to participate in this study under the conditions set out in the Information Sheet.

Signature: Date:

Full Name Printed 


\subsection{Appendix 7: Example of Advertisement for Expressions of Interest in a Focus Group}



\section{ADVERTISEMENT FOR EXPRESSIONS OF INTEREST \\ INVITATION FOR MUSIC THERAPISTS TO TAKE PART IN A FOCUS GROUP ABOUT RESEARCH AND CLINICAL PRACTICE IN STUDENT TRAINING}

Title of research: Perceptions on the integration of research and practice in the education of music therapists at Masters' level.

Dear Music Therapy Colleagues,

I would greatly appreciate your help with some PhD research I am undertaking at Te Kōkī, the New Zealand School of Music, Wellington. I am seeking participants for a focus group of qualified music therapists, attending the World Congress of Music Therapy in Buenos Aires. I would like to undertake this group in July 2008 and to invite you to express interest in being a part of this research. I am hoping to recruit a group of about six people to discuss experiences of, and ideas about, the inclusion of research in their experience of clinical training. During the meeting the aim will be to develop a free-flowing interactive discussion in which we can develop ideas together about the integration of research within music therapy training, and identify strengths and dilemmas in the process of learning and teaching according to your experience and personal view. The focus group will be audio taped and transcribed and the written transcript shared with you.

Depending on the group of people's availability, I intend to convene a group - which I will facilitate as researcher - for no longer than 1 1/2 hours at a Buenos Aires venue, close to the Congress on (date to be inserted). Criteria for inclusion are as follows:

- You will have completed a postgraduate music therapy programme that has included some research as part of the learning.

- You will have graduated with your degree/diploma and be eligible for registration to practice as a music therapist.

I will aim to include music therapists with mixed levels of experience in the focus group: ideally this will be two people with five+ years' experience of practice, two people with one-four years' experience and two new graduates. The first six respondents who meet these criteria will be invited to take part. I will provide refreshments for the evening, and will reimburse local transport expenses. (Unfortunately I do not have research funds for substantial travel expenses).

If you would be interested, are attending the Congress and would like further information about the project and a consent form, please email me: sarah.hoskyns@nzsm.ac.nz and I will return you the forms. Following expressions of interest, I will email potential participants with optional times for the focus group to meet. Thank you very much for your interest!

Kind regards, Sarah Hoskyns, Director of Master of Music Therapy Programme, Te Kōkī NZSM, Wellington. 


\subsection{Appendix 8: Letter of Invitation for Site Visit}

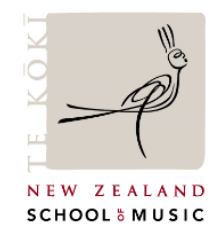

PO Box 2332, Wellington, New Zealand

6140 www.nzsm.ac.nz

Tel: 0064-(0)4-801-5799 x 6410

Date:

To the Heads of Two Music Therapy Departments (Australasia / Europe or America)

Dear XXXXXXXXX (Head of Music Therapy Department)

\section{RE: Invitation to your department to participate in a case study about research and clinical practice.}

I am writing to ask if you and your department would be interested in being participants in a special group case study focussing on the relationship between research and practice in music therapy training? I would greatly value your help with this if you are interested. I am undertaking a $\mathrm{PhD}$ at $\mathrm{Te}$ Kōkī, New Zealand School of Music entitled : Perceptions on the integration of research and practice in the education of music therapists at Masters' level alongside my own teaching and practice and am very interested in your perspectives on this subject.

I plan to undertake two institutional case studies in contrasting settings to explore how individuals and communities respond to the challenges and benefits of combining research and practice in music therapy training. I am using a 'purposeful sampling' method, i.e. I have identified possible centres for music therapy training and research, (in Australasia and in Europe or America) which have an established reputation for research and clinical practice, and staff and students who will have encountered the dilemmas and benefits of combining these processes. The aim will be to recruit two settings with different approaches to research and practice.

I enclose an information sheet and consent form about this stage of my research which will explain the research strategy in more detail, and I would be asking to spend up to a week in your department, at your convenience, to develop interviews with six people who are employed, studying or associates to your department, (NB please see the information sheet for how this is planned).

It would be very helpful to be able to observe any relevant classes about research and clinical practice, while I was in attendance, if that was appropriate, as this would help me develop my own reflective journal, and personal story of experience in this area. However, this would only be at your convenience and with the consent of all parties involved.

I would be glad to undertake these case studies in 2010, as it would suit your department. You are completely free to refuse, and I will be able to approach other institutions if it is not possible for you 
to take part. Please would you kindly let me know if you might be interested or not by (date to be inserted)?

If you would like further information about the case studies, the narrative inquiry approach, or the complete project, please contact me direct, (email: sarah.hoskyns@nzsm.ac.nz) or my supervisors Prof Donald Maurice (Donald.maurice@nzsm.ac.nz), Dr. Sue Cornforth (sue.cornforth@ vuw.ac.nz) or Prof Leslie Bunt (leslie.bunt@uwe.ac.uk).

Thank you very much for your consideration.

Kind regards,

Sarah Hoskyns

Associate Professor,

Director of Master of Music Therapy Programme

Enclosures:

Consent Form

Information Sheet 


\subsection{Appendix 9: Briefing and Prompt Questions available for the Focus Groups}

\section{Frame for the Focus Groups, including the prompt questions that may be used as a guide}

Welcome and thank you to all participants for joining this focus group. The topic of our discussion is your experiences of - and ideas about - combining research and clinical practice particularly in the training of music therapy students. I would like to gather your perspectives on this subject as it is an issue that has stimulated and perplexed me throughout my music therapy career.

To start, I would like to invite you to tell the group something about your experience of this topic. This might be as a student in the past, as a current trainer, as a supervisor of students on placement, or as a member of the practising profession who might need to produce 'evidence'. After we have shared individual starting points, I would like to encourage you to respond to each other. Feel free to debate points that interest you.

Prompt questions to help us (if needed or if we divert from the topic) ${ }^{36}$ :

- Would it be ok to just train good clinicians and not worry too much about research? If so can you justify?

- Are there any benefits to your clinical practice if you undertake practice based research?

- What sorts of research do you think are best for students to undertake?

- What are the main challenges for undertaking clinical research at a student level

- Is the research produced by entry level clinicians of good enough quality? (i.e. Should we wait until practitioners have had more experience before they undertake research?)

- Do you have any recommendations or 'ideals' about how we develop clinical training and research as a profession?

Please could you help me with the transcription by saying your name each time you speak. They will be changed (de-identified) in any write-up of the research, but it will just help keep the continuity of viewpoints. Also please can we all remember to keep confidential any specific personal or identifying information about individuals that is shared during the course of this group.

May 08

\footnotetext{
${ }^{36}$ N.B. These questions aimed to help participants explore challenges and benefits in combining research and practice in training and to consider separating them if relevant. They were planned beforehand in case they were needed. In the event, the Focus Group considered here developed easily from the initial question and the prompts were hardly needed.
} 


\subsection{Appendix 10: Briefing for Site Visit Interviews}

\section{Frame for the individual interviews}

Thank you for agreeing to participate in this Site Visit as part of my $\mathrm{PhD}$ case study research, about the integration of research and practice in student training, based at (Music Therapy

Programme). I would like to leave you as free as possible to tell your own story of experiences in this area in your own way. However, I am here to help clarify the overall agenda of the case study and to encourage and interact with you in any way that is helpful.

You have read the information sheet previously. I will just remind you about your rights and we can check those with the consent form. I reiterate that I will not be using your real name in the write up, and you will have full right to amend and develop the transcript in any way you wish.

Having reviewed and signed the consent form, we will now proceed with the taped interview.

Please can you begin with your name and a little bit about your history in music therapy and your role in this department and then proceed to tell me your story about music therapy research and practice, how they interact (or not) and what is meaningful for you about the relationship between the two processes? It doesn't matter if you go off track, that is often the benefit and interest of other people's stories. But do feel free to ask me anything you need to assist you. I am likely to respond to you with phrases like "Can you tell me a bit more about xxxx", or "xxxx seemed really important as you were describing it. Do you want to clarify?" ...if you get stuck. But otherwise it is your story. 


\subsection{Appendix 11: Examples of Participant Feedback}

\section{Comments about transcripts and findings from some participants at site visits}

\section{Clinical Supervisor: Hilly}

I found reading the transcript very interesting and informing for me personally. I realised how some of my own personal issues were/are still recurring. I also realised that I am now in a different place professionally from where I was when I talked with you some time ago. I have had 2 articles published in a dementia journal, not a peer reviewed Journal I know, but a Journal that is relevant to the other professionals with whom I work. Although the articles were on a slightly different subject from my dissertation, I do think the latter gave me the confidence to approach the journal and eventually get published. I am very happy to be known as 'Hilly' in your research. It seems very appropriate as I live in a hilly area.

\section{Senior Student: Florence}

I am happy with what came out - I guess spontaneous talk is rather like the creating mandalas during music improv. Key things come to the surface in an almost unconscious way.

\section{Clinical Lecturer: Hope}

It's very extraordinary to read about what this person said, and I notice how sorry I feel for her and for her experience. [My client and I ] ... finished working together about a year ago - having had an 8 year journey together. I realised that in a way it was impossible to write about it until we'd stopped working together and the research has assumed a better perspective when considered in the light of the whole period of work. I like the idea of being called 'Hope' and I suppose the fact that I feel I'm now through my grieving makes it seem an appropriate name!

Very interested in the improvisation chapter - it's always interesting when a throw away phrase turns out to be pivotal, and when I think about it those throw away lines are so often what songs get built on. In fact just yesterday I was involved in song writing with 'just a plummer' who found the experience of having his exact words reflected back to him both as spoken and then sung words extraordinary, moving etc. I notice that perhaps you sending me the transcript and the improvisation chapter have been a bit similar.

\section{Programme Leader and Researcher: Beatrice}

How exciting that you are at this fascinating stage of the analysis and pulling the themes together. It reads so well, and is going to be very interesting to read in full. Re: the furrows in the earth, I wonder if it needs a bit more context re why I had this image. I guess you are carefully concealing my identity (thank you), but I think it fair to say that "Beatrice recounts an image that appeared during a Guided Imagery and Music session around the pioneer work etc. I find myself singing "We plough the fields and scatter the good seed in the earth.."! 


\subsection{Appendix 12: Some Examples of Initial Coding for Group-BA: Developing Preliminary Categories}

Category: 'Demanding student workload'

\begin{tabular}{|c|c|c|}
\hline Examples of text & Line numbers & $\begin{array}{l}\text { 'In vivo' or descriptive } \\
\text { code }\end{array}$ \\
\hline $\begin{array}{l}\text { Final project }- \text { block it } \\
\text { out }\end{array}$ & $152-3$ & Overwhelming \\
\hline $\begin{array}{l}\text { lot of hard work to } \\
\text { juggle the hours }\end{array}$ & 165 & Organisational challenge \\
\hline $\begin{array}{l}\text { thesis writing and ethics } \\
\text { as well... provided a lot } \\
\text { of stress }\end{array}$ & 181 & Increased stress \\
\hline $\begin{array}{l}\text { client populations I had } \\
\text { in my training were } \\
\text { very demanding in } \\
\text { terms of getting good } \\
\text { skills }\end{array}$ & $190-191$ & $\begin{array}{l}\text { Demanding to gain } \\
\text { clinical skills }\end{array}$ \\
\hline $\begin{array}{l}\text { Giving students a } \\
\text { traumatic experience }\end{array}$ & $246-7$ & Trauma/stress \\
\hline $\begin{array}{l}\text { Blur around research / } \\
\text { dissociation }\end{array}$ & $248-249$ & $\begin{array}{l}\text { Confusion/dissociation } \\
\text { with research }\end{array}$ \\
\hline $\begin{array}{l}\text { I really wonder if a } \\
\text { student can concentrate } \\
\text { this much on research } \\
\text { while the primary focus } \\
\text { of the training is } \\
\text { learning clinical work }\end{array}$ & $512-513$ & $\begin{array}{l}\text { Hard to focus on } \\
\text { research with clinical } \\
\text { learning }\end{array}$ \\
\hline $\begin{array}{l}\text { and } 2 \text { years is very little } \\
\text { time } \\
\text { that the two years is } \\
\text { very very quick }\end{array}$ & $\begin{array}{l}515 \\
529\end{array}$ & Two years very quick \\
\hline
\end{tabular}

\section{Category: 'Challenges in learning'}

\begin{tabular}{|l|l|l|}
\hline Examples of text & Line numbers & $\begin{array}{l}\text { 'In vivo' or } \\
\text { descriptive code }\end{array}$ \\
\hline $\begin{array}{l}\text { finding ways for } \\
\text { the... academic/researching } \\
\text { experience actually to } \\
\text { inform the kind of live } \\
\text { clinician - without those } \\
\text { two becoming split }- \text { is a } \\
\text { real issue! }\end{array}$ & $86-87$ & $\begin{array}{l}\text { 1.Research } \\
\text { informing live } \\
\text { clinician }\end{array}$ \\
\hline $\begin{array}{l}\text { (helping by) having very } \\
\text { good supervision, great } \\
\text { support }\end{array}$ & $194-5$ & $\begin{array}{l}\text { 2. How not to split } \\
\text { research and } \\
\text { practice }\end{array}$ \\
\hline $\begin{array}{l}\text { we generated all these } \\
\text { questions elsewhere. } \text { (and) } \\
\text { slapped them on to what } \\
\text { you were doing }\end{array}$ & $\begin{array}{l}\text { Help of support and } \\
\text { supervision }\end{array}$ \\
\hline $\begin{array}{l}\text { Relating to the client }- \\
\text { exceptionally difficult }\end{array}$ & 366 & $\begin{array}{l}\text { External questions } \\
\text { slapped on to your } \\
\text { practice }\end{array}$ \\
\hline $\begin{array}{l}\text { Its difficulty is around its } \\
\text { complexity }\end{array}$ & $369-70$ & $\begin{array}{l}\text { Relating to clients } \\
\text { very difficult }\end{array}$ \\
\hline
\end{tabular}




\subsection{Appendix 13: Examples of Core Categories for Focus Group-E}

The following list is the nine categories which were developed as second stage 'pattern coding', from the initial coding of the Group-E transcript. Each category has a short definition to draw together the meaning of the group of codes which were collected together. These categories developed into some of the sub-themes which appear in the findings chapters, or were absorbed and fused with other thematic material from Site visit or other focus group data.

\section{Acknowledging heritage and traditions of knowledge}

This category emphasises what background of training and experience that people have had, and what influences these have had on current thinking and practice. The group members noted many times that the pioneers and past work in the discipline have had profound effects. (Perhaps it also is acknowledging the place and 'culture' of music therapy in this country at this time, and in this training institution?)

\section{Cherishing fire and curiosity}

Facilitating the spark of interest in students. The energy or passion required to go and find things out. Awakening something within people. The participants talked about this both within themselves (what excited them) and recognizing and nurturing it in students. This was linked directly with the process of research. Empowerment and confidence develop through encouraging this spark.

\section{Continually re-aligning the discipline}

The process of change and evolution of the profession was regularly alluded to in the group. Adapting the approach of education/research to meet the needs of the time and being responsive to change. Thus in educational terms, making practitioners ready for the way that ideas and theories change (intra-disciplinary and interdisciplinary processes). They can then take their place in this and know that their work can contribute to it (empowerment).

\section{Developing (flexible) assessments that integrate research and practice}

This theme developed towards the end of the group and concentrated on examples of assessment that might provide a helpful bridge between practice needs and research requirements. Student choice and feedback were valuable parts of the design of new assessment schemes. Traditional employment of the 'University thesis' was challenged in part by professional registration requirements and by the confidence of teachers through experience in research training. Participants felt the need to avoid splits between research and practice in the way the assessment is delivered.

\section{Building-improving on our own training experience}

This theme was rooted in both the frustrating or disappointing aspects of the participants' own experiences as trainee music therapists, and also in the learning that caught their imagination and which they valued and found exciting. Both strands were used to inform participants' values and beliefs about training now in research and practice.

\section{Thinking (carefully) about definitions and language we use}


(Might be a subset of continually re-aligning theme?- but it's to do with the precision of language and how we understand things...)What do participants consider in their definitions of research? This is changing and evolving all the time. The participants played with this idea ('is research too broad a term?') and qualified it to encompass 'search for meaning' which might be a day- to-day (practice linked) definition, and curiosity/reflection etc. and the external 'Research Methodology'. They also questioned language about clinician/ practitioner and how language shapes thinking.

\section{Embedding the research in practice}

Making full use of the ways in which research is a natural part of practice or an extension of normal tasks that occur in music therapy practice with people. These might include processes of documenting, reflecting, questioning, and 'not knowing what to do' and needing to find a solution, asking people, reading, inquiring. This group concentrated on 'embedded' integrated ways rather than teaching research skills and empowering people.

\section{Working bloody hard}

The rigour and systematic nature of enquiry into complex real life environments. Really looking in depth at what you do. Poring over it, working at the materials, going back again and again to seek answers and not leaping to conclusions. This idea linked the processes of pioneers as practitioner music therapists with current requirements for rigorous research work.

\section{Meeting the requirements of the EBP movement}

Evidence-Based Medicine or Evidence-Based Practice is a phenomenon in education and health, and requires professionals to provide evidence for their work. Change and development are brought about through research not just whimsy/anecdotal reports. The training of practitioners and clinicians has been strongly influenced in $21^{\text {st }}$ century by requirements for EBP. Workplace demands for practitioners to audit and research their practice when employed by government agencies has become high priority. Therefore graduates need preparation and research training can be adapted to help this learning. 


\title{
10.14 Appendix 14: Example of an Extract of an Interview Transcript Site FV
}

\author{
Student Participant, 'Florence' from Friendsville Site Visit $\left(2^{\text {nd }}\right.$ February 2010) \\ Line 142-324
}

Florence (Participant)

Yeah, and saying we're going, we've gone off the hook in terms of evidence-based practice and that's, that's what I believe in. But my interest I think has come, because I've had a rigorous scientific training. I think I am in a position to actually put the case of saying, I've had this, and this, these are the methods that are more appropriate for music therapy.

Sarah (Researcher)

Yeah

Florence

... and put that in a convincing way to people who might be sceptical cause they're scientists.

Sarah

And I suppose you have had a foot in both camps. That's sort of leverage where you understand where...

\section{Florence}

Yes.

Sarah

...where the scientists are coming from.

\section{Florence}

Yes, yeah, I think it actually, because all these specialties involve a different language don't they? Depending on who your communicating with, without being patronising in any sense at all, you actually wanting to communicate on the, in the form that people are going to value.

\section{Sarah}

Yes

Florence

And I think there are different ways of presenting the arguments depending on the audience really.

Sarah

Of course yeah.

Florence

So if you're actually presenting evidence to a group of psychotherapists it is very different than presenting it to a group of neuro-scientists.

\section{Sarah}

So that's something that you maybe feel that you could do in this journey of yours?

\section{Florence}

Yes oh definitely and I think because of each of the placements I've been on in the three years I've researched some and read about the evidence and the response in those placements has been very positive. Even in certain settings where they haven't had music therapy before. It is the case of actually getting the word out there, I think, in a lot of settings.

\section{Sarah}

So your interest in research is, is getting the word out a bit more?

\section{Florence}

Yes, yes

Sarah

Can you, can you ... - I don't know if you want this intervention - but I was just wondering about your placements and what kind of area they were in, 'cos this study is going to look at both clinical practice experiences and is it any use for you to tell me about them?

\section{Florence}

Yes the first one was in a special needs school, teaching 5-16 year olds and I was working between 7 and 15 year olds. And that varied from children with PMLD who were cognitively intact but physically disabled to severe mental abnormality, whatever term you want to use these days. And ASD, severe non-verbal ASD, were the main clients I had. 


\section{Sarah}

So that was your very first experience?

\section{Florence}

Yes, yes. Ah prior to that I had very little, I had had some sort of transit work experience doing music enrichment at a special school, but otherwise I hadn't really come across, intellectual disability in young people at all really ah. Because in other disciplines, it's very often hived off to specialty areas. You see the normal healthy child who's a bit sick, rather than this sort of area.

\section{Sarah}

I noticed you said, your first experience of clinical practice was teaching in a special needs school, and I'd wondered if you'd, you know been teaching in that school beforehand...

\section{Florence}

Oh I see, not actually formally teaching, I was there just going in, and I would say it wasn't specifically music therapy we obviously couldn't call it that cause I wasn't qualified or anything. But it was for me to get experience with how people handled and ah involving music with the children.

But not in a, in a truly therapeutic way as I worked on in the placement.

\section{Sarah}

So you had worked in that school before you were a student?

\section{Florence}

Yes, yes I had but quite briefly two terms, three terms. ... My second placement was at a brain injury unit, and there most of the clients were no, there was a variety, a lot of straight head injuries, some were results of strokes, one was a result of TB meningitis and the enormous interest for me was, there was, that I've worked as clinician in a rehab unit some years before and what really pointed out to me was that the music therapeutic context was far more holistic than any other therapeutic intervention... And certainly the clients I saw, you very much felt they could then have something that was directed by them and not being done to them. They were involved in it rather than being passive recipients of some therapy or treatment.

\section{Sarah}

And you found that sort of quite unusual?

Florence

Unusual I don't know, I think it was more that these patients had timetables and it was sort of like going to school; Oh it's physio now, it's OT now, it's speech and language now. And when one woman came in and said, "Well what are we doing then"? And I said, "Well what would you like to do? And she just sort of was, "you mean I can choose?" (Laughs) because it was client-led and because I had done counselling and very much Rogerian-based, it felt holistic and people could have time to talk, have time to express themselves, if they weren't verbal through music, and it was yes a very profound experience for me and certainly made me think that some other roles in the same setting are actually fairly superficial.

\section{Sarah}

Yes I suppose in terms of personally what you can do I presume it has quite an important role in

Florence

What clinically?

Sarah

Yeah setting up treatment plans or interfacing and just sort of making sure that patients are in optimal health.

\section{Florence}

Indeed I mean if someone got a blocked shunt, there's no point giving them a tambourine (laughs) you've got to intervene. But it, it struck me that music therapy can involve all the other aspects of therapy. There's a huge impact on speech and language in terms of singing and patterning. The physiotherapy side of things is vast because you are actually having a really motivating aspect if you want to do pronations, supination, have a drum and they'd do it forever. And OT as well if you're actually encouraging certain sort of activities to develop and strengthening after a stroke or to prevent contractures you are there. Psychologists tend to, tended to do very demarcated psychological assessments which were quite rigid and in flexible and psychiatrists, neuro-psychiatrist again would be concerned whether someone needed treatment for depression or whether they are getting agitated for some other reason other than the head injury and so on. But I just felt in music therapy you could 
actually incorporate aspects of all of that and it was very much a multidisciplinary team. So if I knew, although I was being client-centred in the context of what they did musically, I would talk to the other people and say well we are really trying to get them to do this, what can you suggest so that made it feel part of it, that it sort of felt as if music therapy was the binding of the whole, the whole group. 


\subsection{Appendix 15: Example of Coding and Analytic Memos for Student Florence, Site FV.}

This extract relates to Florence's transcript in the previous Appendix 10 (Site FV). Analytic memos in the left hand column link into the next level of coding.

\begin{tabular}{|c|c|c|}
\hline Student Participant Site FV & Codes & Notes/Memos \\
\hline $\begin{array}{l}\text { Florence (line 167-170) } \\
\text { "Yes, yeah, I think it actually, } \\
\text { because all these specialties } \\
\text { involve a different language } \\
\text { don't they? Depending on who } \\
\text { your communicating with, } \\
\text { without being patronising in any } \\
\text { sense at all, you actually } \\
\text { wanting to communicate on the, } \\
\text { in the form that people are } \\
\text { going to value." }\end{array}$ & $\begin{array}{l}\text { 1. } \begin{array}{l}\text { Different } \\
\text { language }\end{array} \\
\text { 2. } \begin{array}{l}\text { Communicating } \\
\text { to different } \\
\text { groups }\end{array} \\
\text { 3. Finding the right } \\
\text { language }\end{array}$ & $\begin{array}{l}\text { Memo March } 2012 \\
\text { Since reviewing Group E's } \\
\text { codes about language, this } \\
\text { idea of language (altering for } \\
\text { whom you speak to) provides } \\
\text { another angle to Group-E's } \\
\text { evolving language idea and } \\
\text { how therapists talk and write } \\
\text { about work. Didn't notice this } \\
\text { so strongly at first. (Link to } \\
\text { later refs that F makes about } \\
\text { different forms of evidence } \\
\text { and case study evidence in } \\
\text { particular.) }\end{array}$ \\
\hline $\begin{array}{l}\text { Florence (line 197-201) } \\
\text { "Yes oh definitely and I think } \\
\text { because of each of the } \\
\text { placements I've been on in the } \\
\text { three years I've researched some } \\
\text { and read about the evidence and } \\
\text { the response in those } \\
\text { placements has been very } \\
\text { positive. Even in certain settings } \\
\text { where they haven't had music } \\
\text { therapy before. It is the case of } \\
\text { actually getting the word out } \\
\text { there, I think, in a lot of } \\
\text { settings." }\end{array}$ & $\begin{array}{l}\text { 1. Reading about } \\
\text { evidence } \\
\text { 2. Teams are } \\
\text { positive about } \\
\text { MT evidence } \\
\text { 3. Getting the word } \\
\text { out there. }\end{array}$ & $\begin{array}{l}\text { Memo Jan } 2012 \\
\text { The way F talks is often very } \\
\text { passionate - almost } \\
\text { evangelistic. She talks about } \\
\text { the 'born again music } \\
\text { therapist' elsewhere. } \\
\text { Cross reference Group E 'fire' } \\
\text { and Group BA 'aliveness \& } \\
\text { curiosity'. } \\
\text { F is very aware of EBP and } \\
\text { the importance of engaging } \\
\text { with research (particularly } \\
\text { through reading) }\end{array}$ \\
\hline
\end{tabular}


10.16 Appendix16: Examples of Provisional Themes for Two Participants at Site FV: Student Florence and Lecturer Anna
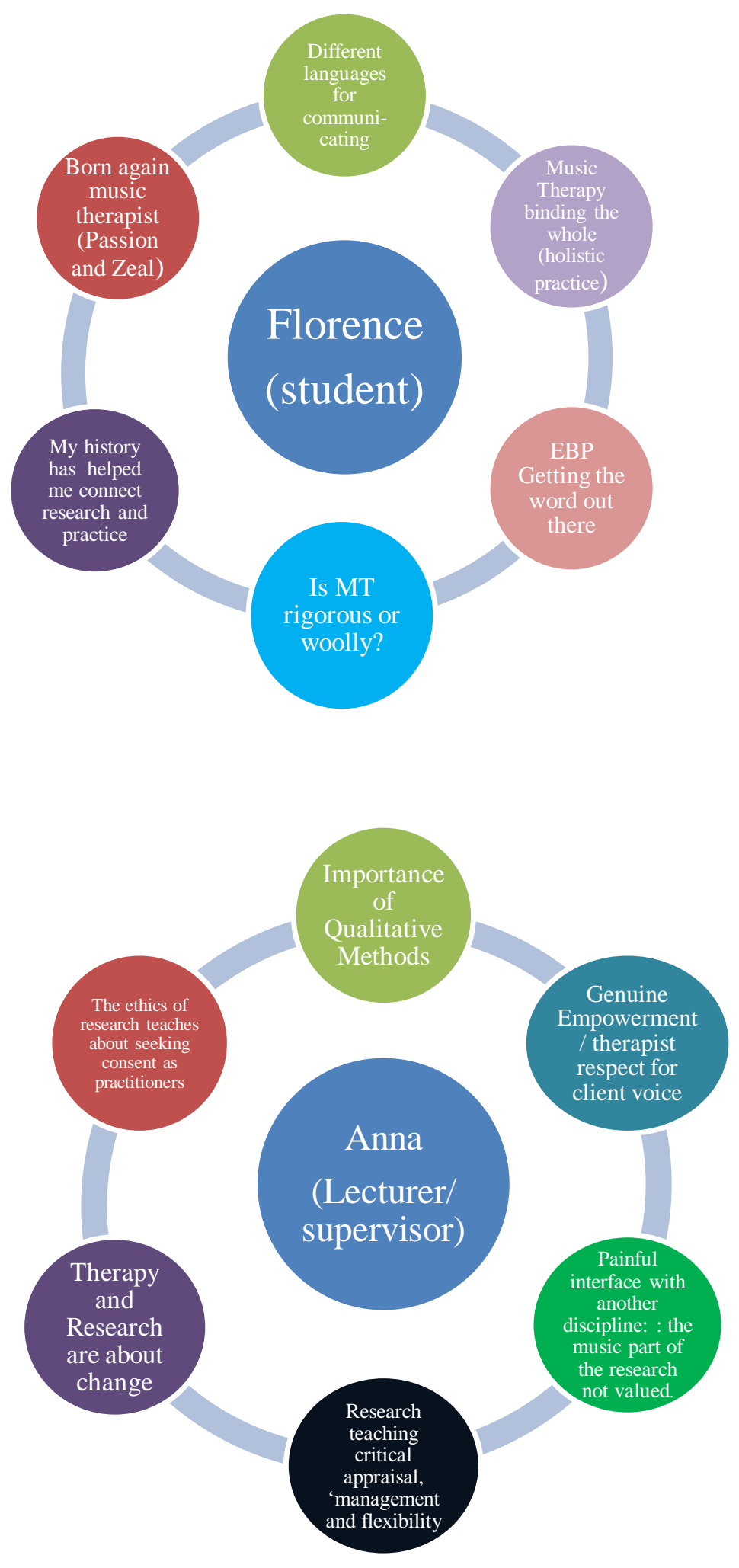


\subsection{Appendix 17: Provisional Themes for Site FV Themes foregrounded at Site FV}

\begin{tabular}{|c|c|c|c|}
\hline & Provisional themes & Codes & Brief memos April 2012 \\
\hline 1. & $\begin{array}{l}\text { Being affected and inspired by } \\
\text { client-led thinking }\end{array}$ & $\begin{array}{l}\text { Voice of the client/advocacy \& } \\
\text { fairness/ research relevant to } \\
\text { patients/ being moved by } \\
\text { practice gains or wisdom } \\
\text { (intensified meaning) / transfer } \\
\text { knowledge to a new client } \\
\text { group/ the case study at the } \\
\text { centre. Student clash of cultures } \\
\text { med/humanistic. Ethical choices } \\
\text { governing research are very } \\
\text { client-led. Sharing research with } \\
\text { client. }\end{array}$ & $\begin{array}{l}\text { 'Embedding the research in } \\
\text { practice' theme and def in } \\
\text { Focus Group BA... useful? } \\
\text { Is this the same thing? } \\
\text { (Possible link to a } \\
\text { 'community of } \\
\text { practitioners'?) } \\
\text { Maybe - note from my } \\
\text { research journal/field notes } \\
\text { here - being struck when } \\
\text { visiting a class about how } \\
\text { curious and interested } \\
\text { students are in each other's } \\
\text { cases. Problem solving } \\
\text { together, taking turns to be } \\
\text { in the hot seat. }\end{array}$ \\
\hline 2 & $\begin{array}{l}\text { Experiencing being at a crossroads } \\
\text { (research precipitating this?) }\end{array}$ & $\begin{array}{l}\text { Chance and opportunity for } \\
\text { change/new experiences } \\
\text { Creativity - new pathways open } \\
\text { up. (Personal development) } \\
\text { Crossroads in thinking - }\end{array}$ & $\begin{array}{l}\text { Interpreted as a kind of } \\
\text { critical thinking? I'm not } \\
\text { sure if this sub-theme lives } \\
\text { here but I like the idea of } \\
\text { micro level of 'crossroads' } \\
\text { - managing the dilemma of } \\
\text { where to go in your } \\
\text { thoughts. }\end{array}$ \\
\hline 3 & $\begin{array}{l}\text { Feeling the perspective's ever } \\
\text { changing }\end{array}$ & $\begin{array}{l}\text { Things constantly move on - } \\
\text { through our own learning, } \\
\text { through research unfolding new } \\
\text { things. }\end{array}$ & $\begin{array}{l}\text { Group E's Profession re- } \\
\text { aligning... this links } \\
\text { perhaps? }\end{array}$ \\
\hline 4 & $\begin{array}{l}\text { Experiencing excitement - passion } \\
\text { to know }\end{array}$ & $\begin{array}{l}\text { Asking questions, curiosity } \\
\text { engagement } \\
\text { enthusiasm for research ethics }\end{array}$ & $\begin{array}{l}\text { Natural intuitive - critical } \\
\text { thinking here? } \\
\text { Engaged pedagogy, link to } \\
\text { bell hooks }\end{array}$ \\
\hline 5 & $\begin{array}{l}\text { Things can get in the way of } \\
\text { integration }\end{array}$ & $\begin{array}{l}\text { The stumbling blocks/ } \\
\text { difficulties in contrasting or } \\
\text { clashing research cultures/lack } \\
\text { of subject specific knowledge/ } \\
\text { is research the right } \\
\text { word?/distress for this group } \\
\text { Low confidence about research. }\end{array}$ & \\
\hline 6 & 'All these meta-layers' & $\begin{array}{l}\text { Reference to music improv } \\
\text { experience but a metaphor for } \\
\text { the research? }\end{array}$ & \\
\hline 7 & $\begin{array}{l}\text { NB some 'Meeting requirements } \\
\text { of evidence based practice' codes }\end{array}$ & $\begin{array}{l}\text { Florence \& Hope - documents } \\
\text { on the modules - research } \\
\text { journal }\end{array}$ & $\begin{array}{l}\text { Probably weave this into } \\
\text { other themes here.... } \\
\text { Need to consider how to } \\
\text { manage this in relation to } \\
\text { the whole findings. }\end{array}$ \\
\hline
\end{tabular}




\subsection{Appendix 18: Provisional Themes for Site KT \\ Themes foregrounded at Site KT}

\begin{tabular}{|c|c|c|c|}
\hline & Provisional themes & Codes & Brief memos May-June 2012 \\
\hline 1. & $\begin{array}{l}\text { Being 'on fire' - searching for } \\
\text { pattern/inquiry/quest }\end{array}$ & $\begin{array}{l}\text { Excitement in traversing new } \\
\text { territory; love to work in an area, } \\
\text { carries you though; helping students } \\
\text { find placements in area of passion; } \\
\text { not knowing what you are doing; } \\
\text { finding connections and patterns; } \\
\text { questioning and challenging } \\
\text { orthodoxy; being alone (courage } \\
\text { through support); Imagery of hard } \\
\text { work. Research was always there } \\
\text { (its not been done before) }\end{array}$ & $\begin{array}{l}\text { Engaged pedagogy again.... } \\
\text { This might link to the crossroads } \\
\text { idea - new paths...? } \\
\text { Beatrice the two furrows - this } \\
\text { example very strong here. }\end{array}$ \\
\hline 2. & $\begin{array}{l}\text { Valuing the inspiration and } \\
\text { influence of mentors (who you work } \\
\text { with?) }\end{array}$ & $\begin{array}{l}\text { Supervisors model (prolific and } \\
\text { excited about their work); seeing } \\
\text { mentors doing research and practice; } \\
\text { students affected by writing and } \\
\text { conversation; taking part in a } \\
\text { mentor's project/ coming back to } \\
\text { people who supported initially; } \\
\text { answering their inspiring questions; } \\
\text { mentors direct your focus; } \\
\text { (sometimes people don't support!) }\end{array}$ & \\
\hline 3. & Finding confidence & $\begin{array}{l}\text { Encouraging to be an independent } \\
\text { thinker; becoming more confident } \\
\text { through extra language and process } \\
\text { students who do more clinical work } \\
\text { another layer of confidence; }\end{array}$ & $\begin{array}{l}\text { Only best students? - Bella } \\
\text { comments on this }\end{array}$ \\
\hline 4. & $\begin{array}{l}\text { Recognising power of the } \\
\text { collaborative/ model of research- } \\
\text { practice learning }\end{array}$ & $\begin{array}{l}\text { Joining mentor's project (clarifies } \\
\text { and simplifies) - strong modelling; } \\
\text { getting inspired by your mentor's } \\
\text { area of interest (like the sciences); } \\
\text { community of researchers getting } \\
\text { people on board. Learning from } \\
\text { other disciplines' research } \\
\text { approaches. Intensive learning on } \\
\text { placement }\end{array}$ & $\begin{array}{l}\text { Research journal input here - } \\
\text { my emerging experience about } \\
\text { collaboration. }\end{array}$ \\
\hline 5. & Developing the profession & $\begin{array}{l}\text { Trend towards music analysis - } \\
\text { supervisor directs; Integrating } \\
\text { methods from other disciplines; } \\
\text { picking up on a mentor's valued } \\
\text { challenge; extending the knowledge } \\
\text { base in uncharted areas; research } \\
\text { ethics changing; }\end{array}$ & $\begin{array}{l}\text { Relates to Group E's 'realigning } \\
\text { the profession'? Is this the same } \\
\text { thing? (Maybe not quite) } \\
\text { Can I connect this to the } \\
\text { community of practice idea? } \\
\text { Joining our community? }\end{array}$ \\
\hline 6. & $\begin{array}{l}\text { Recognising complexity (valuing } \\
\text { simplicity) }\end{array}$ & $\begin{array}{l}\text { So many parts to think about; future } \\
\text { research needs to engage on lots of } \\
\text { levels; what we do is so complex we } \\
\text { barely understand it; finding } \\
\text { connections and patterns }\end{array}$ & $\begin{array}{l}\text { All these metalayers from music } \\
\text { site visit 1) }\end{array}$ \\
\hline 7. & $\begin{array}{l}\text { Things emerging from practice or } \\
\text { from research? }\end{array}$ & $\begin{array}{l}\text { Conundrum in clinical supervision } \\
\text { leads to a research question; } \\
\text { research approach to a setting with } \\
\text { little clinical experience - brings the } \\
\text { medical team on board (clinical } \\
\text { work emerges); }\end{array}$ & $\begin{array}{l}\text { Interesting corollary from Site } \\
\text { visit } 1 \text { ! } \\
\text { Maybe either way round is } \\
\text { possible? }\end{array}$ \\
\hline 8. & ? The question of time and balance. & $\begin{array}{l}\text { Not enough time to reflect in clinical } \\
\text { practice; fitting in research is a } \\
\text { struggle; integrity of their training is } \\
\text { a juggle; stretched and tired... its } \\
\text { gonna happen anyway! } \\
\text { Some people have shit placements! }\end{array}$ & $\begin{array}{l}\text { This may work as a theme in } \\
\text { itself or blended with other areas } \\
\text { in the other data sources. }\end{array}$ \\
\hline
\end{tabular}




\subsection{Appendix 19: Example of a Research Journal Entry}

\section{March 14, 2010 (Following Focus Group E transcription)}

It's fascinating seeing how another training tradition has thought about the issues of integration in research. Really nice for me to witness. It feels complementary but has grown through very different traditions of practice and theory. It was very close to my doorstep, but I didn't know!

Lots of interesting questions are raised - I need to attend to them one by one - but it's exciting all at once. Quentin emphasizes the idea of 'taking time' with your own work. The pioneers took time (when it was precious) to listen back, and concentrate and make notes. It reminds me there about rigour with observation and attention, that I was made aware of through ethology! .....Really looking in detail, sifting the layers.

Kirsty then emphasises that these pioneers both experienced children in music and then thought about it/ listened to it together, so the different processes were held together in the search for meaning. This is obviously one particular way to go about this, but it wasn't somebody else doing the scrutinizing. So the idea is that research grows out of this 'holding together of experience and reflection' and that this is crucial to the understanding. I noted her musical emphasis when she was talking in the transcription (she articulates something important rhythmically!) It would be nice to find ways to re-integrate my sense of music into the research if I can - taking my opportunities where I can?

This is something that Leslie and I addressed in 1987 (BJMT) paper, where we thought forward to the possibility of music therapists looking at others' work. Imagining this might be a step forward, helping the research process, and of course in one direction it might sort out the complexity, but (by this focus group's thinking), something important gets lost, that ties the practice closely in with the research. There's a source of understanding meaning and insight that would be lost.

[Perhaps this is why it might be important for students to do this kind of research early on, because it calls upon them to work at the different sides and process the meaning. However is it too difficult?]. 